\title{
The Anthem Companion to
}
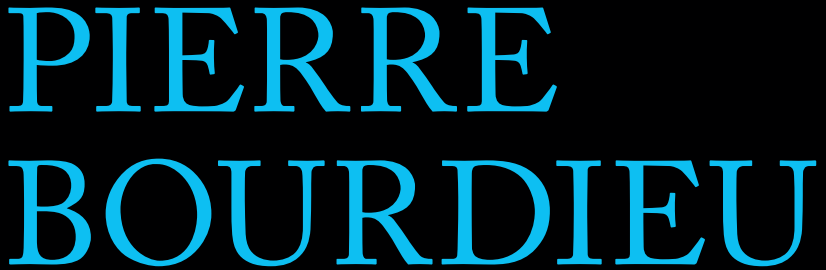

The Anthem Companion to Pierre Bourdieu 


\section{ANTHEM GOMPANIONS TO SOGIOLOGY}

Anthem Companions to Sociology offer authoritative and comprehensive assessments of major figures in the development of sociology from the past two centuries. Covering the major advancements in sociological thought, these companions offer critical evaluations of key

figures in the American and European sociological traditions, and will provide students and scholars with an in-depth assessment of the makers of sociology and chart their relevance to modern society.

\section{Series Editor}

Bryan S. Turner - City University of New York, USA, and Australian Catholic University, Australia

\section{Forthcoming titles in this series include:}

The Anthem Companion to Hannah Arendt

The Anthem Companion to Auguste Comte

The Anthem Companion to Everett Hughes

The Anthem Companion to Karl Mannheim

The Anthem Companion to Robert Park

The Anthem Companion to Talcott Parsons

The Anthem Companion to Phillip Rieff

The Anthem Companion to Georg Simmel

The Anthem Companion to Gabriel Tarde

The Anthem Companion to Ferdinand Tönnies

The Anthem Companion to Ernst Troeltsch

The Anthem Companion to Thorstein Veblen

The Anthem Companion to Max Weber 


\section{The Anthem Companion to Pierre Bourdieu}

Edited by Derek Robbins

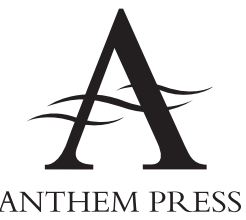




\author{
Anthem Press \\ An imprint of Wimbledon Publishing Company \\ wrwe.anthempress.com \\ This edition first published in UK and USA 2016 \\ by ANTHEM PRESS \\ 75-76 Blackfriars Road, London SE1 8HA, UK \\ or PO Box 9779, London SW19 7ZG, UK \\ and \\ 244 Madison Ave \#116, New York, NY 10016, USA \\ (C) 2016 Derek Robbins editorial matter and selection; \\ individual chapters (C) individual contributors \\ The moral right of the authors has been asserted.
}

All rights reserved. Without limiting the rights under copyright reserved above, no part of this publication may be reproduced, stored or introduced into

a retrieval system, or transmitted, in any form or by any means

(electronic, mechanical, photocopying, recording or otherwise),

without the prior written permission of both the copyright

owner and the above publisher of this book.

British Library Cataloguing-in-Publication Data

A catalogue record for this book is available from the British Library.

\title{
Library of Congress Cataloging-in-Publication Data
}

Names: Robbins, Derek, editor.

Title: Anthem companion to Pierre Bourdieu / edited by Derek Robbins.

Description: London ; New York, NY : Anthem Press, 2016. | Series: Anthem companions to sociology | Includes bibliographical references and index.

Identifiers: LCGN 2016028763 | ISBN 9781783085613 (hardback)

Subjects: LCSH: Bourdieu, Pierre, 1930-2002. |

Sociologists - France. | Sociology - France.

Classification: LCG HM479.B68 A79 2016 | DDG 301.092/2-dc23

LG record available at https://lccn.loc.gov/2016028763

ISBN-13: 978-1-78308-561-3 (Hbk)

ISBN-10: 1-78308-561-4 (Hbk)

This title is also available as an e-book. 


\section{GONTENTS}

Acknowledgements vii

Introduction $\quad 1$

Derek Robbins

\section{PART I: $\quad$ ASPEGTS OF BOURDIEU'S THOUGHT}

Chapter 1. Reading Bourdieu Phenomenologically

Derek Robbins

Chapter 2. The Sociological Challenge of Reflexivity in

Bourdieusian Thought

Simon Susen

Chapter 3. Sociology at the Scale of the Individual: Archer and Lahire contra Bourdieu

Frédéric Vandenberghe

Chapter 4. Bourdieu and International Social Science

Derek Robbins

PART II: $\quad$ GASE STUDIES OF THE INTERNATIONAL DEPLOYMENT OF BOURDIEU'S THOUGHT

Ghapter 5. Bourdieu Inside Europe: The European

Circulation of Bourdieu's Ideas

Marco Santoro and Andrea Gallelli

Chapter 6. The Principle of Differentiation in Japanese

Society and International Knowledge Transfer between Bourdieu and Japan

Shinichi Aizawa and Naoki Iso

Chapter 7. Worlds within and beyond Words: Bourdieu and the Limits of Theory 
Chapter 8. Social Transformation and Cultural

Reproduction: A Bourdieusian Analysis of

Post-Reform China

Yang Yang and Xuanyang Gao

Chapter 9. Bourdieu's Use and Reception: A Latin American

Perspective on the Problems of Conceptual Transfer María-Luisa Méndez

Notes on Contributors

Index of Names

Index of Subjects

Index of Titles of Books by Bourdieu Cited in the Volume 


\section{ACKNOWLEDGEMENTS}

My thanks are due to the contributors to this volume who have all cooperated in its production throughout quite a long period of gestation. I know some personally and others only electronically but the collaboration has been equally satisfying with everyone. I am acutely aware that it is the editor's privilege to have the last word - to give introductory comments on all contributions and to shape the meaning of the collection - and I have used that privilege to write an introduction and separately to offer a first contribution that suggests a reading both of Bourdieu and of the volume. I hope that the contributors will not feel that they have been excessively 'framed' by my editorial direction, and I trust that the volume will generate debate in which they will participate.

My thanks are also due to the editors at Anthem Press for their patience and guidance in seeing the collection safely through to completion. 



\title{
INTRODUCTION
}

\author{
Derek Robbins
}

We are familiar with the tension between quantitative and qualitative research in sociology, between data collection and analysis on the one hand and the recording of narrative on the other. One way to situate Pierre Bourdieu's work in these terms is to understand it as an alternative response to the situation of the natural and cultural sciences identified by Jürgen Habermas.

\section{Habermas's Identification of the Problem and His Proposed Solution}

Just less than half a century ago, Habermas bemoaned the fact that a gulf had developed between the natural sciences, which are taken to be concerned with the formulation of explanatory laws ('nomological sciences'), and the human sciences, which are taken to be concerned with understanding the historically contingent behaviour of people ('historical-hermeneutic sciences') (1988, 1). Even worse, Habermas contended, there was an increasing tendency for nomological science to invade the territory of the hermeneutic. The disposition of economists to generate laws of economic behaviour that are independent of the cultural assumptions of human agents was just one example of this creeping scientistic encroachment. Habermas's perception was a consequence of his immersion in previous German intellectual struggles firstly the Methodenstreit (struggle about method), which pitted scientific and cultural economists against each other in the 1880s and 1890s (Carl Menger versus Gustav von Schmoller) for which Max Weber's economic sociology was an attempted resolution, and, secondly, the Positivissmusstreit (struggle about positivism) of the 1960s, which set Karl Popper against Habermas's mentor, Theodore Adorno.

Habermas argued that the non-communication between the natural and human sciences that he detected was particularly unacceptable in respect of 
the social sciences, which by definition seek to find law-like explanations of human behaviour that do justice to human free will and also offer guidelines to inform social policy making. Accordingly, Habermas was motivated to write Zur Logik der Sozialwissenschaften (On the Logic of the Social Sciences; [1970], 1988). Habermas had previously written a social-historical account of the function and meaning of the 'public sphere', which was first published in 1962 as Strukturwandel der Öffentlichkeit (The Structural Transformation of the Public Sphere; [1962], 1989). He had been an Assistent in the Frankfurt Institute for Social Research from 1956 to 1959 but this topic for his habilitation thesis had been rejected by Max Horkheimer. Habermas wrote it instead under the supervision of Wolfgang Abendroth at the University of Marburg (see Specter 2010, 33). Before taking his position at Frankfurt, Habermas had, in 1954, submitted his doctoral thesis at the University of Bonn on Friedrich von Schelling, a post-Kantian contemporary of G. W. F. Hegel and Johann Gottlieb Fichte. Habermas's doctoral thesis was entitled 'Das Absolute und die Geschichte: Von der Zwiespältigkeit in Schellings Denken' (The absolute and history: on the tension in Schelling's thought). There was a revival of interest in Germany in Schelling's thought at the time, particularly in the lectures that he gave, probably in 1833-4, 'On the History of Modern Philosophy', in which he evaluated historically the development of Western European philosophy from René Descartes until his own day (see Schelling ed. Bowie 1993; Bowie 1994; 2003). At the instigation of Hans-Georg Gadamer and Karl Löwith, Habermas was appointed extraordinary professor of philosophy at the University of Heidelberg in 1962, and then, in 1964, he succeeded Horkheimer in the chair of philosophy and sociology at the University of Frankfurt. These were all value-laden moves. Habermas initially explored in and through the thought of Schelling the tension that he subsequently experienced himself intellectually and institutionally in reflecting on the philosophy of the social sciences. In On the Logic of the Social Sciences, Habermas characterized the 'dualism of the natural and cultural sciences' by reference to representatives of the opposing traditions - Popper of the 'analytical' tradition associated with the Vienna Circle and Hans-Georg Gadamer of the hermeneutic tradition associated with the University of Heidelberg. In outlining the intention of his project, Habermas commented that

this continuing dualism, which we take for granted in the practice of science, is no longer discussed in terms of the logic of science. Instead of being addressed at the level of the philosophy of science, it simply finds expression in the coexistence of two distinct frames of reference. ([1970], 1988, 1-2; italics in original) 
He emphasized that this state of affairs was unacceptable in respect of the social sciences:

Whereas the natural and cultural or hermeneutic sciences are capable of living in mutually indifferent, albeit more hostile than peaceful, coexistence, the social sciences must bear the tension of divergent approaches under one roof, for in them the very practice of research compels reflection on the relationship between analytic and hermeneutic methodologies. ([1970], 1988, 3)

This is a revealing introductory statement. It appears that Habermas was prepared to accept the autonomies of the natural and cultural sciences in their respective spheres but to insist that social science required a mixed mode of analysis. He proposed that his book would consider the existing dualism 'at the level of the philosophy of science' and would propose a philosophical logic for a mixed-mode social science. Although he argued that the 'practice' of research in the social sciences compelled reflection in terms of both the analytic and hermeneutic traditions, his purpose was to contribute to the canon of the 'philosophy of science' rather than to an understanding of the logic of social science in practice. His endeavour tacitly left intact both a positivism of the natural sciences and a hermeneuticism of the humanities, leaving Popper and Gadamer both unscathed in their respective strongholds.

\section{Bourdieu's Response to the Same Situation}

By contrast with Habermas, Bourdieu contended that tout est social (everything is social) (Bourdieu 1992b). This means that, for Bourdieu, the natural and the cultural sciences both have to be understood as the historical products of man's interaction with the environment. There is no context for perception outside immediate situations of engagement. 'Philosophy' is a socially constructed discourse that has advanced and self-fulfillingly reproduced a style of intellectual and social detachment, but the nature of this detachment can always be explained sociologically. For Bourdieu, therefore, the logic of social science has to be understood only as it operates pragmatically in practice, and such an understanding is only an exegesis of particular theoretico-practical engagements and does not reveal universally valid laws of social explanation. In collaboration with Jean-Claude Passeron and Jean-Claude Chamboredon, Bourdieu first clearly articulated a response in Le métier de sociologue (The Craft of Sociology; Bourdieu, Chamboredon and Passeron [1968], 1991) to the situation identified by Habermas. In a section devoted to 'Epistemology of the Social Sciences and Epistemology of the Natural Sciences', Bourdieu et al. 
suggested that philosophical argument that denied the possibility that social science might legitimately imitate the natural sciences always tended to move to the other extreme and see it 'as a reaffirmation of the imprescriptible rights of subjectivity' ([1968], 1991, 7). The way to avoid this continuing polarization of positions is to insist that the validity of social science has to be established in practice and not in philosophical abstraction. As they put this cogently,

The way to move beyond these academic debates, and beyond the academic way of moving beyond them, is to subject scientific practice to a reflection which, unlike the classical philosophy of knowledge, is applied not just to science that has been done - true science, for which one has to establish the conditions of possibility and coherence or the claims to legitimacy - but to science in progress. This specifically epistemological task consists in discovering, within scientific practice itself, which is constantly confronted with error, the conditions in which one can extract the true from the false. ([1968], 1991, 8; italics in original)

Bourdieu's explicit statement that tout est social came late in his career in an interview published in October 1992, which preceded the publication, as $\mathrm{La}$ misère du monde (Bourdieu dir., 1993; The Weight of the World, Bourdieu dir., 1999), of research on the French underclass that had been undertaken in the previous few years under his direction. Bourdieu and his colleagues had attempted to juxtapose their sociologically inspired perspectives of social reality with the expressions of their experience offered by the people with whom they spoke. There was nothing new about this juxtaposition in Bourdieu's work. Indeed, his whole career was marked by a determination to emphasize that the discourse of sociological explanation must remain in a constantly renewed reciprocal relationship with changing social phenomena. He was acutely aware that scientists work within the historical process, that scientific representations of reality constitute new realities that, in turn, demand new representations. His 'Décrire et prescrire: Note sur les conditions de possibilité et les limites de l'efficacité politique' (Bourdieu 1981; 'Description and Prescription: The Conditions of Possibility and the Limits of Political Effectiveness', in Bourdieu 1991, 127-36) was his most direct discussion of the nature of this ongoing conceptual/actual dialectic within history.

In relation to the terms outlined by Habermas, we can say that Bourdieu attempted to subsume science within an historical-hermeneutic orientation. He did so by developing a conceptual framework that correlated both approaches. For Bourdieu, there are 'intellectual fields', whether of art or science, which need to be considered both in terms of the discourses and terminology that they establish for themselves and in terms of the sociopolitical 
conditions that historically shaped their claims to autonomous legitimacy. As Bourdieu argued, 'fields' have to be understood both as 'structured structures' that have their own rules and as 'structuring structures' by which the contingency of their origins is exposed. Unlike Habermas, Bourdieu was a monist who sought to counteract the complacent acquiescence in any dualistic compartmenting of the arts and sciences by insisting that both spheres are equally the products of social construction and, therefore, equally susceptible to a fundamental sociological explanation. He did not confine his hermeneuticism to the aesthetic sphere. Hence his attack on what he took to be Gadamer's unwillingness to allow art to be subject to sociological understanding (in the opening chapter of Les règles de l'art, Bourdieu 1992a; The Rules of Art, Bourdieu 1996). Nor did he countenance the possibility that scientific understanding might be a-historical - see, for instance, his 'La spécificité du champ scientifique et les conditions sociales du progrès de la raison' (The specificity of the scientific field and the social conditions of the progress of reason; Bourdieu [1975a], 1975b). Although Bourdieu and Passeron came to differ philosophically after the beginning of the 1970s, they had collaborated together to write 'Sociology and Philosophy in France since 1945: Death and Resurrection of a Philosophy without Subject' (1967), in which they analysed the historical development of the two disciplines in relation to their genesis in the French post-World War II sociopolitical context that had been defined initially by the effects of the Nazi occupation and the Resistance movement. Subsequently, Bourdieu would additionally have been in agreement with the critique of Popper's attack on 'historicism' made by Passeron in his Le raisonnement sociologique: L'espace non poppérien du raisonnement naturel (Sociological Reasoning: A NonPopperian Space of Argumentation; [1991 and 2006)], 2013).

In another late work - Méditations pascaliennes (Pascalian Meditations; Bourdieu [1997], 2000) - Bourdieu recognized that his intellectual project had always been 'a kind of negative philosophy that was liable to appear self-destructive' ([1997, 15], 2000, 7; italics in original). In considering his own work 'under the shield' of Blaise Pascal, Bourdieu was wanting to confirm that his philosophizing was also concerned with the practical relations between mathematical and scientific discourse and the concerns of everyday existence rather than with the consolidation of a canon of philosophy. In the same way, he could have readily argued that his work had always been a kind of 'negative sociology'. As someone who came to be regarded as a sociologist and who held the chair of sociology at the Collège de France from 1981 until his death, Bourdieu was an extraordinarily intellectual social scientist and yet, as he put it, a person who 'never felt really justified in existing as an intellectual' ([1997, 16], 2000, 7). This ambivalent desire to challenge the intellectual discourse within which he 
was operating was present from the beginning. What he was to describe as his 'Fieldwork in Philosophy' (Bourdieu [1987], 1990, 3-33), his studies in Algeria between 1956 and 1960, was undertaken during the Algerian War of Independence while, initially, he was serving in the French army of occupation. The publications that resulted from these investigations show that Bourdieu immersed himself in the literature about indigenous Algerian communities, some of it written by nineteenth-century colonial administrators and some by orientalists at the University of Algiers, while, at the same time, he observed and participated. The product of his visual observation - his photographs - has been published posthumously with an introduction by Franz Schultheis (Bourdieu 2003). The nature of his active participation was evident in the transcripts appended to Travail et Travailleurs en Algérie (Work and workers in Algeria; Bourdieu, Darbel, Rivet and Seibel 1963), which were made possible by the way in which he organized the ethnic composition of his teams of interviewers. As he discussed in his introduction to part 2 of Travail et Travailleurs en Algérie, Bourdieu wrestled with the moral dilemma involved in trying to carry out ethnographic research from a perspective that was inextricably that of a colonial interloper. Equally, as he considered in his introduction to part 1 of the same text, entitled 'Statistiques et Sociologie' (Statistics and sociology), Bourdieu wrestled with the methodological problem of the relationship between deductions from empirical data and interpretations derived from the responses of interviewees. His situation caused him to consign the transcripts of interviews to appendices as examples of 'spontaneous sociology', while simultaneously wanting to develop a conceptual framework that would enable him to juxtapose his intellectually constructed 'spontaneity' with the experiential statements of his respondents in such a way that the validity of both could be recognized. Even when he found himself teaching philosophy, at first at a lycée in Moulins after leaving the Ecole Normale Supérieure in 1954, and then when he secured a post at the University of Algiers in 1958, the testimony of his students is that he introduced them to the way in which, for instance, Kantian philosophy should be used as a guide to practical action and knowledge rather than be revered for universal insights (see Mauger ed., 2005).

Other examples could proliferate of this constant tendency of Bourdieu to want, as we might put it colloquially, to think outside the box, or, more accurately, to think with a multiplicity of boxes without ever wanting to contribute towards fixing their forms. As I have tried to argue in detail (Robbins 2000), the work that Bourdieu undertook, for instance, in the 1970s on language and communication that led to the publication of Ce Que Parler Veut 
Dire (What speaking means; 1982), was resolutely designed to ensure that communicative situations are understood socio-logically without seeking to contribute to the discipline of sociolinguistics. We can confidently say that Bourdieu practised what he (and Chamboredon and Passeron) preached in Le métier de sociologue when they suggested that social scientific enquiry should involve an ars inveniendi (art of invention) (1991, 5-6). Bourdieu regarded discourses of explanation as socially constructed fictions that have legitimacy precisely because they are socially constructed rather than because they referentially correspond with unchanging social realities. Because discourses have an artificial character, they are deployed pragmatically and strategically in relation to chosen social purposes. They do not encapsulate absolute truths. Since they do not refer to static realities, competing discourses prevail as a consequence of social force majeure rather than in terms of intrinsic merit. Bourdieu articulated this in respect of two of his key concepts - habitus and field - in an article of 1985 in which he commented that his concepts were 'heuristic' devices, strategies for inculcating meaning rather than for representing it (Bourdieu 1985). Passeron's argument with Bourdieu, as stated in his 'Hegel ou le passage clandestin' (Hegel, or the stowaway; Passeron 1986, and republished in Passeron [2006, 169-97], 2013, 211-33) was precisely that he thought that Bourdieu was allowing the concepts that they had developed together, particularly that of 'reproduction', to become prescriptive formulae rather than contingent instruments for social understanding. There is an ongoing debate here. I would argue that Bourdieu satisfied a felt need that his concepts should not be wholly provisional by absorbing his conceptualizations into his personal trajectory so that he could take some responsibility for their activation. His response to contingency was, perhaps, suggestive of Fichtean subjectivity rather more than Hegelian idealism, but, whatever our interpretation, it is clear that Bourdieu's position creates particular problems in endeavouring to commission a collection of essays about his work. The problems are complex because we have to operate on two separate levels to do full justice to his achievement. We have, first of all, to undertake an exegesis of Bourdieu's work that analyses his conceptual apparatus relative to the conditions in which it was constructed and to which it was applied. We must also, secondly, reflexively situate our responses to his work relative to our social and intellectual conditions. In both cases, in other words, Bourdieu's work demands examination in relation to structuring structures - either the structuring structures of his work or the structuring structures of our responsive situations. What is precluded is an extrapolation of his concepts for consideration only within the structured structure of an international discourse of sociology attempting 
to deny the specificity of its different nation-state or cultural identities. The reality, which is unpalatable to those who practice theoretical criticism that is exclusively 'internal' to scientific discourses, what Bourdieu would call 'tautological' criticism, is that form and content were mutually reinforcing in Bourdieu's project. Productive criticism of Bourdieu's work depends on an acceptance that he inserted himself within his model of the relations between traditional subjective/objective or agency/structure dualities, just as he inserted his own social position within the map of academic position taking presented in Homo Academicus (Bourdieu [1984], 1988).

\section{Bourdieu's Conceptual Apparatus}

Bourdieu's conceptual apparatus has to be appreciated as a creative edifice that accreted extended and modified meanings as it was applied in various research situations. This can be briefly indicated in relation to his 'key concepts' - 'capital', 'habitus', 'field', 'reproduction'.

\section{'Capital' (1)}

Bourdieu (with Passeron) developed the concept of 'capital' in trying to find a means to explain the way in which discrimination against provincial and working-class students seemed to persist within higher education. Wanting to resist any suggestion that class and intelligence differences correlated, Bourdieu and Passeron argued that curricula sustained the culture and knowledge already possessed by higher-class entrants, with the result that apparently value-free assessments in fact privileged those students. The immediate provocation for the adoption of the word 'capital' to indicate the prior accumulation of degrees of marketable culture was the publication, in 1964, of Gary Becker's Human Capital (Becker [1964], 1980 ). Bourdieu and Passeron were anxious to develop a terminology about the capacities of individuals that linked these capacities to social and cultural background in opposition to the tendency developing in the United States under the influence of Milton Friedman primarily to assess the economic benefits of higher education and to determine appropriate levels of governmental investment accordingly. Bourdieu and Passeron had already expressed their scepticism about the prevalence of commercial values in the United States and their disquiet at the concomitant degradation of traditional cultural values in an earlier article of 1963 (1963), singling out the adverse influence in France of Michel Crozier's Le Phénomène bureaucratique (The bureaucratic phenomenon; 1963). The development of the concept of 'cultural capital' in the 1960s was a countercultural critique of aspects of American organization theory. 


\section{'Habitus'}

Bourdieu claimed (in Bourdieu 1985) that he had first appropriated the word 'habitus' for his purposes in his 1967 postface to his translation into French of Erwin Panofsky's Gothic Architecture and Scholastic Thought (1967). The word enabled him to give an account of the phenomenon that he had observed in his Algerian fieldwork whereby indigenous tribespeople retained their traditional values while adapting to changed, urban circumstances. The word gave conceptual substance to a process of acculturation but it was also laden with significant connotations and implications. Not only did 'habitus' have a preexistent meaning in scholastic philosophy but it also suited Panofsky in his allegiance to Ernst Cassirer's philosophy of symbolic forms, which, in turn, was a culturalist interpretation of the legacy of Kantian epistemology. At the same time, Bourdieu was anxious that 'habitus' should not be understood simply as a mechanism of intergenerational cognitive transmission. He found support for a broader view in Maurice Merleau-Ponty's use of both 'habitus' and 'hexis' to indicate that cognitive adaptation is a component of physiological adaptation in general (see Merleau-Ponty 1942).

\section{'Field'}

The concept of 'field' was first articulated in 'Champ intellectuel et projet créateur' (Intellectual field and creative project) in 1966 (Bourdieu [1966], 1971b). In this article, which appeared in a number of Les Temps Modernes devoted to the 'problems of structuralism', Bourdieu began the process that led to his redefining his position in respect of 'objectivist' structuralism. He sought to retain the antiexpressivist orientation of structuralist analysis, while insisting that the phenomenon to be understood is the process by which all social agents construct their own structural situations. 'Objectivist' analysis distorts (or, as Bourdieu would say, imposes symbolic violence) because it is as much the immanent construction of meaning on the part of the analyser as a representation of the differently immanent construction of those analysed. The concept of 'field' became an essential element in the framework of thinking that made possible Bourdieu's emphasis on 'reflexivity', but, like 'habitus', it was a word that did not come without connotations. It carried with it the legacy of 'fields of force' from nineteenth-century physics, particularly the work of James Clerk Maxwell in electromagnetics, and it had more recently been deployed by social psychologists such as Kurt Lewin and social philosophers such as Aron Gurwitsch (see Lewin 1952 and Gurwitsch [1957], 1964). There is a sense in which Bourdieu borrowed the word from Gestalt psychology and used it to assist the constitution of what might be called his 'Gestalt sociology', 
that is to say a totalizing sociology of the sort castigated by Raymond Aron as 'sociologism' (see Aron 1962, 20).

\section{'Reproduction'}

Bourdieu and Passeron articulated the notion of 'reproduction' when they came to revisit the sociological studies in relation to education that they had undertaken together throughout the 1960s. La reproduction (Reproduction; 1970) was published with the subtitle: Éléments pour une théorie du système d'enseignement (Elements for a theory of the educational system). The publication coincided with the appearance of Louis Althusser's 'Idéologie et appareils idéologiques d'État: notes pour une recherche' (Ideology and ideological state apparatuses: notes for a research) in which he tried to reformulate the Marxist notion of the relationship between base and superstructure 'on the basis of reproduction' $(1971,136)$. This was followed by the product of Althusserian research on schooling published by Christian Baudelot and Roger Establet as L'école capitaliste en France (The Capitalist School in France; 1971). The subtitle of La reproduction represented Passeron's intention but Bourdieu immediately widened the scope of the text in his 'Reproduction culturelle et reproduction sociale' ('Cultural Reproduction and Social Reproduction'; [1971a], 1973). While Passeron had been content to propose a framework for the analysis of the educational system, Bourdieu sought to integrate his work on education with the findings of his other research projects of the decade on art galleries and photography as well as with his earlier analyses of Algerian acculturation. The word 'reproduction' was used by Bourdieu and Passeron to offer a nonMarxist gloss on Althusser's thinking, but Bourdieu was drawn towards suggesting an alternative, generalizable view of the relationship between state and culture and the intergenerational transmission of privilege, whereas Passeron was more inclined to deploy 'reproduction' as an analytical instrument for understanding historically changing relations.

\section{'Capital' (2)}

By the end of the 1960s, Bourdieu had constructed a conceptual system out of component elements that had each developed in response to particular needs and pressures. Values are transmitted intergenerationally by means of the 'habitus'. This means that 'capital' is passed on unconsciously from one generation to the next. The process is unconscious because the 'habitus' is 'incorporated'. There is a process of 'soft determinism' that is almost a form of biological adaptation, but there is a degree of freedom of choice that enables individual actors to modify their inheritance. In this way, social 
and educational systems are 'reproduced' rather than simply replicated. This system offered a framework within which to conceive 'society' mainly by providing terms to enable the representation of colliding trajectories of individual persons as a sufficient account of the bases of historical social change. It was predicated on the intrafamilial transmission of values and assumed the stability of the nuclear family and of its network of extended relations. Bourdieu often returned to his observations of Kabyle society in Algeria because, in effect, he sought to transfer the essence of its 'gentilitial democracy' (1958) to mainland France. By the end of the 1970s, however, he found that he was in the awkward situation that his reputation was becoming established on the basis of a system of concepts that was becoming increasingly at odds both with new social realities and new philosophical developments. In the period between 1979 and 1982 when his achieved reputation secured him his appointment to the post at the Collège de France, he re-examined the concept of 'capital'. 'Les trois états du capital culturel' (The three forms of cultural capital; 1979) appeared in the same year as La distinction (Distinction; [1979], 1986) and this was also the year of publication of Jean-François Lyotard's La condition postmoderne (The Postmodern Condition; [1979], 1986). Aware of Lyotard's attack on 'grand narratives' of historical progression, perhaps Bourdieu sensed that this was the time for him to free his model from the straitjacket that supposed that the main motor for change was intergenerational or connected to the transition from traditionalism to modernity. In his article, he distinguished between three modes of cultural capital - the 'incorporated', the 'objectified', and the 'instituted'. There was a recognition that the position taking of individuals no longer took place by reference to inherited predispositions so much as through elective affinity with objects or institutions that possess prior social meanings. In La distinction, Bourdieu was prepared to recognize, for instance, that the political allegiances of individuals are mediated by the policies of instituted political parties as much as by their class origins. At the same time, Bourdieu was prepared to acknowledge that the Collège de France, as an institution, was able to bestow authority on his work, to consolidate institutionally the capital that he had acquired in his personal trajectory.

\section{Responding to Bourdieu}

I suggest, therefore, that historical exegesis of Bourdieu's concepts helps explicate their meaning and the significance of his deployment of them. The fabric of his system was a creative invention that was, and remains, aesthetically satisfying and, equally, was, and remains, pragmatically effective. Our 
challenge is to know how to relate to his instrumental fiction, or, perhaps, faction. By analogy with literary criticism, we can suggest that texts should be evaluated in terms of their relationship with the world (mimeticism), with their authors (the intentional fallacy), with their audience (the emotive or affective fallacy) or in the terms that they set for themselves, generating criteria such as 'self-consistency' or 'coherence'. W. K. Wimsatt demolished 'intention' as a criterion (in Wimsatt and Beardsley 1954) at about the time when Bourdieu was similarly inclined to discredit the autonomous self-expressivity of authors. Bourdieu's orientation was sufficiently phenomenological to reject the notion that texts can be judged in relation to a sphere that they can be said to be representing. He was never secure in thinking that his sociological findings were imitative accounts of the world but only of $a$ world that he had methodologically constituted, and hence his meticulous practice of publishing simultaneously his texts and the appendices containing the data on which the conclusions of those texts were founded. As we have seen, however, he rejected purely 'internalist' criticism, supposing that it simply reinforces a game in a way that is designed to minimize the effects of texts on reading publics.

When planning this collection of essays, I was inclined to think that a performative criterion should be adopted in assessing Bourdieu's work, that is to say an approach that accepts that Bourdieu's motivation was pragmatic with the result that it should be examined either in relation to its historical effects or in relation to its contemporary impact. Of course, it was not possible nor desirable for me to prescribe the approach to be adopted by contributors to this volume. However, it is important to make clear that I invited contributions from scholars of different continents precisely so as to explore the consequences for international relations in the present of responding cross-culturally to texts and concepts that Bourdieu developed in the restricted geotemporal context of late twentieth-century France. My intention was that the contributors would analyse the performative validity of Bourdieu's work within their own nation-state situations and that this process would involve them in emphasizing their cultural particularities rather than their membership of an international epistemic community, whether virtually existent through media exchanges or instituted through the migration of university staff. Inasmuch as the contributors address the details of Bourdieu's concepts, this was designed to be an illuminating, but incidental, engagement with the prefabricated, internalist discourse about their intrinsic meanings. This was to be subordinate to securing evidence on which to project an international social science that would not be predicated on the need for homogeneity.

The volume that follows is divided into two parts. In part 1, I endeavour to fulfil my own brief in two chapters. In the first of these I specify the 
interpretation of Bourdieu's work that I offer in this introduction by indicating how I think that work should be understood in relation to constitutive phenomenology. I adopt that orientation in providing a brief summary of the ways in which the perceptions of the contributors suggest an empirically grounded intercultural discourse that is rendered possible by a common point of reference in Bourdieu's theoretical apparatus rather than by any allegiance to a priori sociological principles. I am reminded of Jean-Paul Sartre's account of 'the prose-writer' who is

a man who has chosen a certain method of secondary action which we may call action by disclosure. It is therefore permissible to ask him this second question: 'What aspect of the world do you want to disclose? What change do you want to bring into the world by this disclosure?' The 'committed' writer knows that words are action. He knows that to reveal is to change and that one can reveal only by planning to change. He has given up the impossible dream of giving an impartial picture of society and the human condition. ([1948], $1967,13)$

Bourdieu's inclination was to suppose that Sartre's questions to the 'prosewriter' need to be answered by reference to his inherited dispositions, whereas Sartre emphasized the capacity of the writer to be a free agent. Nevertheless, Bourdieu shared Sartre's view that texts are vehicles for social encounter. Sartre recommended the meeting of freedoms, whereas Bourdieu emphasized the encounter between differently preconstrained positions, but Sartre's comment on how we should relate to a text of Jean Racine can be adapted to offer guidance for the reader of this volume:

To understand what (Phèdre) is, it is necessary only to read or listen, that is, to make oneself a pure freedom and to give one's confidence generously to a generosity. ([1948], 1967, 112)

This volume should be a vehicle for the recognition in generosity of different constraints.

\section{References}

Althusser, L. 1971. Lenin and Philosophy and Other Essays. London: New Left Books.

Aron, R. 1962. Dix-huit leçons sur la société industrielle. Paris: Gallimard.

Baudelot, C. and R. Establet 1971. L'école capitaliste en France. Paris: Maspero.

Becker, G. 1980. Human Capital. Chicago/London: University of Chicago Press.

Bourdieu, P. 1958. Sociologie de l'Algérie. Paris: PUF. 1966. 'Champ intellectuel et projet créateur'. Les Temps Modernes 246: 865-906. 
1971a. 'Reproduction culturelle et reproduction sociale'. Information sur les sciences sociales 10, no. 2: 45-99.

1971b. 'Intellectual Field and Creative Project', in M. F. D. Young ed., 161-88.

1973. 'Cultural Reproduction and Social Reproduction', in R. Brown ed., 71-112. 1975a. 'La spécificité du champ scientifique et les conditions sociales du progrès de

la raison'. Sociologie et sociétés 7, no.1: 91-118.

1975b, 'The Specificity of the Scientific Field and the Social Conditions of the

Progress of Reason'. Social Science Information 14, no. 6: 19-47.

_ 1979. 'Les trois états du capital culturel'. Actes de la recherche en sciences sociales 30: 3-6. 1979. La distinction: Critique sociale du jugement. Paris: Minuit.

1981. 'Décrire et prescrire: Note sur les conditions de possibilité et les limites de

l'efficacité politique'. Actes de la recherche en sciences sociales 38: 69-73.

1982. Ce Que Parler Veut Dire. Paris: Fayard.

1984. Homo academicus. Paris: Minuit.

1985. 'The Genesis of the Concepts of Habitus and Field'. Sociocriticism 2: 11-24.

1986. Distinction: A Social Critique of the Fudgement of Taste. London/New York:

Routledge \& Kegan Paul.

- 1987. Choses Dites. Paris: Minuit.

1988. Homo academicus. Cambridge: Polity Press.

1990. In Other Words. Cambridge: Polity Press.

1991. Language and Symbolic Power. Cambridge: Polity Press.

1992a. Les règles de l'art. Paris: Seuil.

1992b. 'Tout est social'. Magazine littéraire 303: 104-11.

1996. The Rules of Art. Cambridge: Polity Press.

1997. Méditations pascaliennes. Paris: Seuil.

2000. Pascalian Meditations. Cambridge: Polity Press.

2003. Images d'Algérie. Actes Sud/Camera Austria/Fondation Liber.

Bourdieu, P. dir. 1993. La misère du monde. Paris: Seuil. 1999. The Weight of the World. Cambridge: Polity Press.

Bourdieu, P. and J.-C. Passeron. 1963. 'Sociologues des mythologies et mythologies de sociologues'. Les Temps Modernes 211: 998-1021.

1967. 'Sociology and Philosophy in France since 1945: Death and Resurrection of

a Philosophy without Subject'. Social Research 34, no.1: 162-212.

1970. La reproduction: Éléments pour une théorie du système d'enseignement. Paris: Minuit.

Bourdieu, P., J.-C. Chamboredon and J.-C. Passeron. 1968. Le métier de sociologue. Paris: Mouton-Bordas.

1991. The Craft of Sociology. New York: Walter de Gruyter.

Bourdieu, P., A. Darbel, J.-P. Rivet and C. Seibel. 1963. Travail et travailleurs en Algérie, Paris/ The Hague: Mouton.

Bowie, A. 1993. Schelling and Modern European Philosophy. London/New York: Routledge. 2003. Introduction to German Philosophy: From Kant to Habermas. Cambridge: Polity Press.

Brown, R. ed. 1973. Knowledge, Education, and Cultural Change. London: Tavistock.

Crozier, M. 1963. Le phénomène bureaucratique. Paris: Seuil.

Gurwitsch, A. 1957. Théorie du champ de la conscience. Bruges: Desclée de Brouwer. 1964. Field of Consciousness. Pittsburgh, PA: Duquesne University Press.

Habermas, J. [1962], 1989. The Structural Transformation of the Public Sphere: An Inquiry into a Category of Bourgeois Society. Cambridge: Polity Press. 
[1970], 1988. On the Logic of the Social Sciences. Cambridge: Polity Press.

Lewin, K. ed. D. Cartwright, 1952. Field Theory in Social Science: Selected Theoretical Papers. London: Tavistock.

Lyotard, J.-F. 1979. La condition postmoderne: Rapport sur le savoir. Paris: Minuit.

1986. The Postmodern Condition: A Report on Knowledge. Manchester: Manchester University Press.

Mauger, G. ed. 2005 Rencontres avec Pierre Bourdieu. Broissieux: Éditions du Croquant.

Merleau-Ponty, M. 1942. La structure du comportement. Paris: PUF.

Panofsky, E. trans. P. Bourdieu. 1967. Architecture gothique et pensée scolastique. Paris: Minuit.

Passeron, J.-C. 1986. 'Hegel ou le passager clandestin'. Esprit 115: 63-81.

1991 (1st ed. Nathan, Paris) and 2006 (2nd ed. Albin Michel, Paris). Le raisonnement sociologique. Paris.

2013. Sociological Reasoning. Oxford: Bardwell Press.

Robbins, D. M. 2000. 'Bourdieu on Language and Linguistics: A Response to R. Hasan's "The Disempowerment game: Bourdieu on Language and Literacy"'. Linguistics and Education: an International Research fournal 10, no. 4: 425-40.

Sartre, J.-P. [1948], 1967. What Is Literature? London: Methuen.

Schelling, F. W. J. von, ed. A. Bowie. 1994. On the History of Modern Philosophy. Cambridge: Cambridge University Press.

Specter, M. G. 2010. Habermas: An Intellectual Biography. Cambridge: Cambridge University Press.

Wimsatt, W. K and M. G. Beardsley. 1954. The Verbal Icon: Studies in the Meaning of Poetry. Lexington: University of Kentucky Press.

Young, M. F. D. ed. 1971. Knowledge and Control: New Directions for the Sociology of Education. London: Collier-Macmillan. 



\section{Part I}

\section{ASPECTS OF BOURDIEU'S THOUGHT}





\title{
Chapter 1
}

\section{READING BOURDIEU PHENOMENOLOGICALLY}

\author{
Derek Robbins
}

I believe that Pierre Bourdieu is best understood as a phenomenological sociologist and that, equally, responses to his work in the spirit of its production have also to be understood phenomenologically. I first offer a brief justification of that view. I then seek to clarify what I take to be the nature of Bourdieu's phenomenological orientation before proceeding to an elaboration of its implications both for our understanding of Bourdieu's work and for an assessment of the range of responses to his work presented in this volume. In the light of these preliminary remarks, I then offer reflections on each of the contributions as well as some concluding comments.

\section{Bourdieu's Explicit References to Phenomenology}

Bourdieu never wrote explicitly about the influence of the work of Edmund Husserl on his thinking. However, he did offer a few suggestive hints. Asked by Axel Honneth and others in an interview of 1985 what the intellectual situation was like when he was a student, Bourdieu replied,

When I was a student in the fifties, phenomenology, in its existentialist variety, was at its peak, and I had read Being and Nothingness very early on, and then Merleau-Ponty and Husserl; Marxism didn't really exist as an intellectual position, even if people like Tran-Duc-Thao managed to give it a certain profile by raising the question of its relation with phenomenology. ([1987], 1990a, 3)

Notice here that Bourdieu deliberately distinguishes between phenomenology and what he calls phenomenology 'in its existentialist variety'. His comment also suggests that he was led back towards the work of Husserl by first reading Jean-Paul Sartre and then Maurice Merleau-Ponty. 
Asked by his questioners whether he had ever been interested in existentialism, Bourdieu replied later in the same interview,

I read Heidegger, I read him a lot and with a certain fascination, especially the analyses in Sein und Zeit of public time, history and so on, which, together with Husserl's analyses in Ideen II, helped me a great deal - as was later the case with Schütz - in my efforts to analyse the ordinary experience of the social. But I never really got into the existentialist mood. Merleau-Ponty was something different, at least in my view. He was interested in the human sciences and in biology, and he gave you an idea of what thinking about immediate present-day concerns can be like when it doesn't fall into the sectarian over-simplifications of political discussion. ([1987], 1990a, 5)

Notice for the moment that Bourdieu specifically highlights Husserl's Ideen II, which was only first published in German in 1952, rather than Ideen I, which had been first published in German in 1913 and translated into French in 1950. (I emphasize this because the English translation of this passage published in In Other Words wrongly footnotes the English translation of Ideen I.) In the same article, Bourdieu makes it clear that he was reading Husserl in the original and was not dependent on translations when he comments, 'and thanks also to my reading of Husserl, who was still little translated in those days)' ([1987], 1990a, 4).

These hints came in a retrospection, 30 years on, of influences on his thinking during his student days in the early 1950s. Bourdieu was more explicit, though brief, in a one-page response that he wrote at the close of 2001, shortly before his death, to G. J. Throop and K. M. Murphy's 'Bourdieu and Phenomenology', which was published at the end of their 'critical assessment' (2002). Responding to what he took to be the accusation that he was a 'quasi-plagiarist dissimulating his borrowings', Bourdieu insisted that he had 'often declared my indebtedness to phenomenology, which I practised for some time in my youth' (2002a, 209). He proceeded to assert that he had never sought either to 'rephrase' or to 'refute' 'Husserl, Schutz and a few more' and that, rather, 'It is my aim to integrate phenomenological analysis into a global approach of which it is one phase (the first, subjective phase), the second being the objectivist analysis. This integration is in no way an eclectic compilation since the effect is to pass beyond the limits (which I recall in my critique) inherent in each approach, while retaining their essential contributions' (2002, 209; italics in original). Note that, importantly, Bourdieu emphasizes that he had 'practised' phenomenology, not that he had been committed to it as philosophy. He claims that his phenomenological orientation was pragmatic and that it was one component of a methodology 
that always sought to do justice to the dialectical interrelationship between subjective perception and objective analysis. Husserl's phenomenology helped Bourdieu reconcile the opposites in the distinction made by Gottfried Wilhelm Leibniz between 'truths of reason' and 'truths of fact'. ${ }^{1}$ Notice that Bourdieu acknowledges an indebtedness to phenomenological analysis in terms that suggest that he regarded it as a subjectivist contribution to an approach that he had accommodated with objectivist structuralism, treating it, in other words, as synonymous with the ethnomethodological representation of primary experience (as he did in his article of 1973 entitled 'The Three Forms of Theoretical Knowledge' (1973)).

\section{The Nature and Implications of Bourdieu's Phenomenological Orientation}

The way in which Bourdieu 'aimed to integrate phenomenological analysis' was in accord with the way in which contemporary interpretations of Husserl began to emphasize the 'constitutive' dimension of his work. We have to distinguish between 'transcendental' and 'constitutive' phenomenology.

Whether or not Bourdieu used the interpretation of Husserl offered by Jean-François Lyotard in his La phénoménologie (Phenomenology), first published in 1954 , it is a useful source in that it clearly articulated the middling epistemological position offered by Husserl as it was understood in France in the early 1950s. Lyotard began with an account of Husserl's 'psychologistic scepticism', his battle against the view that 'identifies the subject of knowledge with the psychological subject' ([1991], 37, 1999, 9). Lyotard showed that this scepticism extended to all empiricism. He summarized Husserl's position in the following way:

Basically, the assumption at the root of all empiricism is the claim that experience is the sole source of truth for all knowledge - but then this claim must rely, in turn, on the proof of experience. Yet experience, never furnishing more than the contingent and particular, cannot provide science with the universal and necessary principle of such an assumption. Thus, empiricism cannot be understood through empiricism. ([1991], 38, 1999, 11)

To avoid refuge in idealism or logical positivism as a consequence of this recognition of the limits of empiricism, Husserl pursued the essence or 'eidos' underlying experience. As Lyotard continued,

The proceedings of imaginational variation give us the essence itself, the being of the object. [...] The essence, or eidos, of the object is constituted by the 
invariant that remains identical throughout the variations. ([1991], 39, 1999, 12 ; italics in original)

In this 'transcendental' reading of Husserl that derives from an interpretation of his early work, the necessary function of multiple scientific disciplines is to provide variant understandings that will disclose universal invariants. Taking the explanations of the sciences at face value is a necessary prerequisite for understanding the assumptions of human experience on which they all depend. As Lyotard put it in explicating Husserl,

The empiricist interpretation of the formation of the number two presupposes the originary understanding of this number. This understanding is thus a precondition for all empirical science; while the eidos it yields us is only a pure possibility, there is a priority to this possibility with respect to the real which concerns science. ([1991], 40, 1999, 12; italics in original)

The empirical sciences are concerned with contingent facts, but, according to Husserl, as represented by Lyotard, 'the contingency of the fact is related to the necessary essence, since to think of its contingency is to think that it belongs to the essence of the fact that it could be otherwise' ([1991], 41, 1999, 14). The pursuit of the essential is not to be confused with that of the Platonic 'idea'

since it strives to present the knowledge of essences not as the end of all knowledge, but as the necessary introduction to knowledge of the material world. In this sense the truth of the eidetic is the empirical, and this is why the 'eidetic reduction', by which we are invited to pass from the contingent facticity of the object to its intelligible contents, can still be called 'mundane'. ([1991], 42, 1999, 14)

In his early work, Husserl pursued his reductive intention with respect to a series of 'logical investigations' ( [1913a], 1970). By the early 1950s, however, it was becoming accepted that, as Merleau-Ponty put it in 1951, 'the contrast is striking between some early and recent texts' of Husserl (1960, 136). There was a growing awareness that the phenomenological movement did not conceal a revised form of idealism, but instead was conducive to a new kind of empiricism. With the posthumous translation of Husserl's The Crisis of European Sciences and Transcendental Phenomenology and his Experience and Judgement, subtitled Investigations in a Genealogy of Logic, published in German respectively in 1954 and 1948, the view was developing that Husserl's thought was an attempt to articulate the prelogical foundations of logical systems. There was some continuing uncertainty whether there had been a shift of emphasis in Husserl's own thinking, partly as the result of the influence of Martin 
Heidegger, or whether the apparent shift was attributable to the mediation of some of his late work published posthumously by his assistants - Ludwig Landgrebe and Eugen Fink - both of whom were attracted to the tradition of German Kulturgeschichte (cultural history).

Jean Wahl, Paul Ricoeur and Tran Duc Thao were pioneers in exploring the implications of the thinking of 'late' Husserl.

Wahl published two articles, in 1951 and 1952. The first ${ }^{2}$ offered some notes on Experience and Fudgement, and the second ${ }^{3}$ went further in arguing that Experience and fudgement highlights a potentially empirical dimension to Husserl's late work. According to Wahl, Husserl argued in Experience and Fudgement that 'intentionality' - the process of understanding reality logically - is grounded in a sphere that precedes judgement. Wahl saw this as a form of realism that can be exposed in a form of empirical enquiry.

Ricoeur's translation of Husserl's Ideas I (1913b), published in 1950, included a translator's introduction in which, following Fink, ${ }^{4}$ Ricoeur asserted that

Husserl's 'question' [...] is not Kant's; Kant poses the problem of validity for possible objective consciousness and that is why he stays within the framework of an attitude which remains natural. [...] Husserl's question [...] is the question of the origin of the world [...]; it is, if you like, the question implied in myths, religions, theologies and ontologies, which has not yet been elaborated scientifically. (Husserl, ed. Ricoeur 1950, xxvii-xxviii; italics in original)

Ricoeur also wrote two relevant articles in the early 1950s. The first, 'Analyses et problèmes dans Ideen II de Husserl' (Analyses and problems in Husserl's Ideas II, Ricoeur 1951), is important because it was a comparison between Ideen I and Ideen II undertaken on the basis of his reading Ideen II in manuscript before its subsequent publication in 1952, and because, as I have noted above, it was Ideen II rather than Ideen I to which Bourdieu referred in his 1985 interview. Ricoeur also wrote an article for Esprit, a Catholic journal, in 1953 (1953), which began as an attempt to define phenomenology by comparing the phenomenologies of Immanuel Kant and G. W. F. Hegel, but which moved into a detailed critique of Tran Duc Thao's Phénoménologie et matérialisme dialectique (Phenomenology and dialectical materialism) of 1951 (1951).

Tran Duc Thao's book was important because it registered the transition in responses to Husserl, from the existentialist to the social historical or sociological. It was published in two parts in 1951. The first part, written between 1942 and 1950, is a sympathetic historical and critical account of Husserl's philosophical development. The second part is devoted to dialectical materialism and presents phenomenology as the last gasp of the tradition of philosophical idealism that had been attacked by Karl Marx. If, as I am suggesting was 
thought by Wahl and others, Husserl's late work seemed to emphasize a quest for a genetic understanding of human thought, Tran Duc Thao argued that, as the editor of the English translation puts it, 'Genetic understanding entails materialist science, the investigation of the evolutionary biological foundation and historical development of consciousness, and especially of that practical consciousness which is language' (ed. Cohen 1986, viii).

The responses of Wahl, Ricoeur and Tran Duc Thao all indicate that interest in Husserl in France in the early 1950s was shifting towards an interest in the sociohistorical production of forms of knowledge. Husserl's early work was thought to have been in pursuit of universal and ahistorical 'essences' of knowledge, but the interpretation of the 'new Husserl' or the 'other Husserl' was thought to open up the possibility that essences might be geographically and temporally contingent and, as such, susceptible to empirical investigation without sacrificing the fundamental scepticism about the status of the explanations of the discourses of the empirical sciences. Based on his extensive reading of the work of Husserl and of the contemporary secondary literature, Lyotard felt able to comment that

it is clear that the cultural sociological viewpoint already present in Ideas II, and largely dominating the last writings (the Crisis and the letter to Lévy-Bruhl), introduces, by Husserl's own admission, something like a historical relativism - the very thing which transcendental philosophy fought against. ([1991], 1999, 59; italics in original)

It was Aron Gurwitsch who articulated what was meant by constitutive phenomenology in an essay entitled 'The Perceptual World and the Rationalized Universe', probably written in 1953. Gurwitsch wrote,

In the final period of his life, Husserl did, more and more, call attention to the perceptual world, such as the latter plays a role in everyday, natural life. That is the world in which we find ourselves, in which we act, react, and work. It is in that world that we encounter our fellow human beings, to whom we are bound by the most diverse relationships. All our desires and hopes, all our apprehensions and fears, all our pleasures and sufferings (in short, all our affective and emotional life) are related to that world; all our intellectual activities, both practical and theoretical, also refer to it. In describing and analysing the perceptual world, one must take it such as it, in actual fact, offers itself to the natural consciousness of everyday life, such as it appears prior to the idealizations entailed by scientific interpretation and explanation.

The world is conceived by modern civilized human beings in the perspective of the physical sciences, such as they have been established since the seventeenth century. Even when we happen not to be physicists, or when we are not very 
familiar with the theories of physics and with the results arrived at by it, we conceive and interpret the world in relation to the very existence of physics. (ed.

J. Garcia-Gomez 2009, 411-12)

Following the new interpretation, Gurwitsch attributed an emphasis on constitutive phenomenology to 'the final period' of Husserl's life. Following late Husserl, Gurwitsch argued that we all go about our lives in a perceptual world and that the explanations of the sciences are rationalizations or idealizations that are superimposed on our everyday perceptions. Gurwitsch did not suppose, however, that our perceptions remain experiential in an unchanging way. The second paragraph in the quoted passage indicates that, historically, past rationalizations become incorporated into taken-for-granted present perceptions. This can be described as an acceptance that, transculturally and transhistorically, primary perception is susceptible to rational modification.

Put more simply, 'constitutive' phenomenology retained commitment to the primacy of perception underlying all scientific rationalizations but, unlike 'transcendental' phenomenology, did not attempt to disclose the common prepredicative experience of humanity. Instead, it accepted that scientific rationalizations become given components of subsequent experience and perception. It relinquished the legacy of Kant's epistemology but, equally, it did not embrace a Heideggerian critique of epistemology. Rather, it had some affinity with the philosophy of symbolic forms developed by the neo-Kantian Ernst Cassirer during the 1920s and was even able to assimilate intellectually the positivism of Ernst Mach and the logical positivist followers in the Vienna Circle.

Expressed in these terms, it is readily possible to suggest an affinity between the constitutive approach and the approach adopted by Bourdieu throughout his career. A hallmark of his research was that he always endeavoured to supply detailed appendices that offered for scrutiny the process by which he moved from particular findings to general theories, from observed experiences to scientific rationalizations. He always resisted theorizing in relation to previous theories without reference to originary experience. In his article 'Décrire et prescrire' (Description and prescription, [1981], 1991, 127-36), he discussed the extent to which 'descriptions' establish the parameters for future actions and thus mediate prescriptively between perceptions of past, present and future social realities. In an article such as 'Le mort saisit le vif' (Death seizes the living, 1980b), he considered, as his subtitle puts it, 'Les relations entre l'histoire réifiée et l'histoire incorporée' (The relations between reified and incorporated history) or, in other words, the extent to which present experience is constrained or shaped by objectifications of past experiences that have become intrinsic components of future-oriented dispositions. Indeed, Bourdieu's development of the concept of 'habitus' 
was an attempt to encapsulate the notion that we inherit predispositions, which are the raw materials with which we constitute new meanings and understandings. Similarly, he adapted for his own purposes the concept of 'field' to enable both the analysis of the social conditions of genesis of intellectual discourses and the recognition of the achieved, self-referential legitimacy of those discourses. This mode of thinking became increasingly self-regarding or personal. 'The Three Forms of Theoretical Knowledge' (Bourdieu 1973) outlined a procedure that would subject social scientific objectification to sociological enquiry, but it was based on Bourdieu's discomfort with imposing in Algeria an account of indigenous experience derived from the intellectual assumptions generated in colonizing societies. His revisiting of his Algerian fieldwork in a book such as Le sens pratique (The logic of practice, Bourdieu [1980a], 1990b) was, in part, an attempt to analyse the extent to which his interpretations of Algerian social organization correlated with his primary experience in Béarn and also the extent to which those interpretations had modified his behaviour in metropolitan France, causing him to acknowledge the strength of instinctive motivations to strategic action. This was one example of Bourdieu's general disposition to revisit past experience through temporal phases, a tendency that was emphasized, late in life, by his desire to accumulate past articles about his native Béarn in a cumulative volume entitled Le bal des célibataires (The bachelors' ball, Bourdieu [2002b], 2008). Bourdieu's recommendation of scientific 'reflexivity' was designed to communicate a blueprint for all research that would sustain the primacy of experience, but in Réponses (Bourdieu and Wacquant [1992], 1992), which was subtitled Pour une anthropologie réflexive (For a reflexive anthropology) and translated as An Invitation to Reflexive Sociology, it was also an opportunity for Bourdieu to begin to disclose biographical details that would account for the nature of his conceptualizations and relativize them. This was a process that he had already begun in the article 'The Genesis of the Concepts of Habitus and Field' (1985). It was this belief in the necessity for personalized reflexivity that enabled Bourdieu to argue that all intellectual works, including his own, should be understood sociogenetically, that is to say by reference to primary experience more than in relation to constituted discourses (Calhoun, LiPuma and Postone eds., 1993, 263-75).

\section{Implications of Bourdieu's Phenomenological Orientation for Understanding the Constitution of This Volume}

It follows from the above that my attempt in editing this volume to invite a phenomenologically constitutive attitude towards the scrutiny of Bourdieu's 
work is also an attempt to apply his thinking to his own production. In the late 1990s I was invited by Sage Publications to make a four-volume selection of articles about Bourdieu's work (Robbins ed., 2000). I prepared the selection in seven parts, one of which concentrated on the presentation of his key concepts, such as 'cultural capital', 'habitus', 'field' and 'reproduction', and another of which focused on the intellectual fields in which his concepts had been used - education, anthropology, philosophy, sociology, linguistics and cultural studies. I found an opportunity to discuss the content of the four volumes with Bourdieu in advance of publication. As always, he was instinctively directive but ideologically non-interventionist. He challenged nothing and considered it illegitimate to suppose that he might, but he suggested that another part, on 'applications' of his work, should, if possible, be strengthened. He was clear that he was not interested in the exegeses of his concepts. His own thinking and experience had moved on. His concepts had fulfilled functions at particular historical moments and in his own career trajectory. He had incorporated them into his practice but he seemed tired of regurgitating explanations of their 'meanings'. His engagement in the struggle against neo-liberalism and his encouragement of new social movements internationally had become his overriding commitments. True to the orientation articulated as early as 1968 in his 'Structuralism and Theory of Sociological Knowledge' (1968), he commented that much of the research of others that most satisfied him was to be found in articles in which his name was never mentioned. He was aware that it was inescapable that his concepts had now acquired a historically reified status and that new researchers would think with his concepts, reconceptualization being a form of reproduction or reconstitution, but he remained anxious to insist on the primacy of new perspectives and new perceptions that would meet heuristically the new needs of a changing society, developed through the exercise of constantly adapting methodology rather than through the 'symbolic violence' of moribund theory.

The situation of Ludwig Landgrebe vis-à-vis the work of Husserl is paradigmatic for this collection of articles on Bourdieu. Landgrebe eventually completed in 1935 the introduction to Husserl's papers on logic, which he had been first asked by his master to assemble in 1928. Landgrebe's introduction to what was to be published as Erfahrung und Urteil (Experience and judgement) sought to synthesize Husserl's thinking as published in his Formale und tranzendentale Logik (Formal and transcendental logic) (1929) with the prepublication texts of what was to be published as Die Krisis der europäischen Wissenschaften und die transzendentale Phänomenologie (The crisis of European sciences and transcendental phenomenology). In paragraph 10 of his introduction, Landgrebe claimed that 
[t] he task of the elucidation of the origin of the predicative judgment, of establishing its relation to a foundation and of pursuing the origination of prepredicative self-evidence in that of experience, turns out to be, in conformity with our elucidation of the essence of experience, the task of the retrogression to the world as the universal ground of all particular experiences, as the world of experience immediately pregiven and prior to all logical functions. (Husserl, ed. Landgrebe 1973, 41; italics in original)

Importantly, Landgrebe proceeded to clarify that this desired process of 'retrogression' is not ahistorical:

this retrogression to the original life-world is not one which simply takes for granted the world of our experience as it is given to us but rather traces the historicity already deposited in it to its source. (Husserl, ed. Landgrebe 1973, 45)

In short, retrogression recovers the cumulative reconstitution of experience. It is not surprising, therefore, that Landgrebe's subsequent Philosophie der Gegenwart, 1957, (Major Problems in Contemporary European Philosophy: From Dilthey to Heidegger, 1966) attempted an account that problematized philosophical endeavour, seeking to relate its efforts to the 'world of experience' rather than to consider it within its own self-regulated parameters. He sought to question philosophical discourse in the same way as he believed that Husserl had challenged the discourse of logic. Landgrebe thought that his contemporary situation made 'mandatory a basic reappraisal of the nature of philosophy and of its traditional foundations' $(1966,2)$.

In similar fashion and for similar philosophical reasons, this book about Bourdieu's contribution to sociology does not presuppose a normative 'sociology' but discusses his work in relation to systems of reception and application - both temporal and geographical. The systems are constructed fields and these are represented in terms of intellectual fields and their systemically different positions within different nation-state sociopolitical systems. The present Companion to Bourdieu assumes that the likely readership will be familiar with many of the books on Bourdieu's work that have been published in the decade since his death in 2002. In particular, for instance, it assumes that English-speaking readers will be acquainted with collections of essays such as Pierre Bourdieu: Key Concepts, edited by Mike Grenfell (2008 and 2012) and The Legacy of Pierre Bourdieu: Critical Essays, edited by Simon Susen and Bryan Turner (2011). The distinctive rationale for this new collection is that it elucidates Bourdieu's work by applying his own sociological approach to epistemology to his own texts. It seeks to subject the occidental foundations of his conceptualizations to scrutiny by exploring the meanings of his works as they 
have been and are being transferred cross-culturally within discourses that are differently constituted in different societies. Contributors have attempted to analyse reflexively their own responses to Bourdieu's work and their deployment of it within their own societies, and, in doing so, to offer original perspectives on a variety of Bourdieu's texts.

\section{Reading the Contributions}

To adopt a Bourdieusian approach to a volume on his work necessarily involves four dimensions of analysis to enable us to do justice both to his conception of the relationship between diverse primary social experiences and 'fields' of explanation and to his recognition that 'fields' both provide a medium for the articulation of experience and for the constitution of new experience. We can, firstly, endeavour to give an account of his conceptual system, assessing the internal coherence or logic of its interrelated components. Bourdieu was inclined to regard this as a necessary, but tautologuous, procedure, reminiscent of the non-empirical scholasticism about which he wrote in his postface to his translation of Erwin Panofsky's Gothic Architecture and Scholastic Thought (trans. Bourdieu 1967). We can, secondly, attempt to represent the conditions of his practice, elucidating the ways in which he constructed his concepts in response to research problems, thereby suggesting that they had historically contingent validity causing their current value to be interrogated in respect of changing social conditions. Whether or not we examine Bourdieu's concepts within relatively autonomous fields of discourse or whether we examine them as the products of specific structuring conditions, we are, thirdly, able to assess their pragmatic value within new and different conditions. These may be new conditions that are distanced temporally or geographically from those in which Bourdieu generated his explanatory findings. We are obliged, fourthly, to pay attention to our own positions in attempting to make any of the three previous forms of evaluation. In writing 'Projet créateur et champ intellectuel' ('Intellectual field and creative project', Bourdieu 1966, in Young ed., 1971, 161-188), Bourdieu tried to expose the inadequacy of 'structuralist' readings of past cultural relations on the grounds that it was important to acknowledge that these relations were the products of immanent structuration. Nevertheless, he was well aware that this orientation was indicative of his own position taking within the Parisian field of higher education in the 1960s. It is significant that he undertook the analysis shortly afterward of the objective conditions of his own objectivity, which were to be published in Homo Academicus in 1984 (Bourdieu [1984], 1988). It can be argued that this degree of reflexivity leads to a circularity designed to avoid criticism. Far from being obliged to reflect on our own positions, it might be argued that we should 
extricate ourselves from the maze within which Bourdieu entraps us. Bourdieu pre-emptively relativizes the ground on which his relativism might be challenged. I shall return to this point in some concluding comments.

The organization of the volume tries to acknowledge these differences of approach by differentiating between the emphases of two parts, even though there is inevitably some overlap. Part 1 - 'Aspects of Bourdieu's Thought' - gives three further chapters that differently explore the content of Bourdieu's work. Part 2 - 'Case Studies of the International Deployment of Bourdieu's Thought' - provides five chapters that tacitly or explicitly evaluate Bourdieu's work by analysing its reproduction and use in different cultures. In now summarising the chapter contributions, I offer my opinions for consideration and debate.

Simon Susen gives a brilliantly lucid exegesis of Bourdieu's system of thinking, followed by trenchant critical comments. The chapter is an offering within a theoretical discourse and, as such, corresponds to the first possible approach to Bourdieu's work summarized above. Susen and I have exchanged views before about the validity of this kind of critique. I reviewed Susen's The Foundations of the Social: Between Critical Theory and Reflexive Sociology (2010) in an article that I entitled 'The Foundations of Social Theoretical Discourse' (Robbins 2010). More recently, I was invited to be a respondent to Susen's 'Bourdieusian Reflections on Language: Unavoidable Conditions of the Real Speech Situation'. The article and my response were both published in Social Epistemology (Susen 2013, and Robbins 2013), as was his response to my response. My reservations are unchanged and are of two kinds. Susen's accounts of Bourdieu's work are resolutely ahistorical. He deliberately discounts the extent to which Bourdieu's conceptual interventions were strategic or conjunctural. Relatedly, I find Susen's exegeses of Bourdieu to be ambivalent in that he theoretically recognizes the legitimacy of Bourdieu's tacit criticism, especially in his Ce que parler veut dire (What speaking means, Bourdieu 1982), of Habermasian assumptions about the possibility of rational communication, accepting that real speech situations are socially contingent, but he does not accept that the grounds upon which he expresses this critique are themselves contingent and socially constituted. Susen appears to recommend Bourdieu's emphasis of 'reflexivity' in his detailed analysis, but he is not prepared to grapple with the problem whether philosophical debate about social science is necessarily socially contingent rather than philosophically absolute. He does not demarcate the boundaries of the discourse within which he is operating.

My reservations about the foundation of Susen's critique relate to a difference of emphasis that we give in interpreting Bourdieu's attitude to sociology. Susen begins his chapter by outlining three 'distinctive ambitions that characterize "Bourdieu's brand of reflexivity". The third of Bourdieu's 
ambitions is characterized as being "to identify and explore the constitutive components that undergird "the epistemological security of sociology", thereby challenging the view that radical uncertainty permeates all claims to objective, normative, or subjective validity'. The italicized phrase derives, as is indicated in a footnote, from the part of Loïc Wacquant's commentary on Bourdieu's work in An Invitation to Reflexive Sociology (Bourdieu and Wacquant 1992b), which is entitled 'Epistemic Reflexivity'. The actual phrase used by Wacquant states that Bourdieu's brand of reflexivity sought 'not to assault but to buttress the epistemological security of sociology', and he continues, 'Far from trying to undermine objectivity, Bourdieu's reflexivity aims at increasing the scope and solidity of social scientific knowledge, a goal that puts it at loggerheads with phenomenological, textual, and other "postmodern" forms of reflexivity (Platt 1989, Woolgar 1988)' (Bourdieu and Wacquant 1992b, 36-7). Susen uses, and acknowledges, phrases from this sentence in his elaboration of the point. It is clear that Wacquant was anxious to represent Bourdieu's position in opposition to alternative versions of reflexivity and, particularly, in opposition to positions advanced recently at that time in British publications that seemed to recommend postmodern reflexivity. It is interesting to note that these sentences from Wacquant's commentary are taken from two paragraphs that do not appear in the French original of which An Invitation to Reflexive Sociology is a 'translation' (Bourdieu and Wacquant 1992a). Susen's argument here is based on Wacquant's mediation of Bourdieu rather than on Bourdieu's own words. Certainly, Bourdieu was to define his position in relation to the work of Steve Woolgar in his Science de la science et réflexivité (Science of Science and Reflexivity [2001], 2004), but there is no evidence that he sought, around 1990, to 'buttress the epistemological security of sociology' against phenomenological dispositions. The implication of the phrase appears to be that Bourdieu was intent on deploying reflexivity so as to preserve or sustain sociology as an intellectual discipline. I contend that Bourdieu used sociological discourse as a means to secure a phenomenological reduction that would expose the fundamental bases of all rationalizations. He was not seeking to safeguard 'sociology' as such or to privilege 'objectivity' but, rather, to exploit the inheritance of the sociological tradition to clarify and liberate primary experience. The distortion in translation of the title of An Invitation to Reflexive Sociology is indicative of the misappropriation of reflexivity for the maintenance of sociology. The French text was entitled Réponses: Pour une anthropologie reflexive (Replies: for a reflexive anthropology, Bourdieu and Wacquant 1992a).

The notes and references in Susen's contribution in themselves offer invaluable bibliographic information both in respect of Bourdieu's own work and in respect of the secondary literature. These are recommended to the reader. Susen is also meticulous in providing the original French text corresponding with the passages that he quotes in English translation. Again, these endnotes 
are very helpful for those who may be interested in pursuing in more depth the implications for conceptual transfer of linguistic translation (an issue that arises in an interesting manner in the contributions of Aizawa and Iso, and Gao and Yang).

Expressing dissatisfaction with much of the contemporary celebration and criticism of the work of Bourdieu, Frédéric Vandenberghe suggests that 'what is needed [...] is a post-Bourdieusian theory of the social world that is not anti-Bourdieusian'. In the terminology of this introduction, this means that we need criticism that acknowledges the extent to which Bourdieu's work has become constitutive of our current theorizing about society. Like Susen, Vandenberghe does not question the validity of the discourse within which he proposes to undertake his analysis. Bourdieu's 'genetic structuralism now occupies the position of the hegemon within the global field of sociological theory'. This field is now a 'structured structure'. In order to consider the present value of Bourdieu's work, Vandenberghe considers two authors 'at the cutting-edge of contemporary social theory'. This will be an 'exercise in comparative theory', but one that presupposes the global validity of the discourse within which the comparison is to be effected. However, unlike Susen, Vandenberghe cannot obliterate asides that indicate his awareness of contingent factors at the back of his comparison. Bourdieu's genetic structuralism now occupies the position of the hegemon, but this remark is followed by the comment that its status is comparable to that of 'structural functionalism in the post-war period'. He chooses to compare and contrast the work of Margaret Archer and Bernard Lahire. In introducing them, he notes that both are 'European', that 'Margaret Archer worked at the Centre de sociologie européenne in Paris in the early sixties', and that 'Bernard Lahire belongs to the next generation'. The possible implications of geographical and temporal situation are mentioned, therefore, but they are not allowed to impinge on the consideration of the theoretical validity of Bourdieu's concepts. I would argue, however, that the recognition of the importance of time and place is crucial, both for our understanding of Bourdieu and for our appreciation of post-Bourdieusian moves. We need to register that Archer works with some of Bourdieu's concepts primarily in relation to British society and by harnessing elements derived from American pragmatism, whereas Lahire relates primarily to French society, harnessing elements from the French sociological tradition. Vandenberghe reports that, in Lahire's view, in deploying the concept of 'habitus' universally, Bourdieu was 'abusively generalizing a particular model that only holds in exceptional situations'. In respect of the concept of 'field', it is attributed to Lahire that Bourdieu was guilty of 'transforming a regional model into a general theory of the social world'. It is not clear whether Vandenberghe considers that Lahire avoids the same error in his 
retheorization of Bourdieu. He expounds Lahire's thought with great lucidity, but the question of the generalizability of social theory, which is the subtext of this whole volume, remains dormant. Lahire's revision of Bourdieu's concept of the habitus now emphasizes that our dispositions are not exclusively constrained intergenerationally but are developed omnivorously in the context of a multiplicity of potential affinities. Vandenberghe glosses this perception with the comment that 'the cleavage of the habitus that splits class-defectors (transfuges de classe), like Bourdieu himself, is now generalized and democratized as it were'. The Bourdieusian theory beyond which Lahire moves is casually seen to be an expression of Bourdieu's personal, historically situated, social trajectory. Is the theory of the 'omnivore', therefore, a genuinely theoretical modification of Bourdieu's perception or is the new theory simply one that accurately registers the objective changes in social dispositions between the 1960s and the 2000s and the differences of subjective disposition as a consequence of the social trajectories of Bourdieu and Lahire (the latter constituted by the conceptualization of the former)?

Whereas Vandenberghe presents Lahire as 'a determinist', he presents Archer as 'a voluntarist'. He writes on the assumption that the two postBourdieusians have exposed opposite inadequacies in Bourdieu's thinking, even though Bourdieu was always clear that our actions are always 'softly determined' both mechanistically and finalistically. In examining the work of Archer, Vandenberghe provides a clear exegesis of her 'morphogenetic' perspective. He explains how she has developed a 'Structure, Agency, and Culture' model to move beyond the arid legacy of the 'structure/agency' debate. She has articulated her position in a series of books mainly published since Bourdieu's death, but her ideas are not now disconnected from the 'larger concerns that have occupied her since the late 1970's'. 'In direct opposition to her former mentor', Vandenberghe claims, Archer has emphasized a 'turn inwards' that stimulates the kind of rational choice denied by Bourdieu as a consequence of his disinclination to recognize any autonomy for essential selves. She has discarded Bourdieu's 'soft determinism'. In Vandenberghe's representation of Archer's view, people 'choose a modus vivendi as a living compromise between the actual and the possible'. 'In her interviews with people from all walks of life, the British sociologist discovered that reflexivity comes mainly in four modes', and Vandenberghe usefully indicates these. However, he does not pursue the implications of this introductory statement. He is careful to re-emphasize that Archer is a 'British' sociologist, and yet he also seems to imply that the diversity of the interviewees somehow guarantees the universality of Archer's categorization. He does not conceal his uncertainty about the general applicability of the model that he describes. The second category of individual reflexives are 'communicative reflexives'. Vandenberghe comments 
that these are 'mostly women (but this may be an artefact of Archer's initial sample)'. The model of cultural behaviour may, in other words, be culturally specific. As a revision of Bourdieu's thinking, it may be the case that the status of Archer's categorization is problematic because it fails to accept that the distinction between 'critical realism' and 'critical sociology' is founded on a non-recognition of the dialectic active in Bourdieu's work between realism and nominalism. Bourdieu insisted that the language deployed by social scientists, generating science or theory, has some discursive autonomy, but only a relative autonomy in relation to the situation within the described social reality of those social scientists themselves. Our theoretical responses to Bourdieu's work can be located within the different discourses that he strategically occupied at different points in his career (anthropology, philosophy, sociology and more), but the utility of our critiques depends upon our contingently different real circumstances.

Vandenberghe's second section moves beyond consideration of the two 'post-Bourdieusians'. Some of the suppressed uncertainty of the first section is disclosed in the contention that 'sociology as a whole can actually benefit from a critique of sociology (in the sense of Kant)'. More specifically, he goes on to argue that we need 'a philosophical anthropology' so as 'to understand what sociology cannot grasp'. It is in this constructive conclusion that we are in accord. He invokes Georg Simmel, Max Scheler, Helmuth Plessner and G. H. Mead, and offers a few tantalizing comments in a related footnote. Humorously inserting himself, he looks for future 'dialogue with British-style social theorists and German social philosophers (even if they live in Latin America)'. The organization of the present volume is based on a comparable turning towards phenomenology to perform the function that Vandenberghe proposes should be undertaken by philosophical anthropology. The intention of my contribution in the next chapter is to suggest that Bourdieu was himself aware of the need to develop internationally an anthropological reflexivity that might challenge the mutually reinforcing conceptual and political domination of Western European sociology.

I should say very little about my second contribution (Derek Robbins). Susen and Vandenberghe offer perspectives on Bourdieu's work that are not preoccupied with precise consideration of its contextual meaning. I try to indicate the trajectory of Bourdieu's thought as it was affected conjuncturally by his emerging international reputation. I hope, incidentally, that the chapter gives an informative guide to the stages of Bourdieu's career. In part, I attempt to offer the kind of 'sociogenetic understanding' of Bourdieu's work that he requested, and, in part, to suggest that the organization of this volume sustains his vision that the challenge for international intellectuals is to actualize opportunities for socioanalytic encounter in terms of differing dialectics 
between social realities and discourses rather than in terms of an imposed theoretical consensus perpetuating, in mutual reinforcement, detached conceptualization and the social distinction of a minority group.

Part II is devoted to this pursuit. I asked international contributors to provide a new perspective on the work of Bourdieu by assessing its significance within their own national contexts. That is to say that they were asked to write about Bourdieu's work in terms of its relevance to their diverse national situations and not primarily in relation to any supposed international 'field' of sociological or social theoretical discourse. They were asked to consider the structured structure of Bourdieu's oeuvre in relation to the structuring structures of their own societies rather than in respect of any internationally constituted forum of intellectual exchange. Each responded differently and in ways that enable this volume to offer analysis of the work of Bourdieu as a case study for the more general consideration of the universal applicability of the tradition of social scientific explanation generated and maintained within Western Europe over little more than the last 100 years.

Marco Santoro and Andrea Gallelli attempt to measure the reception of Bourdieu's work within Europe. They proceed in three steps. They first offer an account of the 'linguistic and spatial distribution' of Bourdieu's work in Europe. Secondly, they 'focus on the reception of Bourdieu's ideas in and through a bibliometric analysis of journal articles'. Thirdly, they apply network analysis 'to map the relations between European countries and some Bourdieusian key concepts'. The whole analysis provides empirical data for Europe that is a paradigm for consideration of the global dissemination of Bourdieu's work, which is a theme of the volume. In a final section, Santoro and Gallelli 'summarize the main results of this research, locating them in a general consideration about Bourdieu's embeddedness at once in a global and European academic field'.

In 'L'impromptu de Bruxelles' (The Brussels impromptu, Bourdieu 1993), Bourdieu suggested that the development of a European sense of identity and an inter-national sense of intra-European unity should proceed through the recognition of internal differences of political philosophy amongst member states rather than through any central imposition from the European commission. Santoro's chapter offers documentary ammunition to enable us to deploy the reception of Bourdieu's work as a vehicle for just such bottom-up identification. It reminds us that the Western European intellectual tradition is not at all monolithic. Its construction has involved the absorption of diverse interpretive reflections of diverse social realities into a unifying artefact. The intra-European process could be said to be paradigmatic for an intraglobal process, following the process identified by Bourdieu in the 'gentilitial democracy' of the Kabyle in Algeria (see Bourdieu 1958) whereby, he claimed, social 
organization occurred through the interaction of widening concentric circles of responsibility and accountability rather than through the imposition of abstract legal authority. Fittingly, Santoro and Gallelli announce their intention to continue their work so as to 'to deepen the knowledge of the structural properties of the international community of Bourdieu scholars'. This will be an important project even if, however, extremely ambitious. It will statistically complement some of the insights into local situations provided in the chapters of this book. Santoro and Gallelli touch on two key problems of which they are acutely aware. Their analyses of the reception of Bourdieu's work draw attention to the significance of the wider question of the consequences of Anglo-Saxon linguistic domination of international sociological discourse. Their findings here reinforce, firstly, the argument in my chapter where I indicate the implications for Bourdieu's practice of his awareness of the enormous change in his reputation and influence that developed as a result of the English translations published by Polity Press after 1984. Santoro and Gallelli are also sensitive to the inadequacies of the measures that they use. They accept that, as Bourdieu put it, the status of intellectual work is established 'force majeure' as much as in terms of intrinsic merit. This is as true of the diffusion of his work as of the distribution of the secondary literature. He was sceptical about the value of citation indices just as he would have been sceptical about 'league tables' of institutional or individual performance. These statistical instruments have to be held in reciprocal balance with qualitative case studies in the way Bourdieu recommended in his early introduction to the first part of Travail et travailleurs en algérie (Work and workers in Algeria), entitled 'Statistiques et sociologie' (Statistics and sociology, Bourdieu, Darbel, Rivet and Seibel 1963, 9-13).

Shinichi Aizawa and Naoki Iso are young researchers, both of whom earned their doctorates in Japanese universities but both of whom also have studied recently in Western Europe (Aizawa in Oxford and Iso in Paris). Although they do not explicitly make this point, it is important to register that the accounts of the Japanese reception of Western sociology from the 1950s to the 1980s and of the early reception of Bourdieu's works in the 1960s and 1970s, as well as, even, of the translation of La distinction (Distinction) in 1989-90, are historical commentaries related to the period before the birth of the authors or before their youth. They provide, unreflexively, an account of the constituted Japanese discourse by which they have been constituted, the origins of which in Western thinking have been consolidated by their association with Western university institutions. The later parts of their contribution disclose fundamental cultural differences between Western and Japanese society, particularly in respect of attitudes and policies concerning education. Aizawa and Iso are especially convincing about the way in which the different 
weightings given to educational achievement and extracurricular activity in Japan impinge on the validity of Bourdieu's model in relation to educational and cultural reproduction. They also draw attention to the contemporaneity of Bourdieu's lectures given in Japan in late 1989, published in Raisons pratiques (Practical Reason [1994], 1998) and the courses of lectures that he gave at the Collège de France between January 1990 and December 1991, which have been issued posthumously as Sur l'État (On the state [2012], 2014). This recognition needs to be set alongside my representation of Bourdieu's dilemma in respect of internationalization during those years. Aizawa and Iso make important points about the changing Japanese attitudes or self-images in respect of equality/inequality, and they interestingly outline their perspective for the future in which, they think, Bourdieu's conception of cultural capital needs to be challenged. In making these points, they reveal the extent to which they are necessarily 'post-Bourdieusians' in the sense that their adoption of Bourdieu's conceptual framework has enabled them to consider its validity in the Japanese context. They do not countenance an anthropological critique as envisaged by Vandenberghe - one that might consider that the assimilation of Bourdieusian concepts runs the risk of reinforcing a denial of the indigenous values that are still apparent in the balance between cognition and affective well-being in Japanese practice.

Sheena Jain's chapter offers, first, a philosophical discussion that draws attention to the proximity of Bourdieu's thinking to contemporary consideration in, particularly, the work of Ricoeur and Jacques Derrida, of the status of language in mediating between theory and reality. It offers, secondly, a detailed case study of a recent set of labour relations incidents in the Maruti Suzuki car factory at Manesar in Gurgaon, India. This exemplifies the issues announced in the opening discussion and leads clearly into an evaluation of the utility of Bourdieu's work in the Indian subcontinent. The tendency of my phenomenological reading of Bourdieu is to suggest that there might now be a crisis of the global social sciences that can be conceptualized in terms which are similar to those adopted by Husserl when he detected a crisis of the European sciences in the 1930s. The dissociation of rationalized science from originary experience is of a different kind when argued in relation to social behaviour rather than, as in Husserl's case, in respect of the rationalizations of the natural sciences. In the social sciences, rationalizations and internationalizations modify indigenous experience and challenge the primacy of local, affective cultures. Jain's underlying contention is rather that the situation of the working class in India is indicative of the emerging universal condition. Her discussion of the relevance of the work of Bourdieu becomes inseparable from her verdict on the universal validity of Marxist analysis. Jain seems to accept that a universal explanatory discourse already exists with the result 
that there is no need to contemplate either anthropological or phenomenological critiques of sociology or the modifying effects of local conditions, such as the legacy of British colonialism or the persistence of indigenous religious values. This position raises two very pertinent questions about both of which there is a large literature. The first concerns the nature of Bourdieu's relation to Marxist thought, and the second concerns the international validity of that thought. In relation to the former, I recommend reference to Wacquant's 'Further Notes on Bourdieu's "Marxism"' (2001), and in relation to the latter, attention to Justin Rosenberg's The Empire of Civil Society (1994) and, in respect of India, Irfan Habib's 'Marx's Perceptions of India' (1983). I have to say that, for myself, I find definitive Bourdieu's analysis of labour and labour relations in precolonial and colonial Algeria, as found in Travail et travailleurs en algérie (Bourdieu, Darbel, Rivet and Seibel 1963), where he demonstrated that the applicability of Marxist explanation is relative to the specific conditions to be explained, that is to say that the model of Marxist explanation is not universally appropriate. Marxist explanations were listed alongside structuralist ones in 'Three Forms of Theoretical Knowledge' (Bourdieu 1973) as forms of objectivist theorizing that needed to be subjected to sociological scrutiny. Nonetheless, Bourdieu did not seek to negate the insights of Marxist analysis and his 'On Symbolic Power' ([1977], in Bourdieu 1991, 163-70) shows how he attempted to accommodate Marxist ideas within his conceptual schema. Jain is convincing in trying to graft Bourdieusian views onto Marxist assumptions. She welcomes Bourdieu's analyses of domination and reproduction but argues that these relations 'are $[\ldots]$ disinterred from the social relations of wage labour and capital within which in reality they are embedded'. Bourdieu provides a sociocentric gloss on phenomena that are fundamentally economic. 'Bourdieu's political sociology fails to illuminate certain facets of contemporary working class politics', but 'there is nevertheless much that is of value in his theory of practice for analysing significant dimensions of the overall process as it unfolded'. She assigns distinctly subordinate value to Bourdieu's analyses, but she neatly returns to her opening philosophical discussion of the status of explanatory language to acknowledge that the shortcomings she has identified do not entail rejection of his endeavour: Bourdieu's 'theory of practice does not invite a severely judgemental response regarding the accuracy of his conceptual framework, but rather a sensitive appraisal of what it may have to offer'. She accepts that Bourdieu was never working with 'realist' conviction and that, consequently, his concepts retain pragmatic value. In Jain's view, Bourdieu's scepticism about theoreticism is a useful prelude to the recognition of the growing impotence of social theory in times when unreflecting practice is becoming the prevailing motor for change. 
The contribution of Yang Yang and Xuanyang Gao has two distinctive features, inviting comparison with the chapters of Aizawa and Iso as well as of Jain. In the first place, this co-authored chapter is the product of collaboration between a young researcher who has recently completed her doctorate at the University of Cambridge, UK (Yang) and a senior academic (who worked and studied in France during the 1990s). In this regard, the chapter is the expression in conjunction of someone who has lived through many of the upheavals of the second half of the twentieth century and of someone who, like Aizawa and Iso, was not born until the late stages of the historical period described in the text. In the second place, the account is of the reception of Bourdieu's work in a state that has institutionalized the Marxist dogma implicitly embraced by Jain in her thinking.

Gao and Yang first offer an account of Bourdieu's conceptual framework as it developed in the 1960s, explicating the concepts of 'capital, habitus, field, and reproduction'. They then give a historiography of the reception of Bourdieu's work and secondary literature in China that sits alongside the comparable discussions offered by Aizawa and Iso, and Santoro and Gallelli, and Méndez. The account defers to an article by Chen and Zang of 2009, which suggests that 'sociology and political sciences "were re-established"' in the postreform period after 1978. This formulation is slightly at odds with the chapter's recognition that Bourdieu's thinking enables more fundamental consideration of the function of social understanding in facilitating social cohesion. The chapter is persuasive in arguing that Bourdieu's work is relevant in encouraging dialogue between 'New Confucianism' and Communist Party ideology. Bourdieu's influence, in other words, is not to be identified with the imposition of Western social science as an adjunct of the westernizing 'modernization' of Chinese society. The complexity of conceptual transfer is highlighted in an illuminating way by reference to alternative translations of habitus, favouring one that is compatible with indigenous philosophical concerns. The section that follows on a Bourdieusian analysis of the social transformation of China gives a sketch of the radical changes in Chinese society and its economy since 1978 that tends towards the conclusion that these changes have generated conditions conducive to the kind of analysis offered by Bourdieu. Gao and Yang comment that 'the inextricable connection between one's material conditions and social status which unifies Bourdieu's sociocultural analysis was solidified.' They suggest that 'the coexistence of a "quasi-free-market economy" and the State-controlled post-communist system has led to the formation of three "new classes" in China'. These new classes reproduce themselves differently. The 'new middle class' is dependent on cultural capital; the entrepreneurial class depends on the continual conversion between social and economic capital rather than on economic capital alone; and the third class 
constitutes the 'political elite' whose position is defined within the hierarchy of the party. The implication is that a sociocentric interpretation of the work of Bourdieu limits the applicability of his concepts to specific categories of Chinese society rather than to its totality. The dominant authority of political capital within an hierarchical political system is in unresolved tension with the emerging power of social and cultural capitals in non-political spheres. There is a sense that things might have been, and might still be, otherwise. Gao and Yang next consider the particular case of the relevance of Bourdieu's analyses of education to the Chinese situation. His work is 'fallible' on two counts. Whereas Aizawa and Iso suggest that Bourdieu's model does not accommodate the extracurricular emphasis in Japanese education, Gao and Yang argue that it does not accommodate the extent to which the Chinese system is exam oriented and controlled politically. In other words, the Chinese educational system remains subordinated to political authority and does not provide scope for the independent acquisition of social and cultural capitals. The challenge is to consider how far Bourdieu's thinking was framed by his inhabiting a liberal democratic state and whether, therefore, it can provide analytical tools within a different political system without prerequiring that this system should be subverted. Responding to this challenge involves resituating Bourdieu's work within its originary context. It was Raymond Aron who conceived that it should be the function of the research group that he established in 1960 (which was to become the Centre de sociologie européenne) that it would comparatively examine socioeconomic behaviour between differently constituted political regimes. The essential comparison was between command and market economies. Out of this dualistic conceptualization typical of the Cold War period emerged the volume, edited by Robert Castel and Jean-Claude Passeron, entitled Éducation, développement et démocratie (Education, development and democracy, 1967), which published some of the findings of analyses of educational systems within different European political regimes. The issue was whether pedagogic practices and institutions have an intrinsic logic irrespective of political context or whether they are differently constituted by different political systems. Bourdieu and Passeron contributed an introductory chapter entitled 'La comparabilité des systèmes d'enseignement' (The comparability of systems of education), in which they argued that, in every society, the network of relations between subsystems needs to be analysed without privileging a priori either cultural or political determinants. There has been a tendency to consider Bourdieu's analyses of education and culture in France in the 1960s as countercultural with regard to politics, but he never wished to segregate sociology from political science. This became apparent in the work of the late 1980s, evident in the publication of La Noblesse d'Etat (State nobility, Bourdieu [1989], 1996) and in the posthumously published lectures of 1989-92 at the 
Collège de France: Sur l'état (On the state, Bourdieu [2012], 2014). Gao and Yang give a fascinating account of the recent prehistory of East-West relations, impinging on China's search for a 'legitimate culture'. In introducing the potential role to be played by a re-emphasis of Confucian values, they surprisingly comment that 'in fundamental disagreement with what Bourdieu defines, a nation's legitimate culture should never be the culture of the dominating group, but should be that which can resonate to the greatest extent with the society' and proceed to argue that the restoration of Confucian ethical norms has the potential to reactivate popular adherence to a national identity. They detect some affinity between the thought of Bourdieu and of Confucius, but differentiate in the following way: 'The principal distinction between these two paradigms is that Bourdieu's sociology is a sociocultural theorisation of power relations in society, while what Confucius (or Confucianism, when referring to the entire school of thought) has produced is primarily a philosophy on the regimentation of life and the cultivation of proper social behaviours'. I submit that Bourdieu's 'sociocultural theorisation of power relations in society' was part of his strategic endeavour to enable disadvantaged groups to participate culturally and politically in their nation states and thereby to construct themselves the conditions by which they are constrained. His career was devoted to the task of subverting the legitimacy that, de facto, was identified with the culture of the dominating group. Realpolitik may dictate the acceptance of the Communist Party's willingness to revive Confucian influence, but this is a solution that adopts thinking analogous to that of Bourdieu within the social sphere while neglecting his desire to actualize the social construction of politics.

In her opening remarks, María-Luisa Méndez explicitly accepts the task of considering the transferability of Bourdieu's concepts. She specifies that her concern will be with four main topics: firstly, the way in which the observation of a mismatch between habitus and field assisted in analysing malaise in Chile, which had 'experienced rapid processes of social mobility'; secondly, the way in which the same concepts contributed to the understanding of the 'position taking' of the new middle classes; thirdly and fourthly on the value of 'reproduction' as a conceptual tool for identifying inequalities nationally and internationally.

She begins with an introductory section entitled 'The sociopolitical context of a Latin American sociological endogenous thinking'. The choice of the word 'endogenous' encapsulates the problem raised throughout this collection: at what point can intellectual developments that are effected within the geographical contexts of individual nation states (indigenously) as a result of the return of intellectuals trained abroad (exogenously) be considered to be produced endogenously (from within). Méndez considers reflexively the 
implications of the fact that she, and many of her compatriots, have related dialectically with their native social contexts as a consequence of their incorporation of theories produced and disseminated in Western European universities. She recognizes that her experience has exemplified a subjective absorption of an objectivity, has constituted an existential illustration of the theory objectively adumbrated by Bourdieu. She provides an account, supported by charts, of the institutionalization of the social sciences in Chile from the 1950s to the present. As in other chapters, it is clear that this process has been influenced by political changes. A series of dictatorships interrupted the development of social science, but these are presented as essentially institutional rather than ideological interventions. She also has a section in which she situates her own intellectual development within debates in Western Europe and, in particular, in the United Kingdom where she wrote her $\mathrm{PhD}$. She offers a sophisticated analysis of her dilemma. On the one hand, she was articulating a conceptual position within the field of British sociology - and she specifies some of the 'post-Bourdieusians' (see Vandenberghe's chapter) with whose work she was engaging in the early 2000s - while, on the other hand, she was involved in importing new perspectives derived from this source into 'the sociological arena in Chile', using these to argue that 'traditional approaches in social stratification' now lacked 'key elements in addressing cultural change' such that it was necessary to 'develop a more up-to-date research programme'. Significantly, Méndez states that the consequence of the above tension was that she had to 'translate this [British] debate into the interests of the Latin American sociological field', but, for me, the prior question is to consider the extent to which this translation was a response to Chilean social realities or, instead, an assimilation of 'Chilean sociology' to the westernized 'field' of international sociology. The supplement to this prior question, of course, is to ask whether the process of translating Western European concepts to the Chilean context is one that contributes to the generation of a perception of social conditions which is then self-fulfillingly validated in the terminology of the imported analysis. Méndez makes no reference to the indigenous values of Chilean society, which, I imagine, could be said to be dominated by the legacy of Spanish colonization and Catholic proselytism, and, in this respect, she offers no account, which could be compared with the accounts given by Aizawa and Iso, and Gao and Yang, of the traditional cultural contexts of reception of Bourdieu's work. The assimilation of Western European sociological concepts to Chilean sociopolitical conditions runs the risk of segregating an international sociological discourse from immediate social realities. Mendez is right to spend time discussing the relationship between Bourdieu's use of the concept of 'habitus' and his use of the term 'hysteresis'. She suggests that she found Bourdieu's articulation of the latter in Pascalian Meditations 
'extremely persuasive' in relation to the phenomena that she observed when analyzing the adaptation to change of 30 Chilean people 'broadly described as middle class'. She quotes Bourdieu's comment that

in situations of crisis or sudden change, especially those seen at the time of abrupt encounters between civilizations linked to the colonial situation or toorapid movements in social space, agents often have difficulty in holding together the dispositions associated with different states or stages, and some of them, often those who were best adapted to the previous state of the game, have difficulty in adjusting to the new established order. ([1997], 2000, 161)

I think it is worth noting that Bourdieu's emphasis of 'hysteresis' constituted a shift in thinking that he effected relatively late in his career. He developed the concept of habitus in the 1960s in relation to his reflections on his experience in Algeria. The 'habitus' was the word he chose to describe the ways in which the traditional values of Algerian tribespeople had become internalized in a way that dictated their dispositions in relation to modern values. The 'habitus' constituted the instrument for Algerian self-determination in conflict with the impositions of French colonialism. The acquisition of independence provided Algerians with the opportunity to actualize their dispositions in a state whose structure would no longer be predetermined by the colonial power. As indicated at the end of Le déracinement (The uprooting), the education system of the new state should be the mechanism for the negotiation of its own values in a process of socioanalytic encounter. As Bourdieu and Sayad put it,

It is in the permanent confrontation between the expectations of the peasants and the exercises of the élites [...] that an authentic culture can be elaborated a system of models of economic and social behavior which is at once coherent and compatible with objective conditions. $(1964,177)$

Bourdieu sustained this orientation in his work of the 1960s in France but, I suggest, his optimism about the capacity of the dominated to negotiate a unified national identity in encounter with the dominant waned after the failure of the student revolt in 1968. Thereafter, the 'habitus', which was the product of modern thinking had to adapt to postmodern thinking. Predispositions became less determining and Bourdieu explicitly recognized that the position taking of individuals involves the encounter between attitudes constituted within an attitudinal market and objects of potential elective affinity that present themselves in an equally fluid marketplace. He took the opportunity, in a short article of 1979 entitled 'Les trois états du capital culturel' (The three forms of cultural capital, Bourdieu 1979) to articulate a differentiation 
between 'incorporated', 'objectified' and 'instituted' capitals. This coincided with the publication of La distinction. The suggestion is clear. Individuals are now engaged in an open struggle to reconcile their inherited dispositions or values with the two differently constituted cultures that acquire autonomy and dispositional lives of their own. 'Hysteresis' begins to prevail as an explanatory concept from the point at which Bourdieu became disillusioned about the capacity of dominated groups to modify their life chances. 'Habitus' was a concept intended to encourage realistic agency. 'Hysteresis' developed as a concept to account for the incapacity of agents to adapt to changes imposed upon them. It was almost as if Bourdieu sensed late in life that his adherence to his original concept of 'habitus' was an example of a pathological incapacity in himself to adapt to changing circumstances. The shift was symptomatic of Bourdieu's sorrow that, as I describe in my chapter, he had failed to shape world sociology in accordance with his own orientation to anthropological reflexivity. Méndez comments that the descriptions of 'hysteresis' given in Pascalian Meditations complemented the position adopted by Bourdieu and Wacquant in their 'On the Cunning of Imperialist Reason' of 1998 ([1998], 1999). She quotes the expression that they use there to describe the way in which the objective cultures in dominated societies have absorbed the values of 'western' societies: the 'naturalization of the schemata of neo-liberal thought'. Bourdieu and Wacquant articulate passionately their conviction that neo-liberal thought had become a form of conceptual imperialism that was in the process of eclipsing incorporated cultures throughout the world. The ready adoption of 'hysteresis' as an explanatory instrument is, for me, tacit acquiescence in the inevitability of this imperialism and, in the last resort, a tacit admission of the current failure of Bourdieu's intellectual project.

\section{Concluding Comments}

Nevertheless, la lutte continue (the struggle continues). This volume is intended to contribute to that continuation in that it seeks not to reinforce the appropriation of Bourdieu's sociological work to a field of world sociology of which he would not have approved. Bourdieu began his lecture at the Collège de France on 18 January 1990 - which has been published as the first of his lectures Sur l'Etat (On the state, [2012], 2014) - with some reflections on the difficulty of talking about the state from within an epistemic framework constituted by the object of study. He commented,

the further I advance in my work on the state, the more convinced I am that, if we have a particular difficulty in conceiving this object, it is because it is - and I weigh my words - almost inconceivable. If it is so easy to say easy things about 
this object, that is precisely because we are in a certain sense penetrated by the very thing we have to study. ([2012], 2014, 3)

As contributors to this volume, we have the same experience in double form. We write about Bourdieu, but are penetrated by his thought. We write from within epistemic communities that are ambivalently referential - in respect of the state thinking that may have constituted our habitus and in relation to an Anglophone international 'field'.

Bourdieu and Wacquant analysed what they called 'an effect of transcontinental allodoxia' $(1999,48)$ in the diffusion of the concept of 'underclass'. The term is borrowed from Plato's Theaetetus, where Socrates says,

We say that false belief is a kind of interchange of beliefs (allodoxia). It happens when someone [inadvertently] exchanges one thing with another thing in his understanding, and says that [the one] is [the other] [or that the one is true of the other]. In this way, the thinker will always have a belief about what is. But he forms a belief about one thing that is, instead of forming it about another thing that is. (Chappell 2004, 166 para. 189b)

In accordance with his understanding of communication as dependent on social context, Bourdieu interpreted allodoxia as a form of 'symbolic violence' perpetrated by mediators or gatekeepers (passeurs (ferrymen)) using their power to control the migration of ideas between cultures so as to sustain or legitimize their social positions.

We are all passeurs, ferrying Bourdieu's texts across boundaries of time and space. This collection attempts to encourage reflexivity amongst readers by offering contributions that simultaneously describe the natures of the cargo and of the territories crossed.

\section{Notes}

1 Bourdieu would have been especially well aware of this distinction made by Leibniz in his Monadology (1714) as a result of his work for his diplôme d'études supérieures thesis of 1954 on Leibniz's Animadversiones in Partem Generalem Principiorum Cartesianorum (Remarks on the general part of Descartes's principles) of 1692.

2 Wahl 1951.

3 Wahl 1952.

4 Fink 1933.

\section{References}

Bourdieu, P. 1958. Sociologie de l'algérie. Paris: PUF. 1966. 'Champ intellectuel et projet créateur'. Les temps modernes 246: 865-906. 
1968. 'Structuralism and Theory of Sociological Knowledge'. Social Research 35, no. 4: 681-706.

1973. 'The Three Forms of Theoretical Knowledge'. Social Science Information 12, no. 1: 53-80.

- 1979. 'Les trois états du capital culturel'. Actes de la recherche en sciences sociales 30: 3-6. 1980a. Le sens pratique. Paris: Minuit.

1980b. 'Le mort saisit le vif: Les relations entre l'histoire réifiée et l'histoire incorporée'. Actes de la recherche en sciences sociales 32-33: 3-14.

— 1981. 'Décrire et prescrire: Note sur les conditions de possibilité et les limites de

l'efficacité politique'. Actes de la recherche en sciences sociales 38: 69-73.

— 1982. Ce que parler veut dire: L'économie des échanges linguistiques. Paris: Fayard.

1984. Homo Academicus. Paris: Minuit.

— 1985. 'The Genesis of the Concepts of Habitus and Field'. Sociocriticism 11-24.

1987. Choses dites. Paris: Minuit.

1988. Homo Academicus. Oxford: Polity Press.

— 1989. La Noblesse d'État: Grandes écoles et esprit de corps. Paris: Minuit.

1990a. In Other Words: Essays towards a Reflexive Sociology. Oxford: Polity Press.

1990b. The Logic of Practice. Oxford: Polity Press.

1991. Language and Symbolic Power. Oxford: Polity Press.

1993. 'L'impromptu de Bruxelles'. Cahiers de l'Ecole des sciences philosophiques et religieuses 14: 33-48.

1994. Raisons pratiques: Sur la théorie de l'action. Paris: Seuil.

1996. The State Nobility: Elite Schools in the Field of Power. Oxford: Polity Press.

1997. Méditations pacaliennes. Paris: Seuil.

1998. Practical Reason: On the Theory of Action. Oxford: Polity Press.

2000. Pascalian Meditations. Oxford: Polity Press.

2001. Science de la science et réflexivité. Paris: Raisons d'agir.

2002. 'Response to Throop and Murphy'. Anthropological Theory 2, no. 2: 209-10.

2002b. Le bal des célibataires: Crise de la société en Béarn. Paris: Seuil.

2008. The Bachelors' Ball: The Crisis of Peasant Society in Béarn. Oxford: Polity Press.

2012. Sur l'État Paris: Raisons d'agir/Seuil.

2014. On the State. Oxford: Polity Press.

Bourdieu, P., A. Darbel, J.-P. Rivet and C. Seibel. 1963. Travail et travailleurs en algérie. Paris/ The Hague: Mouton.

Bourdieu, P. and A. Sayad. 1964. Le déracinement: la crise de l'agriculture traditionnelle en algérie. Paris: Minuit.

Bourdieu, P. and L. Wacquant 1992a. Réponses: Pour une anthropologie réflexive. Paris: Seuil. 1992b. An Invitation to Reflexive Sociology. Oxford: Polity Press.

1998. 'Sur les ruses de la raison impérialiste'. Actes de la recherche en sciences sociales 121-2: 109-18.

1999. 'On the Cunning of Imperialist Reason'. Theory, Culture and Society 16, no. 1: 41-58.

Calhoun, C., E. LiPuma and M. Postone eds. 1993. Bourdieu: Critical Perspectives. Oxford: Polity Press.

Castel, R. and J.-C. Passeron, eds. 1967. Éducation, développement et démocratie. Paris/The Hague: Mouton.

Chappell, T. D. J. 2004. Reading Plato's Theaetetus. Indianapolis: Hackett.

Fink, E. 1933. 'Die phänomenologische Philosophie E. Husserl's in der gegenwartigen Kritik', Kantstudien 38. 
Gurwitsch, A. ed. J. Garcia-Gomez. 2009. The Collected Works of Aron Gurwitsch, 1901-1973:

Volume I: Constitutive Phenomenology in Historical Perspective. Netherlands: Springer.

Habib, I. 1983. 'Marx's Perceptions of India', Trier: Karl Marx Haus, No. 30.

Husserl, E. 1913a. 2nd ed., Logische Untersuchungen. Halle: Niemeyer.

_ 1913b. Ideen zu einer reinen Phänomenologie und phänomenologischen Philosophie. Halle:

Niemeyer.

1970. Logical Investigations. London/New York: Routledge.

Husserl, E. ed. L. Landgrebe. 1973. Experience and Judgment: Investigations in a Genealogy of Logic. Evanston: Northwestern University Press.

Husserl, E. ed. P. Ricoeur. 1950. Idées directrices pour une phénoménologie. Paris: Gallimard.

Landgrebe, L. 1966. Major Problems in Contemporary European Philosophy: From Dilthey to Heidegger. New York: Frederick Ungar Publishing Co.

Lyotard, J.-F. 1991. Phenomenology. Albany: State University of New York Press. 1999. 13th ed. La Phénoménologie. Paris: PUF

Merleau-Ponty, M. 1960. Signes. Paris: Gallimard

Panofsky, E. trans. P. Bourdieu. 1967. Architecture gothique et pensée scolastique. Paris: Minuit.

Platt, R. 1989. 'Reflexivity, Recursion and Social Life: Elements for a Postmodern Sociology'. The Sociological Review 37: 4, 636-67.

Ricoeur, P. 1951. 'Analyses et problèmes dans Ideen II de Husserl'. Revue de Métaphysique et de Morale 357-94.

1951. 1953. 'Sur la phénoménologie'. Esprit 821-39.

Robbins, D. ed. 2000. Pierre Bourdieu, 4 vols, London/Thousand Oaks/New Delhi: Sage Publications.

2010. 'The Foundations of Social Theoretical Discourse'. Review of Simon

Susen: The Foundations of the Social: Between Critical Theory and Reflexive Sociology Journal of Classical Sociology 10, no. 1: 1-8.

2013. 'Response to Simon Susen's "Bourdieusian Reflections on Language:

Unavoidable Conditions of the Real Speech Situation"'. Social Epistemology 27, nos. 3-4: 261-74.

Rosenberg, J. 1994. The Empire of Civil Society. London: Verso.

Susen, S. 2010. The Foundations of the Social: Between Critical Theory and Reflexive Sociology. Oxford: Bardwell Press.

2010. 2013. 'Bourdieusian Reflections on Language: Unavoidable Conditions of the Real Speech Situation'. Social Epistemology 27, nos. 3-4: 199-246.

Throop, C. J. and K. M. Murphy. 2002. 'Bourdieu and Phenomenology: A Critical Assessment'. Anthropological Theory 2, no. 2: 185-207.

Tran Duc Thao. 1951. Phénoménologie et matérialisme dialectique. Paris: Minh-Tan.

1986. Phenomenology and Dialectical Materialism. Dordrecht/Boston/Lancaster/

Tokyo: D. Reidel

Wacquant, L. 2001. 'Further Notes on Bourdieu's "Marxism"'. International Fournal of Contemporary Sociology 38, no. 1: 103-9

Wahl, J. 1951. 'Notes sur la première partie de Erfahrung und Urteil'. Revue de Métaphysique et de Morale 56, no. 1: 6-34.

— 1952. 'Notes sur quelques aspects empiristes de la pensée de Husserl'. Revue de Métaphysique et de Morale.

Woolgar, S. ed. 1988. Knowledge and Reflexivity: New Frontiers in the Sociology of Knowledge. London: Sage.

Young, M. F. D. ed. 1971. Knowledge and Control: New Directions for the Sociology of Education. London: Collier-Macmillan. 



\title{
Chapter 2
}

\section{THE SOCIOLOGICAL CHALLENGE OF REFLEXIVITY IN BOURDIEUSIAN THOUGHT}

\author{
Simon Susen
}

\section{Introduction}

The main purpose of this chapter is to examine Pierre Bourdieu's conception of reflexivity. The concept of reflexivity plays a pivotal role in Bourdieu's attempt to develop a 'critical sociology' (sociologie critique), often referred to as 'reflexive sociology' in the Anglophone literature. Based on a thorough textual analysis of his key works, the chapter aims to demonstrate that the following twelve elements are particularly important to Bourdieu's conception of reflexivity: (1) 'science', (2) 'vigilance', (3) 'consciousness', (4) 'self-awareness', (5) 'critique', (6) 'self-objectification', (7) 'distance-taking' (8) 'rupture', (9) 'epistemology', (10) 'historicization', (11) 'understanding' and (12) 'emancipation'. Although the concept of reflexivity constitutes a useful methodological tool for the construction of critical epistemologies and for the pursuit of social research, it raises a number of significant questions. It is the task of the final section of this chapter to address several controversial issues that arise when one is faced with the challenge of evaluating the merits of Bourdieu's account of reflexivity. In accordance with the structure of the foregoing inquiry, these issues will be synthesized on the basis of 'twelve theses on Bourdieu's conception of reflexivity'.

\section{'Reflexivity'}

Bourdieu makes extensive use of the concept of reflexivity throughout his writings. Indeed, the vital role that this concept plays in the development of his sociology is illustrated in the fact that it appears in the titles of several studies published by Bourdieu himself ${ }^{1}$ as well as in the titles of numerous 
commentaries concerned with central aspects of his oeuvre. ${ }^{2}$ It is worth taking note of the etymological observation that the term 'reflexivity' is derived from the Latin word re-flectere, meaning 'to bend back', ${ }^{3}$ that is, to recline with the intention of considering or reconsidering something in a paused, contemplative and - if necessary - critical fashion. Before launching into a detailed examination of his writings, let us draw our attention to three distinctive ambitions that characterize 'Bourdieu's brand of reflexivity': ${ }^{4}$

(a) the ambition to shed light on 'the social and intellectual unconscious embedded in analytic tools and operations', ${ }^{5}$ rather than on the individual or psychological unconscious of the seemingly isolated or atomized researcher;

(b) the ambition to provide a critical understanding of social practices by conceiving of social inquiry as 'a collective enterprise ${ }^{6}{ }^{6}$ rather than by reducing investigative activity to 'the burden of the lone academic' ${ }^{7}$ and

(c) the ambition to identify and explore the constitutive components that undergird 'the epistemological security of sociology', ${ }^{8}$ thereby challenging the view that radical uncertainty permeates all claims to objective, normative or subjective validity.

In the Bourdieusian universe, then, the project of developing 'a critical theory of society' ${ }^{9}$ cannot be dissociated from the task of mobilizing the purposive, collective and assertive resources inherent in the exercise of reflexivity. Far from representing a merely playful or self-sufficient endeavour based on arbitrary and disembedded language games, however, the whole point of the Bourdieusian plea for reflexivity is founded on a strong belief in both the possibility and the epistemic authority of 'scientific objectivity' 10 and, hence, in the aspiration to contribute to "increasing the scope and solidity"11 of conceptually informed, methodologically controlled and empirically substantiated inquiries.

In this context, it may be useful to differentiate the following levels of analysis when grappling with the concept of reflexivity: ${ }^{12}$

(a) The level of 'ordinary reflexivity': Insofar as they are 'concept-bearing' ${ }^{13}$ entities capable of attributing meaning to, giving justifications for and coordinating their actions, human subjects are reflexive.

(b) The level of 'scientific reflexivity': Insofar as they are equipped with the theoretical power to generate authoritative and evidence-based knowledge, as well as with the practical power to "inject'14 their epistemic resources into the reality that they aim to study, both the natural sciences and the social sciences are reflexive. 
(c) The level of 'societal reflexivity': Insofar as - by virtue of both their theoretical and their practical tools - they possess the capacity to shape and to control their own civilizational development, human societies are reflexive. ${ }^{15}$

What is missing from these interconnected levels of critical engagement with reality, however, is 'the idea of reflexivity as a requirement and form of sociological work, that is, as an epistemological program in action for social science, and as a corollary a theory of intellectuals as the wielders of a dominated form of domination'. ${ }^{16}$ In other words, it is crucial that researchers and academics learn to face up to their own complicity in the construction of value-laden, meaning-laden, perspective-laden, interest-laden, power-laden and tension-laden realities.

The main implications of the previous considerations for Bourdieu's conception of 'reflexive sociology' can be synthesized as follows:

Reflexive Sociology starts with the 'very primitive assumption that theory is made by the praxis of men in all their wholeness and is shaped by the lives they lead'. ${ }^{17}$

On this view, theory and praxis are inextricably linked: the pursuit of sociological reflexivity would be pointless without recognition of the fact that the objective, normative and subjective representations generated by human subjects emerge within spatiotemporally contingent horizons of action and interaction. 'Reflexivity', understood in this sense, cannot be reduced to the Hegelian notion of Selbstberwusstsein, that is, to an anthropologically constitutive 'reflection of the subject on the subject', ${ }^{18}$ bestowed with the species-distinctive capacity to seek worth of existential significance by immersing itself in processes of mutual recognition. Rather, the purpose of a genuinely sociological reflexivity is to account for the fact that any interpretation of reality is, by definition, pervaded by different forms of bias. To be exact, from a Bourdieusian standpoint, there are at least three types of bias that 'blur the sociological gaze': ${ }^{19}$

(a) The social origin: Fundamental sociological variables - such as class, ethnicity, gender, age and ability - shape the multiple ways in which members of differentiated human life forms perceive, interpret, relate to, act upon and interact with reality. Specialized social scientists are no less influenced by sociological factors than ordinary social actors. For the former are a subcategory of, rather than an aberration from, the latter. ${ }^{20}$

(b) The academic field: The sociologist - like any other researcher in the social sciences - occupies a position not only in the macrocosm of society, and thus 'in the broader social structure ${ }^{21}$ of the human universe, but also, more specifically, 'in the microcosm of the academic field'. ${ }^{22}$ Similar to other social fields, the academic field constitutes a realm composed 
of multiple material and symbolic positions occupied by purposive subjects, who, within their relationally structured spaces of action and interaction, compete over access to resources, influence, status and - ultimately - power.

(c) The intellectualist predisposition: Owing to their tendency to remain caught up in self-referential language games, tension-laden dynamics of ideological positioning and struggles over symbolic power, their 'intellectualist bias [...] entices [them] to construe the world as a spectacle, as a set of significations to be interpreted rather than as concrete problems to be solved practically'. ${ }^{2}$ Such a scholastic - that is, essentially theoreticist - take on reality is deeply problematic in that it can lead social researchers 'to miss entirely the differentia specifica of the logic of practice ${ }^{24}$ - that is, of the codified, and largely implicit, patterns that govern empirically unfolding actions and interactions, whose ineluctable preponderance is inscribed into the daily construction of social reality.

To be clear, following the inquisitive spirit of Bourdieusian sociology, the categorical commitment to the critical exercise of reflexivity is 'neither egocentric nor logocentric but quintessentially embedded in, and turned toward, scientific practice. ${ }^{25}$ If taken seriously, the challenge of 'epistemic reflexivity invites intellectuals to recognize and to work to neutralize the specific determinisms to which their innermost thoughts are subjected, and it informs a conception of the craft of research designed to strengthen its epistemological moorings' ${ }^{26}$ Such a 'reflexive turn', ${ }^{27}$ therefore, is concerned with facing up to the sociohistorical determinacy of the seemingly most autonomous articulations of symbolically mediated claims to objective, normative or subjective validity. The different facets of Bourdieu's multi-layered conception of reflexivity can be traced in his key writings. ${ }^{28}$ As shall be demonstrated in subsequent sections, twelve dimensions are particularly important when seeking to shed light on the principal meanings underpinning Bourdieu's conception of reflexivity.

\section{Reflexivity and science}

The first - perhaps, most obvious - element underlying Bourdieu's conception of reflexivity is science. Irrespective of which particular discipline one may have in mind, social science constitutes a 'reflexive science'. ${ }^{29}$ Regardless of whether one moves within the epistemic horizon of anthropology, economics, political studies, psychology or sociology, genuinely 'scientific work ${ }^{30}$ within these disciplines is inconceivable without their researchers' willingness to commit themselves - albeit, admittedly, to varying degrees - to embarking upon the exercise of reflexivity. 
Tautologically speaking, 'scientific sociology'31 is a 'sociological science'. ${ }^{32}$ Aware of 'the social history of social science', ${ }^{33}$ scholars concerned with 'the sociology of science ${ }^{34}$ are confronted with the challenge of increasing the knowledge of the social determinants of sociological thought and, thus, the effectiveness of critique'. ${ }^{35}$ In this sense, reflexivity permits researchers to become aware of the social embeddedness not only of the knowledge they produce but also, more significantly, of the epistemic parameters on the basis of which their claims to validity are judged and, potentially, applied. Science, in the Bourdieusian sense, involves the methodical study of the social conditions of production that make systematic forms of knowledge generation possible in the first place.

Scientific endeavours permit those involved in them to explore realities whose constitution, functioning and development escape the epistemically limited grasp of everyday experience and common sense. Hence, science 'reveals things that are hidden and sometimes repressed" ${ }^{36}$ including the fact that the systematic exchange of knowledge claims is itself a 'site of a competition', ${ }^{37}$ in which 'the pursuit of specific profits [...], specific interests' ${ }^{38}$ and specific paths potentially, leading to the obtainment of status and recognition - constitutes the precondition for, at worst, survival and, at best, success within the academic field. Rather than succumbing to the quasi-mythological force of 'a scientific hagiography', ${ }^{39}$ sociological reflexivity obliges us to question the validity of the self-fulfilling prophecies that dominate the habitualized interactions taking place within the academic field. Just as symbolic power can be reinforced by institutional mechanisms of consecration, ritualization and legitimization, it can be called into question by critical processes of reflection, investigation and justification. Sociological reflexivity allows for the exposure of the arbitrary nature permeating the criteria employed to raise allegedly disinterested claims to validity.

In fact - and this is what makes the particular difficulty of sociology - these 'interests' and 'passions', noble or ignoble, lead to scientific truth only in so far as they are accompanied by a scientific knowledge of what determines them and of the limits that they set on knowledge. [...] the more advanced a science is, the greater is the capital of knowledge accumulated within it, and the greater the quantity of knowledge that subversive and critical strategies, whatever their 'motivations', need to mobilize in order to be effective. ${ }^{40}$

Critical social scientists need to mobilize their reflexive resources in order to unearth the relationally contingent constraints that define the epistemic scope of the conceptual, methodological and empirical tools employed in their inquiries. Sociological reflexivity permits critical researchers to comprehend 
the extent to which their production of knowledge is never a disinterested, unbiased or neutral affair. To be precise, it enables them to recognize that their investigative activity constitutes a social practice whose spatiotemporally variable direction can be shaped by conservative or subversive, orthodox or heterodox, complicit or rebellious, conformist or dissident strategies. Furthermore, it requires them to concede that these strategies are far from straightforward insofar as they can be employed consciously or unconsciously, explicitly or implicitly, theoretically or practically, deliberately or unwittingly.

As a 'truly reflexive social science', ${ }^{41}$ sociology - understood as a self-critical endeavour - must include 'the sociology of sociology', ${ }^{42}$ prepared to 'guard itself against this epistemocentrism, or this "ethnocentrism of the scientist", which consists in ignoring everything that the analyst injects into his [or her] perception of the object by virtue of the fact that he [or she] is placed outside of the object, that he [or she] observes it from afar and from above'. ${ }^{43}$ Guided by a 'genuine sociological reflexivity', ${ }^{44}$ a 'genuinely reflexive sociology ${ }^{45}$ must avoid falling into the trap of scholastic transcendentalism, which gives researchers the misleading impression that they act as disembodied, disconnected and disembedded subjects, whose free-floating minds have the epistemic capacity to generate disinterested, unbiased and neutral knowledge. Social science - conceived of as a reflexive endeavour - 'is necessarily a "knowledge of a knowledge" and must make room for a sociologically grounded phenomenology of the primary experience of the field' ${ }^{46}$ that is, for the systematic study of the social conditions of production that make the emergence of science possible in the first place. Such a 'sociology of sociology'47 is a reflexive project that 'continually turns back onto itself the scientific weapons it produces'. ${ }^{48}$ As such, it draws attention to the fact that sociological reflexivity obliges those who endorse it to confront the spatiotemporal variability permeating their own claims to scientificity. By means of multiple conceptual, methodological and empirical tools, social researchers are in a position to scrutinize the relational determinacy of human reality, including the contingency that pervades both ordinary and scientific affirmations of validity.

To be sure, for Bourdieu, ' $[\mathrm{t}] \mathrm{o}$ adopt the point of view of reflexivity is not to renounce objectivity', ${ }^{49}$ let alone the claim to scientificity, but, on the contrary, 'to give it its full generality by questioning the privilege of the knowing subject, arbitrarily freed, as purely noetic, from the work of objectivation' ${ }^{50}$ Reflexive sociology, in other words, is the radical transcendence of atomistic versions of the philosophy of the subject and the philosophy of consciousness: it reminds us that all forms of subjectivity and consciousness are socially situated, socially generated, socially reproduced and socially transformed. Hence, 'the sociology of the social determinants of sociological practice ${ }^{51}$ teaches us that the first step towards emancipating ourselves from the constraining power of social 
structures is to recognize and to problematize - rather than to ignore, let alone to deny - their existence. The seemingly most self-determined entity capable of action, reflection and justification cannot escape the existential weight of the multiple structural forces exercising the power of social determination. Sociological reflexivity is about the assertion, rather than the rejection, of scientificity to the extent that it succeeds in exposing the relational constitution of all material and symbolic dimensions permeating the daily construction of human reality. ${ }^{52}$

\section{Reflexivity and vigilance}

The second noteworthy element underlying Bourdieu's conception of reflexivity is vigilance. It is vital to 'subject the operations of sociological practice to the polemics of epistemological reason, ${ }^{53}$ thereby cultivating 'an attitude of vigilance ${ }^{54}$ that permits researchers to develop an 'adequate knowledge of error', ${ }^{55}$ bias and preconception. Genuinely vigilant investigators are aware of the distortive force of misperception, misconception and misrepresentation. The gaze of scientifically motivated minds - although it may be able to challenge the doxic illusions of common sense and everyday experience - is limited in terms of its epistemological capacity to grapple with the intricacies of reality.

The intention of giving the researcher the means of taking on the oversight of his [or her] own scientific work is quite different from the calls to order by censors whose peremptory negativism can only inspire the mortal fear of error and a resigned recourse to a technology invested with the function of exorcism. ${ }^{56}$

To be clear, self-surveillance - in the Bourdieusian sense - is not equivalent to supervising one's own epistemic activities and embodied practices to such an extent that scientific work becomes a stifling exercise of self-paralysis. In fact, if the sociologically motivated 'philosophy of critical vigilance ${ }^{57}$ is converted into a default position of self-destructive cynicism, then it is difficult to see how it is possible to make any individually or collectively empowering contributions to society by virtue of conceptually sophisticated and empirically substantiated inquiries into the constitution, functioning and development of reality. Sociological vigilance requires 'the "psychoanalysis of the scientific mind" .58

the 'psychoanalysis of the scientific mind' is taken further by an analysis of the social conditions in which sociological works are produced: the sociologist may find an exceptionally valuable instrument of epistemological vigilance in the sociology of knowledge, a means of enhancing and clarifying knowledge of error and the conditions that make it possible and sometimes inevitable. ${ }^{59}$ 
Reflexive sociology, then, is the attempt to problematize the social conditions of production shaping both the daily construction and the systematic study of human reality. Put differently, professional researchers are no less embedded in and influenced by relationally constituted - and, thus, historically contingent - circumstances than ordinary people.

Sociological investigators have access to conceptual and methodological tools, by means of which they are able to examine the constitution, functioning and development of reality. Unlike ordinary actors, who are primarily motivated by common sense and who make judgments on the basis of their everyday experiences, social researchers are equipped with the epistemic capacity to distance themselves not only from their object of study but also from themselves. Reflexivity, conceived of in terms of vigilance, permits sociological researchers to scrutinize their own position, as well as their own positioning, in the social universe.

Far from constituting a pristine realm of neutral and unbiased interactions, the scientific field is no less value-laden, meaning-laden, perspective-laden, interestladen, power-laden and tension-laden than other social fields. Notwithstanding the functional specificity of the social field in which they find themselves immersed in a particular - that is, spatiotemporally contingent - context, both individual and collective actors are divided by the unequal distribution of, as well as by the asymmetrically structured access to, material and symbolic resources.

The act of 'epistemological reflection ${ }^{60}$ stands for an exercise of constant vigilance, enabling the sociologist to analyse the 'social conditions of his [or her] sociological practice and his [or her] relation to sociology ${ }^{61}$ with the aim of grasping his or her own relational determinacy, which stems from his or her immersion in a relationally constructed - and, therefore, ceaselessly changing - reality. Understood in these terms, reflexivity is 'the precondition for his [or her] making his [or her] unconscious presuppositions explicit and for a more complete internalization of a more adequate epistemology'. ${ }^{62}$ To recognize the link between sociological reflexivity and epistemological vigilance means to face up to the fact that the sociologist operates within and through - rather than outside, let alone above - society. In other words, we need to consider the farreaching implications of the sociologist's social embeddedness: ${ }^{63}$

Perhaps the most fundamental presupposition that the sociologist owes to the fact that he [or she] is a social subject is the presupposition of the absence of presuppositions which defines ethnocentrism; the sociologist (more than the ethnologist) is vulnerable to the illusion of immediate self-evidence or the temptation to unconsciously universalize particular experience when he [or she] forgets that he [or she] is the cultivated subject of a particular culture and fails to subordinate his practice to a continuous questioning of this relationship. ${ }^{64}$ 
Critiques of and attacks on ethnocentrism need to be 'constantly revived and reinterpreted by epistemological vigilance' ${ }^{65}$ in order to ensure that ritualized dogmatism, canonized ideologism and codified close-mindedness are challenged by openness to argument, enthusiasm for debate and acceptance of contradiction. A sociology without vigilance and reflexivity would be tantamount to a social science incapable of acknowledging its relationally constituted determinacy. ${ }^{66}$

\section{Reflexivity and consciousness}

The third striking element underlying Bourdieu's conception of reflexivity is consciousness. This facet is expressed in the view that the exercise of sociological reflexivity requires an approach comparable to that of psychoanalysis: 'the "psychoanalysis of the scientific mind", ${ }^{67}$ including 'the sociological mind', ${ }^{68}$ is crucial to exploring the researcher's unconscious, comprising his or her 'unconscious presuppositions 69 - regardless of whether they are shaped predominantly by social, cultural, economic, political or ideological factors. On this account, social science is ' $a$ science of the unconscious', ${ }^{70}$ that is, 'an objective archaeology of our unconscious, ${ }^{71}$ which serves the function of 'the instrument of a genuine socioanalysis'. ${ }^{72}$ Social science can be conceived of as 'a social critique ${ }^{\text {'73 }}$ capable of uncovering the hidden causal forces that govern the development of behavioural and ideological patterns and, consequently, people's everyday immersion in, and construction of, reality.

If effective, psychoanalysis may enable individuals to overcome obstacles generated by mental pathologies that put a strain on their quotidian existence, as reflected in different forms of depression or paralysis. In a similar vein, to the degree that it is anchored in day-to-day practices, social critique may permit both small-scale and large-scale communities to cope with dysfunctionalities produced by interactional pathologies that limit the possibilities of human empowerment, owing to the detrimental effects of outcome-oriented and systemically steered rationalization. What is needed is 'a reflexive return to its own practice ${ }^{74}$ and, paradoxically, to 'a social unconscious within the analysis ${ }^{75}$ of the social. To be sociologically conscious, in the Bourdieusian sense, means to be prepared to accept that, in order for a critical social science to come into existence, its defenders need to admit that 'an epistemological reflection upon its practices is inseparable from a political reflection upon both its effects and its function'. ${ }^{76}$ To the extent that science - because it is a value-laden, meaning-laden, perspective-laden, interest-laden, power-laden and tensionladen endeavour - is far from neutral or disinterested, it requires that its participants and defenders be conscious not only of the unconscious of the actors they examine but also of their own unconscious. 
What has to be constantly scrutinized and neutralized, in the very act of construction of the object, is the collective scientific unconscious embedded in theories, problems, and (especially national) categories of scholarly judgment [...]. It follows that the subject of reflexivity must ultimately be the social scientific field in toto. ${ }^{77}$

Sociologically informed reflexivity is inconceivable with the consciousness of one's own unconscious, the awareness of one's own unawareness, the (re-) conceptualization of one's own preconceptions and the attempt to make judgments about one's own prejudgments. In short, 'the historical critique of unconscious presuppositions ${ }^{78}$ is vital if one is willing to recognize that 'the mystical ambition to reach the essence in a single leap ${ }^{979}$ needs to be abandoned in favour of 'the patient reconstruction of genesis', ${ }^{80}$ thereby exposing the potential for the constant transformation of the social world, including the continuous refinement of the conceptual and methodological tools employed to study, and to make sense of, it. ${ }^{81}$

\section{Reflexivity and self-awareness}

The fourth significant element underlying Bourdieu's conception of reflexivity is self-awareness. The centrality of this dimension is synthesized in the Bourdieusian emphasis on 'self-reflexivity', ${ }^{82}$ which may be regarded as an indispensable component of critical sociology. A truly critical sociologist needs to 'subject his [or her] own questioning to sociological questioning', ${ }^{83}$ thereby demonstrating a capacity to convert his or her inquiry into a source of selfreflexivity. Thus, 'the reflexive return to the subjective experience of the social world' ${ }^{\prime 84}$ lies at the core of 'the objectification of the objective conditions of that experience ${ }^{9}{ }^{85}$ Sociohistorically contingent arrangements shape the manifold ways in which subjects perceive, appreciate and act upon the world. All researchers, irrespective of the degree of their conceptual and methodological sophistication, are ordinary actors. As such, they need to grapple with the relationally assembled determinacy not only of their object of inquiry but also of their own analytical gaze, which is located within an embodied - and, hence, dispositionally structured - cognitive entity, concerned with the systematic exploration of reality.

In light of this commitment to conceiving of reflexivity in terms of selfawareness, 'the game of the inaugural lecture on the inaugural lecture', ${ }^{86}$ understood as the critic's willingness to criticize himself or herself, is crucial to the very possibility of developing a sociology whose examination of reality involves the study of its own constitution as a discipline and, thus, of its own claims to validity. A self-reflexive discourse is 'a discourse that conceives of itself as an object', ${ }^{87}$ that is, as an object of contemplation whose significance 
comes to the fore through sociology's 'reflexive return's8 in relation to itself. Such a discourse obliges us to call the allegedly privileged position of the 'knowing subject ${ }^{399}$ into question: sociologically reflexive subjects are aware of the objective, normative and subjective aspects that shape - if not, determine their multifactorially structured - and, hence, constantly shifting - place in the world. A 'sociology of sociology', ${ }^{90}$ in the genuinely reflexive sense, is a sociology of the determinants of sociological practice. Reflexive sociology converts 'its own functioning' ${ }^{91}$ into an object of inquiry, thereby making a case for a form of scientificity based on the critical awareness of the limitations permeating its own epistemic activities. In a Bourdieusian sense, there is no sociological reflexivity without the self-awareness of those who embrace the challenge of scrutinizing the relational constitution of human realities. The capacity to develop 'a point of view on a point of view' ${ }^{92}$ is vital to the construction of a critical attitude motivated by self-awareness and reflexivity ${ }^{93}$

\section{Reflexivity and critique}

The fifth significant element underlying Bourdieu's conception of reflexivity is critique. The critique of critique is an indispensable component of sociological reflexivity insofar as it permits - and, indeed, compels - the critic to criticize the existence of behavioural, ideological or institutional patterns whose legitimacy is objectively, normatively or subjectively questionable. Yet, reflexivity in the Bourdieusian sense - requires not only the critique of different facets of social reality but also the critique of the criticizing gaze itself. In short, social critique is inconceivable without self-critique. ${ }^{94}$ The schizophrenic nature of sociological critique ${ }^{95}$ consists in the fact that it needs to include itself in the realm of the criticized in order to be genuinely critical. Otherwise, it would lead to the pretentious assumption that the critic stands over and above society, rather than being immersed within and dependent upon it. Critical sociology cannot do without the sociology of critique, ${ }^{96}$ because there is no radical way of uncovering, let alone problematizing, the contradictions of social life without recognizing that sociological analysis - since it is undertaken by spatiotemporally embedded, positionally divided and dispositionally equipped actors - forms part of these contradictions, rather than being able to rise above them.

It is possible to conceive of 'the sociologist [as] a social worker'97 in the sense that, if he or she is motivated by a normative mission, his or her work can contribute not only to the empowerment of other individual or collective actors, but also to his or her own empowerment. The ability to step back from both one's external world and one's internal world is vital to the very possibility of sociological reflexivity, giving sociologically inspired actors the 
opportunity to criticize - and, thus, to challenge - mechanisms of disempowerment and domination, whilst exploring resources that can be mobilized in the pursuit of human empowerment and emancipation. ${ }^{98}$

\section{Reflexivity and self-objectification}

The sixth major element underlying Bourdieu's conception of reflexivity is selfobjectification. From a Bourdieusian perspective, it is essential for the researcher to 'objectify the objectifying distance and the social conditions that make it possible, such as the externality of the observer. ${ }^{99}$ Every observer - no matter how removed, isolated or free-floating his or her perceptions, appreciations and actions may appear - is a sociohistorically situated entity, occupying multiple positions in different realms of interaction and developing multiple dispositions in relation to relationally constructed environments. To be sure, whilst a sociological inquiry may be conducted from 'a viewpoint away from the stage on which the action is played out', ${ }^{100}$ researchers are always already immersed within particular scenes of individual and collective performances encountered in their own everyday lives. Indeed, critical investigators are shaped by key sociological variables - such as class, ethnicity, gender, age and ability - to no lesser extent than the actors whose material and symbolic practices they scrutinize within their studies.

From a Bourdieusian perspective, 'every genuine sociological undertaking ${ }^{101}$ is inextricably linked to the exercise of 'a socioanalysis', ${ }^{102}$ that is, to the possibility of objectifying the objectifying gaze itself. Indeed, 'the objectification of objectivity'103 - including the objectification of those who seek to objectify particular aspects of objectivity - allows for 'a genuine self-reappropriation'104 to the degree that it enables researchers to regard themselves - both consciously and critically - as spatiotemporally situated and embodied actors, who are no less influenced by the power of social structures than those whose lives they examine.

It is vital 'to objectify objectification' 105 in order to generate truly reflexive forms of sociological investigation: for without 'a critical objectification' ${ }^{106}$ of 'the epistemological and social conditions' ${ }^{107}$ that undergird specific human including academic and scientific - performances, it is impossible to grasp the extent to which theoretical, explicit and conscious forms of engagement with reality are preceded by actors' practical, implicit and unconscious immersion within it. Put differently, 'to objectivize the objectivizing point of view of the sociologist' ${ }^{\prime 08}$ means 'to objectivize his [or her] position in the universe of cultural production' ${ }^{\prime 109}$ and, thus, in the entire sphere of human constructions. In other words, 'reflexivity conceived of as the task of the scientific objectification of the objectifying subject ${ }^{\prime 110}$ constitutes an integral component of a 
sociology that is critical not only of others but also of itself, that is, not only of the researched but also of the researchers themselves. ${ }^{11}$

\section{Reflexivity and distance-taking}

The seventh core element underlying Bourdieu's conception of reflexivity is distance-taking. One of the principal challenges for the reflexive sociologist is 'to reconcile attachment to the mysteries of internality with the imperatives of distanciation'. ${ }^{112}$ This task has two - seemingly opposed - dimensions.

- On the one hand, reflexive sociologists' motivation, imagination and inspiration are inconceivable without their capacity to wonder about the infinite intricacies of the social world, their willingness to continue to be surprised by the hidden forces shaping the daily construction of human reality and if necessary - their readiness to express a sense of incredulity when trying to make sense of social constellations, especially of those constellations whose constitution, development and functioning are not immediately obvious.

- On the other hand, reflexive sociologists' perceptiveness, thoughtfulness and insightfulness rest upon their ability to describe, to analyse, to interpret, to explain and to assess the unlimited complexities of the social world, their attempt to uncover the underlying determinants of human reality and - if required - their preparedness to take a step back when examining particular sets of cultural arrangements, particularly if they happen to possess a sense of native familiarity with a given sphere or aspect of a relationally constructed entity.

In short, we are confronted with the dialectics of interiority and exteriority, immanence and transcendence, enchantment and disenchantment, attachment and detachment, participation and observation, closeness and remoteness, proximity and distance.

Reflexivity represents an exercise of distance-taking: whilst recognizing every human actor's ineluctable situatedness in reality, it permits the sociologist to embark upon the journey of critical inquiry by employing conceptual and methodological tools designed to scrutinize and to objectify different fields of sociality. Hence, 'the controlled and conscious construction of his [or her] distance from the real and his [or her] action to the real'113 is a prerequisite for the pursuit and defence of a 'reflexive science'. ${ }^{114}$ For without the awareness of the epistemic gap between ordinary belief, common sense and everyday experience, on the one hand, and scholarly knowledge, conceptually and methodologically sophisticated investigation and empirically substantiated theorization, on the other, there is no point in insisting on the scientificity of sociology. ${ }^{115}$ Role-specific distance-taking ${ }^{116}$ forms an enriching ingredient of 
everyday life, expressing actors' ability to step back - if only temporarily - from their immediate immersion in particular domains of society. At the same time, it constitutes an indispensable element of reflexive scientific analysis, conveying a researcher's capacity to take - if only transitionally - an objectifying perspective aimed at the examination of relationally constructed realities. ${ }^{117}$

\section{Reflexivity and rupture}

The eighth central element underlying Bourdieu's conception of reflexivity is rupture. Reflexive sociology, in the Bourdieusian sense, requires the researcher to undertake a double-epistemological rupture: first, the break with the ordinary vision of the world; and, second, the break with the scholastic vision of the world. ${ }^{118}$ 'The former reaffirms the scientific nature of reflexive sociology; the latter emphasises the social embeddedness of reflexive sociology." ${ }^{119}$ This double-epistemological rupture is paradoxical in the sense that it obliges us to call 'the two very conditions of reflexive thought' ${ }^{\text {' }}$ into question: namely, 'the being-in-the-world and the being-beyond-the-world ${ }^{121}$ of reflexive researchers, that is, their simultaneous immanence and transcendence. Insofar as they are immersed in reality, they are constrained by the limitations imposed upon them by objective, normative and subjective patterns of material and symbolic forms of structurality. Insofar as they can step back from reality, they are in a position to identify, to problematize and - if necessary - to challenge the taken-forgrantedness of the givenness that permeates an actor's participation in the performative - and, to a large extent, routinized - construction of everydayness.

The double-epistemological rupture endorsed by reflexive sociology serves two - aforementioned - basic functions: the break with ordinary conceptions of the world and the break with scholastic conceptions of the world. The former constitutes a radical epistemological rupture with cognitive dispositions and predispositions based on conventional belief, common sense and everyday experience. The latter stands for a radical epistemological rupture with cognitive dispositions and predispositions founded on the skholè, ${ }^{122}$ that is, on 'the privileged scholastic situation of freedom from necessity, which allows scholastic thinkers to produce scholastic thought'. ${ }^{123}$

In relation to the first epistemological break, it is essential to examine the relationship between ordinary knowledge and scientific knowledge. ${ }^{124}$ The distinction between these two types of knowledge rests on five central epistemological presuppositions: ${ }^{125}$

(a) A distinction can be drawn between ordinary knowledge and scientific knowledge: they represent two fundamentally different epistemic levels of engaging with and making sense of reality. 
(b) A hierarchy can be established between ordinary knowledge and scientific knowledge: the latter is epistemically superior to the former insofar as its conceptually sophisticated, methodologically regulated, empirically substantiated and intellectually mediated reflexivity rises above the doxically distorted horizon of conventional belief, common sense and everyday experience.

(c) A fundamental difference in terms of priority can be discerned with regard to the relationship between ordinary knowledge and scientific knowledge: by virtue of both theoretically and practically empowering investigative tools, the latter has the enlightening mission to uncover, to demystify and to challenge the misconceptions, misrepresentations and misinterpretations generated within the epistemically limited realm of the former.

(d) A key dissimilarity with respect to their social functionality characterizes the relationship between ordinary knowledge and scientific knowledge: one of the primary functions of the former is to make social order possible by equipping human entities with the ability to draw upon taken-for-granted assumptions when interacting with their natural and cultural environments; by contrast, one of the principal functions of the latter is to scrutinize that is, (i) to describe, (ii) to analyse, (iii) to interpret, (iv) to explain and (v) to assess - the consolidation, reproduction and transformation of social order by unearthing the praxeological power of symbolically codified and materially anchored interactions.

(e) A structural asymmetry lies at the core of the relationship between ordinary knowledge and scientific knowledge: the epistemological discrepancy between these two forms of knowledge is due to the profound positional gap between ordinary subjects, whose actions are, to a large extent, guided by doxic preconceptions derived from everyday experiences and reflexive social scientists, whose task is to shed light on the extent to which quotidian practices are regulated by common sense and, therefore, by effective but, ultimately, misleading - modes of meaning construction. On this account, the positional gap between epistemically unprivileged laypersons and epistemically privileged experts permeates the entire universe of structurally differentiated knowledge production.

In relation to the second epistemological break, it is crucial to consider the nature of scholastic thought. Ten fallacies can be identified to demonstrate that scholastic thought represents a profoundly problematic mode of attributing meaning to reality: ${ }^{126}$

(a) Scholastic theoreticism: Scholastic thought is theoreticist in that it is based on 'theoretical reason', rather than 'practical reason'. ${ }^{127}$ As such, it remains 
caught up in the self-sufficient intellectual exercise of producing theory for the sake of, and only in relation to, theory, instead of recognizing let alone engaging with - the socio-ontological preponderance of everyday practices. ${ }^{128}$

(b) Scholastic intellectualism: Scholastic thought is intellectualist in that it is based on 'intellectual reason', rather than 'socially committed reason'. As such, it permits intellectuals to create a 'theodicy of their own privilege', ${ }^{129}$ removed from the real-world urgencies of both the under- and the non-privileged. ${ }^{130}$

(c) Scholastic universalism: Scholastic thought is universalist in that it is based on the idea of 'universal reason', rather than 'particular reason'. As such, it makes claims to 'universal validity', 'universal legitimacy' and 'universal authority', ${ }^{131}$ which - by definition - rise above the spatiotemporal specificity of relationally constructed realities. ${ }^{132}$

(d) Scholastic rationalism: Scholastic thought is rationalist in that it is based on the idea of 'reasoning reason', rather than 'reasonable reason'. As such, it hinges on the assumption that reason, rather than bodily experience, determines how humans engage with and attach meaning to the world, thereby succumbing to the 'illusion of (intellectual) mastery of oneself that is so deeply ingrained in intellectuals', ${ }^{133}$ whilst failing to face up to the sociohistorical contingency of all forms of human rationality. ${ }^{134}$

(e) Scholastic transcendentalism: Scholastic thought is transcendentalist in that it is based on the idea of 'transcendental reason', rather than 'immanent reason'. As such, it is driven by 'the illusion of the transcendence of transhistorical and transpersonal reason', ${ }^{135}$ capable of escaping the historical and personal constraints to which those who invented, and keep inventing, it are exposed as spatiotemporally situated, physically constituted, as well as both dispositionally and positionally divided actors. ${ }^{136}$

(f) Scholastic purism: Scholastic thought is purist in that it is based on the idea of 'pure reason', rather than 'possible reason'. As such, it is motivated by the myth of the existence of a 'pure subject' equipped with the capacity to generate 'pure knowledge'137 about itself and the world by which it is surrounded, instead of conceding that ' $\mathrm{t}]$ he possibility of purity is built upon the impurity of possibility'. ${ }^{138}$ Put differently, it falls short of admitting that claims to epistemic purity constitute futile attempts to cover up every human subject's conscious or unconscious complicity in the construction of value-laden, meaning-laden, perspective-laden, interest-laden, powerladen and tension-laden realities. ${ }^{139}$

(g) Scholastic foundationalism: Scholastic thought is foundationalist in that it is based on the idea of 'foundational reason', rather than 'historical reason'. As such, it rests on the self-referential assumption that the foundations of reason are to be found in and through, rather than outside of, reason. 
Paradoxically, however, it is perhaps on condition that reason is subjected to the test of the most radical historicization, in particular by destroying the illusion of foundation by recalling the arbitrariness of beginnings and by historical and sociological critique of the instruments of historical and sociological science itself, that one can hope to save it from arbitrariness and historical relativization. ${ }^{140}$

[We need] to sacrifice the anxiety over the ultimate foundation to the historical critique of unconscious presuppositions, to repudiate the mystical ambition to reach the essence in a single leap in favor of the patient reconstruction of genesis. ${ }^{141}$

To the degree that reason is unavoidably embedded in the 'social foundations'142 of human existence, the philosophical project of 'foundationalist rationalism' or 'rationalist foundationalism' needs to be replaced by the sociological project of 'historical rationalism' or 'rationalist historicism'. ${ }^{143}$

(h) Scholastic neutralism: Scholastic thought is neutralist in that it is based on the idea of 'neutral reason', rather than 'interested reason'. As such, it aims to portray interestedness as disinterestedness. Yet, to the extent that all forms of knowledge are - unavoidably - value-laden (Erkenntnisnormativität), perspective-laden (Erkenntnisstandpunkt), interest-laden (Erkenntnisfunktion), power-laden (Erkenntniskampf) and purpose-laden (Erkenntnisnutzung), the illusion of neutrality evaporates in the face of the social contingency permeating all claims to epistemic validity. The most abstract form of rationality cannot bypass the social power of normativity, positionality, functionality, conflictuality and instrumentality. Insofar as every theory of cognition (Erkenntnistheorie) is derived from a practice of cognition (Erkenntnispraxis), there is no such thing as a disinterested form of reasoning. ${ }^{144}$

(i) Scholastic autonomism: Scholastic thought is autonomist in that it is based on the idea of 'autonomous reason', rather than 'dependent reason'. As such, it reinforces the autonomization of reason on two levels: on the symbolic level, scholastic thought asserts its independence from ostensibly inferior facets of meaning production, notably those that are situated outside the realm of philosophy, that is, outside the empire of the queen of knowledge; on the material level, scholastic thought declares its independence from the mundane - notably, physical - dimensions of reality, which it seeks to transcend by virtue of its claims to rationally grounded autonomy.

Those who are immersed, in some cases from birth, in scholastic universes resulting from a long process of autonomization are led to forget the exceptional historical and social conditions that make possible a view of the world and of cultural products that is characterized by self-evidence and naturalness. ${ }^{145}$ 
Whilst concealing its material dependence upon necessity through relative symbolic independence, scholastic thought hides its symbolic dependence upon necessity through relative material independence. ${ }^{146}$

(j) Scholastic hegemonism: Scholastic thought is hegemonist in that it is based on the idea of 'philosophical reason', rather than 'sociological reason'. As such, it is aimed at occupying a position of ultimate hegemony in the sphere of knowledge. This objective manifests itself in 'the age-old battle of philosophy against sociology'. ${ }^{147}$ Sociology means to philosophy what science means to religion: 'a threat to the self-declared ultimate authority of an arbitrary historical authority'. ${ }^{148}$ Whereas philosophy has always been substantially shaped by attempts to make claims to universally defensible validity (Gültigkeit), the whole point of doing sociology is to insist on the contextually contingent preponderance of sociality (Gesellschaftlichkeit) pervading all human engagements with reality (Wirklichkeit). ${ }^{149}$

In short, "the hegemonic ambition"150 of scholastic thought can be conceived of as an expression of the philosophically inspired quest for theory, intellectuality, universality, rationality, transcendentality, purity, foundationality, neutrality and autonomy. It is the task of sociological reflexivity to unmask the illusory nature of the scholastic desire to step outside the horizon of relationally constructed realities.

The break with ordinary conceptions of the world and the break with scholastic conceptions of the world constitute two irreducible components of the social-scientific attempt to engage critically with reality: reflexive social researchers need to aim for both sufficient theoretical distance to question people's common-sense representations of reality and sufficient practical proximity to account for the empirical weight of people's immersion in society. ${ }^{151}$

\section{Reflexivity and epistemology}

The ninth central element underlying Bourdieu's conception of reflexivity is epistemology. To be exact, reflexivity - in the Bourdieusian sense - forms part of a social epistemology. As such, it pursues the project of a 'sociology of knowledge', ${ }^{152}$ which - by definition - consists in 'relativizing the validity of knowledge' ${ }^{\prime 153}$ and, hence, in shattering any illusions about the possibility of developing an epistemology capable of demonstrating the existence of free-floating symbolic forms. To recognize that 'the sociology of sociology' ${ }^{154}$ is inconceivable without 'the sociology of sociological knowledge' 
requires accepting that every claim to epistemic validity takes place within a spatiotemporally contingent realm of sociality. From a Bourdieusian perspective, there is no epistemology without reflexivity, just as there is no reflexivity without epistemology.

Challenging 'the theological or terrorist use of the canonical writings', ${ }^{156} \mathrm{a}$ truly reflexive epistemology permits the researcher to draw upon 'the effectiveness of critique ${ }^{157}$ with the aim of exposing not only the social determinants of human action but also the 'social determinants of sociological thought' itself. Considering the 'social history of the sociology of science', ${ }^{159}$ it is vital not to fall into the trap of 'providing cognitive tools that can be turned back on the subject of the cognition'. ${ }^{160}$ If epistemological devices turn out to be anti-epistemological, this implies that they defeat the whole point of sociological inquiry, which is to generate knowledge with, within and for - rather than without, outside and against - society. To the degree that we are willing to unearth the 'social grounds' ${ }^{161}$ of knowledge - that is, of both ordinary and scientific ways of grasping particular aspects of reality -, we need to be prepared 'to historicize the subject of historicization [and] objectify the subject of objectification'. ${ }^{162}$

Epistemology, understood in sociological terms, involves the effort to gain 'knowledge of its historical presuppositions', ${ }^{163}$ that is, of the social conditions of production in whose context subjects capable of cognition and action operate. Thus, the reason ' $[\mathrm{w}]$ hy the social sciences must take themselves as their object $^{164}$ is that the defence of a self-critical epistemology is a precondition for the possibility of pursuing a reflexive sociology. Hence, 'sociologists have to convert reflexivity into a disposition constitutive of their scientific habitus, that is, into a reflexive reflexivity, capable of acting not ex post, on the opus operatum, but a priori, on the modus operandi. ${ }^{165}$ By so doing, they can contribute to creating a sociology whose epistemology is as reflexive as its reflexivity is epistemological. Within the epistemological horizon of reflexive sociology, there is no place for narcissism or self-complacency, because it is motivated by the ambition to shed light on the intimate link between the production of knowledge and the construction of society. ${ }^{166}$

\section{Reflexivity and historicization}

The tenth chief element underlying Bourdieu's conception of reflexivity is historicization. One of the main tasks faced by reflexive research is to explore the 'historical and social conditions under which sociological practice is accomplished', ${ }^{167}$ including the practices of ordinary actors in their everyday lives. Every social performance is historically situated. It is possible to make sense of 
the historicity that permeates worldly realities by focusing on different levels of analysis, notably the following:

- on the objective level, history can be conceived of as a naturally constituted process, founded on physically organized occurrences;

- on the normative level, history can be interpreted as a culturally constituted process, shaped by socially constructed occurrences;

- on the subjective level, history can be considered a psychologically constituted process, derived from mentally projected occurrences.

However one wishes to conceptualize historicity, one cannot deny the temporal - and, hence, transient - composition pervading all - including the seemingly most consolidated - forms of sociality. Thus, 'to historicize the subject of historicization"168 means to reconstruct 'the genealogy' ${ }^{169}$ of socially assembled realities, comprising both ordinary and scientific attempts to make sense of their temporal contingency. A 'reflexive historico-sociological analysis of science ${ }^{\prime 170}$ is the epistemological precondition for acquiring 'knowledge of its historical presuppositions', ${ }^{171}$ that is, of the sets of principles, criteria and assumptions on the basis of which researchers establish an investigative relation to the aspects of reality that they aim to study. Put differently, 'all social scientists should contextualize themselves by going through a process of sociological self-analysis or rigorous epistemological vigilance. ${ }^{172}$ For without the 'historical critique of unconscious presuppositions ${ }^{173}$ it is impossible to account for the pivotal role that hermeneutically constituted - and, hence, constantly shifting - background horizons play in the construction of meaning. There is no comprehensive form of sociological reflexivity without the researcher's awareness of his or her situatedness in history:

Through the sociologist, a historically situated historical agent and socially determined social subject, history - that is, the society in which the existing remains of history are present - turns for a moment back on itself, and reflects on itself; and, through the sociologist, all social agents are able to know a little more clearly what they are and what they are doing. ${ }^{174}$

Given the temporality that permeates all forms of worldly reality, including epistemic attempts to capture particular aspects shaping the constitution of society, it is one of the key functions of sociological reflexivity to draw attention to the fact that there is no such thing as a transcendental mode of human agency capable of escaping its embeddedness in the horizon of historicity. ${ }^{175}$ 


\section{Reflexivity and understanding}

The eleventh fundamental element underlying Bourdieu's conception of reflexivity is understanding. In this context, it is both possible and useful to distinguish three principal levels of understanding (comprendre or Verstehen), all of which are vital to the possibility of sociological reflexivity:

- understanding in the cognitive sense of comprehending something (Verstehen eines Tatbestandes);

- understanding in the intersubjective sense of comprehending someone else's assertions (Verstehen einer Aussage); and

- understanding in the empathetic sense of comprehending someone else's motives, feelings or situation (Verstehen eines Mitmenschen). ${ }^{176}$

Put differently, sociological reflexivity - in the Bourdieusian sense - comprises a tripartite challenge: the ability to grapple with (a) objective, (b) intersubjective and (c) subjective dimensions of reality. In effect, the conceptual differentiation between these three spheres of existence is somewhat arbitrary: 'objectivity is intersubjectivity ${ }^{177}$ to the extent that, in order to acquire social recognition, it requires 'intersubjective validation'; ${ }^{178}$ objectivity is subjectivity to the extent that, in order to obtain personal legitimacy, it needs to receive subjective validation. Such a constructivist conception of the world 'is opposed to any form of realism seeking to ground truth in "the match between the thing and the spirit", ${ }^{179}$ that is, in a correspondence between reality and representation and, thus, in a homology between 'the way things are' and 'the way things are thought to be'. ${ }^{180}$ The Bourdieusian challenge, then, consists in exposing the social constructedness of human reality in general and of symbolic representations in particular. ${ }^{181}$ In order to comprehend the sociological role of human modes of understanding, we need to examine the social factors shaping our symbolically mediated engagement with the physical, cultural and personal realms of our existence.

Far from being reducible to a monolithic affair, the intimate link between reflexivity and understanding needs to be studied in terms of the multiple dimensions permeating both ordinary people's and social researcher's attempts to attribute meaning to reality. Yet, it is the intersubjectivist constitution of human understanding that deserves particular attention:

to situate oneself at the point where the author was situated, at the point that he [or she] occupied within the social world and from which he [or she] viewed the world; to place oneself at that point means to adopt the point of view on the world that is his [or hers], to understand it as he [or she] understood it, and so, in a sense, to justify it. ${ }^{182}$ 
On this account, reflexivity that is oriented towards understanding is tantamount to a perspective-taking exercise: our capacity to look at the world from the viewpoint of others forms an indispensable component of our ability to develop a sense of empathy as well as, at a more fundamental level, a sense of morality. There is no comprehensive understanding of human reality without recognition of the fact that we, as moral entities, are equipped with the capacity to put ourselves in the shoes of others. Put differently, sociological reflexivity is inconceivable without the ability to see things through the eyes of our fellow human beings by virtue of empathy. It is by learning to communicate with others that we learn to attribute meaning both to our external world and to our internal world. Given the tripartite constitution of our simultaneous immersion in the physical, cultural and personal realms of our lives, the objective, normative and subjective dimensions of our existence are inextricably intertwined. Reflexive sociology, then, constitutes 'a resource to understand the world ${ }^{183}$ that surrounds us and, indeed, a resource through which we can seek to understand the nature of understanding itself. ${ }^{184}$

\section{Reflexivity and emancipation}

The twelfth central element underlying Bourdieu's conception of reflexivity is emancipation. ${ }^{185}$ 'Returning to people the meaning of their actions', ${ }^{186}$ thereby 'learning to know oneself, to situate oneself, to reflect upon one's position $^{\prime 187}$ and, thus, to become aware of both the resources of empowerment and the sources of disempowerment - all of these aspirations were amongst 'Bourdieu's strong demands', ${ }^{188}$ inspired by his ambition to develop a sociology guided by the constant exercise of reflexivity. To be sure, ' $[\mathrm{t}]$ he knowledge of determinisms ${ }^{189}$ - irrespective of whether they are, primarily, of material or symbolic, behavioural or ideological, empirical or representational nature can contribute 'to liberty and to action', ${ }^{190}$ both of which constitute indispensable ingredients of emancipatory forms of transformation. In this way, sociology can be converted into an 'instrument of liberation', ${ }^{191}$ but without thereby ascribing "the role of the liberating hero"192 to the sociologist, as if he or she were the enlightener of the to-be-enlightened. Rather, it is the task of sociology to provide conceptual and methodological tools by means of which it becomes possible not only to uncover and to challenge mechanisms of domination but also to allude to the possibility of creating social conditions allowing for processes of both individual and collective emancipation.

I too sometimes wonder if the completely transparent and disenchanted social universe that would be produced by a social science that was fully developed (and widely diffused, if that could ever be the case) would not be impossible to 
live in. I think, all the same, that social relations would be much less unhappy if people at least understood the mechanisms that lead them to contribute to their own deprivation. ${ }^{193}$

In light of the previous reflection, we are confronted with a curious paradox. On the one hand, a human universe that is utterly shaped - if not, controlled by social-scientific knowledge is not necessarily a viable, let alone a desirable, option for the construction of a society capable of escaping the constraining force of systemically driven determinacy. On the other hand, a world whose development is dictated by mechanisms of domination, rather than by processes of emancipation, can be challenged by exploring the civilizational role of our species-distinctive potential. In other words, reflexive sociologists need to be both realistic and optimistic: they need to be sufficiently realistic to recognize that the construction of an entirely emancipated world is not only unviable but also undesirable. At the same time, they need to be sufficiently optimistic to insist that the construction of a world shaped in accordance with universal human needs, as well as on the basis of a fairly distributed access to material and symbolic resources for action, is an ideal for which it is worth struggling.

The particularity of sociology is that it takes as its objects fields of struggle - not only the field of class struggle but the field of scientific struggles itself. And the sociologist occupies a position in these struggles. ${ }^{194}$

the more advanced a science is, the greater is the capital of knowledge accumulated within it and the greater the quality of knowledge that subversive and critical strategies, whatever their 'motivations', need to mobilize in order to be effective. ${ }^{195}$

On this view, reflexivity is an empowering resource on several counts:

(a) It permits us to conceive of society as an ensemble of fields and, hence, as a set of multiple struggles between asymmetrically positioned individual and collective actors. ${ }^{196}$

(b) It enables us to conceive of sociology as a discipline located within the scientific field and, thus, as an undertaking shaped by both structural and ideological modes of position-taking - not only in relation to its own area of research but also, more generally, in relation to society as a whole. ${ }^{197}$

(c) It allows us to use science as a tool, not in order to authorize or to legitimize research for the sake of research, but, rather, in order to empower the disempowered, give a voice to the voiceless and make visible the invisible. ${ }^{198}$

From a Bourdieusian perspective, then, 'the weapons of criticism have to be scientific in order to be effective'. ${ }^{199}$ That is, reflexivity that shies away from 
making claims to scientific validity fails to overcome the limited status of rhetorically motivated speculation based on common sense and on personal experiences of everyday reality. A socially committed sociology ${ }^{200}$ is a critical undertaking that faces up to the fact that 'scientific work [has] political implications', ${ }^{201}$ even - or, perhaps, especially - if and when these are unintended and not immediately obvious. Sociology cannot escape the horizons of normativity emerging from the construction of value-laden, meaning-laden, perspective-laden, interest-laden, power-laden and tension-laden realities. Aware of both the negative and the positive contributions that science can make to the development of society, sociology has a major task on its hands when drawing on the power of reflexivity in order to contribute to the construction of realities in which - at least in principle - all humans can flourish and which, therefore, deserve to be characterized as 'really or potentially emancipatory'. ${ }^{202}$

\section{Conclusion}

As shown in the preceding analysis, Bourdieu's conception of reflexivity is complex and multifaceted. By means of an in-depth examination of his key works, this chapter has aimed to demonstrate that twelve elements are particularly important to Bourdieu's conception of reflexivity: (1) 'science', (2) 'vigilance', (3) 'consciousness', (4) 'self-awareness', (5) 'critique', (6) 'self-objectification', (7) 'distance-taking', (8) 'rupture', (9) 'epistemology', (10) 'historicization', (11) 'understanding' and (12) 'emancipation'. From a Bourdieusian point of view, the concept of 'reflexivity' plays a pivotal role in the pursuit of sociology. Yet, the previous inquiry raises a number of significant questions about controversial issues that need to be addressed when evaluating the merits of Bourdieu's account of reflexivity. It is the task of this concluding section to consider some of these issues, which - following the structure of the foregoing study - can be synthesized on the basis of 'twelve theses on Bourdieu's conception of reflexivity':

1. Reflexivity needs science, and science needs reflexivity. The danger of falling into the trap of scientism arises, however, to the extent that science is hypostatized and, hence, treated as a catch-all endeavour, capable of producing pristine, infallible and omnipotent forms of knowledge.

2. Reflexivity needs vigilance, and vigilance needs reflexivity. The risk of succumbing to academic narcissism emerges, however, to the extent that vigilance is fetishized and - unwittingly - converted into a source of intellectual paralysis, which may lead researchers to be concerned more with themselves and their objectifying gaze than with their object of investigation. 
3. Reflexivity needs consciousness, and consciousness needs reflexivity. We face the possibility of getting caught up in cognitivism, however, to the extent that we overestimate the civilizational significance of actors' consciousness and underestimate the sociological role of their unconscious. Even the most mindful ways of performing social actions, including those aimed at conducting social-scientific research, cannot do away with the formative influence of constantly shifting - and largely implicit - background horizons.

4. Reflexivity needs self-awareness, and self-awareness needs reflexivity. We are confronted with the issue of subjectivism, however, to the extent that we commit the error of attaching more importance to researchers' attentiveness to their inner world than to their sustained engagement with the external world of those whose lives they set out to examine.

5. Reflexivity needs critique, and critique needs reflexivity. We run the risk of confining ourselves to a stifling position of normativism, however, to the extent that we attribute more weight to the critique of the criticizing gaze than to the critique of the social arrangements put in place to sustain mechanisms of social domination and thereby to undermine processes of human emancipation. Sociologists have described, analysed, interpreted, explained and assessed the world in different ways; the point is to change it.

6. Reflexivity needs self-objectification, and self-objectification needs reflexivity. It is difficult to bypass the problem of objectivism, however, to the extent that reality is conceived of as a conglomerate of merely factual properties, rather than in terms of a combination of objectively established, normatively constructed and subjectively projected assemblies of actuality, which constitute relationally constituted frameworks for human agency.

7. Reflexivity needs distance-taking, and distance-taking needs reflexivity. The epistemological stance of externalism becomes a methodological challenge, however, to the extent that one treats the perspective of the sociological observer as superior to that of the social actor. Immersion can be as much an obstacle to understanding as it can be a key to insight.

8. Reflexivity needs rupture, and rupture needs reflexivity. Instead of submitting to the seductive force of epistemological reductionism, however, to the extent that one considers one mode of knowledge production categorically more valuable than another, it is sensible to recognize the cognitive complexity permeating all symbolically mediated representations of reality.

(a) Scientific knowledge can be superior to ordinary knowledge to the degree that it permits us to uncover underlying causalities that escape our common-sense grasp of reality.

(b) Ordinary knowledge can be superior to scientific knowledge to the degree that it captures the socio-ontological immediacy of people's 
everyday epistemologies: the authenticity of subjectively experienced and intersubjectively shaped processes of perception, appreciation and action escapes the reifying lenses of conceptual sophistication and methodological objectification.

(c) Both ordinary knowledge and scientific knowledge can be insightful to the degree that they can express epistemically forceful modes of attributing meaning to objectively, normatively or subjectively constituted actualities. One of the greatest epistemological challenges for sociology consists in cross-fertilizing - rather than strictly separating - ordinary and scientific ways of relating to, engaging with and acting upon reality.

9. Reflexivity needs epistemology, and epistemology needs reflexivity. The problem of rationalism poses itself, however, to the extent that social-scientific researchers privilege rational over non-rational ways of relating to the world. Seemingly non-rational - notably, artistic - modes of grappling with reality deserve a place in sociology insofar as they contribute to a critical understanding of the world capable of drawing on the purposive, cooperative and creative resources of humanity.

10. Reflexivity needs historicization, and historicization needs reflexivity. The overt or tacit advocacy of relativism becomes apparent, however, to the extent that sociologists - if they choose to do so - follow the constructivist dogma that every worldly phenomenon can be studied in terms of social malleability, cultural contingency and historical indeterminacy. The fact that everything is context-laden does not mean that 'anything goes'.

11. Reflexivity needs understanding, and understanding needs reflexivity. The endorsement of interpretivism is problematic, however, to the extent that 'understanding' and 'explanation' are conceived of as two mutually exclusive, rather than complementary, paradigms. Just as we need to understand the power of explanation, we need to explain the power of understanding. Instead of attaching the sphere of objectivity exclusively to the paradigm of explanation and, correspondingly, the spheres of normativity and subjectivity solely to the paradigm of understanding, we should explore the degree to which the constitutive elements of human reality can be explicated and interpreted in terms of a combination of physical, cultural and personal properties.

12. Reflexivity needs emancipation, and emancipation needs reflexivity. An idealist position that is inspired by the promises of positivist utopianism is misleading, however, to the extent that it portrays sociology as a scientific tool capable of providing a theoretically coherent and practically viable blueprint for the construction of an emancipatory society. It is crucial to reject all forms of socio-ontological romanticism, according to which human lifeworlds constitute power-free realms of pristine intersubjectivity. It is no 
less important, however, to discard all forms of socio-ontological fatalism, according to which all human actions are driven by competitive struggles over power and legitimacy. In contrast to these reductive perspectives, the position of socio-ontological realism does justice to the fact that human life forms are characterized by the tension-laden coexistence of power-laden and power-critical, competitive and cooperative, egoistic and altruistic dimensions, which have always shaped - and which will always continue to shape - the course of history, irrespective of its protagonists' degree of reflexivity.

\section{Notes}

1 See, for instance: Bourdieu 1990, 2001a; Bourdieu and Wacquant 1992a, b.

2 See, for example: Adkins 2003; Adkins 2004; Barnard 1990; Bassett 1996; Bohman 1997; Boschetti 2004; Burkitt 1997; Colliot-Thélène 1995; Dezalay 2005; Engler and Zimmermann 2002; Gaonkar 1997; Geldof 1997; Gingras 2004; Heilbron 1999; Houdart 2004; Inglis 2005; Kögler 1996, 1997a; McNay 1999; Mialet 2003; Moss 2005; Noya 2003a, b; Pels 2000; Schirato and Webb 2003; Stabile 2000; Susen 2007. See also, for instance: Calhoun 2000 (1990); Champagne 2002; Deer 2003; Karakayali 2004; Kenway and McLeod 2004; Kögler 1997b; Lewandowski 2000; Mollet 2003; Raphael 1991; Wacquant 1989; Wacquant 1992a.

3 Wacquant 1992a, 36.

4 Ibid.

5 Ibid. (italics in original).

6 Ibid. (italics in original).

7 Ibid. 36.

8 Ibid. (italics in original).

9 Ibid.

10 On this point, see Wacquant 1992a, 36-7.

11 Wacquant 1992a, 37.

12 On this point, see Wacquant 1992a, 37-8. See also, for instance: Giddens 1977, 1979, 1984, 1987, 1989, 1990, 1991.

13 Wacquant 1992a, 37.

14 See Ibid.

15 On this point, see Susen 2015a, esp. Chapter 1, Chapter 3 and Chapter 4.

16 Wacquant 1992a, 38 (italics in original).

17 Ibid. (italics added); the quoted passage (within this quotation) is taken from Gouldner 1971, 483.

18 Wacquant 1992a, 40 (italics in original).

19 Wacquant 1992a, 39.

20 On this point, see ibid.

21 Ibid.

22 Ibid. (italics in original).

23 Ibid. (italics in original).

24 Ibid. (italics in original). On this point, see Bourdieu 1980 and 1980 (1990). See also, for instance, Bourdieu 1968. 
25 Wacquant 1992a, 46 (italics added).

26 Ibid. (the comma after the word 'subjected' does not appear in the original version).

27 Wacquant 1992a, 42.

28 On Bourdieu's conception of reflexivity, see, for instance: Bourdieu 1976, 104; 1978, 67-8; 1980, 30, 40, 43 and 51-70; 1982a, 8-11, 23-4, 29, 32 and 54; [1984a], 1993, 9-14; [1984b], 1993; 1991, 3-5; 1993, 1389-447; 1995b, 115-116; 1997b, 12-13, 28-9, 43, 113, 140 and 158; 1998, 9; 2001b, 7, 20, 30 and 57; 2001a, esp. 15-20, 154 and 167-220; Bourdieu, Chamboredon and Passeron 1968, 14, 23, 31, 39, 46, 57, 62, 96 and 100-2; Bourdieu and Wacquant 1992c, esp. 68-73; 1992d, 127; 1992f, 214; Wacquant 1992a, 36-42 and 46.

In the secondary literature, see, for example: Bonnewitz 1998, 4, 23-4, 28 and 39; 2002, 36; Boyne 1993, 247 and 250; Champagne 2002; Colliot-Thélène 1995; Cronin 1997; Crowley 2002, 156-7 and 165; de L'Estoile 2003, 129 and 139; de Saint Martin 2003, 331; Duncan 1990, esp. 180; Eickelpasch 2002, 57-8; Engler and Zimmermann 2002; Grenfell and James 1998, 123-7; Griller [1996], 2000, 195-6; Heilbron 1999; Herz 1996, 236-40; Jenkins 1994, 101; Karakayali 2004, esp. 352-4; Kögler 1997a, esp. 154; Lewandowski 2000, esp. 49-50 and 55-6; Mesny 1998, 150-1 and 174; Mesny 2002, 65; Mounier 2001, 161 and 176; Noya 2003b; Panayotopoulos 1999, 327; Pinto 1998, 11, 71-4, 84, 150-63 and 213-15; Revel 2003, 101; Robbins 1999, 310; Singer 1999, 292; Susen 2007, 9, 11, 19, 20, 23, 25, 35, 41, 52, 57, 94, 119, 120, 133-7, 139, 145n.6, 215, 216, 222, 225, 226, 227n.29, 235, 236, 243, 249, 256, 262, 269n.7, 276, 287, 293, 296, 308, 309, 311, 312, 313 and 314; Susen 2011c, 375, 376, 395, 397, 399, 400, 403 and 405; 2011d, esp. 53-55, 69-70 and 75-76; 2011a, 448-58 (esp. 455) and 462; 2013a, 202, 205, 206, 224 and 226; 2013b, 328, 329, 330, 331, 333, 334, 335, 339, $340,341,344,349,357,362,363,364$ and 374; 2014a, 158, 166-7, 167-70, 173-4, 176, 178, 180-6; [2015], 2014, 316, 321-2, 322-4, 326-7, 328 and 330-5; Swartz 1997, 10-11, 270-83 and 293-5; Terray 2003, 303; Vandenberghe 1999, 41; Vázquez García 2002, 177-9, 182-3, 184, 187, 199, 201 and 204; Verdès-Leroux 1996, 181; Wacquant 2004; Webb, Schirato and Danaher 2002, 18-19, 46 and 49-62.

29 Bourdieu, Chamboredon and Passeron 1968, 31 (my translation); original text: 'science réflexive'.

30 Bourdieu, Chamboredon and Passeron 1968, 14 (my translation); original text: 'travail scientifique'.

31 Bourdieu 1982a, 9 (my translation); original text: 'sociologie scientifique'.

32 Bourdieu 1982a, 23 (my translation); original text: 'la science sociologique'.

33 Bourdieu 1982a, 9 (my translation); original text: 'l'histoire sociale de la science sociale'.

34 Bourdieu 1982a, 23 (my translation); original text: 'la sociologie de la science'.

35 Bourdieu 1982a, 23-4 (my translation); original text: 'en accroissant la connaissance des déterminants sociaux de la pensée sociologique, donc l'efficacité de la critique'.

36 Bourdieu 1984a, 9 (1993) (italics added to the words 'reveals' and 'hidden'; the word 'repressed' is italicized in the original version).

37 Ibid. (italics added).

38 Ibid. (italics added to 'profits'; the word 'interests' is italicized in the original version).

39 Ibid.

40 Bourdieu 1984a, 11 (1993) (italics added; the word 'limits' is italicized in the original version).

41 Bourdieu and Wacquant 1992c, 72.

42 Ibid. 
43 Bourdieu and Wacquant 1992c, 69-70 (italics added).

44 Bourdieu and Wacquant 1992c, 72.

45 Bourdieu and Wacquant 1992c, 69.

46 Bourdieu and Wacquant 1992d, 127 (italics added).

47 Bourdieu and Wacquant 1992f, 214.

48 Ibid. (italics in original).

49 Ibid. (italics added).

50 Ibid (italics added).

51 Ibid.

52 On Bourdieu's conception of the relationship between 'reflexivity' and 'science', see, for instance: Bourdieu 1982a, 9 and 22-3; [1984a], 1993, 9-12; 1997b, 140; 2001b, 7, 20, 30 and 57; Bourdieu, Chamboredon and Passeron 1968, 14 and 31; Bourdieu and Wacquant 1992c, 69 and 72; 1992d, 127; Bourdieu and Wacquant 1992f, 214. In the secondary literature, see, for example: Boyne 1993, 247 and 250; Caro 1980, 1177 and 1179; Crowley 2002, 156, 157 and 165; Griller [1996], 2000, 195-6; Susen 2011d, esp. 53-5, 69-70 and 75-6; Terray 2003, 303.

53 Bourdieu, Chamboredon and Passeron 1968, 13 (my translation); original text: 'soumettre les opérations de la pratique sociologique à la polémique de la raison épistémologique'.

54 Bourdieu, Chamboredon and Passeron 1968, 13-14 (my translation); original text: 'une attitude de vigilance'.

55 Bourdieu, Chamboredon and Passeron 1968, 14 (my translation); original text: 'la connaissance adéquate de l'erreur'.

56 Ibid. (italics added) (my translation); original text: 'L'intention de donner au chercheur les moyens d'assumer lui-même la surveillance de son travail scientifique s'oppose aux rappels à l'ordre des censeurs dont le négativisme péremptoire ne peut que susciter la terreur de l'erreur et le recours résigné à une technologie investie de la fonction d'exorcisme.'

57 Bourdieu, Chamboredon and Passeron 1968, 23 (my translation); original text: 'une philosophie de la vigilance critique'.

58 Bourdieu, Chamboredon and Passeron 1968, 14 (italics added) (my translation); original text: 'la "psychanalyse de l'esprit scientifique"'.

59 Ibid. (italics added) (my translation); original text: 'la "psychanalyse de l'esprit scientifique" par une analyse des conditions sociales dans lesquelles sont produites les œuvres sociologiques: le sociologue peut trouver un instrument privilégié de la vigilance épistémologique dans la sociologie de la connaissance, moyen d'accrô̂tre et de préciser la connaissance de l'erreur et des conditions qui la rendent possible et parfois inévitable'.

60 Bourdieu, Chamboredon and Passeron 1968, 67 and 100 (my translation); original text: 'une réflexion épistémologique'.

61 Bourdieu, Chamboredon and Passeron 1968, 100 (my translation); original text: 'des conditions sociales de sa pratique sociologique et de son rapport à la sociologie'.

62 Ibid. (italics added) (my translation); original text: 'la condition préalable de l'explication des présupposés inconscients et du même coup, d'une interiorisation plus complète d'une épistémologie plus achevée'.

63 On this point, see ibid.: 'L'enracinement social du sociologue'.

64 Ibid. (italics added) (my translation); original text: 'Parmi les présupposés que le sociologue doit au fait qu'il est un sujet social, le plus fondamental est sans doute le présupposé de l'absence de présupposés qui définit l'ethnocentrisme; c'est en effet lorsqu'il 
s'ignore comme sujet cultivé d'une culture particulière et qu'il ne subordonne pas toute sa pratique à une mise en question continue de cet enracinement, que le sociologue (plus que l'ethnologue) est vulnérable à l'illusion de l'évidence immédiate ou à la tentation d'universaliser inconsciemment une expérience singulière.'

65 Ibid. (my translation); original text: 'ravivées et réinterprétées par la vigilance épistémologique'.

66 On Bourdieu's conception of the relationship between 'reflexivity' and 'vigilance', see, for instance: Bourdieu 1976, 104; 1978, 67-8; 1980, 30, 40, 43 and 51-70; 1982a, 8-11, 23-4, 29, 32 and 54; [1984a], 1993, 9-14; [1984b], 1993; 1991; 1993; 1995b, 115116; 1997b, 12-13, 28-9, 43, 113, 140 and 158; 1998, 9; 2001b, 7, 20, 30 and 57; 2001a, esp.15-20, 154 and 167-220; Bourdieu, Chamboredon and Passeron 1968, 14, 15, 23, 24, 25, 27, 31, 39, 46, 55, 57, 62, 95-106, 117-20, 121, 134 and 319; Bourdieu and Wacquant 1992c, esp. 68-73; 1992d, 127; 1992f, 214; Wacquant 1992a, 36-42 and 46. In the secondary literature, see, for example: Bonnewitz 1998, 4, 23-4, 28 and 39; 2002, 36; Boyne 1993, 247 and 250; Caro 1980, 1179; Champagne 2002; Colliot-Thélène 1995; Cronin 1997; Crowley 2002, 156-157 and 165; de L'Estoile 2003, 129 and 139; de Saint Martin 2003, 331; Duncan 1990, esp. 180; Eickelpasch 2002, 57-8; Engler and Zimmermann 2002; Grenfell and James 1998, 123-7; Griller [1996], 2000, 195-6; Heilbron 1999; Herz 1996, 236-40; Jenkins 1994, 101; Karakayali 2004, esp. 352-4; Kögler 1997a, esp. 154; Lewandowski 2000, esp. 49-50 and 55-6; Mesny 1998, 150-1 and 174; Mesny 2002, 65; Mounier 2001, 161 and 176; Noya 2003b; Panayotopoulos 1999, 327; Pinto 1998, 11, 71-4, 84, 150-63 and 213-215; Revel 2003, 101; Robbins 1999, 310; Singer 1999, 292; Susen 2007, 134-5; Swartz 1997, 10-11, 270-83 and 293-5; Terray 2003, 303; Vandenberghe 1999, 41; Vázquez García 2002, 177-9, 182-3, 184, 187, 199, 201 and 204; Verdès-Leroux 1996, 181; Wacquant 2004; Webb, Schirato and Danaher 2002, 18-19, 46 and 49-62.

67 Bourdieu, Chamboredon and Passeron 1968, 14 (my translation); original text: "la "psychanalyse de l'esprit scientifique".

68 Bourdieu, Chamboredon and Passeron 1968, 39 (my translation); original text: 'une psychanalyse de l'esprit sociologique'.

69 Bourdieu, Chamboredon and Passeron 1968, 100 and 105 (italics added) (my translation); original text: 'les présupposés inconscients'.

70 Bourdieu 1982a, 10 (italics added) (my translation); original text: 'une science de l'inconscient'.

71 Bourdieu 1998, 9 (italics added) (my translation); original text: 'une archéologie objective de notre inconscient'.

72 Ibid. (italics added) (my translation); original text: 'l'instrument d'une véritable socioanalyse'.

73 Bourdieu 2001b, 7 (italics added) (my translation); original text: 'une critique sociale'.

74 Mounier 2001, 161 (my translation); original text: 'un retour réflexif sur sa propre pratique'.

75 Ibid. (my translation); original text: 'un inconscient social dans l'analyse'.

76 Mounier 2001, 176 (italics added) (my translation); original text: 'une réflexion épistémologique sur ses pratiques est inséparable d'une réflexion politique sur ses effets et sa fonction'.

77 Wacquant 1992a, 40 (italics in original). On this point, see also Bourdieu 2002.

78 Bourdieu 1999, 334. 
79 Bourdieu 1999, 334-5.

80 Bourdieu 1999, 335.

81 On Bourdieu's conception of the relationship between 'reflexivity' and 'consciousness', see, for instance: Bourdieu 1982a, 10; 1998, 9; 1999, 334-5; 2001b, 7, 20, 30 and 57; Bourdieu, Chamboredon and Passeron 1968, 14, 39 and 100. In the secondary literature, see, for example: Celikates 2009; Mounier 2001,161 and 176; Wacquant 1992a, 36 and 40 .

82 On this point, see, for instance: Bourdieu 1978, 67-8; 1980, 43; 1982a, 8, 29 and 54; 1991, esp. 5; 1995a, esp. 3 and 9; 1997b, 12-13; 2004; Bourdieu, Chamboredon and Passeron 1968, 62; Bourdieu and Wacquant 1992f, 214.

83 Bourdieu, Chamboredon and Passeron 1968, 62 (my translation); original text: 'soumet pas ses propres interrogations à l'interrogation sociologique'.

84 Bourdieu 1980, 43 (my translation); original text: 'le retour réflexif sur l'expérience subjective du monde social'.

85 Ibid. (my translation); original text: 'l'objectivation des conditions objectives de cette expérience'.

86 Bourdieu 1982a, 8 (my translation); original text: 'le jeu de la leçon inaugurale sur la leçon inaugurale'.

87 Bourdieu 1982a, 54 (my translation); original text: '[u]n discours qui se prend luimême pour objet'.

88 Ibid. (my translation); original text: 'retour réflexif'.

89 Bourdieu and Wacquant 1992f, 214.

90 Ibid.

91 Bourdieu 1995a, 3 (my translation); original text: 'son propre fonctionnement'.

92 Bourdieu 1991, 5 (my translation); original text: 'un point de vue sur un point de vue'.

93 On Bourdieu's conception of the relationship between 'reflexivity' and 'self-awareness', see, for instance: Bourdieu 1978, 67-8; 1980, 43; 1982a, 8, 29 and 54; 1991, esp. 5; 1995a, esp. 3 and 9; 1997b, 12-13; 2004; Bourdieu, Chamboredon and Passeron 1968, 62; Bourdieu and Wacquant 1992f, 214. In the secondary literature, see, for example: Accardo 1997, 261 and 265; Eickelpasch 2002, 58; Hamel [1997], 2000, 148 and 156-7; Heilbron 1999, 298-304; Herz 1996, 236-40; Revel 2003, 101; Robbins 1999, 310; Singer 1999, 292; Swartz 1997, 270-6 and 293; Verdès-Leroux 1996, 181.

94 On this point, see, for instance, Bourdieu 1997b, 12-13.

95 On this point, see, for instance, Bourdieu 1997b, 113.

96 On this point, see, for example, Susen 2014a and Susen [2015], 2014. See also, for instance, Bénatouil 1999a and 1999b.

97 Bourdieu 2001b, 30 (my translation); original text: 'sociologue travailleur social'.

98 On Bourdieu's conception of the relationship between 'reflexivity' and 'critique', see, for instance: Bourdieu 1982a, 8 and 11; [1984a], 1993, 13-14; 1993; 1997b, 12-13 and 113; 2001b, 7, 20, 30 and 57; Bourdieu and Wacquant 1992c, 69-72; 1992f, 214. In the secondary literature, see, for example: Boltanski, Honneth and Celikates [2009], 2014; Bonnewitz 1998, 23 and 28; Celikates 2009; Eickelpasch 2002, 57-8; Susen 2011 a.

99 Bourdieu 1980, 29-30 (italics in original) (my translation); original text: 'objectiver cette distance objectivante et les conditions sociales qui la rendent possible, comme l'extériorité de l'observateur'.

100 Bourdieu 1980, 30 (my translation); original text: 'un point de vue situé hors de la scène où se joue l'action'. 
101 Bourdieu 1980, 40 (my translation); original text: 'toute entreprise sociologique véritable'.

102 Ibid. (my translation); original text: 'une socio-analyse'. On this point, see also Bourdieu 1998, 9. Cf. Susen 2016c.

103 Bourdieu 1980, 40 (my translation); original text: 'l'objectivation de l'objectivité'.

104 Ibid. (my translation); original text: 'une véritable réappropriation de soi'.

105 Bourdieu 1980, 51 (my translation); original text: 'objectiver l'objectivation'.

106 Bourdieu 1980, 43 (my translation); original text: 'une objectivation critique'.

107 Ibid. (my translation); original text: 'les conditions épistémologiques et sociales'.

108 Bourdieu and Wacquant 1992c, 69.

109 Ibid.

110 Bourdieu 1995b, 116 (my translation); original text: 'La reflexivite conçue comme travail d'objectivation scientifique du sujet objectivant'.

111 On Bourdieu's conception of the relationship between 'reflexivity' and 'self-objectification', see, for instance: Bourdieu 1976, 104; 1980, 30, 40, 43 and 51; 1982a, 9; 1995a, 3 and 9; 1995b, 115-16; 1997b, 43; Bourdieu and Wacquant 1992c, 63, 68 and 69. In the secondary literature, see, for example: Accardo 1997, 261 and 265; Bonnewitz 1998, 4, 23, 24, 28, 33, 34 and 39; Boyne 1993, esp. 250; Breslau 1997, 218; ColliotThélène 1995, 662 and 665-9; Crowley 2002, 156, 157 and 165; Duncan 1990, 180; Karakayali 2004, 352 and 354; Kögler 1997a, 154; Lewandowski 2000, 49, 50, 55-6; Vázquez García 2002, 177-9, 182-184, 187, 199, 201 and 204.

112 Bourdieu, Chamboredon and Passeron 1968, 31 (my translation); original text: 'réconcilier l'attachement aux mystères de l'intériorité avec les impératifs de la distanciation'.

113 Bourdieu, Chamboredon and Passeron 1968, 57 (italics added) (my translation); original text: 'la construction contrôlée et consciente de sa distance au réel et de son action sur le réel'.

114 Bourdieu, Chamboredon and Passeron 1968, 31 (my translation); original text: 'science réflexive'.

115 On this point, see, for example, Bourdieu and Wacquant 1992c, 70.

116 On this point, see, for instance, Bourdieu 1997b, 29.

117 On Bourdieu's conception of the relationship between 'reflexivity' and 'distance-taking', see, for instance: ibid.; Bourdieu, Chamboredon and Passeron 1968, 31 and 57; Bourdieu and Wacquant 1992c, 70. In the secondary literature, see, for example: Boltanski 2003, 153; Colliot-Thélène 1995, 631-2, 662, 665, 667 and 669; Mesny 1998, 150-1 and 174; Pels 2000, 81-8 and 92; Susen 2007, 135-7.

118 On this point, see, for example:

- Bourdieu 1980, 61: 'C'est seulement par une rupture avec la vision savante, qui se vit elle-même comme une rupture avec la vision ordinaire, que l'observateur pourrait prendre en compte dans sa description de la pratique rituelle le fait de la participation (et du même coup le fait de sa propre rupture): [...] une conscience critique des limites inscrites dans les conditions de production de la théorie'. (Italics in original.)

- Bourdieu, Chamboredon and Passeron 1968, 46: 'la dénonciation rituelle des prénotions communes [...] [et] la mise en question des prénotions savantes'.

119 Susen 2007, 135 (italics in original).

120 Ibid.

121 Ibid.

122 On the notion of the skholè, see, for example: Bourdieu 1980, 47; 1994, 234 and 265; 1995b, 115; 1997b, 9, 15, 22, 24, 131 and 143; 2001b, 15. See also, for 
instance: Ambroise 2004, 260; Bonnewitz 1998, 37; Herz 1996, 237; Singer 1999, esp. 282-4; Weiss 1999, 318.

123 Susen 2007, 158.

124 On the Bourdieusian distinction between ordinary knowledge and scientific knowledge, see, for example: Bourdieu 1980, 24, 43-5, 48-50 and 61; 1982a, 10, 15 and 32; 1982c, 18-19; 1995a, esp. 3-5 and 10; 1997b, 119, 163, 217-18 and 225-6; 1999, 334-5; 2000; 2001b, 15; Bourdieu, Chamboredon and Passeron 1968, 27-49 and 100-2; Bourdieu and Eagleton 1992, esp. 117; Bourdieu, Schultheis and Pfeuffer [1999/2000], 2011; Bourdieu and Wacquant 1992e, 150; 1992f, 213.

For critical commentaries on the Bourdieusian distinction between ordinary knowledge and scientific knowledge, see, for example: Acciaioli [1981], 2000, 94-5; Bohman 1997, 177 1999, 135; Boltanski 1990a, 37-40; 1990b; 1998, 248-51; 19992000, esp. 303-6; Boltanski, Honneth and Celikates [2009], 2014, esp. 561-5, 570-3, 576-80 and 580-7; Boltanski, Rennes and Susen 2010, 155-6; [2010], 2014, 597-8; Bonnewitz 1998, 27-8 and 34-9; Brubaker 1985, 754; 1993, 216-17; Caro 1980, 1177; Cicourel 1993, 90 and 93; Corcuff 2002a, 147 and 153-4; 2002b, esp. 66, 68 and 70; Cronin 1997, esp. 206-7; Crowley 2002, 155-8; de Fornel 2003, 222-4; Dodier 2003, esp. 8-11; Eickelpasch 2002, esp. 50, 54-6 and 59; Engler and Zimmermann 2002, esp. 36-40 and 44; Grenfell and James 1998, 124; Griller [1996], 2000, 196; Hamel [1997], 2000, esp. 150; Heilbron 1999, esp. 301; Héran [1987], 2000, 4-5 and 7; Herz 1996, 236-7; Hoarau 1996, esp. 107 and 110; Holton 2000; Jenkins 1992, 68-73, 156 and 177; Karakayali 2004, 351-4; Karsenti 1995, 664; Kauppi 1996 (2000), 220-7 and 229-34; Kögler [1992], 1996, 220-7 and 229-33; König 2003, 86; Mesny 1998, 143-90; Mesny 2002, esp. 60-1 and 63-5; Monod 1995, 1602; Mounier 2001, 211; Pinto 1995, 619; Robbins 1998; 2000, esp. Chapters 2, 3, 7, 8 and Conclusion; Robbins 2002; 2003; 2006, Section 5; 2010; 2011; 2013; Susen 2007, 135-7; 2011 a, esp. 450-8; 2011c, 375-7, 378-80 and 403-5; 2011d, 49-53, 73-5 and 81; 2013a, 205-8 and 223-4; 2013b, 333, 335, 339-41, 378n.158; 2014c, 98-9; 2014a, 167-70, 181-4 and 184-6; [2015], 2014, 322-4, 332-4 and 335; 2014b, 634-5, 643, 647, 650 and 688; Susen and Turner 2011, xxi-xxii; Swartz 1997, 56-60 and 274; Vandenberghe 1999, 40-43; Wagner 2003, 217-18; Webb, Schirato and Danaher 2002, 45, 52-4, 65-7 and 77-84.

125 See Susen 2007, 135-7.

126 See Susen 2007, 158-67.

127 See Bourdieu 1980, 43-244: 'Livre 1 - Critique de la Raison Théorique'.

128 On 'scholastic theoreticism', see, for example: Bourdieu 1997b, 64, 66, 68, 75-6, 80, 97-8, 115 and 164-5; 2001a, 78.

129 Bourdieu 1980 (1990), 28.

130 On 'scholastic intellectualism', see, for example: Bourdieu 1980, 49; 1997b, 16, 131 and 160; 2005 (2005), 209; 2001b, 15; Singer 1999, 282-3; Sintomer 1996, 93.

131 See Bourdieu 1997b, 37.

132 On 'scholastic universalism', see, for example: Bourdieu 1997b, 90, 93, 96, 99-100, 113,143 and 265.

133 Bourdieu and Wacquant 1992d, 132.

134 On 'scholastic rationalism', see, for example: Ambroise 2004, 262; Bourdieu 1997b, 64, 75, 97, 130 and 265.

135 Bourdieu 1997b, 143 (my translation); original text in French: 'l'illusion de la transcendance d'une raison transhistorique et transpersonnelle'. In the published English 
translation the word et, between the words transhistorique and transpersonnelle, has been replaced by a comma. See Bourdieu [1997], 2000, 120.

136 On 'scholastic transcendentalism', see, for example: Bourdieu 1980, 48-9; 1997b, 56, 137 and 141.

137 Bourdieu [1980], 1990, 28.

138 Susen 2007, 163.

139 On 'scholastic purism', see, for example: Bourdieu 1997b, 31, 88 and 97; 1997a, 15; 2001a, 78 and 91; Dortier 2002, esp. 4.

140 Bourdieu 1997 (2000), 93 (italics added).

141 Bourdieu 1999, 334-335 (italics added).

142 Bourdieu 2001a, 16 (my translation); original text: 'fondements sociaux'.

143 On 'scholastic foundationalism', see, for example: Bourdieu 1997b, 136-7, 139, 144-5 and 149; 1997 (2000), 93; 2001a, 8, 108 and 160; Wacquant 1992b, 47.

144 On 'scholastic neutralism', see, for example: Bourdieu 1976, 90; 1982a, 15; 1982b, 9; 1982c, 18; 1984b (1993), 53; 1984c (1993), 58; 1997b, 136; Bourdieu 2001b, 33; 2001a, 91; Bourdieu, Chamboredon and Passeron 1968, 69; Bourdieu and Wacquant 1992c, 71; 1992e, 141.

145 Bourdieu 1997 (2000), 25 (italics added).

146 On 'scholastic autonomism', see, for example: Bourdieu 1997b, 30, 36, 39, 64 and 116; Pels 1995, esp. 81-3.

147 Bourdieu 1999, 335.

148 Susen 2007, 166.

149 On 'scholastic hegemonism', see, for example: Bourdieu 1975, 4; 1997b, 10, 36, 39 and 125; Hacking 2004, esp. 147-148; Wacquant 1999, 275; 2003, esp. 61-2 and 65 .

150 Bourdieu 1997b, 42 (my translation); original text: 'l'ambition hégémonique'.

151 On Bourdieu's conception of the relationship between 'reflexivity' and 'rupture', see, for instance: Bourdieu 1980, 61; 1999, 334-5; 2000; Bourdieu, Chamboredon and Passeron 1968, 46; Bourdieu, Schultheis and Pfeuffer [1999/2000], 2011. In the secondary literature, see, for example: Barnard 1990, 72; Boyne 1993, 247 and 250; Caro 1980, 1177 and 1179; Cicourel 1993, 93; Cronin 1997, 206; Crowley 2002, 156-7 and 165; Engler and Zimmermann 2002, 35-7 and 43; Hanks 1993, 140; Karakayali 2004, 352-6 and 359-61; Lewandowski 2000, 49, 50, 55 and 56; Mesny 1998, 150-1 and 174; Pels 2000, 81-8 and 92; Robbins 1998; 2000, esp. Chapters 2, 3, 7, 8 and Conclusion; Robbins 2002; 2003; 2006, Section 5; 2010; 2011; 2013; Susen 2007, 135-7 and 262; 2011 a, esp. 450-8; 2011d, 50, 63-4, 69, 75, 76 and 82; Vandenberghe 1999, 37, 40, 41, 59 and 60; Vázquez García 2002, 177-9, 182-4, 187, 199, 201 and 204.

152 Bourdieu, Chamboredon and Passeron 1968, 102 (italics added) (my translation); original text: 'la sociologie de la connaissance'. Cf. Bourdieu, Chamboredon and Passeron 1968, 95.

153 Bourdieu, Chamboredon and Passeron 1968, 102 (italics added) (my translation); original text: 'relativiser la validité du savoir'.

154 Ibid. (my translation); original text: 'la sociologie de la sociologie'.

155 Ibid. (my translation); original text: 'la sociologie de la connaissance sociologique'.

156 Bourdieu 1982a, 11 (my translation); original text: 'l'utilisation théologique ou terroriste des écrits canoniques'.

157 Bourdieu 1982a, 24 (my translation); original text: 'l'efficacité de la critique'. 
158 Bourdieu 1982a, 23-4 (my translation); original text: 'des déterminants sociaux de la pensée sociologique'.

159 Bourdieu 2001a, 19 (my translation); original text: 'histoire sociale de la sociologie de la science'.

160 Bourdieu 2001a, 15 (my translation); original text: 'fournir des instruments de connaissance qui peuvent se retourner contre le sujet de la connaissance'.

161 Bourdieu 2001a, 16 (my translation); original text: 'fondements sociaux'.

162 Bourdieu 2001a, 168 (my translation); original text: 'historiciser le sujet de l'historicisation, objectiver le sujet de l'objectivation'.

163 Ibid. (my translation); original text: 'la connaissance de ses présupposés historiques'.

164 Bourdieu 2001a, 167 (my translation); original text: 'Pourquoi les sciences sociales doivent se prendre pour objet'. On this point, see ibid., 167-220.

165 See Bourdieu 2001a, 174 (italics in original; except for 'a priori', which is not italicized in the French version) (my translation); original text: 'les sociologues doivent convertir la réflexivité en une disposition constitutive de leur habitus scientifique, c'est-à-dire une réflexivité réflexive, capable d'agir non ex post, sur l'opus operatum, mais a priori, sur le modus operandi.

166 On Bourdieu's conception of the relationship between 'reflexivity' and 'epistemology', see, for instance: Bourdieu 1976, 104; 1982a, 11 and 23-4; 2001a, 15-20, 154 and 167-220; Bourdieu, Chamboredon and Passeron 1968, 100-2; Bourdieu and Wacquant 1992f, 214. In the secondary literature, see, for example: Engler and Zimmermann 2002, 35-6 and 43; Hamel [1997], 2000, 148 and 156-7; Mounier 2001, 161 and 176; Noya 2003b, 44-5; Susen 2011a; 2011d; Webb, Schirato and Danaher 2002, 47, 49-50, 52, 54 and 56.

167 Bourdieu, Chamboredon and Passeron 1968, 96 (my translation); original text: 'conditions historiques et sociales dans lesquelles s'accomplit la pratique sociologique'.

168 Bourdieu 2001a, 168 (my translation); original text: 'historiciser le sujet de l'historicisation'.

169 Bourdieu 1995b, 116 (my translation); original text: 'la généalogie'.

170 Bourdieu 1997b, 140 (italics added) (my translation); original text: 'analyse réflexive historico-sociologique de la science'.

171 Bourdieu 2001 a, 168 (italics added) (my translation); original text: 'la connaissance de ses présupposés historiques'.

172 Robbins 1999, 310 (italics added).

173 Bourdieu 1999, 334.

174 Bourdieu 1982a, 29 (my translation); original text: 'A travers le sociologue, agent historique historiquement situé, sujet social socialement déterminé, l'histoire, c'est-à-dire la société dans laquelle elle se survit, se retourne un moment sur soi, se réfléchit; et, pat lui, tous les agents sociaux peuvent savoir un peu mieux ce qu'ils sont, et ce qu'ils font.'

175 On Bourdieu's conception of the relationship between 'reflexivity' and 'historicity', see, for instance: Bourdieu 1980, 30, 40 and 43; Bourdieu 1982a, 9, 11, 23-4 and 29; Bourdieu 1995b, 115-16; Bourdieu 1997b, 43 and 140; Bourdieu 1999, 334-5; Bourdieu 2001a, 154 and 167-220; Bourdieu, Chamboredon and Passeron 1968, 96. In the secondary literature, see, for example: Accardo 1997, 261 and 265; Breslau 1997, 218; Colliot-Thélène 1995, 662 and 665-9; Duncan 1990, 180; Giner 1999, 323; Heilbron 1999, 298-304; Mesny 1998, 150-1 and 174; Panayotopoulos 1999, 327; Robbins 1999, 310; Susen 2016a; Swartz 1997, 59, 270-6 and 293.

176 Susen 2013b, 326. 
177 Bourdieu 2001 a, 154 (my translation); original text: 'L'objectivité est intersubjectivité'.

178 Ibid. (my translation); original text: 'validation intersubjective'.

179 Ibid. (my translation); original text: 's'oppose donc à toute forme de réalisme visant à fonder la vérité sur l' "adéquation de la chose et de l'esprit".

180 On this point, see ibid.

181 On this point, see Susen 2016a.

182 Bourdieu 2001a, 184 (italics added) (my translation); original text: 'se situer au point où se situait l'auteur, au point qu'il occupait dans le monde social et à partir duquel il voyait le monde; se situer en ce point, c'est prendre sur le monde le point de vue qui est le sien, le comprendre comme il le comprenait, donc, en un sens, le justifier.'

183 Boltanski 2003, 153 (my translation); original text: 'une ressource pour comprendre le monde'.

184 On Bourdieu's conception of the relationship between 'reflexivity' and 'understanding', see, for instance: Bourdieu 1993; 2001a, 154, 168, 173, 174 and 184-220. In the secondary literature, see, for example: Boltanski 2003, 153; Boltanski, Honneth and Celikates [2009], 2014; Celikates 2009; Colliot-Thélène 1995, 665-9; Hamel [1997], 2000, 148 and 156-7; Lewandowski 2000, 49, 50 and 56; Susen 2011a; 2011d; 2013a, 203-4 and 222; 2013b, 326.

185 On the concept of 'emancipation', see, for example, Susen 2015b. See also, for instance: Browne and Susen 2014; Holloway and Susen 2013; Susen 2008a; 2008b; 2009; 2010c; 2011a; 2011b; 2012a; 2012b; 2013a; 2013b; 2014a; 2014c; [2012], 2014; [2015], 2014; 2016b.

186 De Saint Martin 2003, 331 (my translation); original text: 'Restituer aux hommes le sens de leurs actes'.

187 Ibid. (my translation); original text: 'apprendre à se connaître, à se situer, réfléchir sur sa position'.

188 Ibid. (my translation); original text: 'des exigences fortes de Bourdieu'.

189 Ibid. (my translation); original text: 'La connaissance des déterminismes'.

190 Ibid. (my translation); original text: 'à la liberté et à l'action'.

191 Ibid. (my translation); original text: 'instrument de libération'.

192 Bourdieu 1984, 16 (my translation); original text: 'le rôle du héros libérateur'. On this point, see de Saint Martin 2003, 331.

193 Bourdieu [1984a], 1993, 17. On this point, see also, for instance, Susen 2007, 122-4 and 129-30n.66.

194 Bourdieu [1984a], 1993, 10 (italics added).

195 Bourdieu [1984a], 1993, 11 (italics added).

196 See Susen 2010a, esp. 151-82 and 198-208, as well as Susen 2010b, 268-74.

197 See Susen 2011d, esp. 58-60, 64-8 and 77-82, Susen 2013a, 205-13 and 223-8, as well as Susen 2014c, esp. 91-6 and 98-9.

198 See Susen 2012a, esp. 295-8 and Susen 2012b, esp. 713-19.

199 Bourdieu [1984a], 1993, 11.

200 On this point, see Pinto 1998, 197.

201 Pinto 1998, 190 (my translation); original text: 'le travail scientifique avait des implications politiques'.

202 On Bourdieu's conception of the relationship between 'reflexivity' and 'emancipation', see, for instance: Bourdieu 1980, 40; Bourdieu [1984a], 1993, 10-11. In the secondary literature, see, for example: Boyne 1993, 247 and 250; Celikates 2009; Herz 1996, 230-3; Crowley 2002, 156, 157 and 165; de Saint Martin 2003, 331; Evens 1999, 5; 
Lewandowski 2000, 49 and 55; Mesny 2002, 65; Mounier 2001, 161 and 176; Pinto 1998, 11, 74, 84, 190, 191, 197, 199, 200 and 218; Schirato and Webb 2003, 544-5 and 551-2; Susen $2011 \mathrm{a}$; Susen 2011d; Terray 2003, 303.

\section{References}

Accardo, Alain. 1997. Introduction à une sociologie critique, Lire Bourdieu, Bordeaux: Le Mascaret. Acciaioli, Gregory L. [1981], 2000. 'Knowing What You're Doing: A Review of Pierre Bourdieu's Outline of a Theory of Practice', in Derek Robbins (ed.) Pierre Bourdieu. Volume 1, London: Sage, pp. 93-117.

Adkins, Lisa. 2003. 'Reflexivity: Freedom or Habit of Gender?', Theory, Culture E Society 20, 6: 21-42.

2004. 'Reflexivity: Freedom or Habit of Gender?', Sociological Review 52, no. s2: 191-210.

Ambroise, Bruno. 2004. 'Wittgenstein et Pierre Bourdieu', Europe 82, no. 906: 258-71.

Barnard, Henry.1990. 'Bourdieu and Ethnography: Reflexivity, Politics and Praxis', in Richard Harker, Cheleen Mahar and Chris Wilkes (eds.) An Introduction to the Work of Pierre Bourdieu: The Practice of Theory, Basingstoke: Macmillan, pp. 58-85.

Bassett, Keith. 1996. 'Postmodernism and the Crisis of the Intellectual: Reflections on

Reflexivity, University, and the Scientific Field', Environment and Planning D: Society and Space 14, no. 5: 507-27.

Bénatouil, Thomas. 1999a. 'Critique et pragmatique en sociologie. Quelques principes de lecture', Annales HSS 2, Mars-Avril: 281-317.

-1999b. 'A Tale of Two Sociologies: The Critical and the Pragmatic Stance in Contemporary French Sociology', European Fournal of Social Theory 2, no. 3: 379-96.

Bohman, James. 1997. 'Reflexivity, Agency and Constraint. The Paradoxes of Bourdieu's Sociology of Knowledge', Social Epistemology 11, no. 2: 171-86.

1999. 'Practical Reason and Cultural Constraint: Agency in Bourdieu's Theory of Practice', in Richard Shusterman (ed.) Bourdieu: A Critical Reader, Oxford: Blackwell, pp. 129-52.

Boltanski, Luc. 1990a. L'amour et la justice comme compétences, Paris: Métailié. -1990b. 'Sociologie critique et sociologie de la critique', Politix 10-11: 124-34. .1998. 'Critique sociale et sens moral. Pour une sociologie du jugement', in Tetsuji Yamamoto (ed.) Philosophical Designs for a Socio-Cultural Transformation: Beyond Violence and the Modern Era, Tokyo/Boulder, CO: École des Hautes Études en Sciences Culturelles; Rowman \& Littlefield, pp. 248-73.

-1999-2000. 'Une sociologie sans société?', Le genre humain, Hiver-Printemps: 303-11. 2003. 'Usages faibles, usages forts de l'habitus', in Pierre Encrevé and RoseMarie Lagrave (eds.) Travailler avec Bourdieu, Paris: Flammarion, pp. 153-61.

Boltanski, Luc, Axel Honneth and Robin Celikates. [2009], 2014. 'Sociology of Critique or Critical Theory? Luc Boltanski and Axel Honneth in Conversation with Robin Celikates', in Simon Susen and Bryan S. Turner (eds.) The Spirit of Luc Boltanski: Essays on the 'Pragmatic Sociology of Critique', trans. Simon Susen, London: Anthem Press, pp. 561-89.

Boltanski, Luc, Juliette Rennes and Simon Susen. 2010. 'La fragilité de la réalité. Entretien avec Luc Boltanski. Propos recueillis par Juliette Rennes et Simon Susen', Mouvements 64: $151-66$. 
Boltanski, Luc, Juliette Rennes and Simon Susen[2010], 2014. 'The Fragility of Reality: Luc Boltanski in Conversation with Juliette Rennes and Simon Susen', in Simon Susen and Bryan S. Turner (eds.) The Spirit of Luc Boltanski: Essays on the 'Pragmatic Sociology of Critique', trans. Simon Susen, London: Anthem Press, pp. 591-610.

Bonnewitz, Patrice. 1998. La sociologie de P. Bourdieu, Paris: Presses Universitaires de France. 2002. Pierre Bourdieu: Vie, œuvres, concepts, Paris: Ellipses.

Boschetti, Anna. 2004. 'Réflexion sur le langage et réflexivité', in Louis Pinto, Gisèle Sapiro and Patrick Champagne (eds.) Pierre Bourdieu, sociologue, Paris: Fayard, pp. 161-83.

Bourdieu, Pierre. 1968. 'Structuralism and Theory of Sociological Knowledge', Social Research 35, no. 4: 681-706.

1975. 'Méthode scientifique et hiérarchie sociale des objets', Actes de la recherche en sciences sociales 1: 4-6.

- 1976. 'Le champ scientifique', Actes de la recherche en sciences sociales 8-9, no. 2-3: 88-104.

1978. 'Sur l'objectivation participante. Réponse à quelques objections', Actes de la recherche en sciences sociales 23: 67-9.

- 1980. Le sens pratique, Paris: Minuit.

1982a. Leçon sur la leçon, Paris: Minuit.

1982b. 'Introduction', in Pierre Bourdieu, Ce que parler veut dire. L'économie des échanges linguistiques, Paris: Fayard, pp. 7-10.

1982c. 'L'économie des échanges linguistiques', in Pierre Bourdieu, Ce que parler veut dire. L'économie des échanges linguistiques, Paris: Fayard, pp. 11-21.

1984. Homo academicus, Paris: Minuit.

1990. In Other Words: Essays towards a Reflexive Sociology, trans. Matthew Adamson,

Cambridge: Polity Press.

[1980], 1990. The Logic of Practice, trans. Richard Nice, Cambridge: Polity Press.

- 1991. 'Introduction à la socioanalyse', Actes de la recherche en sciences sociales 90: 3-5.

1993. 'Comprendre', in Pierre Bourdieu (ed.) La misère du monde, Paris: Seuil, pp.

$1389-447$.

- [1984a], 1993. 'A Science that Makes Trouble', in Pierre Bourdieu, Sociology in Question, London: Sage, pp. 8-19.

- [1984b], 1993. 'For a Sociology of Sociologists', in Pierre Bourdieu, Sociology in Question, London: Sage, pp. 49-53.

[1984c], 1993. 'The Paradox of the Sociologist', in Pierre Bourdieu, Sociology in Question, London: Sage, pp. 54-9.

1994. Raisons pratiques: Sur la théorie de l'action, Paris: Seuil.

_ 1995a. 'La cause de la science', Actes de la recherche en sciences sociales 106-7: 3-10.

-1995b. 'Sur les rapports entre la sociologie et l'histoire en Allemagne et en France', Actes de la recherche en sciences sociales 106-7: 108-22.

- 1997a. Les usages sociaux de la science: Pour une sociologie clinique du champ scientifique,

Paris: INRA.

- 1997b. Méditations pascaliennes, Paris: Seuil.

1998. La domination masculine, Paris: Seuil.

1999. 'Scattered Remarks', European Fournal of Social Theory 2, no. 3: 333-40.

2000. 'Mit Weber gegen Weber: Pierre Bourdieu im Gespräch', in Pierre Bourdieu,

Das religiöse Feld: Texte zur Ökonomie des Heilsgeschehens, ed. Franz Schultheis, Andreas

Pfeuffer and Stephan Egger, trans. Stephan Egger, Konstanz: Universitätsverlag

Konstanz, pp. 111-29.

— [1997], 2000. Pascalian Meditations, trans. Richard Nice, Cambridge: Polity Press. 
2001a. Science de la science et réflexivité, Paris: Raisons d'agir.

2001b. 'Si le monde social m'est supportable, c'est parce que je peux m'indigner': Entretien avec Antoine Spire, Paris: Éditions de l'Aube.

2002. 'Les conditions sociales de la circulation internationale des idées', Actes de la recherche en sciences sociales 145: 3-8.

2004. Esquisse pour une auto-analyse, Paris: Raisons d'agir.

[2000], 2005. The Social Structures of the Economy, trans. Chris Turner, Cambridge: Polity Press.

Bourdieu, Pierre, Jean-Claude Chamboredon and Jean-Claude Passeron. 1968. Le métier de sociologue: Préalables épistémologiques, Paris: Éditions de l'École des Hautes Études en Sciences Sociales / Mouton.

Bourdieu, Pierre and Terry Eagleton. 1992. 'Doxa and Common Life', New Left Review 191: 111-21.

Bourdieu, Pierre, Franz Schultheis and Andreas Pfeuffer. [1999/2000], 2011. 'With Weber against Weber: In Conversation with Pierre Bourdieu', in Simon Susen and Bryan S. Turner (eds.) The Legacy of Pierre Bourdieu, trans. Simon Susen, London: Anthem Press, pp. 111-24.

Bourdieu, Pierre and Loïc Wacquant. 1992a. An Invitation to Reflexive Sociology, Cambridge: Polity Press.

1992b. Réponses: Pour une anthropologie réflexive, Paris: Seuil.

1992c. 'Sociology as Socioanalysis', in Pierre Bourdieu and Loïc Wacquant, An Invitation to Reflexive Sociology, Cambridge: Polity Press, pp. 62-74.

-1992d. 'Interest, Habitus, Rationality', in Pierre Bourdieu and Loïc Wacquant, An Invitation to Reflexive Sociology, Cambridge: Polity Press, pp. 115-40.

-1992e. 'Language, Gender, and Symbolic Violence', in Pierre Bourdieu and Loïc Wacquant, An Invitation to Reflexive Sociology, Cambridge: Polity Press, pp. 140-74.

1992f. 'The Personal is Social', in Pierre Bourdieu and Loïc Wacquant, An Invitation to Reflexive Sociology, Cambridge: Polity Press, pp. 202-15.

Boyne, Roy. 1993. 'Pierre Bourdieu and the Question of the Subject', French Cultural Studies 4, no. 3: 241-51.

Breslau, Daniel. 1997. 'Is the Sociology of Knowledge Unethical?', Social Epistemology 11, no. 2: 217-22.

Browne, Craig and Simon Susen. 2014. 'Austerity and Its Antitheses: Practical Negations of Capitalist Legitimacy', South Atlantic Quarterly 113, no. 2: 217-30.

Brubaker, Rogers. 1985. 'Rethinking Classical Theory: The Sociological Vision of Pierre Bourdieu', Theory and Society 14, no. 6: 745-75.

-1993. 'Social Theory as Habitus', in Craig Calhoun, Edward LiPuma and Moishe Postone (eds.) Bourdieu: Critical Perspectives, Chicago: University of Chicago Press, pp. 212-34.

Burkitt, Ian. 1997. 'The Situated Social Scientist: Reflexivity and Perspective in the Sociology of Knowledge', Social Epistemology 11, no. 2: 193-202.

Calhoun, Craig. [1990], 2000. 'Putting the Sociologist in the Sociology of Culture: The Self-Reflexive Scholarship of Pierre Bourdieu and Raymond Williams', in Derek Robbins (ed.) Pierre Bourdieu. Volume 3, London: Sage, pp. 59-65.

Caro, Jean-Yves. 1980. 'La sociologie de Pierre Bourdieu. Éléments pour une théorie du champ politique', Revue française de science politique 30, no. 6: 1171-97.

Celikates, Robin. 2009. Kritik als soziale Praxis. Gesellschaftiche Selbstverständigung und kritische Theorie, Frankfurt am Main: Campus Verlag. 
Champagne, Patrick. 2002. 'La sociologie réflexive de Bourdieu', Sciences Humaines, Numéro Spécial : L’œuvre de Pierre Bourdieu: 96-100.

Cicourel, Aaron V. 1993. 'Aspects of Structural and Processual Theories of Knowledge', in Craig Calhoun, Edward LiPuma and Moishe Postone (eds.) Bourdieu: Critical Perspectives, Chicago: University of Chicago Press, pp. 89-115.

Colliot-Thélène, Catherine. 1995. 'La sociologie réflexive, l'anthropologie, l'histoire', Critique 51, no. 579-80: 631-45.

Corcuff, Philippe. 2002a. 'Pour une nouvelle sociologie critique. Éthique, critique herméneutique et utopie critique', in Jean Lojkine (ed.) Les sociologues critiques $d u$ capitalisme. En hommage à Pierre Bourdieu, Paris: Collection Actuel Marx Confrontation, Presses Universitaires de France, pp. 147-60.

_ 2002b. 'Respect critique', Sciences Humaines, Numéro Spécial : L'œuvre de Pierre Bourdieu: 64-71.

Cronin, Ciaran. 1997. 'Epistemological Vigilance and the Project of a Sociology of Knowledge', Social Epistemology 11, no. 2: 203-15.

Crowley, John. 2002. 'Pierre Bourdieu's Anti-Politics of Transparency', Innovation: The European Fournal of Social Science Research 15, no. 2: 149-66.

de Fornel, Michel. 2003. 'Habitus et ethnométhodes', in Pierre Encrevé and Rose-Marie Lagrave (eds.) Travailler avec Bourdieu, Paris: Flammarion, pp. 219-26.

de L'Estoile, Benoît. 2003. 'Entrer dans le jeu: La science comme croyance', in Pierre Encrevé and Rose-Marie Lagrave (eds.) Travailler avec Bourdieu, Paris: Flammarion, pp. 129-39.

de Saint Martin, Monique. 2003. 'Une inflexible domination?', in Pierre Encrevé and Rose-Marie Lagrave (eds.) Travailler avec Bourdieu, Paris: Flammarion, pp. 323-31.

Deer, Cecile. 2003. 'Bourdieu on Higher Education: the Meaning of the Growing Integration of Educational Systems and Self-Reflective Practice', British Fournal of Sociology of Education 24, no. 2: 195-207.

Dezalay, Yves. 2005. 'Une leçon de réflexivité', in Gérard Mauger (ed.) Rencontres avec Pierre Bourdieu, Broissieux, Bellecombe-en-Bauges: Éditions du Croquant, pp. 233-8.

Dodier, Nicolas. 2003. 'L'espace et le mouvement du sens critique', INSERM-EHESS, Working Paper, Paris, 43 pages.

Dortier, Jean-François. 2002. 'Les idées pures n'existent pas', Sciences Humaines, Numéro Spécial : L'œuvre de Pierre Bourdieu: 3-8.

Duncan, Ian. 1990. 'Bourdieu on Bourdieu: Learning the Lesson of the Leçon', in Richard Harker, Cheleen Mahar and Chris Wilkes (eds.) An Introduction to the Work of Pierre Bourdieu: The Practice of Theory, London: Basingstoke, pp. 180-94.

Eickelpasch, Rolf. 2002. 'Parteiliche Unparteilichkeit: Paradoxien in der Begründung einer kritischen Soziologie bei Pierre Bourdieu', in Uwe H. Bittlingmayer, Rolf Eickelpasch, Rolf Kastner and Claudia Rademacher (eds.) Theorie als Kampf? Zur politischen Soziologie Pierre Bourdieus, Opladen: Leske \& Budrich, pp. 49-60.

Engler, Steffani and Karin Zimmermann. 2002. 'Das soziologische Denken Bourdieus Reflexivität in kritischer Absicht', in Uwe H. Bittlingmayer, Rolf Eickelpasch, Rolf Kastner and Claudia Rademacher (eds.) Theorie als Kampf? Zur politischen Soziologie Pierre Bourdieus, Opladen: Leske \& Budrich, pp. 35-47.

Evens, T. M. S. 1999. 'Bourdieu and the Logic of Practice: Is All Giving Indian-Giving or Is "Generalized Materialism" Not Enough?', Sociological Theory 17, no. 1: 3-31.

Gaonkar, Dilip Parameshwar. 1997. 'Resistance to Reflexivity', Social Epistemology 11, no. 2: $165-70$. 
Geldof, Koenraad. 1997. 'Authority, Reading, Reflexivity: Pierre Bourdieu and the Aesthetic Judgment of Kant', Diacritics 27, no. 1: 20-43.

Giddens, Anthony. 1977. Studies in Social and Political Theory, London: Hutchinson.

1979. Central Problems in Social Theory: Action, Structure and Contradiction in Social Analysis, London: Macmillan.

1984. The Constitution of Society: Outline of the Theory of Structuration, Cambridge: Polity Press.

1987. Social Theory and Modern Sociology, Cambridge: Polity Press.

1989. 'A Reply to My Critics', in David Held and John B. Thompson (eds.)

Social Theory of Modern Societies: Anthony Giddens and His Critics, Cambridge: Cambridge

University Press, pp. 249-301.

1990. The Consequences of Modernity, Cambridge: Polity Press.

1991. Modernity and Self-Identity: Self and Society in the Late Modern Age, Cambridge: Polity Press.

Giner, Salvador. 1999. 'The Social Structure of Critical Minds', European Fournal of Social Theory 2, no. 3: 321-6.

Gingras, Yves. 2004. 'Réflexivité et sociologie de la connaissance scientifique', in Louis Pinto, Gisèle Sapiro and Patrick Champagne (eds.) Pierre Bourdieu, sociologue, Paris: Fayard, pp. 337-47.

Gouldner, Alvin Ward. 1971. The Coming Crisis of Western Sociology, London: Heinemann.

Grenfell, Michael and David James. 1998. Bourdieu and Education: Acts of Practical Theory, London: Falmer Press.

Griller, Robin. [1996], 2000. 'The Return of the Subject? The Methodology of Pierre Bourdieu', in Derek Robbins (ed.) Pierre Bourdieu. Volume 1, London: Sage, pp. $187-211$.

Hacking, Ian. 2004. 'Science de la science chez Pierre Bourdieu', in Jacques Bouveresse and Daniel Roche (eds.) La liberté par la connaissance: Pierre Bourdieu (1930-2002), Paris: Collège de France, Odile Jacob, pp. 147-62.

Hamel, Jacques. [1997], 2000. 'Sociology, Common Sense, and Qualitative Methodology: The Position of Pierre Bourdieu and Alain Touraine', in Derek Robbins (ed.) Pierre Bourdieu. Volume 3, London: Sage, pp. 143-59.

Hanks, William F. 1993. 'Notes on Semantics in Linguistic Practice', in Craig Calhoun, Edward LiPuma and Moishe Postone (eds.) Bourdieu: Critical Perspectives, Chicago: University of Chicago Press, pp. 139-55.

Heilbron, Johan. 1999. 'Reflexivity and its Consequences', European Fournal of Social Theory 2, no. 3: 298-306.

Héran, François. [1987], 2000. 'La seconde nature de l'habitus. Tradition philosophique et sens commun dans le langage sociologique', in Derek Robbins (ed.) Pierre Bourdieu. Volume 2, London: Sage, pp. 3-32.

Herz, Martin. 1996. Disposition und Kapital: Ein Beitrag zur Bourdieu-Debatte, Wien: Braumüller. Hoarau, Jacques. 1996. 'Note sur la critique de la sociologie critique', Actuel Marx 20, Deuxième Semestre: 105-16.

Holloway, John and Simon Susen. 2013. 'Change the World by Cracking Capitalism? A Critical Encounter between John Holloway and Simon Susen’, Sociological Analysis 7, no. 1: 23-42.

Holton, Robert. 2000. 'Bourdieu and Common Sense', in Nicholas Brown and Imre Szeman (eds.) Pierre Bourdieu: Fieldwork in Culture, Boston: Rowman \& Littlefield Publishers, pp. 87-99. 
Houdart, Pascal. 2004. Objectivité et réflexivité dans l'œuvre de Bourdieu, DEA de Philosophie, sous la direction de Christiane Chauviré et Bruno Karsenti, Université de Paris I, 20032004, unpublished.

Inglis, David. 2005. 'Pierre Bourdieu, Science of Science and Reflexivity', European Fournal of Social Theory 8, no. 3: 375-9.

Jenkins, Richard. 1992. Pierre Bourdieu, London: Routledge.

1994. 'Language, Culture and Sociology: Pierre Bourdieu in Context', History of the Human Sciences 7, no. 4: 95-104.

Karakayali, Nedim. 2004. 'Reading Bourdieu with Adorno: The Limits of Critical Theory and Reflexive Sociology', Sociology 38, no. 2: 351-68.

Karsenti, Bruno. 1995. 'Le sociologue dans l'espace des points de vue', Critique 51 (579-80): 661-73.

Kauppi, Niilo. [1996], 2000. 'Scientific Practice and Epistemological A Priori: Durkheim, Mauss, Lévi-Strauss, Bourdieu', in Derek Robbins (ed.) Pierre Bourdieu. Volume 1, London: Sage, pp. 229-43.

Kenway, Jane and Julie McLeod. 2004. 'Bourdieu's Reflexive Sociology and "Spaces of Points of View": Whose Reflexivity, Which Perspective?', British Journal of Sociology of Education 25, no. 4: 525-44.

Kögler, Hans-Herbert. 1996. 'The Self-Empowered Subject: Habermas, Foucault and Hermeneutic Reflexivity', Philosophy \& Social Criticism 22, no. 4: 13-44.

Kögler, Hans-Herbert.[1992], 1996. The Power of Dialogue: Critical Hermeneutics after Gadamer and Foucault, trans. Paul Hendrickson, Cambridge, MA: MIT Press.

1997a. 'Alienation as Epistemological Source: Reflexivity and Social Background after Mannheim and Bourdieu', Social Epistemology 11, no. 2: 141-64.

1997b. 'Reconceptualizing Reflexive Sociology: A Reply', Social Epistemology 11, no. 2: 223-50.

König, Markus. 2003. Habitus und Rational Choice. Ein Vergleich der Handlungsmodelle bei Gary S. Becker und Pierre Bourdieu, Wiesbaden: Sozialwissenschaft, Deutscher Universitäts-Verlag.

Lewandowski, Joseph D. 2000. 'Thematizing Embeddedness: Reflexive Sociology as Interpretation', Philosophy of the Social Sciences 30, no. 1: 49-66.

McNay, Lois. 1999. 'Gender, Habitus and the Field: Pierre Bourdieu and the Limits of Reflexivity', Theory, Culture \& Society 16, no. 1: 95-117.

Mesny, Anne. 1998. 'The Appropriation of Social Science Knowledge by "Lay People": The Development of a Lay Sociological Imagination?'. PhD diss., Faculty of Social and Political Sciences, University of Cambridge.

Mesny, Anne. 2002. 'A View on Bourdieu's Legacy: Sens Pratique v. Hysteresis', Canadian Fournal of Sociology 27, no. 1: 59-67.

Mialet, Hélène. 2003. 'The "Righteous Wrath" of Pierre Bourdieu (Review of Pierre Bourdieu, Science de la Science et Réflexivité)', Social Studies of Science 33, no. 4: 613-21.

Mollet, Eric. 2003. Bourdieu et Laruelle. Sociologie réflexive et non-philosophie, Paris: Pétra.

Monod, Jean-Claude. 1995. 'Les deux mains de l'État. Remarques sur la sociologie de la misère de Pierre Bourdieu', Esprit 214: 156-71.

Moss, Pamela A. 2005. 'Toward "Epistemic Reflexivity" in Educational Research:A Response to Scientific Research in Education', Teachers College Record 107, no. 1: 19-29.

Mounier, Pierre. 2001. Pierre Bourdieu, une introduction, Paris: La Découverte.

Noya, Javier (ed.) 2003a. Cultura, desigualdad y reflexividad. La sociología de Pierre Bourdieu, Madrid: Los Libros de la Catarata. 
2003b. 'La reflexividad de la sociología y la sociología de la reflexividad', in Javier Noya (ed.) Cultura, desigualdad y reflexividad. La sociología de Pierre Bourdieu, Madrid: Los Libros de la Catarata, pp. 42-64.

Panayotopoulos, Nikos. 1999. "The Thinker of the "Primitive Thought" of the Thinkers of "Primitive Thought", European fournal of Social Theory 2, no. 3: 327-33.

Pels, Dick. 1995. 'Knowledge, Politics and Anti-Politics: Toward a Critical Appraisal of Bourdieu's Concept of Intellectual Autonomy', Theory and Society 24, no. 1: $79-104$.

2000. 'Reflexivity: One Step Up', Theory, Culture \& Society 17, no. 3: 1-25.

Pinto, Louis. 1995. 'La théorie en pratique', Critique 51 (579-80): 610-30. 1998. Pierre Bourdieu et la théorie du monde social, Paris: Albin Michel.

Raphael, Lutz. 1991. 'Forschungskonzepte für eine "reflexive Soziologie" - Anmerkungen zum Denk- und Arbeitsstil Pierre Bourdieus', in Stefan Müller-Doohm (ed.) Fenseits der Utopie, Frankfurt am Main: Suhrkamp, pp. 236-66.

Revel, Jacques. 2003. 'Une histoire qui n'existe pas?', in Pierre Encrevé and Rose-Marie Lagrave (eds.) Travailler avec Bourdieu, Paris: Flammarion, pp. 101-10.

Robbins, Derek. 1998. 'The Need for an Epistemological "Break", in Michael Grenfell and David James, Bourdieu and Education: Acts of Practical Theory, London: Falmer Press, pp. 27-51.

1999. 'The Shield of Pascal', European fournal of Social Theory 2, no. 3: 307-16. 2000. Bourdieu and Culture, London: Sage.

2002. 'Sociology and Philosophy in the Work of Pierre Bourdieu, 1965-75', fournal of Classical Sociology 2, no. 3: 299-328.

2003. 'The Responsibility of the Ethnographer: An Introduction to Pierre Bourdieu

on "Colonialism and Ethnography", Anthropology Today 19, no. 2: 9-12.

2006. On Bourdieu, Education and Society, Oxford: Bardwell Press.

2010. 'Review Essay: The Foundations of Social Theoretical Discourse. Simon Susen, The Foundations of the Social: Between Critical Theory and Reflexive Sociology. Oxford: Bardwell Press, 2007', Fournal of Classical Sociology 10, no. 1: 87-94.

2011. 'Social Theory and Politics: Aron, Bourdieu and Passeron, and the Events of May 1968', in Simon Susen and Bryan S. Turner (eds.) The Legacy of Pierre Bourdieu: Critical Essays, London: Anthem Press, pp. 301-27.

- 2013. 'Response to Simon Susen's "Bourdieusian Reflections on Language: Unavoidable Conditions of the Real Speech Situation"', Social Epistemology 27, no. 3-4: 261-74.

Schirato, Tony and Jen Webb. 2003. 'Bourdieu's Concept of Reflexivity as Metaliteracy', Cultural Studies 17, no. 3/4: 539-52.

Singer, Brian C. J. 1999. 'Médiations pascaliennes: The Skholè and Democracy', European fournal of Social Theory 2, no. 3: 282-97.

Sintomer, Yves. 1996. 'Le corporatisme de l'universel et la cité', Actuel Marx 20, Deuxième Semestre: 91-104.

Stabile, Carol A. 2000. 'Resistance, Recuperation, and Reflexivity: The Limits of a Paradigm', in Nicholas Brown and Imre Szeman (eds.) Pierre Bourdieu: Fieldwork in Culture, Boston: Rowman \& Littlefield Publishers, pp. 44-64.

Susen, Simon. 2007. The Foundations of the Social: Between Critical Theory and Reflexive Sociology, Oxford: Bardwell Press.

2008a. 'Poder y anti-poder (I-III)', Erasmus: Revista para el diálogo intercultural 10, no. 1: 49-90. 
2008b. 'Poder y anti-poder (IV-V)', Erasmus: Revista para el diálogo intercultural 10, no. 2: $133-80$.

2009. 'Between Emancipation and Domination: Habermasian Reflections on the Empowerment and Disempowerment of the Human Subject', Pli: The Warwick fournal of Philosophy 20: 80-110.

2010a. 'Los movimientos sociales en las sociedades complejas', in Celia Basconzuelo, Teresita Morel and Simon Susen (eds.) Ciudadanía territorial y movimientos sociales. Historia y nuevas problemáticas en el escenario latinoamericano y mundial, Río Cuarto: Ediciones del ICALA, pp. 149-226.

2010b. 'The Transformation of Citizenship in Complex Societies', Fournal of Classical Sociology 10, no. 3: 259-85.

2010c. 'Remarks on the Concept of Critique in Habermasian Thought', fournal of Global Ethics 6, no. 2: 103-26.

2011a. 'Kritische Gesellschaftstheorie or kritische Gesellschaftspraxis? Robin Celikates, Kritik als soziale Praxis. Gesellschaftliche Selbstverständigung und kritische Theorie (Frankfurt am Main: Campus Verlag, 2009)', Archives Européennes de Sociologie/European Fournal of Sociology 52, no. 3: 447-63.

2011b. 'Bourdieu and Adorno on the Transformation of Culture in Modern Society: Towards a Critical Theory of Cultural Production', in Simon Susen and Bryan S. Turner (eds.) The Legacy of Pierre Bourdieu: Critical Essays, London: Anthem Press, pp. $173-202$.

2011c. 'Afterword: Concluding Reflections on the Legacy of Pierre Bourdieu', in Simon Susen and Bryan S. Turner (eds.) The Legacy of Pierre Bourdieu: Critical Essays, London: Anthem Press, pp. 367-409.

2011 d. 'Epistemological Tensions in Bourdieu's Conception of Social Science', Theory of Science 33, no. 1: 43-82.

2012a. "Open Marxism" against and beyond the "Great Enclosure"? Reflections on How (Not) to Crack Capitalism', Fournal of Classical Sociology 12, no. 2: 281-331.

- 2012b. 'Une sociologie pragmatique de la critique est-elle possible? Quelques réflexions sur De la critique de Luc Boltanski', Revue Philosophique de Louvain 110, no. 4: $685-728$.

2013a. 'Bourdieusian Reflections on Language: Unavoidable Conditions of the

Real Speech Situation', Social Epistemology 27, no. 3-4: 199-246.

2013b. 'A Reply to My Critics: The Critical Spirit of Bourdieusian Language', Social Epistemology 27, no. 3-4: 323-93.

2014a. 'Une réconciliation entre Pierre Bourdieu et Luc Boltanski est-elle

possible? Pour un dialogue entre la sociologie critique et la sociologie pragmatique de la critique', in Bruno Frère (ed.) Le tournant de la théorie critique, Paris: Desclée de Brouwer, pp. 151-86.

2014b. 'Luc Boltanski and His Critics: An Afterword', in Simon Susen and Bryan S. Turner (eds.) The Spirit of Luc Boltanski: Essays on the 'Pragmatic Sociology of Critique', London: Anthem Press, pp. 613-801.

2014c. 'Reflections on Ideology: Lessons from Pierre Bourdieu and Luc Boltanski', Thesis Eleven 124, no. 1: 90-113.

- [2012], 2014. 'Is There Such a Thing as a "Pragmatic Sociology of Critique"?

Reflections on Luc Boltanski's On Critique, in Simon Susen and Bryan S. Turner (eds.)

The Spirit of Luc Boltanski: Essays on the 'Pragmatic Sociology of Critique', trans. Simon Susen,

London: Anthem Press, pp. 173-210. 
2014, [2015]. 'Towards a Dialogue Between Pierre Bourdieu's "Critical Sociology" and Luc Boltanski's "Pragmatic Sociology of Critique", in Simon Susen and Bryan S. Turner (eds.) The Spirit of Luc Boltanski: Essays on the 'Pragmatic Sociology of Critique', trans. Simon Susen, London: Anthem Press, pp. 313-48.

2015a. The 'Postmodern Turn' in the Social Sciences, Basingstoke: Palgrave Macmillan.

2015b. 'Emancipation', in Michael T. Gibbons, Diana Coole, Elisabeth Ellis and Kennan Ferguson (eds.) The Encyclopedia of Political Thought, Vol. 3, Oxford: Wiley Blackwell, pp. 1024-38.

2016a. Pierre Bourdieu et la distinction sociale. Un essai philosophique, Oxford: Peter Lang. 2016b. 'Towards a Critical Sociology of Dominant Ideologies: An Unexpected Reunion between Pierre Bourdieu and Luc Boltanski', Cultural Sociology 10, no. 2: 195-246.

2016c. 'Scattered Remarks on the Concept of Engagement: A Socio-Philosophical Approach', Philosophy and Society 27, no. 2: 459-463.

Susen, Simon and Bryan S. Turner. 2011. 'Introduction: Preliminary Reflections on the Legacy of Pierre Bourdieu', in Simon Susen and Bryan S. Turner (eds.) The Legacy of Pierre Bourdieu: Critical Essays, London: Anthem Press, pp. xiii-xxix.

Swartz, David. 1997. Culture and Power: The Sociology of Pierre Bourdieu, Chicago: University of Chicago Press.

Terray, Emmanuel. 2003. 'Propos sur la violence symbolique', in Pierre Encrevé and RoseMarie Lagrave (eds.) Travailler avec Bourdieu, Paris: Flammarion, pp. 299-304.

Vandenberghe, Frédéric. 1999. " "The Real is Relational": An Epistemological Analysis of Pierre Bourdieu's Generative Structuralism', Sociological Theory 17, no. 1: 32-67.

Vázquez García, Francisco. 2002. Pierre Bourdieu: La sociología como crítica de la razón, España: Montesinos, Biblioteca de Divulgación Temática.

Verdès-Leroux, Jeannine. 1996. Le savant et la politique. Essai sur le terrorisme sociologique de Pierre Bourdieu, Paris: Bernard Grasset.

Wacquant, Loïc 2004. 'Critical Thought as Solvent of Doxa', Constellations 11, no. 1: $97-101$.

1989. 'Towards a Reflexive Sociology: A Workshop with Pierre Bourdieu', Sociological Theory 7, no. 1: 26-63.

— 1992a. 'Epistemic Reflexivity', in Pierre Bourdieu and Loïc Wacquant, An Invitation to Reflexive Sociology, Cambridge: Polity Press, pp. 36-46.

- 1992b. 'Reason, Ethics, and Politics', in Pierre Bourdieu and Loïc Wacquant, An Invitation to Reflexive Sociology, Cambridge: Polity Press, pp. 47-59.

- 1999. 'Introduction: The Double-Edged Sword of Reason - The Scholar's Predicament and the Sociologist's Mission', European Fournal of Social Theory 2, no. 3: 275-81.

2003. 'Zwischen Soziologie und Philosophie - Bourdieus Wurzeln', in Boike Rehbein, Gernot Saalmann and Hermann Schwengel (eds.) Pierre Bourdieus Theorie des Sozialen: Probleme und Perspektiven, Konstanz: UVK, pp. 59-65.

Wagner, Hans-Josef. 2003. 'Kultur - Sozialität - Subjektivität: konstitutionstheoretische Defizite im Werk Pierre Bourdieus', in Boike Rehbein, Gernot Saalmann and Hermann Schwengel (eds.) Pierre Bourdieus Theorie des Sozialen: Probleme und Perspektiven, Konstanz: UVK, pp. 203-30.

Webb, Jen, Tony Schirato and Geoff Danaher. 2002. Understanding Bourdieu, London: Sage. Weiss, Johannes. 1999. 'Méditations pascaliennes?', European Fournal of Social Theory 2, no. 3: 317-20. 



\title{
Chapter 3
}

\section{SOCIOLOGY AT THE SCALE OF THE INDIVIDUAL: ARCHER AND LAHIRE GONTRA BOURDIEU}

\author{
Frédéric Vandenberghe
}

Since the turn of the century, the international reception of the work of Pierre Bourdieu has steadily gathered pace and taken on such a magnitude that we can say (with some exaggeration) that genetic structuralism now occupies the position of the hegemon within the global field of sociological theory, comparable perhaps to the one of structural functionalism in the post-war period. Nowadays, one can like or detest Bourdieu's critical sociology; however, one cannot afford to ignore it. He is the main 'attractor' in the field of sociology (with Michel Foucault playing a similar role within the rival, anti-disciplinary field of the so-called 'Studies'). His critical sociology with its highly sophisticated integration of the classics - not just Karl Marx, Max Weber and Émile Durkheim but also any major sociologist and philosopher of the twentieth century one can think of - into a unified theory of the social world, allied to a rigorous empirical exemplification of the concepts of field, habitus and symbolic violence, Bourdieu is the epitome of sociology: Mister Sociology himself. But even if - or, perhaps, precisely because - he incarnates in person what sociology stands for, his brand of sociology has also become a counterexample and a foil for all those who want to break with the scientism, rationalism, structuralism, determinism, materialism, utilitarianism and so forth, they associate with his critical sociology.

For the inveterate criticasters, his theory of reproduction represents only a hypercritical (in)version of structural functionalism that exacerbates all the defaults that were once associated with the Parsonian system: 'overintegrated vision of society' (Lockwood 1992) + 'oversocialized conception of Man' (Wrong 1994). Like its negative counterpart, the critical theory of the Frankfurt School, it inverts functionalism. By putting it back on its feet, however, it reinforces its vices. ${ }^{1}$ Being myself a great, though not uncritical 
admirer of Bourdieu (Vandenberghe 1998), I am neither interested in principled critiques of Bourdieu nor in uncritical celebrations of his work, not to mention the unimaginative renderings of his sociology one finds in every textbook of sociology by now. There are too many of those already. Rather, what is needed, I think, is a post-Bourdieusian theory of the social world that is not anti-Bourdieusian. A respectful discussion of the great sociologist and his monumental oeuvre demands nothing less than a rigorous discussion and critical evaluation of the philosophy, the theory, the methodology and the findings of his ambitious research program.

In this chapter, I do not offer such an evaluation (see Lahire 1999a; de Fornel and Ogien 2011; Susen and Turner 2011). Instead of a discussion of Bourdieu, I focus on two European authors at the cutting edge of contemporary social theory who were significantly influenced by Bourdieu, yet have explored other avenues beyond the ones that he has opened up with so much talent, sophistication and dedication. More particularly, I take a closer look at the theories of action of Bernard Lahire and Margaret Archer, as exemplified in two landmark books: L'homme pluriel (Lahire 2001, translated in English in 2010) and Structure, Agency and the Internal Conversation (Archer 2003). ${ }^{2}$ Archer worked at the Centre de sociologie européenne in Paris in the early sixties and although she has criticized Bourdieu for over three decades (Archer 1983, 1993, 2010b, 2012, 87-124), she is much more lenient with him than she ever was with Anthony Giddens. Lahire belongs to the next generation. Although he systematically disarticulates all of the master's categories from within, his dispositional sociology is so through and through Bourdieusian that he could well be considered the heterodox successor to the master (Loï Wacquant being the official one).

The investigation of their work in this Companion to Bourdieu is justified by the fact that both authors have developed their own research programme as an open challenge and explicit alternative to critical sociology. Given that we know where they come from and what they react to, we can investigate in detail how they actually dismount some of the central assumptions of critical sociology and set up their categories so as to escape its spell. To know a theory is to know how it is constructed. To develop an alternative theory, one has to know how to deconstruct it and push it in a different direction. The exercise in comparative theory I propose is a triangular one. Through selective use of the scholastic technique of the 'compare and contrast essay', I explore convergences and divergences not only among their theories and Bourdieu's but also among their respective theories. The chapter proceeds in two moments: first, I present the contextual and dispositional sociology of Lahire and the morphogenetic explanatory framework of Archer. Following the exposition of both research programmes, I next bring them into a dialogue 
and show how they can benefit from each other. The intent is not to weaken them; rather, by uncovering their hidden angles, I wish to strengthen them and indicate possibilities for the development of a post-Bourdieusian sociology of reflexive dispositions in context.

\section{Lahire versus Archer: Sociology at the Scale of the Individual}

In the most recent phase of their intellectual trajectory, Archer and Lahire have started working on themes that are at the threshold of sociology and psychology. Within the French tradition, Lahire has taken up Durkheim's idea of a sociological psychology - 'the whole of sociology is psychology, but a psychology sui generis' (Durkheim, in Lahire 1998, 223). With her interest in internal conversations, Archer has also entered the space of the sociology of the mind, but like Norbert Wiley's (1995) pioneering investigations of internal speech, she has sought her bearings in American pragmatism (Charles Sanders Peirce, William James and George Herbert Mead rather than Durkheim, Marcel Mauss and Maurice Halbwachs, as is the case with Lahire). At the frontier between sociology and psychology, both are developing a social psychology of a new kind. Unlike the more traditional social psychology that analyses how individuals behave in small groups, this new social psychology reverses the perspective and investigates how groups, large and small, behave within the individual mind. To explain how the individual behaves in society, one has to understand how society behaves in the individual. Sociology turns inwards and encounters the psyche at the intersection of society and the individual.

Both Archer and Lahire have embarked on a similar quest: to understand individual biographies sociologically. They both work with the same unit of analysis - a life - and they both want to understand how and why actors make the decisions they make and live the lives they live. But albeit their quest is similar, their way of approaching their subjects is rather different in tone, style and approach. Whereas Archer wants to understand the present of her subjects through investigation of their future projects (their feasibility in the current context with its constraints and opportunities), Lahire explains the present and the future in terms of the past (dispositions and their activation in particular contexts in the present). Where she foregrounds the personal power of the individuals and thinks of internal conversations as mechanisms that empower, enlighten and help individuals to make up their minds and realize their dreams in given circumstances, he emphasizes above all the enduring power of socialization. His actors are pushed by their dispositions, while hers are pulled forward by their projects. He is a determinist, she is a voluntarist and I am a bit of both. 


\section{Lahire: dispositions, contexts and practices}

Lahire is at once the fiercest critique of Bourdieu and his most faithful disciple. Different from the hard-liners who impersonate the master and the 'soft-liners' who think 'with Bourdieu, against Bourdieu', to use a crisp formula of Jean-Claude Passeron (2003, 124), the young sociologist has the ambition of doing something different altogether. He knows the work of Bourdieu like no one else does, and does it over as it were, pushing it in a rather different direction. Like a computer worm that infects a hard disk and takes over the operations of its host, he has installed himself deep down into the program of critical sociology, replicating, extending, correcting, subverting and, ultimately, radically rewriting it from within. Although his earlier work in the sociology of education is not centrally concerned with the work of the sociologist of the Béarn - its focal points are the reading and writing practices among popular classes (Lahire 2000) -, his later research on cultural consumption and literary production confronts Bourdieu head on.

Lahire is a Stakhanovist who turns out, on average, a book per year. Piling them up high, we find L'homme pluriel (The plural actor) (the only book translated so far into English), his most explicitly theoretical and programmatic book, at the base. ${ }^{3}$ Assailing the concept of habitus, putting it under the microscope, it offers a systematic outline of a contextual and dispositional sociology at the individual scale. Each of the terms is significant, starting with sociology. Although his theme brings him close to psychology and psychoanalysis, his approach is, in fact, 110 per cent sociological. Radicalizing the gesture of Durkheim, Halbwachs, Norbert Elias and Bourdieu, Lahire has a mission: to demonstrate that sociology can understand the individual in all its complexity and explain his or her behaviour in all its details. Not afraid of imperial overreach, his ambition is to show that the social goes down all the way, that it extends its reach to the innermost core of the person and that, therefore, to vary a political slogan, the personal is social through and through. Like Bourdieu's, his research program is not only sociological and scientific (borderline sociologistic and scientistic) but also resolutely dispositional and contextual. As an alternative to the famous synthetic formula of Bourdieu: '[(habitus) $($ capital) $]+$ field $=$ practices' $(1979,112)$, Lahire proposes, 'Dispositions + Contexts $=$ Practices' $(2012,18,24$, passim $)-$ or, in a slightly more expanded variation: 'Incorporated past + Present context of action $=$ Observable practices' (2012, 25, passim) as the unifying formula of his scientific program for dispositional-contextualist sociology: ${ }^{4}$

This program, which responds to the question why people behave, think, feel, etc. the way they do, can be summarized in a rather simple scientific 
formula: Incorporated past + Present context of action $=$ Observable practices. It condenses the research intention to think practices at the intersection of incorporated dispositions and competences (produced by the more or less assiduous frequentation of past frames of socialization) and the always specific context of action. $(2012,12)$

The most individual practices, all of them, whether they are conscious, semiconscious or subconscious, can be understood, according to Lahire, by reference to a myriad of processes of socialization (in the family, at school, by the peers, at work and so on) that find their corporal, mental and emotional sedimentations in a stock of dispositions (tendencies, inclinations, habits, capabilities, competences and so on) of various kinds (bodily, mental, discursive, perceptive, evaluative and so forth). These dispositions may be activated or inhibited, released or suspended, reproduced or transformed in determinate contexts of action (social spaces, systems of action, situations of interaction and so on). An individual usually has multiple dispositions. Occasionally, these may work at cross purposes and be inappropriate to the situation, causing friction, fracture and even outright crisis.

While dispositions incorporate the past and refer to tendencies within the individual, the contexts of action represent constraints and enablements external to the individual that release and activate or inhibit and switch off the dispositions that produce the practices. 'Contexts' is a bit of an umbrella concept, however, that encompasses everything (class, power, organizations, institutions and so forth) that the actors encounter in their environment and that impinges on their action from without and in the present. It can refer to abstract social spaces that are vertically and hierarchically structured in terms of class and power differentials (Marx's system of classes, Weber's field of power, Bourdieu's social space), to horizontally differentiated functional or institutional domains (Weber's spheres of values, Bourdieu's fields, Howard Becker's worlds, Niklas Luhmann's subsystems and so forth) of complex societies, but, occasionally, it is also used to refer to the more concrete microcontexts (families, schools, factories, sport clubs and the like) and situations (Georg Simmel's sociations, Erving Goffmann's interaction orders, Harold Garfinkel's Haecceities and so forth) that form the immediate background of action. Together, the structural, institutional and interactional contexts of action that trigger or inhibit the dispositions, and the dispositions themselves are sufficient, according to Lahire, to fully explain why the actors act the way they act (or refrain from doing so), think the way they think (or not), talk they way they talk (or not), feel the way they feel (or not) - in sum: are the way they are.

In spite of the fact that the field is now replaced by a multiplicity of contexts of action, all this is still more or less compatible with Bourdieu's classical 
theory of the habitus. But as soon as Lahire varies the scale, changes the focal and zooms in on the individual to analyse in detail the concrete workings of the dispositions at a microscale, everything changes. ${ }^{5}$ The tribute to the master quickly turns into a masterful critique of his concept of the habitus that is so powerful that it risks bringing down the whole theoretical edifice. For generative structuralism, the change of scale is simply 'catastrophic' (in the sense of Benoit Mandelbrot). Putting a Google Earth into critical sociology leaves nothing unchanged. When one changes the focal length, augmenting the resolution to watch society at the individual level, one does not just see it differently; rather, at 'street level', one sees different things altogether. This is 'fractal sociology', sociology of the individual as an infinitely complex, self-similar entity that can be split into parts, each of which is a miniature of society.

At the level of the individual, one no longer sees the coherence and homogeneity of the habitus that Bourdieu attributed to individual dispositions at the class level. Rather one starts to see the individual as a complex, more or less unified and layered being with a plurality of heterogeneous habits, dispositions, schemes, competences, appetencies and capabilities that are themselves the result of multiple socializations (by the family, neighbours, teachers, friends and so on) and that may act jointly or at cross purposes. To deconstruct the habitus, the sociologist from Lyon (1998, 9 sq., 19 sq., 81 sq., passim; 1999a, 23-57) latches onto the more technical aspects of the definition that everybody knows by heart by now ('systems of durable and transposable dispositions'), questions each and every word (durable? transposable? system of dispositions?), shows all the intellectual antecedents that are smuggled into the concept (Durkheim, Mauss, Edmund Husserl, Maurice Merleau-Ponty, Jean Piaget and so on), and accuses Bourdieu of abusively generalizing a particular model that only holds in exceptional situations (such as traditional societies and total institutions).

He does the same for the concept of the field (Lahire 1999a, 23-57; 2012, 143-212), asking innocuous questions about ordinary actors (such as manual workers, cleaning ladies, retirees and so forth), activities (such as domestic cooking, pub crawling, traveling on the bus and so on), populations (popular classes, housewives, unemployed) and institutional orders (first and foremost families, but also neighbourhoods, peers and other instances of primary socialization) that fall outside of the field. In Monde pluriel (Plural world) he offers a theoretical synthesis of his research on the fields of literary production and cultural consumption and, once again, he shows that the field represents only a particular case of the possible, accusing Bourdieu of transforming a regional model into a general theory of the social world.

The focus on the individual that comes with the variation of scale turns Bourdieu inside out: what was outside (the social as a field of struggles) now 
reappears inside (the individual as a plural actor struggling with him- or herself). When the social space is thus analysed from the point of view of the individual, the latter is, literally, refracted by and in the former. In a brilliant application of the Leibnitzian baroque metaphor of the 'fold', which one also finds in Gilles Deleuze, Michel Serres and Bruno Latour, Lahire explains the incorporation of the social into the individual as a 'crumpling' of the social space:

If one represents the social space in all its dimensions (economical, political, cultural, religious, sexual, familial, moral, sportive, etc.) in the form of a sheet of paper or a piece of tissue [...] every individual is like a crumpled sheet or a rumpled rag. $(1998,233)$. [...]

Thus, we find within each of us the social space in crumpled state. $(2005,120)$

Projected onto and folded into the individual, all the different provinces and fields of the social world, as well as all the different positions within each of the fields, can now potentially operate simultaneously within a single actor. The struggles that are waged between and within the fields now take place within the individual. The cleavage of the habitus that splits 'class defectors' (transfuges de classe), like Bourdieu himself, is now generalized and democratized as it were.

Although the degree of coherence varies from person to person, internal pluralism is the rule, not the exception. When the actor is considered not in bulk, but in detail, s/he becomes a 'plural actor': a man or a woman society endows with a heritage of dispositions that, depending on the context of action, may converge or diverge, be activated or switched off, temporarily or permanently. There is no reason to assume a priori that domestic or religious dispositions will automatically gel with class, professional or educative ones, and fuse into a single master disposition that controls and integrates them all into a single generative formula, as is the case in Bourdieu. Instead of a monolithic habitus that unifies all the acts of the individual in all spheres of life - from the intellectual to the carnal, from the books one reads to the food one eats - one can now sociologically analyse the actor as a plural one in all its bewildering complexity.

In the field of cultural consumption, for instance, an actor can be, without contradiction, rather highbrow in her literary choices and a real junkie when it comes to films or, to take another example, can go the opera on Friday night and to the karaoke bar with her pals the next night. As a matter of fact, the consonant profiles in cultural consumption one would expect from a Bourdieusian perspective are not statistically dominant: omnivorous consumption of culture and dissonant profiles are the rule (Lahire 2004). Once again, the variation in 
scale changes everything. It allows the researcher to investigate in detail not just inter- and intraclass variations, even within a single family (Lahire 2005), but also and above all inter- and intra-individual ones. If one were to analyse the public at, say, the Comédie Française in Paris, the Metropolitan Opera in New York or the Sala Cecília Meireles in Rio de Janeiro, in detail and without preconceptions, one would, for sure, find a predominantly upper-class, culturally sophisticated and socially self-satisfied and carefully dressed up public. If instead of taking them as a class fraction, however, one were to take each of them one by one seriatim in order to register their tastes, one would discover that the same individuals who listen to erudite music are also quite likely to attend the circus, watch action films, read detective novels and listen to AC/DC. Disaggregating class data of cultural consumption and reaggregating them at the individual level, Lahire arrives at the following profile of the omnivorous consumer:

The public of the prestigious Salle Richelieu [of the Comédie française] goes definitely more often to variété spectacles [than those with less legitimate tastes] (37\% against $10 \%$ ) and the circus (23\% against $8 \%$ ), a bit more often to theme parks and just slightly less to discotheques (22\% against $27 \%)$, public balls ( $18 \%$ against $21 \%)$ and paid football games (16\% against $20 \%) .(2004,145)$

Over the years, the logic of fractals has pushed Lahire to an ever more detailed, close-up analysis of the multiple socializations that find their sedimentation in a multiplicity of dispositions of all types. To analyse how dispositions are actualized, inhibited or transformed in a variety of contexts of action, and investigate whether schemes of action are transferred and transposed from one context to another, or not, in Portraits sociologiques (Sociological portraits) he has set up an unprecedented experimental methodology. ${ }^{6}$ In a sequence of six rather lengthy in-depth interviews in which he has asked eight respondents detailed questions about their practices in various domains of life (school, work, family, friends, leisure, going out, food and health), he has developed a new genre of sociological biographies that convincingly proves the viability of his dispositional and contextual sociology at an individual scale. As if the fine-grained, high-resolution portraits were not yet detailed enough to make his point about the power of the past (embodied dispositions) into the present (context), more recently Lahire has also gone though the whole literature by, on and about a famous Czech novelist (all his texts, letters, diaries, all the testimonies of his contemporaries, and a good deal of the secondary literature too), and drawn an even more detailed portrait of a most singular individual: Franz Kafka. Following the travails of the full-time insurance officer and occasional novelist, his intent is to show, through close reading of some 
key texts and without much reference to the literary field (Kafka is the opposite of Gustave Flaubert in that regard), that the rather difficult relations with his father, which now reappear transfigured in his novels and his nightmares, offer the main key to his work. The ambition of this vast exercise in sociological psychoanalysis is not a minor one. Lahire wants to explain everything -'why he writes what he writes as he writes' (2010, 10, 69), and he wants to do it sociologically.

\section{Archer: structure, reflexivity and agency}

Archer is one of Europe's most systematic theorists and the main representative of critical realism within sociology. ${ }^{7}$ In direct association with Roy Bhaskar, the 'founding father' of critical realism, she has elaborated his realist theory of society and developed the morphogenetic approach in sociology as a methodological complement to his complex social ontology. The morphogenetic approach offers, first and foremost, a cohesive explanatory framework that analyses social structure, culture and agency, as well as their linkages, in realist, relational and processual terms. Over a period of over forty years, Archer has carefully crafted out a series of fundamental concepts, most notably analytical dualism, the morphogenetic sequence and causal emergent powers, and stuck to them to resolve some of the central problems of social theory, starting with the problem of how to link structure and agency without reduction or, as she dubs it, 'conflation' (1988, pt. 1; 1995, pt. 1). Against individualists who reduce structure to agency ('upwards conflation') and structuralists who deduce agency from structure/culture ('downwards conflation'), the British sociologist insists on the relative independence of the strata: 'Social life comes in a SAC - always and everywhere', says she (2013, 5), using shorthand for structure, agency and culture.

Against Giddens and Bourdieu, who commit the fallacy of 'central conflation' (Archer 1988, 72-100 and 1995, 87-134), typical of praxeological theories that conceive of the whole social world (society, culture and personality) as being constituted by social practices, she argues with Bhaskar (1979) that it is essential to operate with an emergentist social ontology, a stratified conception of society and a transformational model of social action. ${ }^{8}$ Over and against ontologies of practice that ignore the phenomenon of emergence, critical realism underscores the dualism of agency and structure. Structure and agency are neither different aspects of a same entity ('duality') nor different moments of a single process ('practice'). Rather, they are different kinds of emergent entities, with different levels of complexity that presuppose but cannot be reduced to each other. Although the existence of social structures (systems of relations between social positions, akin to Bourdieu's fields) and 
cultural structures (systems of relations between ideas, akin to Ferdinand de Saussure's language) presuppose action and interactions as a condition of their possibility, to properly track their interrelations, it is essential to analytically distinguish the systemic levels and the interactive levels of society ('analytical dualism'). At the systemic level, we are dealing with relations between 'parts', while at the interactive level with relations between 'people' (Lockwood, 1964). Relations between parts (social positions and ideas) and interactions between people (persons and groups) function not only at a different level of complexity but also operate at different times. To the extent that sociocultural systems pre-exist the actors, one cannot say that the actors produce these; rather, through their actions, they reproduce or transform the sociocultural systems they inherit from their predecessors. As preconditions of action, social and culture structures necessarily predate the social practices that reproduce and/ or transform them. Similarly, the culture and structure that are transformed and/or reproduced by these practices necessarily post-date the practices from which they result.

Borrowing some insights from Walter Buckley's cybernetic study of the feedback mechanisms of 'deviation-amplification' that trigger systemic change, the morphogenetic perspective decomposes those dynamics in a series of endless cycles of 'systemic conditioning', 'socio-cultural interaction' and 'systemic elaboration' whereby the particular configuration of the system (at $\mathrm{T} 1$ ) conditions the practices of the life world (at T2), which aim to reproduce or transform the system and lead, eventually (at T3), to a new elaboration of the system, which will be contested and modified in a second cycle, and so forth.

In a lengthy sequence of weighty books, Archer has fleshed out her morphogenetic perspective into a general social theory of culture (1988), social structure (1995) and human agency (2000). The point of the whole exercise, however, is not just to reconceptualize structure, culture and agency in the realist language of 'emergent causal powers' but also to analyse how structural, cultural and personal powers actually work together or block each other in concrete historical formations, ensuing either in morphogenesis and social change or in morphostasis and social reproduction. Archer argues that cultural systems can influence social structures and vice versa, but they can only do so indirectly and mediately by structuring the situation of actions through constraints and enablements. The force of the latter depends, objectively, on the social position of the agents and, subjectively, on their projects, the two being linked to a certain extent by what Bourdieu would call the 'causality of the probable', which adjusts projects to possibilities. As individuals and groups are acting in situations to defend their vested interests and to realize their projects, they reproduce or transform the structural and cultural conditions that 
impinge on them, but in this process they are themselves being transformed from involuntarily placed agents into social actors and individual persons (double morphogenesis).

It is at this point where the structural, cultural and personal powers intersect that the sociology of the individual is fully integrated into the morphogenetic perspective and the contrast with Bourdieu's derogation of the subject becomes starker. In order to reclaim the actor from postmodernists (like Richard Rorty) and social constructivists (like Rom Harré) who dilute the subject into never-ending chains of discourses, Archer ties agency to reflexivity (2000), reflexivity to internal conversations (2003) and internal conversations to social mobility (2007) and social change (2012). This turn inward should, thus, not be disconnected from the larger concerns that have occupied her since the late 1970s, namely to offer a solid realist theory of society that solves the agency-structure problem without reduction and without dismissing the reflexive capacities of the agent. In direct opposition to her former mentor, who emphasizes the role of the unconscious and systematically downplays conscious and conscientious behavior, Archer brings the reflexive subject back into the picture to break with the semiautomatic reproduction of structures of domination one finds in critical sociology. With force and conviction, she rehabilitates reflexivity and uses it as the wedge that severs the habitus from the field and opens up the possibility of a double morphogenesis of the self and society - significant social change as a result of self-transformation on a massive scale. Through reflection and deliberation, the agents ponder what they want to do not only in their life but also with their life, and the differential answers they give to these existential questions have implications for the reproduction and transformation of society.

Archer's central thesis - let us call it the thesis of the mediation of meditation can now be formulated: reflexivity is exercised through people holding conversations with themselves in which they clarify, organize and systematize their 'ultimate concerns' in an existential and personal project to which they commit themselves. To find out who they are and what their 'mission' is in this life, people have to decide 'what they really care about' (Frankfurt 1988), and they do so through an inner dialogue with themselves and significant others. It is this meditation of the actors on what really matters to them and what they are willing to forgo, or to invest in, in order to realize what they care about and have 'devoted' themselves to that constitutes the mediatory mechanism which links the causal powers of structure to agency.

Social structures and cultural systems exercise their causal powers, according to Archer, by structuring the situation of action through constraints and enablements, but to the extent that the activation of those causal powers depends on the existential projects that the actors forge in foro interno (no 
projects: no constraints or enablements), actors can be said to actively mediate their own social and cultural conditioning. They are determined, but unlike in Bourdieu, only to the extent that they determine themselves and choose a project. Through internal deliberation about the feasibility of their projects in given circumstances, a deliberation that takes the dialogical form of an internal conversion between the Me (the past self), the I (the present self) and the You (the future self), they actively choose a modus vivendi as a living compromise between the actual and the possible. When the circumstances change, the projects may be discarded, revised or realized. Inversely, a change in the projects is likely to affect the perception and the evaluation of the concrete contexts of action and, therefore, also of what is possible and what is not. In any case, it is through internal conversations with themselves that actors interweave the past (Lahire's dispositions), the present (his contexts of action) and the future (Archer's projects) and reflect on the feasibility of possible courses of action in the given circumstances.

In her interviews with people from all walks of life, the British sociologist discovered that reflexivity comes mainly in four modes, namely the communicative, the autonomous, the meta and the fractured mode of thinking about and working through one's life course. They correspond to four types of reflexive individuals. In order to bring some developmental logic into the sequence, I order them according to their degree of consciousness, starting with fractured reflexivity - which, for drama's sake, I will call the 'ground zero' of the quest of an authentic self - and ending with full metareflexivity. ${ }^{9}$ Fractured reflexives are lost souls. They correspond more or less to the downtrodden and the dominated at the bottom of society who operate outside or at the margins of the field. The more they think, the less they succeed in bringing order to the chaos of their lives. Their narratives are disconnected, they get lost in their thoughts, there is no flow, their dispositions work at cross purposes and their life does not lead anywhere. They are lost, depressed, alienated, in crisis or otherwise unable to function properly. To get out of this sorry state of mind, they need help from others and that is where the communicative reflexives come in. They are the kind souls of this world. They are mostly women (but this may be an artefact of Archer's initial sample). When asked what is most important in their life and what they care about most, they will give a domestic answer: definitely family and friends, pets and plants, perhaps also the local pub and the village. Communicative reflexives care about the others. They are willing to sacrifice their own life plans and curtail their own ambitions to stay close to the significant others who give meaning to their lives. They stay put. They are rather traditional and, with all respect, we could describe them as 'happy Bourdieusians'. They are responsible for the reproduction of the life world. They do not move up or away, but stay close to the ones they 
love. They are not overly self-conscious and do not have that many internal conversations. They do not think; rather, they talk. In talking, they think. As soon as they have a new idea, they need to share it with others and talk it through (by calling their mum on the phone, for instance). Thanks to their help and their kindness, fractured reflexives can slowly recover their reflexive capabilities and become more autonomous. Autonomous reflexives, mostly men, are above all concerned with work. They are active minds. They think and act; they think to act. In their head, they plan and think ahead, proactively looking for solutions they encounter in their everyday life, be it at work, at home, in the car or on their holidays. Focused, they are professionals with ambition and a career plan. They are on their way up in society. They are members of the dominant fractions of society or, as petit bourgeois, they aspire to join them. They have not only a sense of justice and fairness but also care about others. Yet, unlike metareflexives, ethics is not what moves them and makes them move. Metareflexives have principles and values. They are idealists, not opportunists. They are dreamers. They continuously think about the good life in and for others in just institutions and how to realize it. They are searching, seeking to realize what they believe in, seeking to realize themselves. They yearn for authenticity and want to integrate their projects into a coherent narrative that makes sense and endows their lives with a purpose. They are critical, both about themselves and the contexts of action. That is their greatness, but also their drama. They are never satisfied. Not with themselves, nor with the world. Somehow, always, something is missing. Something is not right. They get into an existential crisis, fracture and move on. 'What does not kill them makes them stronger' (Nietzsche). Metareflexives are fractured reflexives who, with a little help from their friends, have overcome their existential crisis, regained their autonomy and cannot stop thinking about what they want to do with their lives and how they could possibly achieve some harmony and transform their lives into a symphony of sorts.

\section{Towards a Sociology of Reflexive Dispositions}

Archer's investigation of reflexivity comes at the end of a lifelong reflection on how SAC work together or at cross purposes in different social formations. While her work is more macro than Lahire's, his is more structural than hers. Even if his work is much more influenced by microsociology than hers, she seems much further removed from Bourdieu's system than he is. Instead of battling with Bourdieu, trying to trump him at his own game, she has not only introduced a level of reflexive self-determination between the field and the habitus, but also, eventually, she has discarded the habitus altogether (Archer 2010, 2012), arguing that in late modern societies, there is no space anymore 
for morphostatic reproduction of traditional environments and modes of thinking. Lahire for his part has radicalized Bourdieu by bringing his sociology to the deepest recesses of the individual. In the same way as Goffman and Garfinkel transposed Durkheim's sociology to the microlevel, uncovering a microsystem of constraints that is not less, but more deterministic than the macrosystem, he seems to have transposed Bourdieu's sociology of the field within the individual, fracturing the habitus, yet still refracting the multiple determinations of society. But instead of simply opposing Archer to Lahire, let us see how we can bring them into dialogue, pair their strengths and make them work in tandem in a reflexive, dispositional and contextual sociology at the scale of the individual.

I discuss convergences and divergences between Archer and Lahire under three headings: philosophical anthropology, conversations and dispositions, and micro-macro:

\section{Philosophical anthropology}

A first difference, and perhaps the strongest one, is to be found in their research posture. In spite of all his critiques of Bourdieu, Lahire sees himself as heir to the master. Like the sociologist of the Collège de France, he carries the banner of science and, not afraid of polemics, he militates for sociology as a rigorous science. The standards he has set for himself and for the others are rather high, not to say exclusive. Any sociology that respects itself must necessarily exhibit 'a high degree of argumentative persuasion, methodological exigency and empirical rigor' (Lahire 2005, 18). Without the former, sociology degenerates into the sloppiness of journalism; without the latter, it becomes mere speculation, empty theory, social philosophy. Within sociology there should be no space for either, according to Lahire. Without excuses or qualifiers, he derides theorists as 'forgers (without field, without material, without method)' $(2000,12)$ who should be forced to work in the field or leave the discipline. Speculative sociology (social philosophy, theoretical syntheses, metatheory), postmodern essays and journalistic reports are explicitly earmarked for extinction as 'poles that should disappear from the field of a more demanding discipline' (Lahire 2002, 46n. 6). To the extent that this excommunication is mainly addressed to French competitors in the field, I like to think that it does not exclude dialogue with British-style social theorists and German social philosophers (even if they live in Latin America).

In a more constructive spirit, I would, therefore, like to suggest that sociology as a whole can actually benefit from a critique of sociology (in the sense of Immanuel Kant). By pushing sociology to its limits, Lahire helps us make clear that it needs a more philosophical approach to sustain it. While sociological 
logic leads one to track the effects of socialization into the most hidden recesses of the individual, leaving no space for anything that is not social, that does not and cannot mean, of course, that there is nothing that escapes society - only that sociology cannot grasp it. To understand what sociology cannot grasp, one needs a philosophical anthropology, a vision of the human being that includes the partial vision of sociology as well as of the other sciences, but completes them by showing, be it with Simmel, Max Scheler, Helmut Plessner or Mead, that socialization can never be complete. ${ }^{10}$ Philosophical anthropology completes and transcends the sciences by introducing what the sciences cannot grasp, but always already presuppose as a condition of their possibility, namely that at least some human acts are their own cause and can, therefore, not be explained by antecedent causes.

Like Bourdieu, Lahire works not with a philosophical but with a sociological anthropology in which it is society, rather than the individual, that gives meaning to life or takes it away (Peters 2012). To the extent that his vision of man can be reconstructed, one gets the impression that he considers humankind a rather dangerous species, capable of the worst against which, like in Thomas Hobbes, Bourdieu and Jean-Paul Sartre, individual subjects have to continuously protect and defend themselves. In any case, society appears more as a kind of opaque and menacing Kafkaian universe with institutional machinations and interpersonal intrigues that can hurt the individual, than a place that offers refuge, comfort and friendship. Aware of the fact that the human being is always bounded by something that transcends it, Archer avoids the hyperdeterminism of her French colleague. In accordance with Bhaskar's critical realism and rather weary of 'oversocialized' conceptions of man (Archer 2000), she not only accepts the existence of personal causal powers as a matter of principle but her philosophical credo also informs her empirical research on the 'ultimate concerns' behind the existential projects that her respondents pursue.

If we compare Lahire's formula (Dispositions + Contexts $=$ Practices) with Archer's (Contexts + Projects = Agency), we immediately sense the difference philosophical anthropology makes. The distinction between action and practices is a subtle one (Reckwitz 2002). They have not only different pedigrees, with agency going back to Kant, Weber and Alfred Schütz and practices to Durkheim, John Dewey and Ludwig Wittgenstein, but they also have distinct associations and implications: action presupposes reflexivity and conscious deliberation about conditions, ends, means and ultimate values, whereas practices are more about the ordinary capabilities and tacit knowledges that allow actors to go through their routines without having to think all the time about how to proceed. Whereas the theory of action presumes that subjects are capable of conscious reflection and deliberation, the theory 
of practices assumes that agents are driven primarily by internalized dispositions. Lahire does not deny reflexivity. To the contrary, he fully recognizes the actors' capacity for reflection, deliberation and planning, and criticizes Bourdieu for restricting reflexivity to exceptional situations of crisis. Yet, when it comes to explaining why the actors say what they say and think what they think, he reactivates Bourdieu's 'principle of non-consciousness' and explains personal practices in terms of social determinations of which the actors are not aware. Where Archer sees personal deliberations, he seeks the imprint of society. With excruciating detail, he shows the omnipresence of the social and traces it to the innermost recesses of the individual. She is more like a counsellor who carefully listens to her subjects to find out what they want to do with their life, while he is more like a psychoanalyst who tries to find out what life has done to them. Her subjects are determined to the extent they determine themselves, while his are determined by society even in their most personal determination. His are pushed, whereas hers jump.

\section{Conversations and dispositions}

With Archer, we can bring back agency, reflexivity and a modicum of freedom into Lahire's sociology of dispositions and make it less deterministic. If we assume with Archer that social structures do not directly determine conduct, but that their causal powers have to be activated by the actors themselves to be effective, the mediation of internal conversations can help better explain why actors who basically confront similar contexts may nevertheless make different choices and behave differently. Furthermore, thanks to the sociology of internal conversations, we may explore how internal conversations can lead the actors to adopt a reflexively controlled project to slowly and consciously modify their moral, mental, sentimental and corporal dispositions. Lahire recognizes the possibility of a conscious and willed transformation of one's dispositions, but due to his lack of interest in practical philosophy, he does not take up the classical idea of virtue ethics according to which we are, ultimately, responsible for our own habitus and moral character.

However with Lahire, we can make Archer's scheme not only more flexible but also more realist. It is more flexible, because instead of using the distinctions between types of reflexivity as a kind of disguised personality test, we can simply assume, as a matter of course, that all individuals display the various modes of reflexivity and investigate in detail in which contexts some particular modes are activated, put on hold or switched off. If we relax the hypothesis that individuals can be sorted out according to the different modes of reflexivity they practice in their conversations, we might think of internal conversations as the mechanism through which individuals actually decide for 
themselves which mode of reflexivity they will follow. With a closer inspection of contexts and dispositions, we can investigate in what circumstances some modes of reflexivity have free play, while others are inhibited, switched off, remade or transformed.

Using the whole array of concepts that critical realism has on offer to theorize causal powers (Harré 1970, Bhaskar 1975) as tendencies that may be real, but not actual, actual but not empirical and so forth in open laminated systems (with multiple generative mechanisms operating at the same time at different levels) and applying them to analyse how society acts at an individual level will certainly enrich the close descriptions of practices one finds in Lahire. After all, like the habitus, dispositions are generative mechanisms that are not visible as such. The practices are empirically observable, but the mechanisms that cause the practices are not; rather, they have to be inferred by the analyst through 'retroduction' from the practices.

Critical realism could also benefit from a more detailed investigation of the interrelations between dispositions, projects and practices in concrete contexts and situations of action. Although one should not give up the voluntarism that is part and parcel of the realist conception of personal causal power, understood as 'capability to act otherwise and make a difference', one should not refrain from analysing how processes of socialization influence the conversations people have with themselves when they ponder how to negotiate circumstances and integrate their projects in a feasible plan (a modus vivendi, as Archer would say).

In Archer, socialization, understood with Bourdieu and Lahire as the internalization of society and its sedimentation in dispositions, competences and schemes of action that produce practices that reproduce society, is downplayed. It is not that the actors have no history, but, more often than not, their history is something to which they more or less consciously subscribe (as is the case with communicative reflexives) or try to flee from (as with autonomous and metareflexives). Like history, culture is also something they encounter in the situation of action, something they face a fronte rather than something that pushes them a tergo. Culture structures the situation from outside, not from inside in the form of subconscious schemes of perception, judgment and interpretation that prestructure the world and canalize action, excluding some options even before the actor becomes conscious of the situation.

Somehow, a subtle articulation between dispositions and projects that does not reduce the latter to the former ('downwards conflation'), or vice versa ('upwards conflation'), must be possible. Perhaps a morphogenetic reformulation can help, not only to avoid that society and agency are collapsed into each other ('central conflation'), which is bound to happen when the individual is conceived of as a self-similar 'refraction' of society, but also to properly parse 
out the linkages between agency and structure. Instead of opposing dispositions to conversations, the external to the internal, the objective to the subjective, I suggest we place them on a continuum and investigate in concrete situations of action when practical consciousness trumps reflexive consciousness, and when it is the other way around. Only when concrete situations of action are taken into account will we be able to do what Archer did for structuration theory: indicate when dispositions have the upper hand and reflexivity is relatively weak or, conversely, when dispositions are out of sync with the contexts and reflexivity is relatively strong.

\section{Micro-macro}

Lahire's work brilliantly demonstrates how variations of scale can contribute to a finer analysis of the relations between the individual and society, but to the extent that he denies the ontological difference between actors and society and has no proper theory of emergence, I am afraid his dispositional theory of socialization cannot offer a satisfying account of the 'micro-macro link'. For Lahire, micro and macro, agency and structure do not refer to differences in kind but rather to different approaches of a self-same single reality, viewed at a different scale. The whole issue of agency and structure is not solved, however, but simply sidestepped when it is considered a question of variable resolution and scale. The question is not how we investigate both at the same time, but, rather, how we can interrelate them in such a way that their interplay can be theoretically understood and empirically demonstrated. The linkage of agency and structure is not a methodological problem. It is an ontological one. Agency and structure are ontologically different moments not only of the analysis but also of the very constitution of society. The variations of scale may be continuous; however, the passage from one level to another of society is not. Society is not flat, but, as a result of emergence, it is stratified in different levels of increasing complexity (Sawyer 2001). Structures at higher levels cannot be reduced without loss to structures at lower levels, though one can, presumably, analyse structures of a given level at a higher or lower scale of resolution. As a result of relations between elements, as well as relations between relations (of first, second and higher order), structures emerge at different levels of complexity that follow their own laws and function in their own way. If that were not the case, sociology would be superfluous. It could be reduced to social psychology, which could be reduced to individual psychology, which could be reduced to neurology and so forth.

Following Buckley's early systems theory of amplification and deviation, Archer $(1988,1995,2003)$ has modelled and analysed the interplay between structure, culture and agency as a morphogenetic sequence that distinguishes 
analytically, yet interrelates dialectically, the past, the present and the future into a temporalized account. The question is now whether we can transfer the morphogenetic sequence to the individual level and parse the interplay between dispositions, reflections and contexts of action into a sociological theory of selfand social transformation. ${ }^{11}$ Is it possible to consider dispositions as structural preconditions (T1) of internal conversations about projects-in-contexts (T2) that reconfigure and modify or reproduce and reinforce the ingrained habits of the individual person (T3)? Thanks to the interpolation of such a reflexive moment between the structural preconditions of action at the individual level and their eventual reproduction or transformation, the mediation between the field and the habitus can be understood as a personal accomplishment of the actor. Both the maintenance of an independent moment of personal reflection between ingrained dispositions and actual practices, and the conceptualization of the internal conversation as an active form of mediation highlight the personal power of self-transformation. Instead of downplaying internal conversations as actualizations of dispositions-in-contexts through which the power of society is extended deep into the psyche and the body of the individual, the morphogenetic perspective on social action aims to reintroduce the power of people and their capacity to determine themselves into sociological analysis as a matter of principle. Of course, the strength of this transformative capacity can vary. Depending on the mode of reflexivity and the circumstances of action, it can be stronger or weaker, but it cannot be dismissed by a mere reference to facts. At the limit, even the self-reproduction of fractured reflexives can be understood as an attempt at self-transformation that failed. Clinical psychoanalysts know that every repetition is a frustrated attempt to change.

\section{Conclusion}

In this chapter I have analysed the sociologies of Bernard Lahire and Margaret Archer. Both have been explicitly formulated in opposition to critical sociology. While they are critical of Bourdieu, they are also indebted to him. Neither Archer nor Lahire could have developed her or his research programmes if Bourdieu's had not existed. Bourdieu is and remains their point of departure - the point from which they depart is also the point from which they flee. In this sense, their theories are definitely post-Bourdieusian. It is not so much by standing on the shoulders of a giant that they have seen further, as Isaac Newton would have it, but it is by embracing his work and constructively dismounting it from within to reassemble it in a different way that they have been able to see different things. Through critique and subversion they have demonstrated the productivity of critical sociology and, thereby, paid homage to Bourdieu. 


\section{Notes}

This text continues in writing the ongoing conversations I have had over many years with Margaret Archer (since 1994) and Bernard Lahire (since 2008). I thank both of them for their willingness to discuss their theories and their relation to Bourdieu with me. I have greatly benefited from detailed comments by Archer of a first version of this chapter.

1 The 'overintegrated conception of society' and the 'oversocialized conception of Man' are actually two sides of the same coin. What distinguishes the normative functionalism of the Harvard School from the critical functionalism of the Frankfurt School is not the analysis but the diagnosis. In the diagnosis of the Frankfurt School, Talcott Parsons's 'problem of the social order' appears, indeed, as a problem - the normative-ideological integration of society and the socialization-indoctrination of its members explains why social change is necessary, yet impossible.

2 This chapter is part of larger piece of work in comparative theory that will also include the work of Axel Honneth, Luc Boltanski and Laurent Thévenot. All of them have been profoundly influenced influenced by Bourdieu.

3 Synthetic programmatic statements can also be found in Lahire, 1996a and b, 1999b, 2002: 389-425, and 2004: 695-736.

4 Both L'homme pluriel (Lahire, 1998) and Monde pluriel (Lahire, 2012) are theoretical parentheses that systematize reflections based on his empirical research. While the first reflects on dispositions (habitus), the second theorizes the contexts of action (fields).

5 Thanks to the reception of Italian 'microhistory' (microstoria) of Carlo Ginzburg and Giovanni Levi, historians are well acquainted by now with the variations of scale (see Revel 1996 and Ricoeur 2000, 267-301). But as far as I know, Lahire is the only sociologist who has extensively theorized and experimented with variations of scale.

6 Detailed sociological portraits of individual subjects are now part of his repertoire. Although the transcription of life stories can easily degenerate into a writing machine that produces texts by the meter, because of its liberating effects, I still would highly recommend his Portraits sociologiques to anyone. Reading the 400 pages of interviews can certainly help liberate any researcher from the inhibition that quantitative preconceptions of scientific research still impose on in-depth qualitative research.

7 Critical realism is a worldwide philosophical movement in the natural, social and human sciences inspired by Roy Bhaskar's trenchant critique of positivism (see Bhaskar 1978, 1979 and Archer et al. 1998 for the essential readings; see Vandenberghe 2014 for a reconstruction of Bhaskar's philosophical system). For a concise outline of the morphogenetic perspective, see Archer 2011; for a first-person account, see Archer 2007b; for a third-person account, see Vandenberghe 2005.

8 Archer has a tendency to lump together structuration theory and genetic structuralism. While Giddens is definitely guilty of 'central conflation', I am not convinced that Bourdieu collapses the field and the habitus into practices. For sure, the relation between field and habitus is homologous - the latter being an internalization of the former, the former an exteriorization of the latter ('duality') - but as deep structures without (the field) and within (the habitus) the individual, they are genuine generative mechanisms that operate at a different level and at a different time of the practices they regulate.

9 What follows is a rather free account of the modes of reflexivity one finds in Archer 2003, 2007 and 2012 - from the 'ground zero' of fractured reflexivity to the full 
consciousness of the metareflexives. Archer eschews classifying individuals into orders of increasing self-consciousness. For her, all souls are equally near to God.

10 By philosophical anthropology, I do not mean to refer to all speculative visions that one finds throughout the ages in all civilizations, but to a specific perspective or, perhaps, even a discipline that investigates the specifically human relation between Life and Spirit. The discipline thrived in Weimar Germany, but has since been discontinued (though one still finds echoes of it in Honneth's work). For an overview, see Fischer 2008.

11 Here I will only focus on self-transformation. The program of a sociological hermeneutics of self-transformation would be to link and think through the connections between self- and social transformation - how transformed selves change interaction orders that transform institutions that transform social transformations that change the world or, in a more critical and disillusioned vein, how the reproduction of the world system percolates down all the way to the reproduction of dominant and dominated selves.

\section{References}

Archer, M. 1983. 'Process without System'. Archives européennes de sociologie 24: 196-121. 1988. Culture and Agency: The Place of Culture in Social Theory. Cambridge: Cambridge University Press.

1993. 'Bourdieu's Theory of Cultural Reproduction: French or Universal?'. French Cultural Studies 4: 225-40.

1995. Realist Social Theory: The Morphogenetic Approach. Cambridge: Cambridge University Press.

2000. Being Human: The Problem of Agency. Cambridge: Cambridge University Press. 2003. Structure, Agency and the Internal Conversation. Cambridge: Cambridge University Press.

2007a. Making Our Way through the World: Human Reflexivity and Social Mobility.

Cambridge: Cambridge University Press.

2007b. 'The Trajectory of the Morphogenetic Approach: An Account in the First

Person'. Sociologia: Problemas e práticas, 54: 35-47.

Archer, M. ed. 2010a. Conversations about Reflexivity. London: Routledge.

Archer, M. 2010b. 'Routine, Reflexivity, and Realism'. Sociological Theory 28: 272-303.

2011. 'Morphogenesis: Realism's Explanatory Framework', in A. Maccarini,

E.Morandiand R.Prandini, R.(eds.)2011. SociologicalRealism.London:Routledge:59-94.

2012. The Reflexive Imperative in Late Modernity. Cambridge: Cambridge University Press.

Archer, M. ed. (2013) 'Introduction: Social Morphogenesis and the Prospects of

Morphogenic Society', in Social Morphogenesis. New York: Springer.

Archer, M. et al. 1998. Critical Realism: Essential Readings. London: Routledge.

Bhaskar, R. 1975. A Realist Theory of Science. Brighton: Harvester Press.

1979. The Possibility of Naturalism. Brighton: Harvester Press.

De Fornel, M. and Ogien, A. eds. 2011. Bourdieu: Théoricien de la pratique (Raisons pratiques, no. 21). Paris: EHESS.

Fischer, J. 2008. Philosophische Anthropologie: Eine Denkrichtung des 20. Jahrhunderts. Munich: Alber.

Frankfurt, H. 1988. The Importance of What We Care About: Philosophical Essays. Cambridge:

Cambridge University Press.

Harré, R. 1970. The Principles of Scientific Thinking. London: Macmillan. 
Lahire, B. 1996a. 'Éléments pour une théorie des formes socio-historiques d'acteur et d'action'. Revue européenne des sciences sociales 34, no. 106: 69-96.

1996b. 'La variation des contextes en sciences sociales. Remarques épistémologiques'. Annales. Histoire, sciences sociales 2: 381-407.

Lahire, B. ed. 1999a. Le travail sociologique de Pierre Bourdieu: Dettes et critiques. Paris: La Découverte.

Lahire, B. 1999b. 'Esquisse du programme scientifique d'une sociologie psychologique'.

Cahiers internationaux de sociologie 56: 29-55.

2000. Culture écrite et inégalités scolaires: Sociologie de l'échec scolaire' à l'école primaire.

Lyon: Presses universitaires de Lyon.

2001. L'homme pluriel: Les ressorts de l'action. Paris: Nathan.

2002. Portraits sociologiques: Dispositions et variations individuelles. Paris: Nathan.

2002b. 'Utilité: entre sociologie expérimentale et sociologie sociale', in Lahire, B.

(ed.) À quoi sert la sociologie? Paris: La Découverte, 43-66.

2004. La Culture des individus: Dissonances culturelles et distinction de soi. Paris: La Découverte.

2005a. Tableaux de familles: Heurs et malheurs scolaires en milieux populaires. Paris:

Gallimard/Seuil/Ecole des Hautes Études. 2005b. L'Esprit sociologique. Paris: La Découverte.

2006. La Condition littéraire: la double vie des écrivains. Paris: La Découverte.

2010. Franz Kafka: Éléments pour une théorie de la création littéraire. Paris: La Découverte.

2010b. 'Postface: Freud, Elias et la science de l'homme', in Norbert Elias, Au-delà de

Freud: Les rapports entre sociologie et psychologie. Paris: La Découverte, 187-214.

2012. Monde pluriel: Penser l'unité des sciences sociales. Paris: Seuil.

Lockwood, D. 1992. Solidarity and Schism: The Problem of Disorder in Durkheimian and Marxist Sociology. Oxford: Clarendon Press.

1964. 'Social and System Integration', in G. Zollschan and W. Hirsch (eds.)

Explorations in Social Change. London: Routledge, 244-57.

Passeron, J. C. 2003. 'Mort d'un ami, disparition d'un penseur. Revue européenne des sciences sociales 41, no. 125: 77-124.

Peters, G. 2012. 'The Social as Heaven and Hell: Pierre Bourdieu's Philosophical

Anthropology'. Fournal for the Theory of Social Behaviour 42, no. 1: 63-86.

Reckwitz, A. 2002. 'Toward a Theory of Social Practices: A Development in Culturalist

Theorizing'. European Fournal of Social Theory 5, no. 2: 245-265.

Revel, J. ed. Feux d'échelles: La micro-analyse de l'expérience. Paris: Gallimard.

Ricoeur, P. 2000. La mémoire, l'histoire, l'oubli. Paris: Seuil.

Ryle, G. 1949. The Concept of Mind. London: Hutchinson.

Sawyer, R. 2001. 'Emergence in Sociology: Contemporary Philosophy of Mind and Some

Implications for Sociological Theory'. American fournal of Sociology 107, no. 3: 551-85.

Susen, S. and Turner, B. (eds.) 2011 The Legacy of Pierre Bourdieu: Critical Essays. London: Anthem Press.

Swidler, A. 1986. 'Culture in Action. Symbols and Strategies'. American Sociological Review 51, no. 2: 273-86.

Vandenberghe, F. 1999. “The real is relational”. An Inquiry into Pierre Bourdieu's

Constructivist Epistemology'. Sociological Theory 17, no. 1: 32-67.

2005. 'The Archers: A Tale of Folk (Final Episode?)'. European Fournal of Social Theory 8, no. 2: 227-37.

2013. What's Critical about Critical Realism? Essays in Reconstructive Social Theory.

London: Routledge.

Wrong, D. 1994. The Problem of Order: What Unites and Divides Society. New York: Free Press. 


\title{
Chapter 4
}

\section{BOURDIEU AND INTERNATIONAL SOCIAL SCIENCE}

\author{
Derek Robbins
}

\section{Introduction}

" "The point of view", says Ferdinand de Saussure, "creates the object". This is the opening sentence of part 2 of Le métier de sociologue: Préalables épistémologiques (The craft of sociology: epistemological preliminaries), which Pierre Bourdieu coproduced with Jean-Claude Chamboredon and Jean-Claude Passeron in 1968 ([1968], 1991, 33). The co-authors proceeded to quote from Karl Marx and Max Weber to suggest that there was an epistemological principle articulated in the Saussurean statement that unified social science practice in spite of ideological differences, one that involves seeing science as 'an instrument for breaking with naive realism' ([1968], 1991, 33). The whole text can be said to have been a manifesto against 'hyperempiricism, which abdicates the right and duty of theoretical construction in favour of spontaneous sociology' ([1968], 1991, 38). Failure to construct the object, they argued, necessarily involved 'abandoning research to preconstructed objects' ([1968], 1991, 34)either those of everyday common sense or those of the professional scientific community. They attempted to recommend a scientific practice that would be independent both of popular perceptions and of professional predispositions. As quoted, however, Saussure's remark is unsatisfactory. It seems to posit an abstract correlation between 'the point of view' and 'the object', and to avoid asking either what creates the point of view or what might be the relation between the created object and reality. Do different points of view create the same object differently or do they create different objects? Are there criteria that enable us to decide whether some points of view are more valid than others? Are objects exclusively the creations of points of view or do they also reflect categories of things, either actually (a realist correspondence theory) or in their mode of presentation (a phenomenological theory of intentionality)? What is in epistemological contention in the account given in Le métier de 
sociologue derives proximately from Immanuel Kant's attempt to reconcile the claims of a priorism and empiricism and from anti-Kantian or neo-Kantian efforts either to criticize or refine the reconciliation that he offered. 'Things-inthemselves' are inaccessible. We can either be sensitive to the extent to which our knowledge is the product of an encounter between changing experience and the stable characteristics of human reason (the Kantians) or we can question the supremacy of reason and explore the nature of subjective, affective or volitional forces determining our pursuit of knowledge (Johann Gottlieb Fichte and other critics of Kant).

Le métier de sociologue involved uneasy compromises between the co-authors, to such an extent that they announced in a preface to the second edition of 1972 that they would not be preparing two further volumes as originally planned. In later writing, Passeron dissociated himself from Bourdieu's thinking as it subsequently developed. Passeron insisted that all sociological explanation must be historical. One way of expressing the disagreement is to suggest that Passeron sought to retain a detached perspective on the historically fluctuating correlations between points of view and objects, whereas Bourdieu assimilated his objectifying practice to his subjective trajectory. For Passeron, the function of sociology was to understand the contingent relations between concepts and objects, whereas, for Bourdieu, it was to understand the sociogenetic origins of all concepts, including his own.

The production of Le métier de sociologue came at a turning point in Bourdieu's attitude towards the relationship between spontaneous and objective sociology. He was aware of the continuing need to be present intellectually within the field of sociology, but he also wanted to ensure that this field remained in contact with the social conditions of its own construction, that his professional practice should not be set in opposition to primary experience but, rather, that his 'scientific' point of view should be juxtaposed equitably with other modes of expression and experience.

The purpose of this chapter is to consider how Bourdieu attempted to reconcile his evolving philosophy of social science during his career with the parallel development of his international reputation. I first consider the specifically French context of his early work and the specifically French character of his intellectual formation. I then examine the shift in his philosophy of social science at the end of the 1960s whereby he began to regard his constructed science as an instrument of social action, a means of intervention fully integrated with his personal trajectory rather than of detached observation. As his texts began to be translated in the 1970s and, particularly, as they began to be published in English translation from the mid-1980s onwards, it became clear that he could not easily retain control of his own griffe (brand label) (as he described it in Bourdieu and Delsaut 1975, making an analogy 
between intellectual and fashion production). The phenomena that he analysed in relation to taste in La distinction ([1979], 1986) were also observable in respect of the commodity market within which his texts were beginning to circulate internationally. I examine the way in which Bourdieu sought, in the late $1980 \mathrm{~s}$, to ensure that his conception of social science would prevail within the field of international social scientific discourse. That is to say that he tried to appropriate the field of international science to advance a position that would simultaneously and covertly subvert the domination of a class of international intellectuals. On the international stage, this was the procedure that he endeavoured to follow nationally in exploiting the 'institutional capital' of the Collège de France for the benefit of disadvantaged French citizens. I finally reflect on the implications of Bourdieu's apparent acceptance at about 1993 that his view of the social function of social science would not prevail internationally and of his revived emphasis of his Frenchness as one national 'point of view' among many to be proffered in the interest of advancing inter-national socioanalytic encounter.

\section{Bourdieu's French Sociopolitical and Intellectual Origins}

Bourdieu was born in Gascony, in provincial France. He was schooled within the French educational system, at primary, secondary and tertiary levels, between the mid-1930s and the mid-1950s. He was employed, first in a lycée in Moulins in the Bourbonnais for the academic year 1954-5 and, on his return to France from military service in Algeria, wholly within the French higher education system from 1960 until his death in 2002. The period spent in Algeria (between 1955 and 1957 in the army there, and between 1957 and 1960 as a lecturer in the University of Algiers) was his only substantial absence from mainland France. According to Bourdieu's account in his posthumously published Esquisse pour une auto-analyse (Sketch for a Self-Analysis, 2003), his father admired 'Robespierre, Jaurès, Léon Blum, Édouard Herriot' (2003, 112) - all iconic figures of the specifically French Left. According to his posthumous account, again, Bourdieu was influenced at the École Normale Supérieure by Martial Guéroult and Jules Vuillemin - both philosophers of science who, respectively, wrote critical commentaries on the work of Leibniz and Kant. The thesis that Bourdieu wrote in 1954 for a diplôme d'études supérieures was supervised by Henri Gouhier, who had written extensively on Auguste Comte and on other philosophers in the French tradition. The thesis involved a translation from Latin of Leibniz's critique of Cartesian epistemology and a commentary and, as such, it offered Bourdieu the opportunity to take a position in relation to the Cartesian legacy in French thought. The doctoral thesis that Bourdieu proposed in 1955 (never to be undertaken) was to be supervised by 
Georges Canguilhem, who was a hero of the Resistance. The topic was to be on 'the temporal structures of affective life', which suggests that it was heavily influenced by Bourdieu's reading of Edmund Husserl, but it is also the case that the interest in 'time' was an important aspect of the legacy of Henri Bergson and that Bourdieu's interpretation of Husserl was mediated by the influence of Maurice Merleau-Ponty.

Bourdieu was conscripted into the French army and he set foot in Algeria in October, 1955. This was part of a renewed French initiative to suppress the emergent insurrection, which as the war of Algerian independence, was to lead to the recognition of the independent state of Algeria in 1962. By the constitution of the French Fourth Republic of 1946, Algeria had been divided into three departments of metropolitan France. Constitutionally, the French intervention was an internal matter, one that was designed to suppress civil war, rather than a question of international conflict. Bourdieu was posted initially in an air force unit of the military staff of the French administration 150 kilometres west of Algiers, but in the early spring of 1956 he obtained a post in Algiers with the Service de documentation et d'information of the Gouvernement Général, which possessed one of the most well-stocked libraries in Algeria. He then obtained a position at the University of Algiers, where he taught sociology and philosophy. He gave lectures on key anthropologists, such as J. G. Frazer, Bronisław Malinowski, Franz Boas and Ruth Benedict, rather than on Marx, Émile Durkheim or Weber. Late in life, Bourdieu gave a talk in which he outlined the situation in which he had worked at the University of Algiers, commenting that 'in the late 1950s and early 1960s, everything relating to the study of North Africa was dominated by a tradition of Orientalism' (ed. Yacine 2013, 289). He elaborated the point, commenting that 'the Marçais family offered the example in Algeria of Arabist scholars, lacking any specific training, who reigned over the Algiers faculty, distributing research topics and representing what was called colonial ethnology' (ed. Yacine 2013, 289). In parallel with his teaching responsibilities, Bourdieu travelled inland in Algeria and befriended indigenous ethnologists. He also worked with officials of the Institut National de la Statistique et des Études Économiques (INSEE). He carried out two major investigations, the first on the notion of labour in the urban situation and the second on the peasants 'uprooted' in resettlement centres. These were undertaken at the request of the Association pour la Recherche Démographique, Économique et Sociale (ARDES) and financed by the Caisse Algérienne de Développement. An official census of the Algerian population was begun at the end of 1959. The INSEE officials were aware of the difficulties of accumulating data when the 'facts' to be ascertained were dependent on culturally divergent concepts, such as work and unemployment, and they sought assistance from Bourdieu. 
Between 1957 and 1960, therefore, Bourdieu was immersed in empirical research in collaboration with government statisticians with a view to informing social policy and development studies, and, at the same time, wrestling with conceptual problems of cross-cultural analysis. His projects involved 'action research' in the sense that he was committed to working with Algerian investigators who operated in pairs - an Algerian and a French person or a man and woman - with the intention that the process would encourage bicultural awareness and contribute as such to encouraging Algerian selfdetermination. As Bourdieu wrote very late in life, 'I was an angry young man, I hope I shall be an angry old man; it is a kind of fidelity to the idea that I have of myself' (quoted in Alain Garrigou, 'Un jeune homme en colère' (An angry young man), in Mauger ed. 2005, 143-4). It was in this period as well that he produced his first publications - Sociologie de l'Algérie (Sociology of Algeria), published in 1958 by the Presses Universitaires de France in its Que Sais-je series (1958), and two contributions to a book entitled Le sous-développement en Algérie (Underdevelopment in Algeria), which was published in 1959 in Algiers by the Secrétariat social (1959a and b). Both publications were designed to inform and, by informing, to encourage mutual recognition of cultures. The first represented the diversity of indigenous Algerian culture to the metropolitan French readership, and the second emphasized rather more within Algeria the logical validity of 'traditional', precolonial social organization.

Tassadit Yacine suggests, 'based on information obtained from relatives and friends' (Bourdieu ed. Yacine [2008b], 2012, 340), that 'Bourdieu was threatened, and forced to leave Algeria' ([2008b], 2012, 22) at the end of 1959. Raymond Aron took him on as his assistant at the Sorbonne at the beginning of 1960, and Bourdieu also became secretary to the research group entitled the European Centre of Historical Sociology that Aron founded that year. Jean-Claude Passeron was appointed assistant to Aron at the same time and, together, Bourdieu and Passeron carried out research projects within what was renamed the Centre de sociologie européenne (CSE). There were three main research projects during the $1960 \mathrm{~s}$, each of which enabled Bourdieu to retain his commitment to the value of socially dominated cultures and to criticize forms of cultural oppression within France that were analogous to the forms of colonial oppression in Algeria. Bourdieu and Passeron led a team of researchers in French universities in a project that examined the extent to which the curriculum in French higher education institutions (whose raison d'être was supposedly to equalize educational opportunities) actually legitimated the performance of those privileged students who already were familiar with the cultural content of courses before their admission, and diminished the performance of those students who possessed an equally valid, but 'unconsecrated', prior culture. Bourdieu directed a second project that investigated 
the institutionalization of photographic practice. He had hoped that photography might be a technological cultural form that would lead to a democratization of aesthetic judgement, but the findings of the project suggested that photographic clubs reproduced the socially based hierarchies of taste of traditional art appreciation. Thirdly, Bourdieu directed a project that investigated the nature of attendance at museums and art galleries, at first just in France and then, subsequently, extended to include scrutiny in other European states. In part this was a project in opposition to the cultural initiatives of the French Minister of Culture who was establishing maisons de culture throughout France in order to bring high culture to the people. Bourdieu's finding was that established museums and art galleries tended to perpetuate a state culture that tacitly denigrated the cultures of many citizens. Although these three projects were partly inspired by Aron's belief that, post-World War II, a new world community was emerging that would be transformed by the proper use of industry and technology, they were nevertheless focussed on France.

Bourdieu remained an angry young man during these projects, seeking still to advance the interests of the socially disadvantaged, but it is one thing to be engaged in committed research and another to disseminate findings more widely through publication without compromise. By the time of his return to France, Bourdieu had only published his Sociologie de l'Algérie and his two contributions to an Algerian publication with only a small distribution. A second edition of Sociologie de l'Algérie was published in 1961, but this was still constrained by a short, statutory length for the series. From his Algerian research projects Bourdieu still possessed a mass of unpublished material. No longer active within the war zone, Bourdieu extrapolated findings, constrained by the orientations of journals. Articles appeared in Études méditerranéennes, Esprit, Les temps modernes, Études rurales and Sociologie du travail. In 1962, an English translation of Sociologie de l'Algérie was published by Beacon Press, Boston (Bourdieu 1962a). Aron wrote a preface to this text. The Algerians was augmented in ways that indicated the influence of Claude Lévi-Strauss's binary classification of phenomena.

Bourdieu's reports on his two major projects were not published until after his return to France in 1960. The second, Le déracinement: la crise de l'agriculture traditionnelle en algérie (The uprooting: the crisis of traditional agriculture in Algeria, Bourdieu and Sayad 1964), gave an account of the consequences for traditional social organization of the French colonial policy of 'containing' indigenous Algerians in camps. The first, Travail et travailleurs en Algérie (Work and workers in Algeria, Bourdieu et al. 1963), was methodologically significant. It was presented in two parts, the first of which was statistical and quantitative, and the second of which was analytical, based on qualitative findings derived from interviews and questionnaires. Bourdieu introduced the first part with 
an essay on 'Statistiques et sociologie' (Statistics and sociology), in which he considered the validity of the findings of the two parts, reaching the phenomenologically oriented conclusion that the derivation of meaning in social science research depends on a continuous reciprocity between quantitative and qualitative methods that does not presuppose the primacy of either. The book also offered a series of appendices, some of which elaborated on the categories deployed in the statistical analyses and some of which provided transcripts of interviews or extracts of interviews that constituted the preanalysed testimonies of the observed social agents. In particular, one appendix offered the long self-analysis of an indigenous chef as 'spontaneous sociology'.

\section{Bourdieu's Sociology in the 1960s as Suppressed Phenomenology}

While Bourdieu was directing research projects within the CSE during the 1960 s, we can say that his phenomenological orientation remained dormant, or suppressed. The texts that he published in this period - Les héritiers: les étudiants et la culture (The inheritors; Bourdieu and Passeron 1964), Un art moyen: essai sur les usages sociaux de la photographie (A middle-brow art, Bourdieu et al. 1965), and L'amour de l'art, les musées d'art et leur public (The love of art, Bourdieu et al. 1966) - secured his reputation as a sociologist of education and culture. They were contributions to objective sociological discourse but, importantly, they were also meticulous in providing annexes that detailed the sources of the findings. They all sought to be transparent in indicating the procedures by which their explanations or analyses were the consequence of generalizations from particulars. In spite of the status of the texts within the objective field of sociology, therefore, the mode of presentation showed that Bourdieu was still anxious to expose 'findings' to scrutiny by reference to the primary material that had generated them. One specific text that was the outcome of a personal research project of the early 1960s suggests that Bourdieu's interest in the relationship between 'objective' and 'spontaneous' sociology was not philosophically abstract but, rather, crucial to his attempt to reconcile his own familial 'habitus' with his acquired analytical capacity. In 'Célibat et condition paysanne' (Gelibacy and the peasant condition, Bourdieu 1962b), Bourdieu reported on his analysis of a social predicament in his native Béarn. In the company of his father, he interviewed their local contemporaries in such a way as to be able to juxtapose the unreflecting articulation of experience with detached analysis of that experience. In respect of his own affectivity, in other words, Bourdieu sought to explore the extent to which his objectification of his primary experience corrupted or clarified it. Sometimes the locus of his publications imposed an objectivity with which he was not at ease. What was 
published in the journal Sociologie du travail in 1963 as 'La société traditionnelle: Attitude à l'égard du temps et conduite économique' (Traditional society: attitude to time and economic behaviour, Bourdieu 1963), closely related to his analyses in Travail et travailleurs en algérie, was published a year later in English in revised form in an anthropological collection edited by Julian Pitt-Rivers entitled Mediterranean Countrymen with the title: 'The Attitude of the Algerian Peasant toward Time' (Bourdieu 1964). One aspect of research that had been sociopolitically engaged in particular circumstances was expropriated for inclusion in a volume that suggested general characteristics of 'Mediterranean' or 'peasant' societies. This was an early example of the consequences of the conceptual distortion effected by cross-field transfer of which Bourdieu was to become acutely aware as his career progressed.

By the mid-1960s, Bourdieu was beginning to disclose his antipathy towards the dominantly structuralist mode of anthropological analysis, as represented in the work of Lévi-Strauss. I want to refer to four important articles of this period: firstly, 'Condition de classe et position de classe' (Class condition and class position), published in 1966 in Archives européennes de sociologie, but not subsequently translated into English (Bourdieu 1966a); secondly, 'Champ intellectuel et projet créateur', first published in 1966 (Bourdieu 1966b) and translated into English as 'Intellectual field and Creative Project' in Social Science Information in 1969 (Bourdieu 1969a) and then in M. F. D. Young's collection of 1971 entitled Knowledge and Control: New Directions for the Sociology of Education (Bourdieu 1971); thirdly, 'Sociology and Philosophy in France since 1945: Death and Resurrection of a Philosophy without Subject', written with Passeron and published in English in Social Research in 1967 (Bourdieu and Passeron 1967); and, lastly, 'Structuralism and Theory of Sociological Knowledge', published in English in Social Research in 1968 (Bourdieu 1968). These all appeared shortly before the publication of Le métier de sociologue, written with Passeron and Chamboredon, published in 1968 and translated into English in 1991 as The Craft of Sociology, to which I have already referred.

I want to make four main points concerning these four publications.

The first point is that Bourdieu was clearly articulating his position in relation to some aspects of structuralism. In the opening sentence of his 'Structuralism and Theory of Sociological Knowledge' Bourdieu acknowledged that structuralism had been valuable in advancing the view that social science can be objective science as much as the natural sciences. It had advanced the view that human behaviour can be analysed systematically without submersion in the subjective impressions of participants. It had counteracted the influence of hermeneutic or humanistic orientations. However, Bourdieu's 'Champ intellectuel et projet créateur' had been first published in a number of Les temps modernes devoted to 'the problems of structuralism'. Bourdieu emphasized that 
the important structure in respect of the production of knowledge or art is the one perceived by artists and intellectuals themselves whereby they situate themselves socially. This structure is to be distinguished from that imposed ex post facto by present analysts of either contemporary or historical production. The structure imposed by these contemporary structuralist analysts constitutes an instrument in their position taking in response to their appreciation of the structural context within which they operate analytically. For Bourdieu, the weakness of this contemporary form of structuralism was that it attempted to identify common, universal characteristics in disparate behaviours and different cultural contexts. In 'Condition de classe et position de classe', Bourdieu took the understanding of the peasant condition as a case in point. Perhaps conscious of the way in which his studies of Algerian peasants had been appropriated in the anthropological literature to be about peasants in general, Bourdieu insisted that the peasant 'condition' is not universally the same but, rather, is dependent in different cultural contexts on the ways in which peasants position themselves or are positioned within their own societies.

The second point is that Bourdieu and his collaborators insisted on the historical contingency of the construction of the field of sociological explanation. 'Intellectual field and creative project' analysed the ways in which the 'intellectual field' secured autonomy in the eighteenth and nineteenth centuries. By this Bourdieu mainly meant that a sector of the population established itself in such a way as to generate self-contained or self-referential mechanisms of judgement - criteria of value exercised in differently self-regulated contexts, either in universities or journals - independent of the previously dominant cultural authorities, either the church or the aristocracy. Bourdieu argued that it was possible to analyse the degrees of relative autonomy of different modes of intellectual production, on a continuum from journalistic subordination to commercial pressures to aesthetic detachment and apparent commercial indifference. Ostensibly, 'Intellectual field and Creative Project' seemed to concentrate on artistic production, but it is clear that the general position applied equally to the field of sociological production. 'Sociology and Philosophy in France since 1945' begins with a cross reference to 'Intellectual Field and Creative Project' and the whole article is an attempt to write a social historical account of the relationship between sociology and philosophy in postwar France so as to explain sociologically the emergence of the kind of work practised by Bourdieu and his colleagues in the CSE, Paris, by contrast both with the dominant existentialist philosophy stimulated by the Resistance and the Liberation, the humanist structuralism of Lévi-Strauss, and the spuriously aphilosophical neo-positivism of Americans, such as Paul Lazarsfeld.

The third point is that Bourdieu and his collaborators tried to use the publication of Le métier de sociologue as a way of consolidating their distinctive 
mode of sociological practice. In 'Structuralism and Theory of Sociological Knowledge', Bourdieu developed his philosophy of social science philosophically. The unity of sociological discourse or, if you like, of the 'field' of sociology had to be dependent on the adoption of common methodological procedures rather than on common theoretical interpretations of the social world. As he put it,

The theory of sociological knoweledge, as the system of principles and rules governing the production of all sociological propositions scientifically grounded, and of them alone, is the generating principle of all partial theories of the social and, therefore, the unifying principle of a properly sociological discourse which must not be confused with a unitary theory of the social. (Bourdieu 1968, 681; italics in original)

This meant that the unifying principle of social science had to be independent of competing ideological grand narratives. As Bourdieu continued in 'Structuralism and Theory of Sociological Knowledge',

It follows, on the one hand, that the plurality of theories of the social system must not conceal the unity of the meta-science upon which all that in the former stands out as scientific is founded: scholars such as Marx, Durkheim and Weber, totally different in their views of social philosophy and ultimate values, were able to agree on the main points of the fundamental principles of the theory of knowledge of the social world. It follows, on the other hand, that what is usually called the 'unity of science' is nothing but the unity of meta-science, the identity of principles upon which all science, including the science of man, is founded. $(1968,682)$

The purpose of Le métier de sociologue was to exemplify this thesis by introducing selections from key sociologists that demonstrated that their practices could all be contained within a unifying methodological formula derived from Gaston Bachelard - that all social science advances in three stages, by winning social facts, constructing them and confirming them. It was the contention of Le métier de sociologue that by adhering to this common procedure sociologists would be able to establish an epistemic community within which research findings could be tested and refined. This community would acquire scientific credentials, which would mean that it was not subject to the whim of cultural fashion or political trend. Le métier de sociologue was published in 1968. It was tacitly sympathetic with the Marxist view current with students participating in the May events that sociology was an instrument of the oppression of the capitalist state apparatus, but Bourdieu reacted at first to this situation by asserting the 
autonomy of social scientific methodology. He was as concerned that autonomy would be forfeited by enactment of the revolutionary demands of the students as by state oppression and, as a consequence, he maintained his position at the Ecole des Hautes Etudes en Sciences Sociales and resisted joining the staff of the new university of Paris 8 at Vincennes. Le métier de sociologue was designed as a handbook for research students that would consolidate methodological autonomy. The last paragraph of the concluding section of the Introduction to Le métier de sociologue is important:

In short, the scientific community has to provide itself with specific forms of social interchange, and, like Durkheim, one is entitled to see a symptom of its heteronomy in the fact that, in France at least, and even today, it is too often responsive to the non-scientific enticements of intellectual 'worldliness': 'We believe', wrote Durkheim at the end of The Rules of Sociological Method, 'that the time has come for sociology to renounce worldly successes, so to speak, and to take on the character which befits all science. Thus it will gain in dignity and authority what it will perhaps lose in popularity'. (Bourdieu et al. [1968], 1991, 77)

In the terms outlined by Bourdieu in 'Intellectual Field and Creative Project', therefore, it was necessary for social science in France in 1968 to consolidate its autonomy and to become the scientific equivalent to nineteenth-century 'art for art's sake' in denying immediate relevance or journalistic popularity. However, there was an ambivalence in the use of Bachelard - an ambivalence that may in part arise from the tension between the positions of the co-authors. Bachelard's formula - his notion of the need for 'epistemological rupture' - was both the foundation for the unification of social scientific practice and, at the same time, the blueprint for demonstrating the historical arbitrariness of the construction of the field of sociological explanation at all.

The fourth point in relation to this early cluster of articles is to reiterate that the horizon was specifically French. Not only, therefore, is it the case that Bourdieu's early work was stimulated by the objective social conditions of France (and Algeria) but also that his conceptualization of that condition derived substantially from a French intellectual tradition. ${ }^{1}$ Bourdieu and his collaborators were updating Durkheim's philosophy of social science but retaining his commitment to the social function of social science. They were appropriating the social science of other intellectual and cultural traditions, mainly German and Anglo-American, and subsuming their work within a specifically French tradition, in part derived from Comte and positivism and, in part, derived from a line of mainly neo-Kantian French philosophers of science. The argument of Le métier de sociologue is heavily dependent on the 
work of Georges Canguilhem and Bachelard, and extracts from their texts preponderate in the selections provided for the guidance of research students.

\section{The Challenge for Bourdieu of His Emergent International Reputation: The Conflicting Claims of Particularism and Universalism}

\section{The 1970s}

Neither 'Sociology and Philosophy in France since 1945' (Bourdieu and Passeron 1967) nor 'Structuralism and Theory of Sociological Knowledge' (Bourdieu 1968) was published in French. Bourdieu and Passeron were attempting to conquer the field of French social science, to reassert a French tradition against the encroachments of post-war American sociology, most notably represented in France in the work of Michel Crozier, but they chose to confront the malign influences at source rather than at home. This was the first sign that they were beginning to exploit the international market of knowledge circulation to endeavour to ensure that their particular methodological orientation might prevail internationally. During the 1960s, very few of Bourdieu's texts were translated from French. Other than the essays contributed to the anthropological collection of Augustus Pitt-Rivers (Bourdieu 1964a) to which I have referred and to another collection edited by J. G. Peristiany (Bourdieu 1965), the only texts translated from French before 1970 were a Spanish translation in 1965 of Le déracinement (Bourdieu 1964b) and Italian translations, in 1966 (Bourdieu 1966c), of Bourdieu's 'Le paysan et la photographie' (The peasant and photography, (Bourdieu and Bourdieu 1965) and, in 1969 (Bourdieu 1969b), of his 'Langage et rapport au langage dans la situation pédagogique' (Language and the relation to language in the pedagogical situation, Bourdieu and Passeron 1965). This situation changed in the early 1970s. Two major collections were published in Germany. The first - Zur Soziologie der symbolischen Formen (On the sociology of symbolic forms, Bourdieu 1970b) - picked up, as the title suggests, on the fact that, in 1967, Bourdieu had published his translation (Panofsky trans. Bourdieu 1967) of a text by Erwin Panofsky, who was a disciple of Ernst Cassirer. The second - Die Illusion der Chancengleichheit (The illusion of equal opportunity, Bourdieu and Passeron 1971c) - collected extracts from Les héritiers (Bourdieu and Passeron 1964) and La reproduction (Reproduction, Bourdieu and Passeron 1970a) as well as essays related to education. In April 1970, Bourdieu gave a paper on 'Cultural Reproduction and Social Reproduction' to a conference of the British Sociological Association, which was then published in several English collections during the 1970s, while the publication of two of Bourdieu's articles in a collection edited in 1971 by M. F. D Young entitled Knoweledge and Control 
(Bourdieu 1971a and 1971b) established Bourdieu's reputation in England as a significant contributor, along with Basil Bernstein, to the development of a new sociology of education. In 1971, a collection of articles was published in Italian as Mitosociologia: Contributi a une sociologia del campo intellettuale (Metasociology: contributions to a sociology of the intellectual field, Bourdieu and Passeron 1971), and a different collection was published in Romanian as Sociologia francezâ contemporanâ (Contemporary French sociology, Bourdieu $1971 d)$.

This is not the place to analyse in detail the transnational reception of Bourdieu's work in terms of the different emphases that were thought to be relevant to different national contexts. My intention is simply to indicate that, suddenly, at about 1970, that work began to be disseminated outside France, and to explore the implications of the fact that, at approximately the same moment, Bourdieu was forced to reconsider his position in the aftermath of the unsuccessful student revolt (in France and other Western European contexts) of May 1968.

Aron indicated his lack of sympathy with the activities of the students in his column in Le Figaro during the events and collected these articles later the same year in a book entitled La révolution introuvable (The unrealizable revolt, 1968). This caused Bourdieu to dissociate the CSE from his mentor's scepticism and to seize control of the research group. Bourdieu was associated during the events with a call for the setting up of an Estates General on education and research, after the manner of the Estates General that preceded the French Revolution (see the text published in Bourdieu ed. Poupeau and Discepolo 2002, 63-8 [2008a], 41-5). ${ }^{2}$ The argument of the call was, in part, that there needed to be a general assembly representative of the whole population because the inadequacy of the French university system needed to be articulated by those who were eliminated from it as much as by those currently enjoying its advantages. Bourdieu was consistent in seeking to give a voice to the socially excluded, but he cannot have been unaware that what was seen to be his kind of sociology was in danger of emphasizing a detachment from the conditions of students and would-be students. At about the same time, Jacques Rancière was disowning the magisterial indifference to the student revolt of his mentor - Louis Althusser. He made public his rift with Althusser in his La leçon d'Althusser (Althusser's Lesson) of 1974. Perhaps with the benefit of some hindsight, Rancière has recently, in a reissue of the original text, situated it in its original historical context in language that reflects retrospectively his contemporary assessment of the inadequacy of the sociology of education offered by Bourdieu and Passeron in their La reproduction of 1970 (1970). Writing in 2011, Rancière recalls that his main targets in 1968 were all 'those who operate in effect on the basis of the same presupposition - that domination 
functions thanks to a mechanism of dissimulation that makes those whom it subjugates unaware of its laws by presenting them with a reverse reality' $(2011,12) .{ }^{3}$ It was this assessment of the shortcomings of the sociology of education in the context of the bid for educational revolution that led Rancière subsequently to brand Bourdieu as a 'Sociologist-King' in the same mould as Plato's 'philosopher-king' (in Le philosophe et ses pauvres (The philosopher and his poor, 1983, 2007). Whether or not Bourdieu encountered this criticism, articulated in these terms, at the end of the 1960s, it seems clear that he began to develop a particular methodology of social scientific explanation that reconsidered the relationship between the 'spontaneous sociology' that he had disparaged in Travail et travailleurs en algérie and the epistemic autonomy that he (or he and his co-editors) had recommended in Le métier de sociologue as a necessary prerequisite for the future development of professional sociology. For a while, conflicting emphases coexisted. In 1970, an article that was a product of his Algerian research, 'La maison kabyle ou le monde renversé' (The kabyle house or the world turned upside down), was published in a collection of articles assembled in honour of Lévi-Strauss on the occasion of his sixtieth birthday (Bourdieu 1970). Just two years later, Bourdieu republished this article in his Esquisse d'une théorie de la pratique, précédé de trois études d'ethnologie kabyle (Outline of a theory of practice, preceded by three studies in kabyle ethnology, 1972). In its new context, Bourdieu presented the early article and then proceeded to subject it and two other early studies to criticism, exposing the inadequacy of their structuralist assumptions. These early ethnological studies had been guilty of the error that he had articulated in his 'Champ intellectuel et projet créateur' (1966) in that they had imposed the pursuit of explanatory order of the analyst on phenomena that actually manifested the immanent structuration of their own situations by participants. Bourdieu's self-criticism in Esquisse d'une théorie de la pratique contained a passage that was published in English as an extract in 1973 with the title 'The Three Forms of Theoretical Knowledge' (1973), well before the 'translation' of the whole book, which as Outline of a Theory of Practice (1977a), was, in fact, a revised representation of the original that transformed the earlier critique of structuralism into a manifesto statement for a new kind of poststructuralism. 'The Three Forms of Theoretical Knowledge' proposed that knowledge is established through a series of 'epistemological breaks'. The primary, unreflecting knowledge of their situations possessed by social actors - 'spontaneous sociology' - is turned into scientific knowledge by detached observers in a conscious process of objectification. This first epistemological break that enables scientific knowledge, however, has to be followed by a second break whereby the social conditions of construction of the objective science are themselves analysed sociologically. The third break, which leads to what Bourdieu initially called 'praxeological' knowledge 
is necessary to ensure that objective science does not simply impose the prejudices of the analysts on observed social realities. The model was inspired by Bourdieu's earlier disquiet at his position as a colonial ethnologist of colonized social groups, but it was to become the basis for his attempt to ensure that his sociological analyses would not fall into the trap identified during the May events and articulated by Rancière - of deploying intellectual privilege surreptitiously to sustain social and political domination. Whereas Le métier de sociologue had used Bachelard's notion of 'epistemological breaks' to specify the procedure to be adopted in order to legitimate social scientific knowledge, Bourdieu now used the same notion with a phenomenological tinge in order to subject sociological analysis to metasociological scrutiny so as to prevent the exercise of 'symbolic violence'. The three 'breaks' were no longer recommended as a means of establishing the credentials of social science but, rather, as a means of locating that science in the context of other perceptions of reality possessing equal validity.

By contrast with the deconstructionism advanced contemporaneously by Jacques Derrida as his response to the work of Husserl, Bourdieu's poststructuralism related to the interpretation of Husserl's phenomenology as 'constitutive' as represented by Aron Gurwitsch and Merleau-Ponty. That is to say that, for Bourdieu, the interpretation of the meanings of actions is accretive rather than reductive. His 'post-structuralism' did not negate the achievements of structural analyses. Rather, Bourdieu was setting up an interpretation of understanding as the product of subjective/objective encounter and, crucially, of encounter between perceptions that are all sociologically explicable. Famously, in Esquisse and in Outline of a Theory of Practice, Bourdieu argued that it was necessary to supplant the orientation to understand people's behaviours by reference to 'rules' only perceived by sociologists and anthropologists by an orientation to understand the 'strategies' adopted themselves by social actors. It was not immediately clear, however, that Bourdieu was beginning to represent his science as his personal strategy as a social actor. In 'L'opinion publique n'existe pas' (Public opinion does not exist, Bourdieu 1971e), for instance, Bourdieu argued that political scientists used opinion polls to fabricate a 'public opinion' on issues that was spurious because the fabrication was a consequence of posing questions that largely excluded portions of the population without registering the significance of non-responses. This was a form of argument that was typical of Bourdieu's inclination to identify mechanisms of conceptual exclusion but, nevertheless, he still wanted to justify social science as an objective discourse that could carry out analyses of the social conditions that generated the questions deployed by dominant political scientists to preserve their sociopolitical domination. The second epistemological break provided a critique of political science but was not yet self-regarding. 
During the first half of the 1970s, therefore, Bourdieu developed a theory of agency or practice without fully applying that theory to his own endeavours. It was in this period that he expanded on the concept of 'field' that he had used in 1966. A paper that he gave at Harvard in 1973 was particularly important. It was published first as 'Sur le pouvoir symbolique' (On symbolic power, 1977b). 'Fields' are contingent intellectual discourses that are sustained by procedures of institutional reproduction. That is to say, for instance, that social scientific discourse developed in France at the end of the nineteenth century when Durkheim began to develop concepts and methodology representing a distinctive way of analysing occurrences in society, such as the phenomenon of suicide, and when chairs of sociology began to be established within French universities. Bourdieu's contention was that the existence of 'fields' necessitated two forms of analysis, corresponding with the epistemological breaks recommended in 'The Three Forms of Theoretical Knowledge'. Scientific explanations are advanced and discussed within intellectually and institutionally constructed contexts according to rules and criteria developed specifically for those contexts, but the nature of the explanation possible in these contexts is preconditioned by the way in which they achieve autonomy. In his words, Bourdieu argued that all scientific explanations need to be understood both as 'stuctured structures' that generate tautologuous discourse, and as the products of 'structuring structures'. It is often emphasized that Bourdieu's concept of 'field' was a means to enable him to counteract the direct correlation between base and superstructure proposed in Marxism. It operationalizes a 'soft determinism' by acknowledging that structures that are the constructs of class conditions acquire autonomous power that enables them to modify the conditions for future structuration. But the range of Bourdieu's thinking was much wider than this. The concept of 'field' was a product of the contemporary philosophical debate about Husserl to which Derrida notably contributed in his diplôme études supérieures of 1953-4, eventually published in 1990 as Le problème de la genèse dans la philosophie de Husserl (The problem of genesis in the philosophy of Husserl, 1990), and in a paper given at a colloquium in 1959 entitled “"Genèse et structure” et la phénoménologie' ('Genesis and structure' and phenomenology, 1965). Derrida argued that Husserl did not focus on genetic or structuralist explanations as opposed alternatives but, rather, used both fluidly, the former to counteract a priori idealism and the latter to counteract psychologism. ${ }^{4}$ Bourdieu used the concept of 'field' in a similarly fluid or strategic fashion. By the 1970s, Bourdieu had discarded the epistemological dualism that had seemed to be embodied objectively in the colonizer/colonized relationship. 'The Three Forms of Theoretical Knowledge' and 'On Symbolic Power' seemed to be envisaging a dialectical relationship between primary experience and objective analysis, and one that might facilitate 
conceptual convergence. Bourdieu proceeded to explore the relations between 'structuring' and structured structures in his theoretical thinking. Bourdieu's article of 1975 on 'L'ontologie politique de Martin Heidegger' (The political ontology of Martin Heidegger, 1975), which was to be revised and published as a book with the same title in 1988 (1988), can be read as an attempt, in part, to demonstrate the dangerous consequences resulting from the fact that Heidegger allowed the popular language associated with völkisch sentiments (as disseminated in the novels of Ernst Jünger) to become assimilated to his philosophical endeavour. The virtues of philosophical autonomy were abused by an excessive submission to populism. It is significant that in the same year, 1983, Bourdieu published both a sociological critique of 'The Philosophical Establishment' (1983a) and a critique of the use of the term 'popular' in his 'Vous avez dit “populaire”?' (Did you say 'popular’?, 1983b). Facing both ways simultaneously, Bourdieu argued that the problem lay in the 'application of dualistic categories' ${ }^{5}$

The homology between Bourdieu's thought and practice meant that his strategic actions were comparably multivalent. In 1975, Bourdieu established a journal, Actes de la recherche en sciences sociales, as an organ for the dissemination of the work of the CSE. Luc Boltanski, who was Bourdieu's prime assistant in the venture in the early days, has recollected that one of the impulses towards establishing a new journal was the exasperation of Bourdieu and his colleagues at the 'censure' exercised by established journals such as the Revue française de sociologie. ${ }^{6}$ The consequence was, therefore, that Bourdieu was advancing a social scientific methodology that would enable it to act as a device for disclosing the primary perceptions of observed social actors, at the same time as he was seeking to publish the findings of such projects within an epistemic community that was itself attempting to subvert the authority of the structured structure of the sociological establishment. The Actes de la recherche en sciences sociales, emphasizing at inception that it would be presenting 'research acts' or research in progress rather than peer-reviewable 'findings', was a means by which convergence between structuring and structured structures could be engineered, mirroring conceptually, both describing and prescribing (see Bourdieu 1981), processes of social mobility.

\section{From the mid-1980s}

I am arguing that by the mid-1970s Bourdieu had successfully established a situation for himself within France whereby his developed philosophy of social science and his research group and its journal were mutually reinforcing intellectual and institutional elements in a process that was seeking to offer a form of mediation between dominated and dominant factions in French 
society. Some translations of his work occurred beyond those already mentioned, but these were still mainly intra-European language transfers, with, perhaps, dominant reception in German rather than English. There still remained the possibility that the role assumed in France sociopolitically might be extended to influence the development of the European Union. The transformation occurred as a result of the establishment in 1984 at Cambridge, United Kingdom, of Polity Press, edited initially by David Held, Anthony Giddens and John Thompson. Polity Press rapidly acquired a near monopoly of the English publication of Bourdieu's work. Bourdieu wrote a preface to the English edition of the first of his books translated for Polity Press - Homo academicus (1984) - published in English in 1988 (1988). He endeavoured to argue that the text should be read as a paradigm for the encouragement of similar research within the intellectual fields occupied by its readers. It was not to be received as a 'realist' analysis of Parisian higher education but as the particular French variant of comparable structures in other societies. In recommending pragmatism, Bourdieu was trying to ensure that his text exemplified the processes of structuring structure and would not be taken to illustrate a static, structured structure. By 1990, when Polity published translations of Choses dites (Bourdieu 1987) as In Other Words (Bourdieu 1990a); of Le sens pratique (Bourdieu 1980) as The Logic of Practice (Bourdieu 1990b); of Un art moyen (Bourdieu et al. 1965) as Photography: A Middle-brow Art (Bourdieu et al. 1990); and of L'amour de l'art (Bourdieu et al. 1966) as The Love of Art (Bourdieu et al. 1990), it was no longer possible for Bourdieu to attempt to dictate the way in which he wanted his texts to be read. His texts had become components of an international market of symbolic goods and, as such, they were susceptible themselves to analysis in the way that he had developed in respect of aesthetic tastes in La distinction (1979).

Translation into English during the period increasingly generated international accessibility as a result of the global domination of the English language. The consequence was that Bourdieu became increasingly aware that the dominant field of reception for his work was Anglo-American or AngloSaxon. It should also be said that Bourdieu's appointment to the chair of sociology at the Collège de France in 1981 caused some social and physical detachment from the researchers of the CSE. These changes and the contemporary rise of postmodernist thinking contrived to emphasize the exchange of Bourdieu's ideas within a self-referential structured structure of international sociology at the expense of engagement with the social conditions of their production and reception.

How did Bourdieu respond to this challenge? In a paper that he gave in 1989 at the Maison Descartes, Amsterdam, entitled 'Penser les limites' and translated in Theory, Culture and Society in 1992 by Roy Boyne as 'Thinking 
about Limits', Bourdieu reasserted his commitment to the methodological position articulated by Bachelard, which had provided the organizing principle of Le métier de sociologue. Bourdieu said,

The conquest of the given is a central concept in Bachelard's thought, and he sums it up in the term, 'epistemological break'. Why is this phase of scientific research important, and why does it separate, as seems to me to be the case, the tradition I represent from the dominant Anglo-Saxon tradition? It is because to say that the scientific fact has to be fought for is radically to defy, in this regard, all of the 'givens' that social scientific researchers find before them. Researchers in the social sciences have, within arms' reach, just at their fingertips, preconstructed facts which are wholly fabricated; so many terms, so many subjects. At conferences, you can listen to these preconstructed concepts being exchanged, dressed up in theoretical tinsel, and having the air of scientific facts. This is currently how subjects and their limits are defined; the preconstructed appears to be everywhere. (1992, 42; italics in original)

This jaundiced view of international conferences is reminiscent of the experience captured by Jean-François Lyotard in his 'postmodern fable' entitled 'Marie Goes to Japan' ([1993], 1997, 3-17). Bourdieu bitterly regrets the domination of the 'preconstructed', that is to say the prevalence of structured structures in overriding awareness of the conditions of their construction.

I want now to consider a second cluster of texts. These emerged from the periods that Bourdieu passed in Chicago in the late 1980s. Interviews that Bourdieu had with Loïc Wacquant in the presence of an interdisciplinary group of doctoral students in the University of Chicago in the spring of 1988 were combined with other interviews to constitute the book that was published in 1992 as Réponses: Pour une anthropologie reflexive (Bourdieu and Wacquant 1992a), and published the same year in English as An Invitation to Reflexive Sociology (Bourdieu and Wacquant 1992b). A social theory group had been formed at the Centre for Psychosocial Studies in Chicago in 1983. The group had undertaken discussions of Bourdieu's work. Bourdieu joined these discussions on two occasions, including at a conference from 31 March to 2 April 1989, which led to the publication, edited by Craig Calhoun, Edward LiPuma and Moishe Postone, of Bourdieu: Critical Perspectives (Calhoun et al. eds. 1993), for which Bourdieu wrote a piece entitled 'Concluding Remarks: For a Sociogenetic Understanding of Intellectual Works'. Finally, there is the 'Epilogue: On the Possibility of a Field of World Sociology', which was his contribution to a conference that was held at the University of Chicago from 5-8 April 1989, which led to the publication, edited by Bourdieu and 
James Coleman, of Social Theory for a Changing Society in 1991 (Bourdieu and Coleman 1991).

Again, I just want to highlight a few points and add some contextual detail. The key link between this cluster and the earlier cluster discussed above was the publication of Homo Academicus in 1984. This text was based on research that Bourdieu had undertaken in 1968. In origin it had been a sociology of the intellectual field of Parisian higher education, undertaken as a case study analysis of an intellectual 'field' as outlined in 'Intellectual Field and Creative Project', serving as a paradigmatic exemplification of the kind of reflexivity necessary methodologically within an autonomous epistemic community as advocated within Le métier de sociologue. Between the two periods, however, as we have seen, there was an increased inclination to situate sociologically the producer of the 'field' within his production. It was no longer so much the case that the autonomy of sociological discourse had to be consolidated by a process of internal self-referentiality and self-validation, but rather more that the contingency of that discourse had to be recognized as a function of the social position taking of individuals possessing different amounts and kinds of social and cultural capital. Bourdieu carried over this ambivalent orientation, between consolidating an universal discourse of sociological explanation on the one hand and emphasizing the contingency of the particular conditions of social production of this discourse on the other into the situation in which his local research products were becoming immediately universalized. The publication of a translation of Homo Academicus into English in 1988 by Polity Press initiated a succession of translations of Bourdieu's work into English, sometimes the translation of earlier texts of the 1960s and sometimes the increasingly rapid translation of new texts. It was typical of Bourdieu's thinking in the period that I am calling that of the second cluster, that he should write a preface to the English translation of Homo Academicus that deliberately discussed what should be the appropriate reception in the English-speaking world of a book written about the specifics of knowledge production in French higher education.

For a short period of time, Bourdieu was tempted to try to dominate the field of world sociology, and this was associated with his belief that, politically, the world needed the input of analysis undertaken by international sociologists operating independently of national affiliations in accordance with the norms and values of an international scientific community. There was the same sense that there had been in Le métier de sociologue that adherence to a common methodology could transcend ideological differences. Bourdieu tried to dominate international sociology by outlining a possibility for world sociology conceptualized in terms of his own understanding of the social construction of intellectual discourses. In other words, a surreptitious substantive 
domination masqueraded as a non-ideological, formal domination of unified science. In his own words, Bourdieu stated in his 'Epilogue: On the Possibility of a Field of World Sociology' the questions that he would address in his contribution. These were the following:

Does the sociological universe presently function in a manner of a unified scientific field on a world scale? Is it possible to contribute to the unification of this world sociology beyond the mere 'growth and consolidation of an international scientific community' (Bottomore and Nisbet 1978, xiv), in particular by controlling the purely social effects of domination that are exercised under scientific guises? Is it possible to circumvent the barrier of the nationalisms that hinder the free circulation of ideas and set back the unification of a sociological problematic, that is, the formation of a world-wide space of social-scientific discussion and critique? Is it possible to create such a space of discussion unified around purely scientific questions, rather than to continue to perpetuate the sort of intellectual protectionism fostered by all forms of closure and division into theoretical, methodological, and national traditions and schools? (Bourdieu and Coleman 1991, 374; italics in original)

The new factor in this second cluster, I believe, is that Bourdieu had relinquished the notion of methodological consensus that had been the organizing principle of Le métier de sociologue. Instead, and this is my first main point about this second cluster of texts, Bourdieu sought to embrace the possibility that a world sociology might be constructed on the basis of the articulation of difference. Presenting his contribution explicitly as a reflection on the multinational conference held at Chicago in 1989 to which I have referred, Bourdieu continued that his purpose was

to explicate the full meaning, the scientific raison d'être, of this peculiar scientific gathering. This conference is peculiar inasmuch as it brings together sociologists who belong to different nations, different generations, and especially - very different, even antagonistic, theoretical and methodological traditions, not to mention wide differences in political vision. Indeed, it seems to me that, by convening sociologists who ordinarily do not communicate with one another - and who all too often do not even read one another - by forsaking, if only for a moment, the quasi-ritual strategies of mutual avoidance, mutual ignorance, and, perhaps, mutual contempt that routinely impose themselves upon the occupants of opposed positions in the scientific field, we have thrown one another - and ourselves - a challenge. (Bourdieu and Coleman 1991, 374)

Arguing in his conclusion for the need to construct a space for intellectual dialogue, Bourdieu made his rejection of the quest for consensus quite explicit: 
We must work to build such a space of play not on the basis of moral prescriptions and proscriptions but by creating, as we collectively tried to do with this conference, the social conditions of a rational confrontation aimed at establishing not what Erving Goffman would call the working consensus of an orthodoxy sustained by complicity with the powers that be but at least a working dissensus founded upon the critical acknowledgement of compatibilities and incompatibilities. This space of regulated confrontation can be the fount of the freedom that sociologists can give themselves by collectively working to uncover the most specific social determinations that bear upon the functioning of the sociological field and thus upon their very thinking. (Bourdieu and Coleman 1991, 384; italics in original)

It is this new emphasis on the need to construct a multi-perspectival sociology based on the recognition of difference that is consistent with the second point that I want to draw from the second cluster of articles. This was the period in which Bourdieu began cautiously to issue details of his upbringing and social background. When asked by Wacquant in An Invitation to Reflexive Sociology why he had always shown 'this unwavering reticence to speak about the private person Pierre Bourdieu', Bourdieu replied, consistent with his overall position about the impossibility of producing asocial self-expression,

My sociological discourse is separated from my personal experience by my sociological practice, which is itself in part the product of a sociology of my social experience. (Bourdieu and Wacquant 1993, 203)

Bourdieu proceeded to give some autobiographical hints that were gradually to be released during the 1990s in a genre that is now popularly known as autoethnography, but which, in his posthumous work, Bourdieu called autoanalysis. Alongside Bourdieu's interest in the construction of an autonomous, international field of sociology, therefore, was his commitment to founding international sociology on the basis of prediscursive, anthropological reflexivity and encounter. It is significant that the French title of An Invitation to Reflexive Sociology was Réponses: Pour une anthropologie réflexive, and the kind of encounter that Bourdieu sought in a conference of international sociologists in Chicago in 1989 was followed through in the activation of encounters between advantaged researchers and disadvantaged people shortly afterwards in the early 1990s in La misère du monde (Bourdieu dir. 1993). Bourdieu's turn towards an emphasis of French intellectual particularity and engagement with French political activism in the late 1990s arose partly from a disillusion with the possibility of generating a politically neutral space for international social science but also partly from a conviction that the articulation of the particular was a necessary prerequisite for the production of an inclusive universality. 
These remarks bring me back to the passage quoted above in which Bourdieu condemned the triviality of much conference discussion of 'social theory'. Speaking in 1989, in the same breath, he insisted that it had to be understood that he was working within a French intellectual tradition that was different from the Anglo-American. His opposition was to premature attempts to homogenize social theory, a process that he regarded as one of symbolic violence in which the dominant intellectually coerce the dominated. Bourdieu adopted this position at the time in which he was engaged in dialogue within the developing field of international sociology. He began to offer his personal trajectory and the Frenchness of his thought as his contribution to a process of socioanalytic encounter within this field. He wanted to emphasize that the international field had to be constructed and should not be thought to possess a priori, essential reality. Perhaps the 'preconstructed' began to prevail over his sense of the necessary foundation of fields in relation to diverse primary experiences. We can detect a withdrawal from international conceptual conflict by the early 1990s and the corollary of this withdrawal was the aggressive attempt, which characterized the last decade of his life, to maintain social commitment within France against the incursions of antipathetic neo-liberalism and to espouse the causes of the socially dominated in underdeveloped countries rather than reinforce the perceptions of socially privileged intellectual observers.

\section{Notes}

1 From the evidence of Bourdieu's citations and footnotes, the main exceptions to this point appear to have been his familiarity with the American literature of the 1960s on acculturation (indicated in the bibliography of Sociologie de l'algérie, Bourdieu 1958) and his familiarity with some English work on culture and society (Raymond Williams) and also with Levin Schücking's Sociology of Literary Taste, both apparent from the references in 'Champ intellectuel et projet créateur', Bourdieu 1966b.

2 For further discussion of Aron, Bourdieu and Passeron in relation to the 'events' of May, 1968, see Robbins 2011, in Susen and Turner eds. 2011.

3 For detailed discussion of Rancière's critique of Bourdieu, see Robbins 2015.

4 For an important discussion of this issue that does not mention Bourdieu, see Norris 2000.

5 For a more extended discussion of Bourdieu's move away from dualism, see Robbins 2008.

6 See Boltanski 2008, 15.

\section{References}

Aron, R. 1968. La révolution introuvable: Réflexions sur les événements de Mai. Paris: Fayard.

Boltanski, L. 2008. Rendre la réalité inacceptable. Paris: Demopolis.

Bourdieu, P. 1958. Sociologie de l'algérie. Paris: PUF. 
1959a. 'La logique interne de la civilisation algérienne traditionnelle', in Le sousdéveloppement en algérie. Algiers: Social Secretariat, 40-51, trans. in Bourdieu. ed. Yacine. 2013, 72-82.

1959b. 'Le choc des civilisations', in Le sous-développement en Algérie, Algiers: Social Secretariat, 52-64, translated in Bourdieu. ed. Yacine. 2013, 39-51.

1962a. The Algerians. Boston: Beacon Press.

_ 1962b. 'Célibat et condition paysanne'. Études rurales 5-6: 31-136.

1963. 'La société traditionnelle: Attitude à l'égard du temps et conduite économique'. Sociologie du travail 1: 24-44.

1964a. 'The Attitude of the Algerian Peasant toward Time', in J. Pitt-Rivers (ed.)

Mediterranean Countrymen. Paris/The Hague: Mouton, 55-72.

_ 1964b. Argelia entra en la historia. Barcelona: Editorial Nova Terra.

— 1965. 'The Sentiment of Honour in Kabyle Society', in J. G. Peristiany (ed.) Honour and Shame. The Values of Mediterranean Society. London: Weidenfeld and Nicholson, 191-241.

- 1966a. 'Condition de classe et position de classe'. Archives européennes de sociologie 7 , no. 2: 201-23.

1966b. 'Champ intellectuel et projet créateur'. Les temps modernes 246: 865-906.

1966c. 'I contadini e la fotografia'. Rivista di economia agraria 21, no. 3: 50-8.

1968. 'Structuralism and Theory of Sociological Knowledge'. Social Research 35, no. 4: 581-706.

- 1969a. 'Intellectual Field and Creative Project'. Social Science Information 8, no. 2: 89-119.

— 1969b. 'Il linguaggio nell' apprendimento'. Scuola e città 7-8: 331-4.

1970. 'La maison kabyle ou le monde renversé', in J. Pouillon and P. Maranda (eds.) Échanges et communications: Mélanges offerts à Claude Lévi-Strauss à l'occasion de son 60e anniversaire. Paris/The Hague: Mouton.

197 1a. 'Intellectual Field and Creative Project', in M. F. D. Young (ed.) Knowledge and Control: New Directions for the Sociology of Education. London: Collier-Macmillan, 161-88.

— 1971b. 'Systems of Education and Systems of Thought', in M. F. D. Young (ed.) Knowledge and Control: New Directions for the Sociology of Education. London: CollierMacmillan, 189-207.

_ 1971c. Die Illusion der Chancengleichheit. Stuttgart: E. Klett Verlag

- 1971 d. Sociologia francezâ contemporanâ. Bucharest: Ed. Politicâ.

- 1971 e. 'L'opinion publique n'existe pas'. Noroit, 155.

1972. Esquisse d'une théorie de la pratique, précédé de trois études d'ethnologie kabyle. Geneva: Droz.

1973. 'The Three Forms of Theoretical Knowledge'. Social Science Information 12, no. 1: 53-80.

1975. 'L'ontologie politique de Martin Heidegger'. Actes de la recherche en sciences sociales 5-6: 109-56.

- 1977a. Outline of a Theory of Practice. Cambridge: Cambridge University Press.

1977b. 'Sur le pouvoir symbolique'. Annales 3: 405-411.

1979. La distinction: Critique sociale du jugement. Paris: Éd. de Minuit.

1980. Le sens pratique. Paris: Éd. de Minuit.

1981. 'Décrire et prescrire: Note sur les conditions de possibilité et les limites de

l'efficacité politique'. Actes de la recherche en sciences sociales 38: 69-73.

- 1983a. 'The Philosophical Establishment', in A. Montefiore (ed.) Philosophy in France

Today. Cambridge: Cambridge University Press. 
1983b. 'Vous avez dit “populaire”?'. Actes de la recherche en sciences sociales 46: 98-105. 1984. Homo academicus. Paris: Éd. de Minuit.

1986. Distinction: A Social Critique of the Fudgement of Taste. London/New York:

Routledge and Kegan Paul.

1987. Choses dites. Paris: Éd. de Minuit.

1988. Homo academicus. Oxford: Polity Press.

1990a. In Other Words. Oxford: Polity Press.

1990b. The Logic of Practice. Oxford: Polity Press.

1992. 'Thinking about Limits'. Theory, Culture and Society 9: 37-49.

Bourdieu, P. dir. 1993. La misère du monde. Paris: Seuil.

Bourdieu, P. ed. Poupeau, F. and T. Discepolo. 2002. Interventions, 1961-2001: Science sociale and action politique. Marseilles: Agone.

Bourdieu, P. 2003. Esquisse pour une auto-analyse. Paris: Raisons d'Agir.

Bourdieu, P. ed. Poupeau, F. and T. Discepolo. 2008a. Political Interventions: Social Science and Political Action. London/New York: Verso.

Bourdieu, P. ed. Yacine, T. 2008b. Esquisses algériennes. Paris: Seuil.

Bourdieu, P. ed. Yacine, T. 2013. Algerian Sketches. Oxford: Polity Press.

Bourdieu, P. and M.-C. Bourdieu. 'Le paysan et la photographie'. Revue française de sociologie 6, no. 2: 164-74.

Bourdieu, P. and J. Coleman eds. 1991. Social Theory for a Changing Society. Boulder/San Francisco/Oxford: Westview Press.

Bourdieu, P. and Y. Delsaut. 1975. 'Le couturier et sa griffe: Contribution à une théorie de la magie'. Actes de la recherche en sciences sociales 1: 7-36.

Bourdieu, P. and J.-C. Passeron. 1964. Les héritiers, les étudiants et la culture. Paris: Éd. de Minuit.

1965. 'Langage et rapport au langage dans la situation pédagogique', in P. Bourdieu

J.-C. Passeron and M. de Saint Martin (eds.) Rapport pédagogique et communication. Paris/ The Hague: Mouton, 9-36.

1967. 'Sociology and Philosophy in France since 1945: Death and Resurrection of a Philosophy without Subject'. Social Research 34, no. 1: 162-212.

- 1970a. La reproduction: Éléments pour une théorie du système d'enseignement. Paris: Éd. de Minuit.

— 1970b. Zur Soziologie der symbolischen Formen. Frankfurt: Suhrkamp-Verlag.

1971. Mitosociologia: Contributi a une sociologia del campo intellettuale. Bologna/ Florence: Guaraldi Editore

Bourdieu, P. and A. Sayad. 1964. Le déracinement: la crise de l'agriculture traditionnelle en algérie. Paris: Éd. de Minuit.

Bourdieu, P. and L. Wacquant. 1992a. Réponses: Pour une anthropologie réflexive. Paris: Seuil. 1992b. An Invitation to Reflexive Sociology. Chicago/Oxford: U. of Chicago Press/ Polity Press.

Bourdieu, P., J.-C. Chamboredon and J.-C. Passeron. 1968. Le métier de sociologue: Préalables épistémologiques. Paris: Mouton-Bordas.

— 1991. The Craft of Sociology: Epistemological preliminaries. Berlin/New York: Walter de Gruyter.

Bourdieu, P., A. Darbel and D. Schnapper. 1966. L'amour de l'art: les musées d'art et leur public. Paris: Éd. de Minuit.

1990. The Love of Art. Oxford: Polity Press.

Bourdieu, P., L. Boltanski, R. Castel and J.-C. Chamboredon. 1965. Un art moyen: essai sur les usages sociaux de la photographie. Paris: Éd. de Minuit. 
1990. Photography. A Middle-brow Art. Oxford: Polity Press.

Bourdieu, P., A. Darbel, J.-P. Rivet and C. Seibel. 1963. Travail et travailleurs en Algérie. Paris/ The Hague: Mouton.

Calhoun, G., E. LiPuma and M. Postone eds. 1993. Bourdieu: Critical Perspectives. Oxford: Polity Press.

Derrida, J. 1965. "Genèse et structure” et la phénoménologie', in M. de Gandillac L. Goldmann and J. Piaget (eds.) Entretiens sur la notion de genèse et structure, Paris/The Hague: Mouton, 243-60. 1990. Le problème de la genèse dans la philosophie de Husserl. Paris: P.U.F.

Lyotard, J.-F. 1993. Moralités postmodernes. Paris: Éd. Galilée. 1997. Postmodern Fables. London/Minneapolis: University of Minnesota Press.

Mauger, G. ed. 2005. Rencontres avec Pierre Bourdieu. Broissieux: Éditions du Croquant.

Norris, G. 2000. 'Structure and Genesis in Scientific Theory: Husserl, Bachelard, Derrida'. British Fournal for the History of Philosophy 8, no. 1: 107-39.

Panofsky, E. trans. P. Bourdieu. 1967. Architecture gothique et pensée scolastique. Paris: Éd. de Minuit.

Rancière, J. 2007. Le philosophe et ses pauvres. Paris: Flammarion. 2011. La leçon d'Althusser. Paris: La Fabrique.

Robbins, D. M. 2008. 'Indigene Kultur und Symbolische Gewalt' (Indigenous Culture and Symbolic Violence), in R. Schmidt and V. Woltersdorff (eds.) Symbolische Gewalt. Herrschaftsanalyse nach Pierre Bourdieu. Konstanz: UVK Verlagsgesellschaft mbH, 59-74.

2011. 'Social Theory and Politics: Aron, Bourdieu and Passeron, and the Events of May 1968', in S. Susen and B. Turner (eds.) The Legacy of Pierre Bourdieu: Critical Essays. London/New York/Delhi: Anthem Press, 301-27.

2015. 'Pierre Bourdieu and Jacques Rancière on Politics and Aesthetics: An Historical Comparison'. British fournal of Sociology 66, no. 4. doi: 10.1111/1468-4446.12148 


\title{
Part II
}

\author{
CASE STUDIES OF \\ THE INTERNATIONAL \\ DEPLOYMENT OF \\ BOURDIEU'S THOUGHT
}





\title{
Chapter 5
}

\section{BOURDIEU INSIDE EUROPE: THE EUROPEAN GIRGULATION OF BOURDIEU'S IDEAS}

\author{
Marco Santoro and Andrea Gallelli
}

\section{Introduction}

In his mature life, especially after the eighties and the fall of the Berlin Wall, Pierre Bourdieu was one of the harshest critics of Europe as a political reality, or better as that political reality created and performed in the last decades of the twentieth century as the European Union $(\mathrm{EU}){ }^{1}$

Bourdieu's positions against the EU have attracted much attention among scholars and commentators, and political actors as well. However, Bourdieu's relation with Europe cannot be reduced to his cries and attacks against Brussels, the EU rules, its institutional powers and its economic policies. Europe is much more than its current political embodiment as the EU. Indeed, we could say that in order to fully appreciate his cries and criticisms against the EU we have to investigate Bourdieu's idea of Europe and his life in Europe as both a scholar and an educated man. We could even say that this investigation is a condition for a full understanding of Bourdieu's social theory, as Europe has provided not only a material location for his intellectual work as a writer and a teacher - after all, France is in Europe, and Paris one of the historical capitals of Europe as a cultural entity - but also a strong reference point and a research object. ${ }^{2}$

Bourdieu was clearly a European thinker: a French sociologist and intellectual who had a strong sense of France's embeddedness in a larger space that included not only French colonial possessions in Northern Africa - the first place where he did social research as a young social ethnographer working in a colonial region - but also all the countries sharing with France the common cultural heritage of ancient Greece, Latin Rome, Christianity (Reform included) and the birth of modernity (in the economic, political, intellectual 
and aesthetic fields). In this sense, Bourdieu has never ceased to be an intellectual of the "old Europe" - his intellectual genealogy being rooted in classics of Western (read European) thought as Aristotle, St. Thomas, Thomas Hobbes, Niccolò Machiavelli, Baruch de Spinoza, Gottfried Wilhelm Leibniz, Karl Marx, Edmund Husserl, Émile Durkheim, Max Weber, Martin Heidegger, Ernst Cassirer and so on. As a sociologist, not only was his lineage strongly European but he also had a strong sense of the European roots of sociology to be contrasted with its American subsequent development - a major critical spring of his work being his differentiation from what he called the 'Capitoline triad' of Talcott Parsons, Robert King Merton and Paul Lazarsfeld, chosen as representatives of that mainstream American sociology that hegemonized French (and more generally European) sociology in the decades after World War II. European roots may be larger than these, however. As Raewynn Connell (2007) has argued, Bourdieu's social theory - not differently in this respect from Parsons's and Merton's - is part and parcel of what could be labelled 'Northern theory', the social theory grounded in the historical, political and cultural experience of the Global North whose historical and geographical core is in any case Europe. His foundational work on colonial Algeria and his early 'postcolonialist' attitude notwithstanding, Bourdieu's eurocentric attitude is embedded in his same intellectual and moral education - in his habitus we could say.

A chapter on Bourdieu in Europe could deal with many different topics: Bourdieu's plea for the resurgence of a European brand of sociology against its subordination to American sociology as the globally dominant national field; or Bourdieu's work for the edification of an European cultural space through transnational cultural enterprises - a the journal Liber for example; or how Bourdieu's social theory has been used to make sense of Europe as a new political structure (that is, as the EU). ${ }^{3}$ The focus of this chapter is however another: how Bourdieu and his work have circulated among scholars working in Europe, that is across research centres and academic institutions located in this region of the world. We explore how Bourdieu's social theory has been received and how Bourdieu's toolbox has been deployed by researchers working in Europe. This is clearly a very difficult and even elusive topic, as there is not at present any official European intellectual space and social scientists continue to play on national fields. National research fields are institutionally differentiated, sociologically complex and not easily accessed - also for language reasons. How, how much, when, why and with what effects an author has been used in a specific country are questions that only detailed investigations in situ could hope to seriously address.

In recent years, a fruitful research stream has been developing focused on the international circulation of ideas as a means to study both reputation building 
processes and social mechanisms at work in intellectual production and creativity. Bourdieu's sociological theory has been pivotal in launching this research stream (see Bourdieu 2002), and it is not surprising that his own work and its international circulation have been elected as a major topic of research in this field (for example, Robbins 1989; 2008; Wacquant 1993; Swartz 2006; Sallaz and Zavisca 2007; Santoro 2008; Sapiro and Bustamante 2009; Sapiro 2014). This chapter is firmly embedded in this tradition of research with three specificities: (1) a precise geographical perspective, centred on Europe, providing a general overview and outlining internal differentiation; (2) a content-oriented focus, aimed at identifying how Bourdieu's work has been variously received and adopted across Europe, tracing the links among specific research objects and different national research contexts; (3) the suggestion of some methodological tools for doing social research on the spatial circulation of ideas.

Our approach is strongly empirical: our aim is not to provide a critical interpretation of the many ways in which Bourdieu's texts or ideas have been read and understood in specific countries by selected European scholars (a large literature already exists on this issue: see, for example, Robbins 2008; Gemperle 2008; Callejo 2008; Rahkonen 2008; Bibkov 2009; Santoro 2009; Sapiro 2015), but to map how Bourdieu has been received and used in Europe across countries. To employ a common image, it is a cartography of a social theory that we draft, a cartography not in a metaphorical sense but in its more literal meaning of the study and practice of representing spatial relations among differently located objects.

We proceed in three steps. First, we give some ideas about the structure of the linguistic and spatial distribution of Bourdieu's work through a description of the patterns and timing of translations of his books in European countries. Our main source in this section is Sapiro and Bustamante (2009): even if no longer up to date, their data are still useful to identify deep patterns of reception and circulation whose impact on current intellectual production is supposedly still alive. A closer look at a specific national case - 'a case of the possibles' in the Bachelardian words so beloved to Bourdieu -offers the opportunity to focus on some puzzling aspects of reception processes that risk being neglected or hidden in reconstruction based on quantitative data, which are indeed the main data of our chapter. Second, we focus on the reception of Bourdieu's ideas in and through a bibliometric analysis of journal articles, which are the most influential means of scientific communication. We have identified 3,005 journal articles from Scopus, ${ }^{4}$ the major European database of peer-reviewed periodical literature, containing the word 'Bourdieu' in the title, the abstract or the keywords, 1,559 of which were authored by researchers based in Europe. Even if these articles represent inevitably a selection of what has been written and published on and about Bourdieu from writers working 
in European research institutions, we can assume they are a good proxy at least of the most influential European scientific production on Bourdieu, or using Bourdieu as a key reference. ${ }^{5}$ On this assumption, our third step is to map the relations between European countries and some Bourdieusian key concepts, through an application of network analysis to the same dataset used in the second part. A final section summarizes the main results of this research, locating them in a general consideration about Bourdieu's embeddedness at once in a global and European academic field.

\section{The Diffusion of Bourdieu's Ideas in Europe through Book Translations}

As book translations are a crucial vehicle for the international circulation of ideas in the social sciences and humanities, a look at table 5.1 offers some first indications about the timing and structure of the reception of Bourdieu's work in Europe, from his first book, published in 1958, until 2008. Germany, Spain, the United Kingdom and Italy are the four leading countries in this reception process, with Italy having the primacy in the first period, Germany in the second and Spain the third. Greece figures prominently in this process, as the fifth in the general ranking, and the fourth in the third period, ex aequo with the United Kingdom.

The map of Bourdieu's reception through book translations is clear enough: Germany, Spain, the United Kingdom and Italy are clearly the European countries where Bourdieu's work has been received mostly, at least through the book industry and market. Together they account for more than half (53 per cent) of the translations of Bourdieu's books published in Europe between 1958 and 2008. They are followed by a group of countries typically located at the periphery of the continent, both South (Greece, Portugal) and North (Denmark, Sweden, Norway, Finland). Eastern Europe has generally been less receptive than Western, Southern and Northern, but has not been alien to the circulation process, especially after the nineties. Romania, Poland and Hungary have all been more receptive than Russia. Recent countries of the former Soviet Union (as Estonia, Georgia, Ukraine) and Yugoslavia (Serbia, Slovenia, Croatia) also contributed to the European circulation. Albeit not linguistically autonomous, Belgium and Austria contributed as well. Looking at timing, a few distinctive temporal patterns emerge: the circulation was strong originally in Italy and Germany, remained strong in Germany and increased in both the United Kingdom and Spain (while declining in Italy). The circulation process expanded from the original 8 countries (still in 1980) to 17 in 1995, to 27 in 2008 - with the growing presence of countries from East and South Europe. 


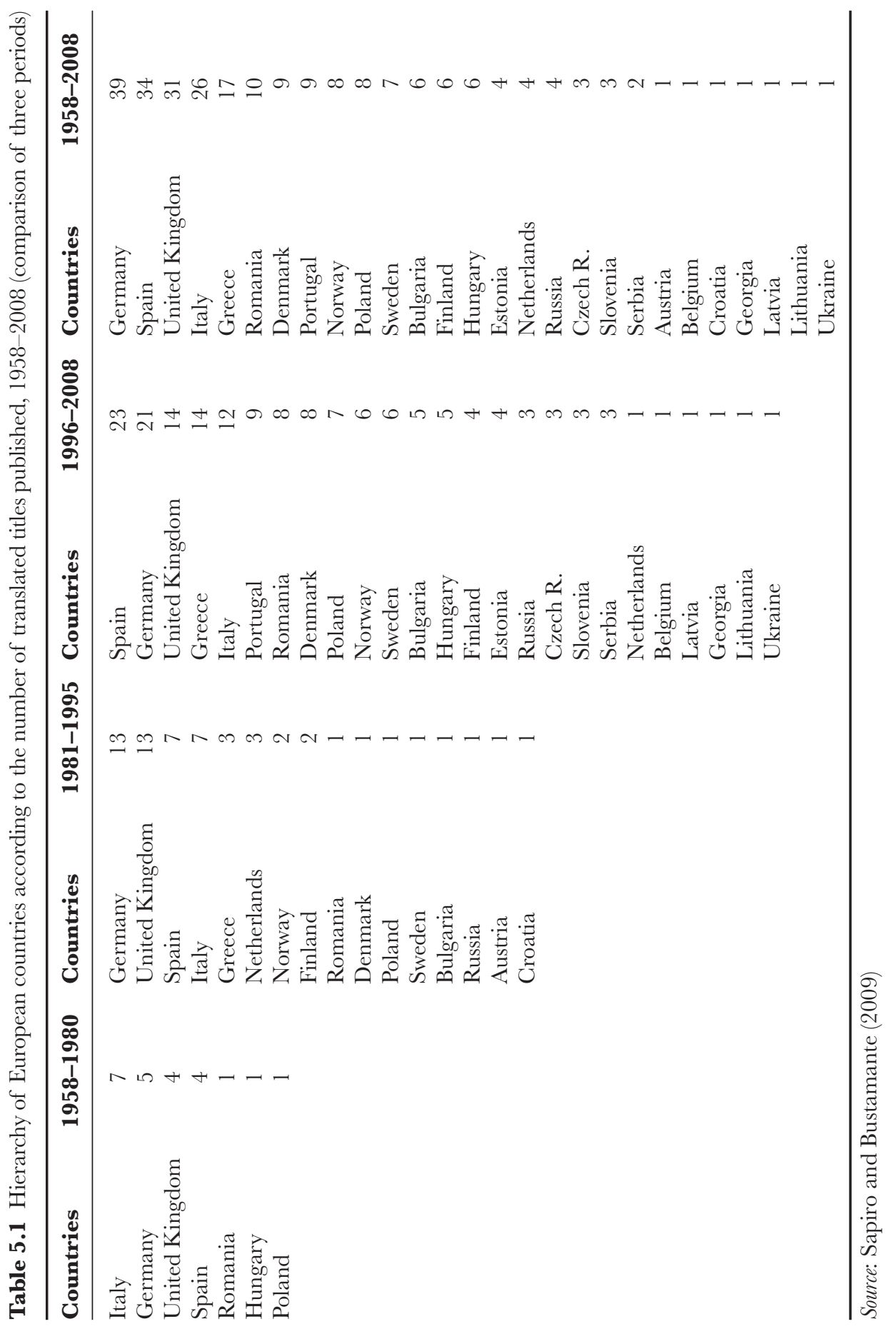




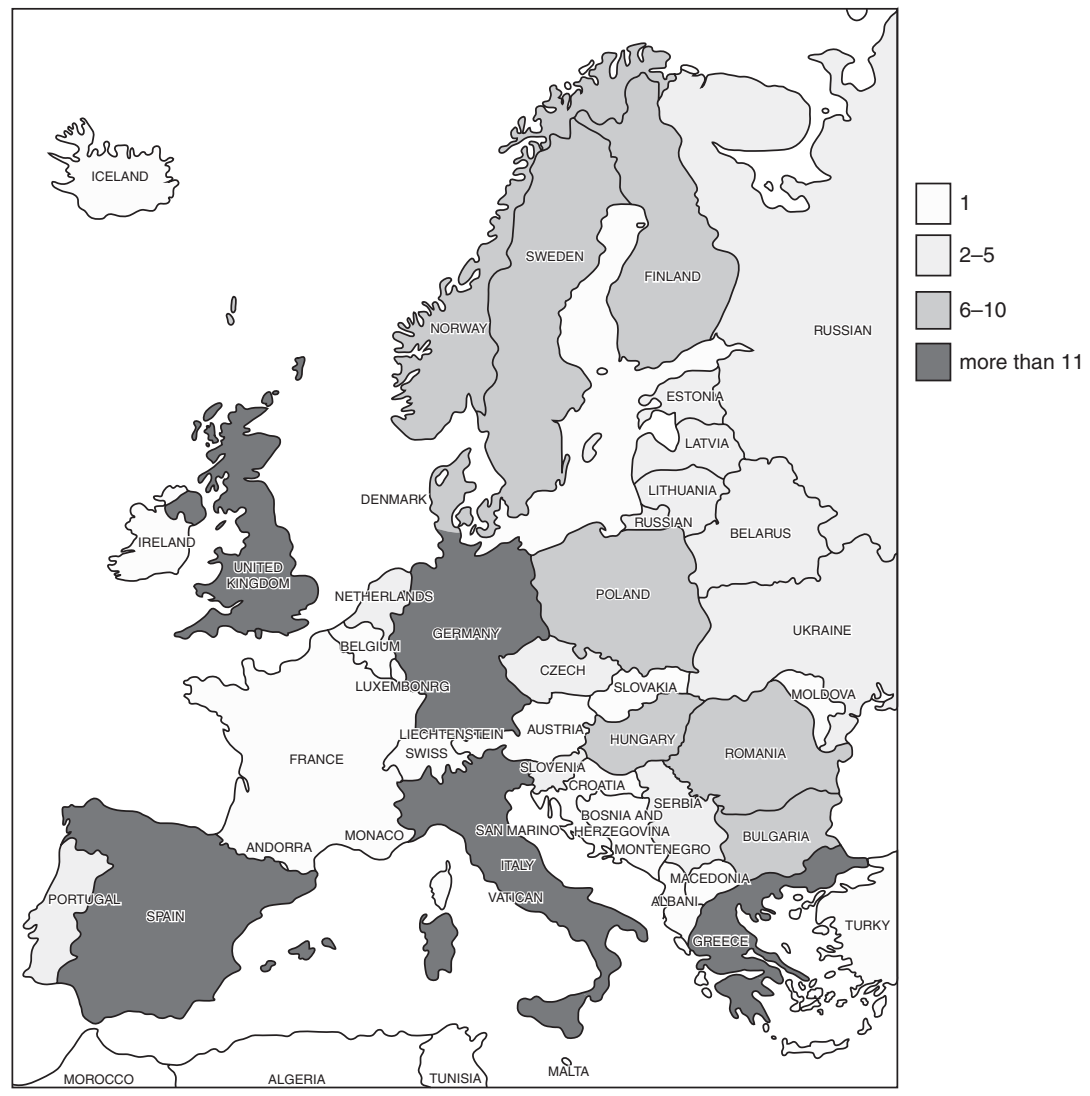

Figure 5.1 A map of Bourdieu's book translations in Europe, 2008

While few European countries have not been involved in this process, the historical geography of translations clearly exhibits trends and inequalities, with Germany, the United Kingdom, Spain and Italy as the most receptive countries in Europe in the international circulation of Bourdieu's ideas at least through book translations (see also figure 5.1). This is a pattern already visible in the early period (1958-1980), and confirmed also in subsequent years with the adding of Greece as the fifth country in the ranking. From a geographical perspective, the pattern may be easily explained in terms of spatial proximity to France, with Greece as an apparent exception. Interestingly, the reception in Eastern Europe started early, albeit with caution. However, Eastern countries figure systematically at the lower levels in the overall rankings - with Romania, Poland and even Bulgaria higher than Russia.

However, the impact of book translations on intellectual reception, concrete research practices and academic production is far from being direct and linear. 
Indeed, it is possible to imagine a situation in which even a wide availability of translated books is not matched by a corresponding adoption in research practices. This is indeed far from being an imaginary situation: this is exactly what occurred in Italy, one of the most receptive countries to Bourdieu's book production (with twenty-six book translations until 2008), where Bourdieu's ideas encountered much difficulty in being received and adopted by scholars working just in Bourdieu's research field, that is, sociology. A closer look at this national case may be of help in setting the scene for the rest of this chapter: as a 'case of the possibles', Italy is indeed a strategic site for where to look regarding the kind of mechanisms and pitfalls at work in reception processes (Santoro 2009, 2014).

The first Italian translation of a Bourdieusian text occurred in 1966: it was a short article originally coauthored by Bourdieu with his wife (whose name disappeared in the Italian edition) on the social uses of photography among farmers. Published in a journal devoted to rural economics, it went unnoticed among sociologists. Education was indeed the field in which Bourdieu first made an impact in Italy, via the translation in 1970 of Les héritiers and a couple of texts included in a successful reader in the sociology of education (Barbagli 1972). Between 1969 and 1976 a series of books were published introducing in this manner Bourdieu's work in its many facets - with the notable exception of anthropology, in Italy a small and weak disciplinary field where Bourdieu's praxeology had to wait until the new millennium to be seriously noticed. Published by a small militant publisher (firmly located on the left) and promoted by a then young, and militant sociologist (Giovanni Bechelloni), these books undoubtedly made the name of Bourdieu well known among the new generation of sociologists who were trying in the seventies to give new substance and an institutional basis to the discipline that had only recently become accepted in the academic system (the first chair in sociology dates back to 1950, but it was only during the sixties that a field of sociology began to develop and coalesce). Strongly associated with critical and radical sociology, when not to some brand of (neo-)Marxism, Bourdieu's name followed the destiny of both with the end of mass mobilization and the intellectual demise of Marxism.

In the eighties, Bourdieu's name and especially his style of research and set of concepts almost disappeared from the horizon of Italian sociologists. This notwithstanding the publication of the translation of La distinction in 1983 (only four years after its French edition, and one year before its English translation) for what is probably - and surely was at the time - the academic publisher with the greatest amount of symbolic capital in Italy, Il Mulino. With apparently idiosyncratic textual cuts, with no iconic apparatus, without any introduction or preface (by Bourdieu himself or some local scholar), the book 
started a kind of schizophrenic life with a persistent market success decoupled from intellectual impact, especially apparent in the sociological field. The story of Bourdieu's reception in the last two decades of the twentieth century is one of substantial exclusion not only from the local mainstream - ever and ever oriented towards that mix of methodological individualism and rational action theory to which are associated the names of Raymond Boudon, John Goldthorpe and Jon Elster - but also from any systematic association with a publisher or an intellectual circle. Book translations continued to appear, even if at a slower pace, from many different publishers, usually without any editorial or intellectual strategy behind them.

The first signs of an inversion in this trend appeared in the new millennium, with the discovery of Bourdieu as a sociologist of arts and culture - two research areas that for a long were at the margins of the national academic field but that began growing, starting in the nineties, reaching maturity in the first decade of the 2000s. But it was through exposure to Anglo-American scholarship that a new generation of scholars had a new chance to meet Bourdieu - usually in English even before in Italian translation or in French. To explain this marginality at least three factors should be mentioned. The first is the strong bias against the 'structuralist' (objectivist) approach rooted in the Italian intellectual habitus - at least since Benedetto Croce's dominance of the intellectual field in the early decades of the twentieth century - and the correlative appeal of more 'subjective' approaches such as phenomenology on the more humanistic side and rational action theory on the would-be scientific, or scientist, side. The second is the original imprinting on postwar Italian sociological theory of what Bourdieu ironically labelled as the 'Capitoline triad' of Parsons, Merton and Lazarsfeld. Indeed, it has long been difficult for people who had been educated as sociologists through the teaching of these mainstream US sociologists to come to terms with a social theory that presented itself as alternative to them. The third factor is the legacy of an indigenous brand of realist and critical social theory that at least in part anticipated what Loïc Wacquant called Bourdieu's political sociology of symbolic forms - scholars like Vilfredo Pareto and Antonio Gramsci, that is, what is internationally known as the Italian elitist school. Bourdieu never referred to this Italian scholarship as a source for his own intellectual project, and famously negated any possible intellectual link with Gramsci's ideas on hegemony, possibly the strongest antecedent to Bourdieu's notion of symbolic power. Bourdieu's reluctance to discuss his links with these Italian authors has had less impact however than the sense of déjà vu that the average Italian social scientist feels when reading Bourdieu, which is especially difficult to manage as Pareto and Gramsci in Italy have for some time become much less sources of sociological ideas than objects of historical research in the field of 
political philosophy. This explains why Bourdieu has found in Italy an audience in the humanities - literary criticism as well as philosophy and history which is maybe still wider than in the social sciences. Even today, Bourdieu is however more like a 'guest' - not especially welcomed or regarded (Salento 2010) - than a central intellectual reference for Italian social scientists.

If Italy probably represents an extreme case of mismatch between reception through translation (that is, through the publishing market) and intellectual reception (in the intellectual and academic field), other countries experienced an analogous mismatch in a different, if not inverted, form. This seems to be the case of Norway, where it is possible to illustrate the reception of Bourdieu among scholars insisting on the impact of the first English translations on local production - and this notwithstanding the (few) translations in Norwegian available at least since the eighties. With the number of book translations up to 2008 amounting to only eight (less than one-third of the Italian ones), Norway has been much more receptive to Bourdieu's ideas and, especially, methods than Italy. Suffice to say that no research project has ever been pursued in Italy similar to Lennart Rosenlund's work on Stavanger, the 'oil capital' of Norway, possibly one of the best studies of urban space in the whole Bourdieusian tradition, which later inspired and was used as a template for other Scandinavian lifestyle and Distinction-like studies (compare Rosenlund 2000, 2009), and that multiple correspondence analysis (MCA) is an exotic method of data analysis for Italian social scientists, still much more attuned with (loglinear) regression analysis than with any other technique including network analysis. Nobody in Italy has attempted to map the structure of the field of power as did Hjellbrekke et al. (2007; see also Denord et al. 2011) in a research project developed through collaboration with French scholars who had been working within the Bourdieusian tradition for some time. Even if Norway has clearly a much smaller academic field than Italy, the gap between the two experiences of reception is remarkable.

In sum, as we have tried to show with these two selected European case studies, book translations only imperfectly can be used as proxy for evaluating and mapping the international circulation of ideas, for which we would do better to look for other indicators and sources.

\section{The Girculation of Bourdieu's Ideas in Europe through Scientific Journals}

In order to evaluate the circulation of Bourdieu's ideas among European scholars we have chosen to focus on how Bourdieu has been referred to in scientific journals by scholars working in Europe (that is, in European research centres and institutions). The source for our inquiry is the Scopus database, from which 


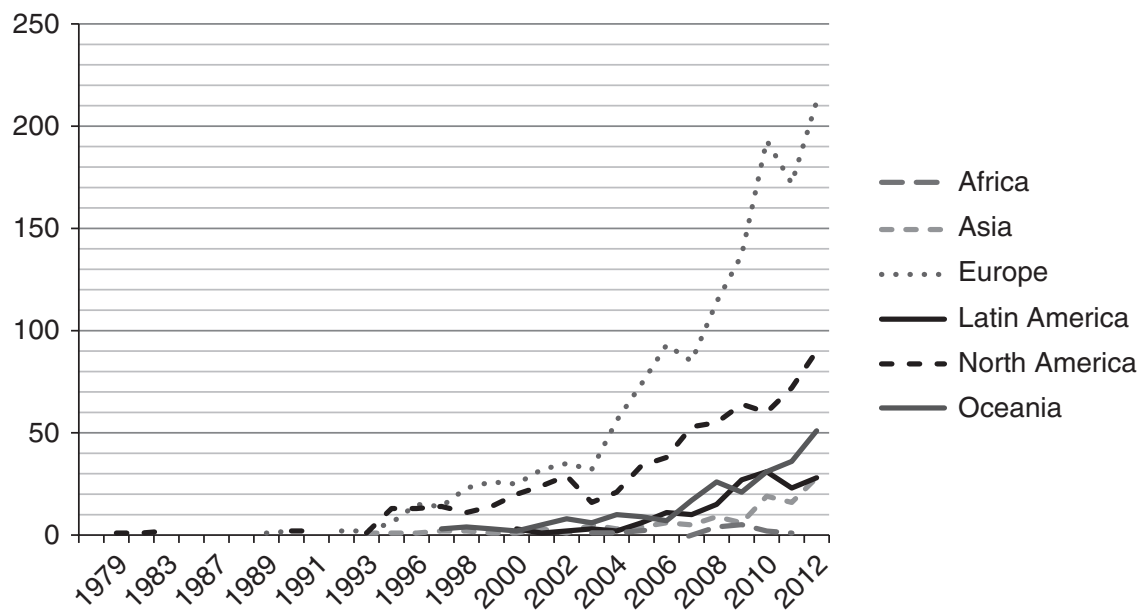

Figure 5.2 Number of articles on Bourdieu by continent, 1979-2013

Source: Elaboration from Scopus

we have extracted a dataset that comprises all the journal articles containing 'Bourdieu' in the title, the abstract or the keywords $(\mathrm{N}=3005)$. Figure 5.2 shows the distribution of those articles, from 1979 to 2013, distinguishing between those written by scholars working in Europe (that is, with a European professional location) and scholars active in other continents in the world.

According to these bibliometric data, the international scientific recognition of the French sociologist did not start until the middle of the nineties. Even if many of the most relevant of Bourdieu's books were translated relatively early in other languages (especially in German, Italian and English, as we have seen in the previous section), the reference to Bourdieu's ideas as a topic in itself or as a central research tool for social scientists is a matter of the last decade of the millennium. Not surprisingly, Bourdieu's sudden death in 2002 acted as a catalyst for the massive and ever-increasing circulation of his theory and conceptual repertoire, and this was the case all over the world. As figure 5.2 clearly shows, the circulation of Bourdieu through scientific journals (and among academically oriented or based scholars) has, however, been greater in Europe than elsewhere, including North America and therefore the United States. Indeed, it seems the reception started in North America, advanced for a few years jointly in both North America and Europe and then found a strong increase in Europe. As a result, almost 50 per cent of the total number of articles published all over the world between 1979 and 2013 have been authored by European (or Europe-based) scholars, three times the number of the articles published by US scholars (see table 5.2). 
Table 5.2 Articles with 'Bourdieu' in the title, the abstract or the keywords, by regions and number of citations

\begin{tabular}{lrr}
\hline & Articles & Citations \\
\hline Europe & 1559 & 12498 \\
United States & 524 & 10424 \\
Australia & 226 & 1373 \\
Canada & 191 & 2517 \\
Brazil & 138 & 157 \\
New Zealand & 40 & 305 \\
South Africa & 30 & 140 \\
Israel & 21 & 127 \\
Turkey & 16 & 38 \\
Argentina & 14 & 13 \\
Mexico & 14 & 28 \\
Hong Kong & 13 & 69 \\
Singapore & 13 & 50 \\
China & 12 & 14 \\
Taiwan & 12 & 19 \\
South Korea & 9 & 36 \\
Other & 56 & 143 \\
Missing & 117 & 483 \\
Total & 3005 & 28434 \\
\hline
\end{tabular}

Data show that the distribution of these articles in Europe (figure 5.3) is strongly unbalanced, with researchers based in the United Kingdom producing over 50 per cent of the total scientific production on, or using, Bourdieu. The remaining 50 per cent is unequally distributed among all the other countries, with a prevalence of, in order, Germany, France, Denmark, Spain, the Netherlands, Sweden, Norway, Belgium, Finland, Ireland, Switzerland, Poland, Austria, Portugal, the Czech Republic, Italy, Croatia, Lithuania, Russia and 2.4 per cent of other countries having less than five articles.

What these data say is that the scientific literature currently available on Bourdieu or about Bourdieu is mainly European, and especially British. The United Kingdom committed to the discussion of Bourdieu's ideas more than did the United States. However, taken together, the United Kingdom, the United States and Australia account for 50 per cent of the global production of articles on or about Bourdieu. These data tell a simple story. It is a story of a massive diffusion and spread of a sociological work across countries including smaller and peripheral ones, where a few have a leading role - typically English-speaking countries - but where a large cultural area emerges among the others as the pillar of Bourdieu's circulation, and this is Europe. In any case, even if Bourdieu's theory and concepts are widely diffused in European 


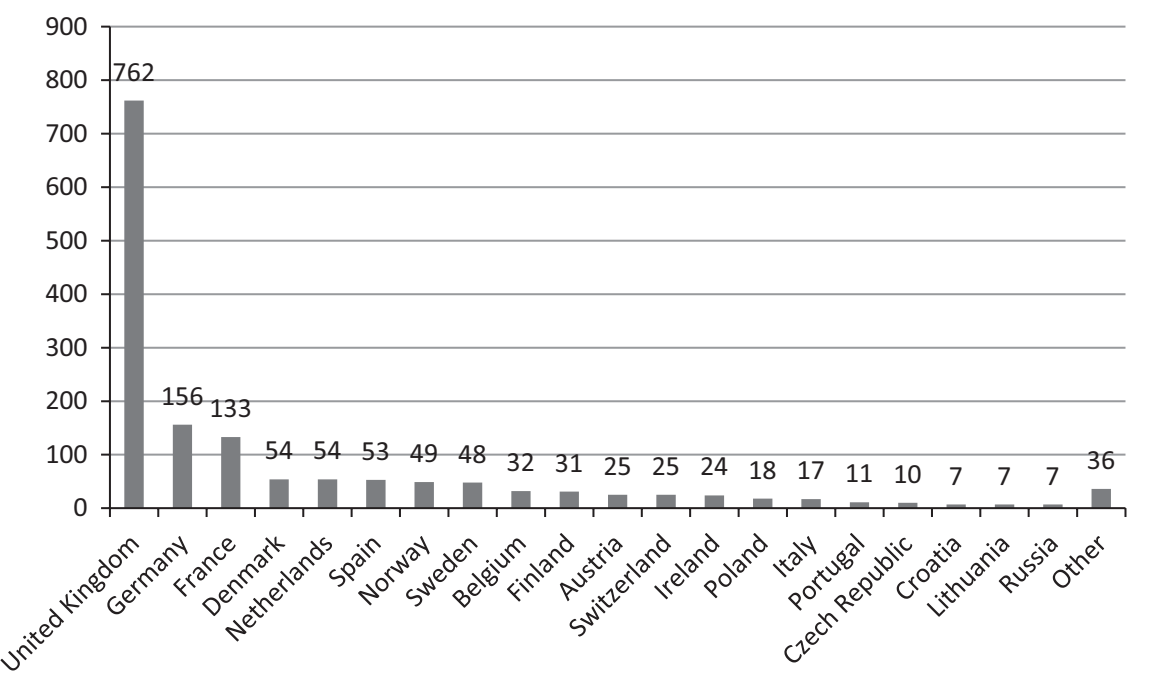

Figure 5.3 Distribution of articles on Bourdieu, by European countries Source: Elaboration from Scopus

social sciences and humanities, their reception is not uniformly distributed throughout the continent's countries. Such an imbalance is of course predictable as European countries are highly differentiated in their scholarly communities (surely by size) and in their rate of scientific production. But the varied reception of Bourdieu across different national contexts has to do also with less evident and banal mechanisms of circulation.

Articles on an author or that make use of an author's ideas are certainly a crucial vehicle for the circulation and reception of that author. We know, however, that articles are not equal in their circulation and that some are more influential than others. Also the citations of articles that name Bourdieu are therefore indexes of his international circulation. In other words, we can have an indirect measure of one author's recognition - and some ideas about a crucial mechanism at work in circulation processes - through the number of citations received by the articles using him or her as a key reference. All the selected articles (worldwide) get a o total number of 27,471 citations. Just for the sake of comparison with other influential European social scientists, the $(2,261)$ articles on/about Jürgen Habermas indexed in Scopus total 10,249 citations, those $(\mathrm{N}=750)$ on/about Anthony Giddens 5,580, and those $(\mathrm{N}=767)$ on/about Norbert Elias 1,382. This is a simple but effective measure of the massive reception of Bourdieu in the global academic field. In figure 5.4 the two curves represent the citations of European and non-European articles (that is, authored by authors based in European or non-European institutions, 


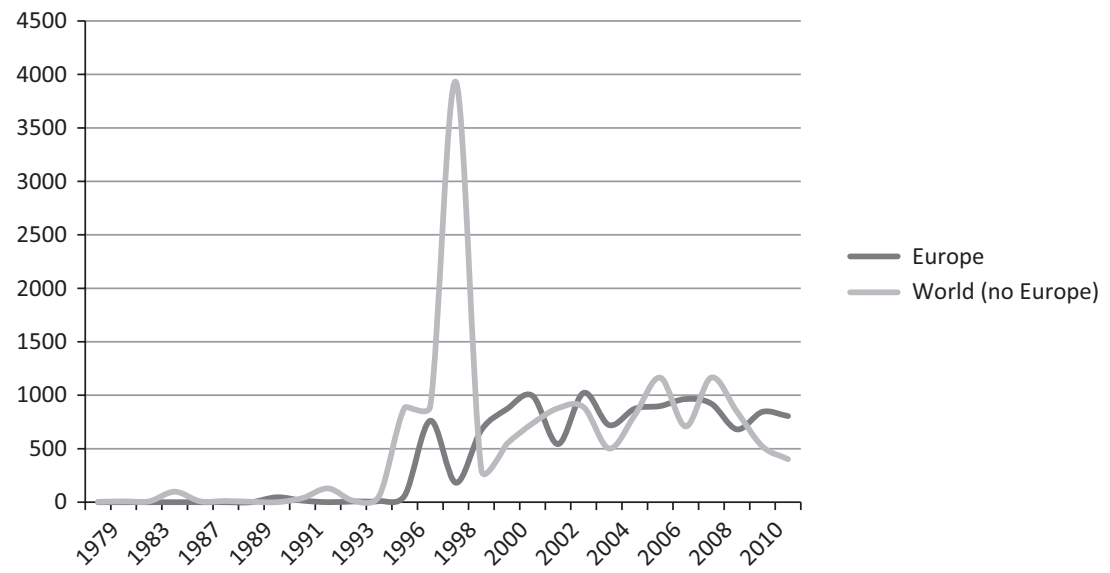

Figure 5.4 Number of citations of articles with 'Bourdieu' in the title, the abstract or the keywords, 1979-2011, by year of article's publication

Source: Scopus

respectively). ${ }^{6}$ Surprising at first sight is the peak of 4,113 citations received by the articles published in 1998. Actually this data comprise the 2,727 total citations of just one article, Alejandro Portes's Social Capital: Its Origins and Applications in Modern Sociology, published in the Annual Review of Sociology - an article that has had a crucial impact on the many scientists working on this topic. Portes introduced Bourdieu's contribution to thinking on social capital, which, at the time, was relatively misrecognized at least in comparison with other more acknowledged contributors, such as Robert K. Putnam and James Coleman. Apart from this exception, during the first decade of the new millennium the European scientific production in the social sciences that used Bourdieu as a key reference generated a number of citations between 500 and 1,000 each year. ${ }^{1}$

Europe and the United States have the same number of citations and cover almost half the number of total citations each, but Europe counts three times the number of articles of the United States, which look therefore much more 'productive' or efficient in their capacity to be quoted and therefore to circulate in turn (table 5.2). In the international circulation of Bourdieu, in sum, the production of scientific papers is not proportional to consumption, and scholars located in the United States who have written on Bourdieu have many more chances to be quoted by other scholars than European scholars. A similar imbalance exists between Australia and Canada, where the former is more productive but the latter is more cited, and the same occurs between Brazil and New Zealand. We have here a clear index of how strong is the effect of 
the language - a veritable form of capital in itself - in which the articles are written. Indeed, the major part of the citations to European articles are those written not only in English but specifically by United Kingdom-based scholars (71 per cent). This means that if the landscape of the production of articles using Bourdieu's work in Europe has its major centre in the United Kingdom, the consumption, so to speak, of that work is even more skewed in favour of the more productive country - something like a Matthew effect at the ecological level. This imbalance is indeed a major structural feature of the global academic field, where a few countries occupy central positions, while others occupy either (semi)peripheral or marginal ones. As our data clearly confirm, among these marginal countries there are many European ones.

As Bourdieu emphasized, the international circulation of ideas does not occur in a social vacuum, but through social processes and in a social space a structured space made of positions and relations among positions. Book translations never simply happen: they are embedded in social relations linking agents in and across national fields. The same is true for scientific articles of course. There are some individuals who act - with different degrees of consciousness - as brokers, as bridges, as vehicles among authors and scientific communities in the circulation processes. Thus, we can use the number of articles (on/about Bourdieu) produced by each author and the citations that these articles have received, as indicators of the authors' relevance as players in the process of diffusion of Bourdieusian work and concepts. It may happen of course that an author publishes one single paper, which obtains in time many citations. A case in point is United States-based sociologist Portes, whose article on social capital is the most cited in our whole database: with this article specifically devoted to tracing the genealogy and assessing the value of the notion of social capital, Portes indirectly contributed to the circulation and even recognition of Bourdieu's name, especially among scholars working in that research field. According to our data, however, this article is the only one authored by this scholar explicitly referring to Bourdieu (in the keywords). This comes as no surprise, as Portes is hardly a follower or even a supporter of the brand of critical sociology Bourdieu professes and practices. But there are other authors, some of them working in the European context, who never reached the peak of citations gained by that article but whose name is recurrent among the authors of articles having Bourdieu as a key reference (in the title, the abstract or the keywords). In sum, an author may be very productive in what we may call 'the Bourdieusian field' but be comparatively less cited. That is the case of Wacquant, a former student of Bourdieu in Paris, $\mathrm{PhD}$ in sociology at the University of Chicago, currently professor at the University of California, Berkeley, and researcher at the Centre européenne de sociologie et de science politique in Paris. With 21 articles, he is the most recurrent author 
in our general dataset. As a Frenchman based in the United States, he should not be counted among European scholars according to our definition - but he still hold positions in Paris and therefore we included him. He is followed by three British scholars: sociologist Will Atkinson, currently lecturer in social research at the University of Bristol (11 articles); Mike Savage, a professor of sociology formerly at the University of Manchester and the University of York, and now at the London School of Economics, and a leading sociologist in the field of social stratification and cultural sociology (10 articles); and Diane Reay, a leading sociologist of education at Cambridge University (7 articles).

Having a high score of citations in just one pertinent text (having a hit, we may say) cannot be enough for being recognized as a key agent in the circulation process - or at least cannot be considered the only factor at work in the process. We therefore calculated a simple index, multiplying the citations for the number of articles, so that both dimensions are kept into account as measures of the impact in the circulation of Bourdieu's work. We report in table 5.3 a list of authors that, for the number of articles they wrote and the number of citations they gain, may be considered as key agents in the global academic field with respect to Bourdieu's reception and circulation. Ten out of twenty authors work in European universities or research institutions, especially British ones. Data still show that European scholars may publish more on Bourdieu, but that non-Europeans, and especially US researchers, may have more impact with fewer papers of greater success. A closer look at the table is however necessary, as these author names may still offer some information. First, at least one of the United States-based scholars comes indeed from Europe. ${ }^{7}$ Second, looking for specialties, we could notice a concentration of scholars working on education (Reay, Mills, Rawolle, Hardy, Dumais), followed by scholars working on culture (Atkinson, Crossley, Lizardo), inequalities (Wacquant, Savage), management (Levina, Vaast, De Clercq), medicine (Carpiano), marketing (Holt) and social theory (Robbins, but also Wacquant, Savage and Lizardo). Except for Wacquant, who prefaced a few book translations and even authored a book with Bourdieu (Bourdieu and Wacquant 1992), and Derek Robbins, who has devoted a large part of his intellectual career to introducing Bourdieu to an Anglo-American audience through books and conferences, the list does not include a few crucial scholars whose names are commonly associated with Bourdieu's international circulation in the Englishspeaking world, such as John B. Thompson, Paul Dimaggio, Rogers Brubaker, Craig Calhoun and, more recently, George Steinmetz, Alan Warde and Philip Gorsky. Indeed, this happens for diverse reasons, including the fact they have worked on Bourdieu mainly as editor(s) of books devoted to him or his legacy (see, for example, Thompson 1993; Silva and Warde 2012; Gorsky 2014) or 


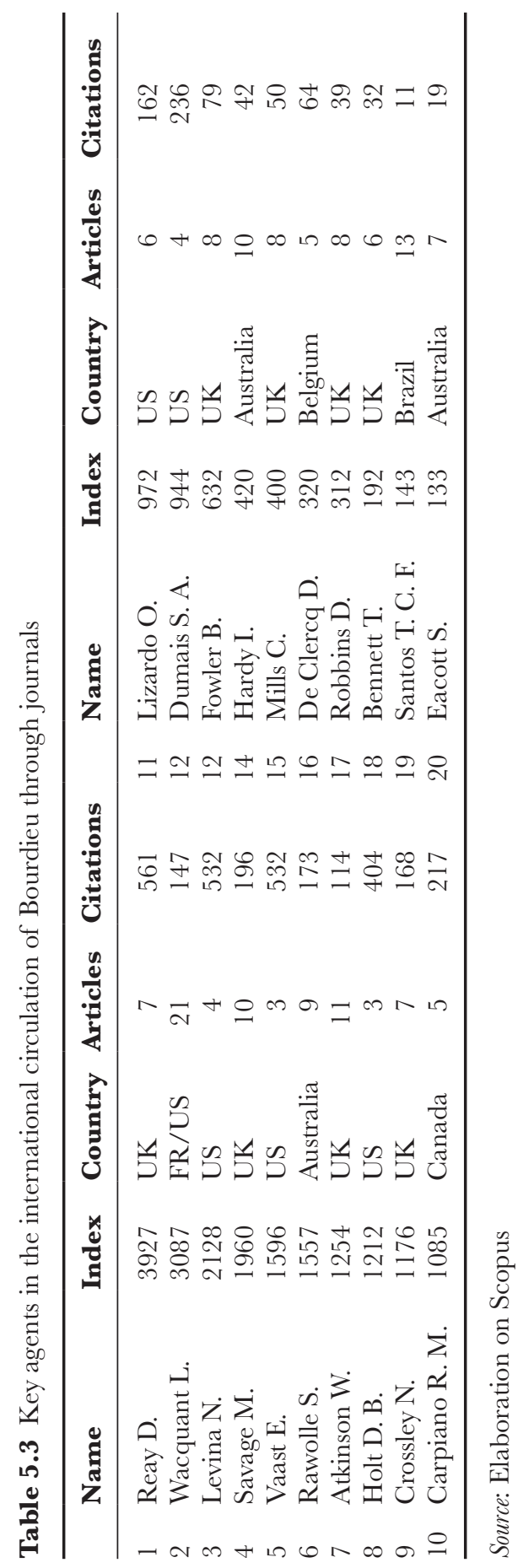


the number of published articles on Bourdieu coupled with their citations are not enough to gain the first twenty positions. ${ }^{8}$

Along with individual scholars, journals are central vehicles of scientific circulation. Indeed, we may speculate they are still more relevant, as journals exist as institutions and their impact on the social world is both deeper and more durable than are individuals. Table 5.4 ranks the first 25 journals in our general dataset ( $N=3005$ articles) according to the number of articles published and the first 25 journals according to the number of citations received. Once again journals published in Europe total fewer citations than journals published in America. In Europe, the United Kingdom is the most recurrent country - with 13 journals - followed by Germany (two) and the Netherlands (in both cases they are journals located in the Netherlands but run also from the United States). We have to notice that one European journal at least - the Italian based Sociologica: Italian Fournal of Sociology online ${ }^{9}$ - does not figure in this list notwithstanding its active involvement in the 'Bourdieusian field' by hosting a special symposium on Bourdieu's global circulation in three parts (and issues), as well as by publishing articles and a forum devoted to discussing Bourdieu's concepts such as cultural capital (for example, Goldthorpe 2007) and distinction (for example, Warde 2008; Lizardo 2008). Paradoxically, the journal founded in 1975 and directed by Bourdieu until his death, Actes de la recherche en sciences sociales, which is still the journal of the Centre de sociologie européenne, does not figure in the list as our dataset comprises only eight articles published in this journal. This happens probably because it would be pleonastic to refer to Bourdieu (in the title or the abstract or the keywords) in a journal strongly inspired and driven by Bourdieusian ideas.

These data confirm what we already suspected, which is the central role played by journals located in a few countries, especially English-speaking countries, in the international circulation of Bourdieu's ideas - a common pattern in the realm of the social sciences in general. British journals contribute more than American ones to the overall production of articles on Bourdieu, even if they are less cited than American ones. Journals located in non-English-speaking countries, as Theory and Society and Poetics (both based in the Netherlands), figuring in our list, are indeed partially run from the United States and are published in English. Only three journals disconfirm the rule: two German sociological reviews (publishing in German), and one Brazilian journal devoted to nursing (publishing in Portuguese). A look at the title of the journals says a lot about the disciplines where, and through which, Bourdieu's ideas circulate: sociology is clearly the central one, followed by transdisciplinary formations such as cultural studies, sport studies and educational studies. Education is indeed prominent also inside sociology (at the top is an influential journal in the sociology of education), followed by the 


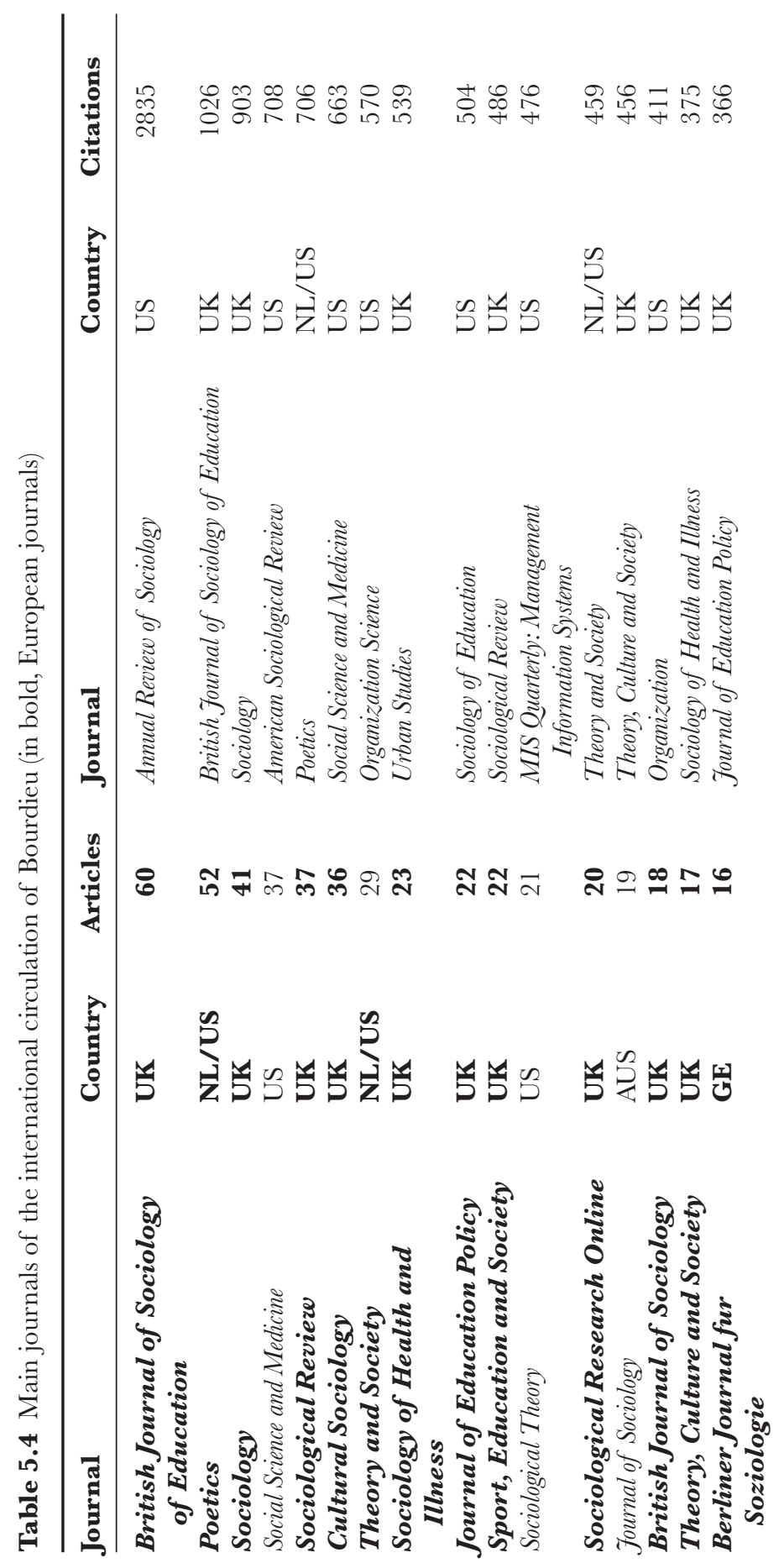




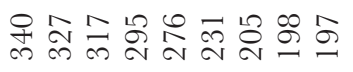

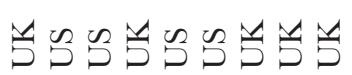

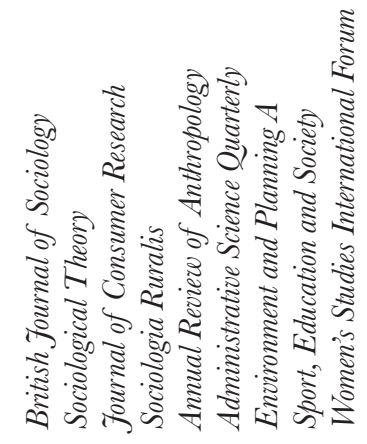

붑므묨ำ

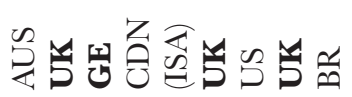

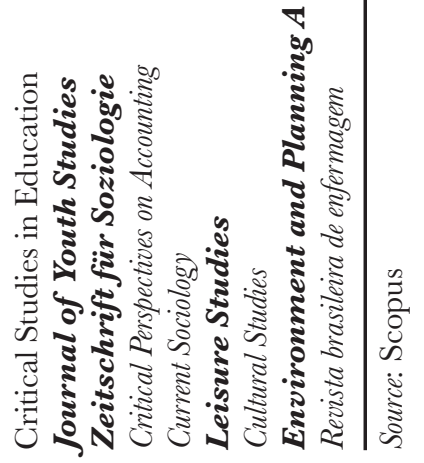


Table 5.5 Number of articles and relative citations by language different from English (only European countries)

\begin{tabular}{lcc}
\hline Language & Articles & Gitations \\
\hline German & 109 & 179 \\
French & 80 & 79 \\
Spanish & 39 & 10 \\
Portuguese & 24 & 14 \\
Groatian & 8 & 1 \\
Czech & 8 & 7 \\
Dutch & 8 & 12 \\
Italian & 8 & 0 \\
Polish & 8 & 1 \\
Lithuanian & 7 & 0 \\
Norwegian & 5 & 1 \\
Slovenian & 5 & 3 \\
Swedish & 4 & 1 \\
Romanian & 3 & 0 \\
Slovak & 3 & 0 \\
Serbian & 2 & 1 \\
Hungarian & 2 & 0 \\
Estonian & 1 & 0 \\
Russian & 1 & 0 \\
Total & 323 & 309 \\
\hline
\end{tabular}

sociology of culture, of the arts and medical sociology. These are clearly the most receptive research areas to Bourdieu's ideas in Europe, even if it is noteworthy that elsewhere they have an impact also on accounting.

To deepen our knowledge of Bourdieu's circulation in Europe we have to focus on countries other than the United Kingdom and especially on languages different from English: this is indeed the space where the circulation of ideas occurs just at the local level. Table 5.5 gives us some useful information. First, it confirms the primacy of German as the linguistic vehicle of Bourdieu's ideas in Europe - more than Spanish and even French. Scholars located in Germany, in Austria and in Switzerland adopt this language, which may thus benefit from a kind of transnational diffusion that may also benefit French (with Belgium as well as French Switzerland as other Francophone countries besides France). Greek is notable for its absence - and this notwithstanding the wide availability of Bourdieu's books in translation (see table 5.1). Still, the relative high ranking of a few East European languages, such as Croatian, Czech and Polish, is to be noted, especially because a database like Scopus inevitably reflects the state of disciplines as they exist at the intersection of the national and the international level. Some countries and languages are much 
more represented in the database because of their stronger or more central (or less peripheral if you prefer) participation to the international market of ideas, and this is not necessary a function of the status of the pertinent disciplines in those countries. The relative underrepresentation of East European journals in the Scopus database - itself an effect of both the relative marginal status of sociology in some (but not all) of these countries and of their limited international orientation - has to be considered when reading these data. ${ }^{10}$

In the previous analyses we observed a sort of mismatch between the dimension of the production and the dimension of the consumption of scientific products focused on Bourdieu. There is a Matthew effect regarding the United Kingdom, which is the country with 50 per cent of the European scientific production on Bourdieu and it gets 70 per cent of the citations. Moreover, we saw a polarization between European and American scientific journals: while European ones host most of the material concerning Bourdieu's work, the articles published in American journals gain most of the recognition in the scientific community.

\section{The Girculation of Bourdieu's Key Concepts in the European Field of Scientific Journals: A Network Perspective}

So far we have analysed the reception of Bourdieu's work in Europe looking at some dimensions such as the diffusion of articles on and about him with their citations in time, their distribution by countries and languages, the presence of key authors acting as brokers and a focus on the main journals involved in the reception process. In this section we propose a further step, focusing on the content of the articles using Bourdieu's theory and concepts. We want to see whether there exist associations between specific research objects and national contexts: are Bourdieu's ideas equally received in the European space or are there local peculiarities in the ways in which his ideas have been read and used by locally based scholars? Are there national or even supranational patterns of reception with respect to Bourdieu's work and its circulation across Europe? The diffusion and reception of intellectual ideas do not spread uniformly within space, and allowing these relations to emerge from data reveals differences at the national level in the reception of Bourdieu's concepts and at least in part in scientific production based on Bourdieu's work.

We utilize network analysis (Scott 1991; Hanneman and Riddle 2005) to capture the relations among the countries and the keywords associated with each paper, in order to verify the presence of relational patterns linking concepts as research objects or theoretical domains with specific national fields. We can interpret this relational space as a two-mode network (Borgatti and Everett 1997). This is a particular form of network in which ties are observed 


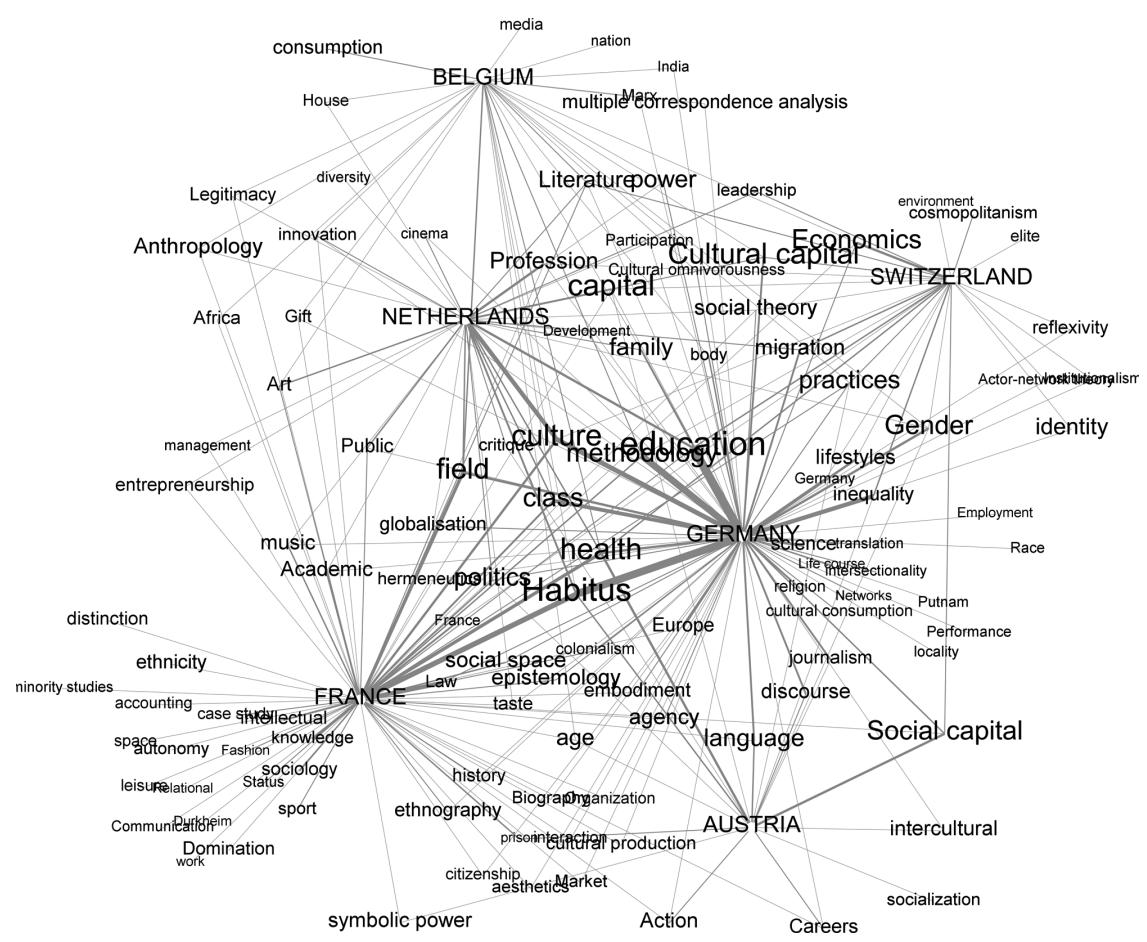

Figure 5.5 Two-mode network of keywords in central European countries

between two different kinds of objects, in our case keywords and countries. We selected all the keywords (up to five per paper) associated with each article in our dataset and after some elaboration we came to identify a list of 156 master keywords that figured at least five times in the Scopus dataset. ${ }^{11}$ For each article we registered a tie between the keywords and the country in which the author is based. As a result, we constructed a social space in which all the different research objects are related to all the countries. This procedure has the advantage of providing a double relational perspective. When we observe the social space made by the relations between keywords and countries, we are indirectly observing also the relations among the countries, and the relations among the keywords. When two different countries are tied to the same concept, they are in turn connected to one another, and we can say that two countries have a research topic in common, and if one country uses two different concepts, the latter are tied to one another by the fact of sharing a country.

For illustrative purposes, figure 5.5 offers a graphical representation of this relational space for the countries of Continental (Western) Europe. 
Countries are tied through their shared keywords, whose dimensions are proportional to the times they have been used in the whole dataset. The thickness of the lines expresses, in network language, the strength of the tie between two nodes, and gives an idea of how many articles (containing the word 'Bourdieu' in the title, the abstract or the keywords) have been published by researchers working in that specific country on that specific topic.

From this information we know that there are some themes and concepts, such as habitus, education, field, culture, health and social capital, which are the most used in the countries under observation. We can also see that some of these themes are strongly tied to some countries, such as field and habitus for France; education, methodology and culture for Germany; social capital and health in Austria; and culture in the Netherlands. Furthermore, the very added value of such an analysis is that we can clearly observe the research objects in common among the countries, highlighting patterns of similarities and specificities among the different national research programmes in the international reception of Bourdieu.

Many of the most important concepts of the Bourdieusian repertoire are, predictably, common to the research agenda of all the countries observed, but with some peculiarities at the local, that is, national level: social capital figures in France, Germany, Austria and Switzerland but not (apparently) in Belgium and the Netherlands; field does not seem to be a relevant focus of interest in Austria and Switzerland; Switzerland is the only country whose researchers do not use the concept of habitus; and the Netherlands did not publish any article with the keyword practices. Concerning some of the key themes, we see that France and the Netherlands have art in common, and some other research fields in the same semantic area such as music, literature, taste and culture. Considering Austria, Germany and Switzerland, the keywords they have in common are gender, inequality, health, practices, capital and social capital, which may be ascribed to the general domains of social inequalities and individual well-being. There is no reason why all the countries must share research topics converging on clear semantic areas, but with this method we are able to identify the existence of fields of inquiry around which scholars variously located in European countries tend to gravitate with more or less intensity.

So far we concentrated only on countries belonging to the central (western) European area in order to illustrate our approach. Now we expand our focus to Europe at large. Which are the most common or typical topics addressed by scholars when working on Bourdieu? Which among Bourdieu's ideas have attracted more attention from scholars? The list is a long one, indeed (we have been able to identify 156 master keywords), but education, habitus, capital, culture, health, cultural capital, field, class, economics, gender, methodology, social capital, politics, practices, family, language, power, age, identity, literature and profession are the most 
used keywords in the European scientific production that identify Bourdieu as a key reference. These topics are those being used at least by 10 of the 30 countries. We are not (or not most of all) interested in the use per se of the keywords, but our analysis is directed at the common use among the countries. Thus, our counts are not operated on the basis of their absolute value, but in function of the number of countries that adopted them as research objects. Notice that seven of these words are Bourdieu's analytical categories, and the remaining ones are research topics. This is interesting because it gives an idea about the presence of some important research topics, which are dealt with in Bourdieusian categories by the European academic community but may not have been studied by Bourdieu himself. This could be the case, in particular, for health and for 'profession' - the latter being indeed a topic Bourdieu addressed in a critical vein as an ideological artefact, while at the same time offering a different set of concepts for dealing with 'professional' things, such as field autonomy and cultural capital.

We can further the knowledge of this scientific landscape by applying some useful metrics from social network analysis. The degree in social networks is a measure of connection (Freeman 1977). It describes the number of links held by the nodes. As previously noted, we are observing a two-mode network, in which two different kinds of entities are connected. On the one hand, for the whole dataset, the average degree of the countries is 28.53. This value means that the European countries used on average 28.53 keywords each. ${ }^{12}$ The standard deviation of 30.91 expresses a high dispersion of the number of keywords around the mean, indicating that some countries are active in research on a high variety of topics, while others concentrate only on a few. In fact in our dataset the degree ranges between the United Kingdom articles, which used 147 keywords (out of a total of 156), and Cyprus, which used 3 keywords. Obviously the degree distribution reflects the different productivity of the countries.

On the other hand, for the keywords we have an average degree of 5.48, indicating that each keyword has been used on average by at least five countries, with a standard deviation of 3.80. This value clearly indicates that there is a European common space of scientific production focused on Bourdieu. But this space is concentrated around some particular topics and countries.

The density (Scott 1991) is a metric that counts the maximum possible number of ties over the number of existing ties in a network, indicating how 'loose-knit' or 'tight-knit' the network is. Our two-mode network would be maximally dense if every country was connected to every keyword, and the metric would assume the value 1 (that is, 100 per cent of existing ties over the possible ones). But in that case we would observe an equal distribution of the topics among the countries, and no patterns of scientific specialization would 
exist. In our keywords-countries network the density is 0.183 , indicating that, on average, each country is connected to 18.3 per cent of the keywords, and, vice versa, each keyword is used by 18.3 per cent of the countries. These metrics are useful in order to have an overview of the structural properties of the network, to identify particularly central or peripheral countries or topics, and to evaluate the general relational dimension.

We are now interested, with an explorative purpose, in finding specific combinations of countries that can be seen as similar, because of specific research interests they have in common. We follow a precise analytical strategy and propose some relevant examples. The concept of structural equivalence in social networks (Sailer 1979) interprets the roles of people and organizations as functions of their positions. This relational perspective tries to go beyond the common understanding of social diversity (or equality) based on individual properties. Following a relational point of view, the position of a subject is a function of the relations owned. As a result, if two subjects under observation have the exact same relations with the others in the network, we can say they are structurally equivalent. This principle is suitable in our case, because if two countries are structurally equivalent (that is, they are tied to the exact same keywords), this means that they do research on the exact same topics, occupying the same position in the international scientific research agenda. It should be noted that it is rare to find this situation in real life. And it is nearly impossible to find two countries whose researchers published articles on Bourdieu, using the same (and the same number of) keywords. But the concept of structural equivalence can be relaxed, and measured, so that we can ask to what extent the countries are similar because they have keywords in common.

The algorithm implemented in the software Ucinet (Borgatti et al. 2002) calculates the similarities between any couple of countries as a proportion of the number of keywords they share (the matrix with all the values is found in the appendix; higher values indicate higher similarity).

On the basis of these similarities we highlight the presence of some clusters. United Kingdom, Germany, France and Spain form the most cohesive group, with a density (as noted, the proportion of existing ties over the possible ones) of 0.580 . Actually the fact that these countries are so similar is mostly because they are the most productive countries in the dataset, causing them to have many keywords in common, such as habitus, field, health, class, politics, capital, economic, market, interaction, careers, academic, practices, music, cultural production, action, social theory, gift, language, hermeneutics, history, colonialism and globalization.

Another group of countries with many keywords in common comprises Denmark, Norway, Sweden and Finland. The density of this subnetwork is 0.487 , indicating a good level of country-keyword cohesion. In this case there is a correspondence between the geographical position of the countries in the 


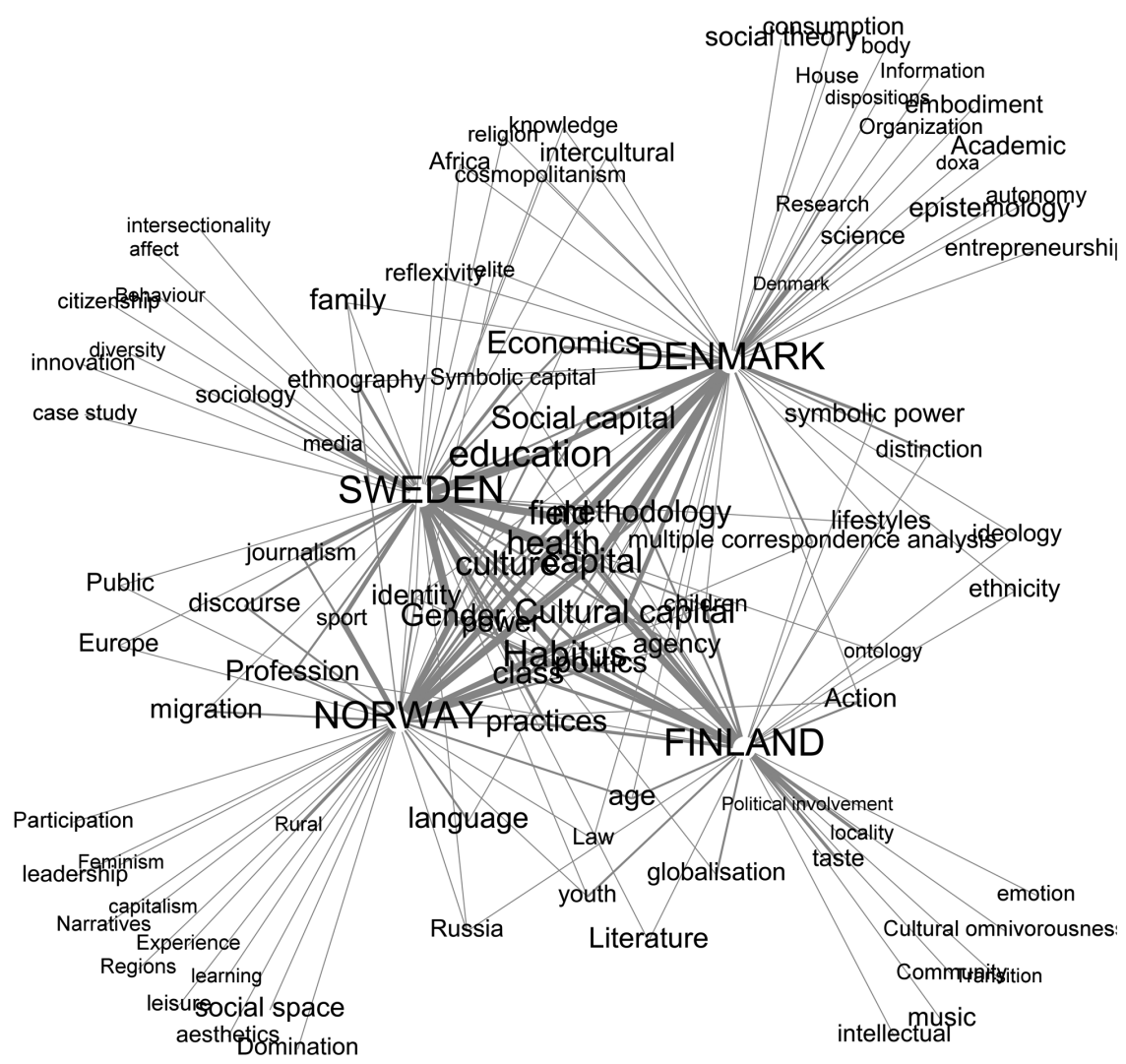

Figure 5.6 Two-mode network of keywords in Sweden, Denmark, Finland and Norway

continent and the use of Bourdieu in scientific research. Figure 5.6 represents the countries and their keywords.

In the centre of the network, at the intersection of the four countries, there are the keywords shared by all of them: identity, power, politics, field, habitus, education, health, cultural capital, methodology, culture, class, agency, capital. Also the other groups of keywords may indicate more coherent research fields in common by the countries, as in the case of the topics Africa, intercultural, religion and cosmopolitanism shared by Denmark and Sweden. Another interesting element in this group is the presence of the keyword multiple correspondence analysis, used by Norway, Denmark and Finland, three among the seven countries that used it in all the whole continent.

Even if the case of the Scandinavian countries expresses a correspondence between geographical (and therefore cultural) proximity and the reception of 
Bourdieu, this does not occur for other European areas. For example Russia, Latvia, Estonia and Lithuania have no topics in common if considered together. The only existing ties are between Russia and Estonia, where the keyword in common is Russia; between Estonia and Lithuania, where the keyword is social space; and between Lithuania and Latvia, through the keyword capital. Croatia has more topics in common with Ireland and Poland than with Serbia and Slovenia. Even though this topic needs further research, the first evidence shows a relative autonomy of the academic field from the historical and cultural contexts of the nations in large regions of the continent.

As mentioned above, we can distinguish the strength of the relations between countries and topics. The number of articles on specific research fields, and therefore the relative keywords, is an indicator of how much the reception of Bourdieu is focused around specific concepts and objects. We conclude this preliminary exploration of the academic field in the international reception of Bourdieu with an overview of the strongest ties between countries and keywords, also with the purpose of highlighting common patterns.

We selected only the links with a value equal to or greater than three. This means that the graph comprises the keywords that have been used at least three times by the same country. Figure 5.7 presents this graph. The thickness of the lines is proportional to the tie strength, indicating greater attention on that topic. Only the United Kingdom has been removed from the graph. As it is the most central country, it is connected with almost all the keywords and its presence would make it impossible to distinguish the other relations.

The first information concerns the so-called isolates, that is, all the nodes, countries and keywords that are not tied to any other because their relations are weaker than three. This gives an immediate representation of the central and peripheral countries and themes in the international circulation of Bourdieu's thought, and the differentiated dimension of the words, as already noted above, highlights the role of some key topics such as health, education and culture, and key Bourdieusian concepts, such as field, habitus and capital. At the centre of the graph we find the most relevant connections. Very few of them are dyads, relations between one topic and one country, unconnected from the rest of the network. These cases are particularly interesting because they denote peculiar thematic specializations in Bourdieu's reception. These cases are consumption in Lithuania and aesthetics in the Czech Republic. Many of the most central topics, as already mentioned in the previous analyses, bridge many countries. Concepts like field, habitus and capital are part of the common legacy of Bourdieu, and they are frequently used by European researchers regardless of their nationality. But there are other interesting spaces of common specialization that give an idea of new areas of social inquiry on which the Bourdieusian categories are being applied. Economics is frequently used 


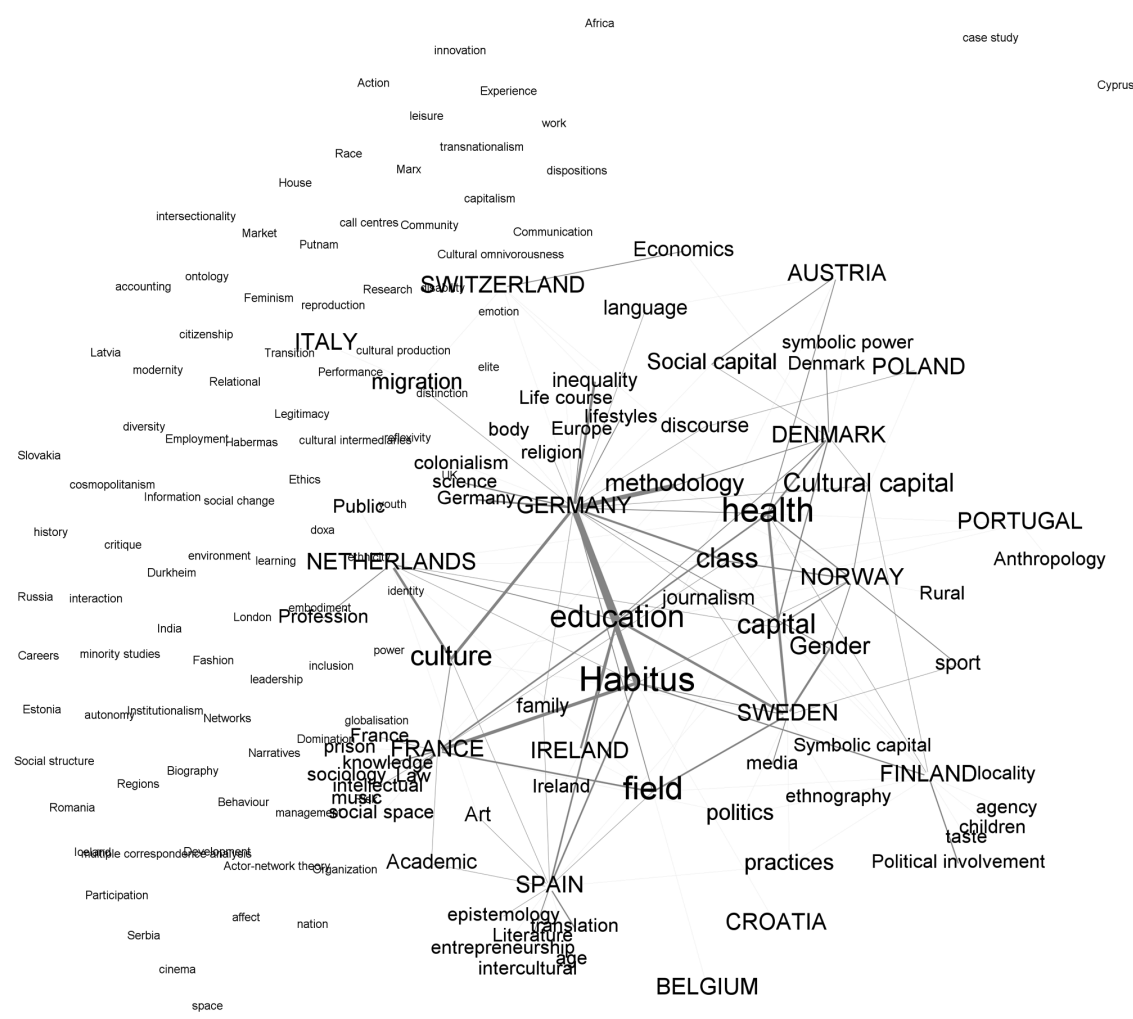

Figure 5.7 Two-mode network of keywords in Europe, ties stronger than three

by Swiss and Danish researchers; Dutch and Spanish social scientists have a common interest in the arts; the same is the case between France and Spain in the study of the academic field, and between Italy, Switzerland and Germany in studying migrations.

\section{Concluding Remarks}

Sociology is a European invention, ${ }^{13}$ and it is from Europe that the most influential sociologists still come: the late Ulrick Beck, Bruno Latour, Habermas (more known as a philosopher than a sociologist, to be sure), Giddens and, the most influential of all, Bourdieu. The only exception is Erving Goffman a Canadian who spent his academic life in the United States - whose intellectual genealogy is however strongly European (from Durkheim through Alfred Radcliffe-Brown to W. Lloyd Warner). Of course, Americans have and still are greatly contributing to the field - and certainly for a period it 
was an American scholar who lead the field (Parsons, also mainly nurtured by European social science however). Indeed, it is true for the central decades of the twentieth century that sociology, like the social sciences more generally, was American, and it was towards the United States that scholars in Europe in the fifties and sixties looked to get financial sources, ideas and especially methods.

If we consider at least its current key authors, sociology still appears to be a major European endeavour, and there is no doubt that the French Bourdieu worked hard to make this possible.

Bourdieu's defence of a European sociology against the US dominance of the field, and US imperialism, is well known: but what he called the Capitoline Triad of Parsons, Merton and Lazarsfeld was indeed deeply impregnated with European values and ideas. Lazarsfeld was certainly a truly European scholar, from Vienna. Of Russian (and Jewish) origins, Merton was educated as a sociologist, studying closely Durkheim and Weber, while having a Russian sociologist (Ptrim Sorokin) as PhD tutor and assisting in teaching an Italian scholar (Corrado Gini) visiting Harvard in 1937. Parsons developed his system of sociology by notoriously putting aside American sources (from institutionalists to Chicagoans) and grounding his programme of generating sociology as a synthetic science of social action (later of the social system) on truly European authors such as Durkheim, Pareto, Weber and Alfred Marshall.

However, European sociology was not in good health after World War II, and this is the historical context against which to assess Bourdieu's (and other scholars' as well) work for its resurgence also against what could seem and probably was at the time an overwhelming presence of American social science. In this process, very few noticed that the world was bigger than the complex United States plus Europe, and that something like a Eurocentric perspective was shared by both North American and European scholars. Even Bourdieu was not totally immune from a Eurocentric attitude - in part tempered by his work as a social researcher in Algeria and his intellectual participation in the anticolonial movement in the fifties. Indeed, while Bourdieu often reacted against charges of being too French in his works, showing how these criticisms missed the point (they were looking at the specific contents instead of the relations or structures of thoughts, the first being local and context specific, the second generalizable and therefore universal), he did not seem to have realized how deeply his theories and models were embedded in European intellectual history - something that is apparent when listing the many sources he made use of in his whole trajectory. ${ }^{14}$

Bourdieu is undoubtedly one of the most important references in contemporary social sciences - second probably only to Michel Foucault. Indeed in our analyses we showed the relevance of his intellectual impact on contemporary 
social research, arguing that even though most of the scientific production is tied to the European continent, the 'consumption', that is, the global system of citations, is closely linked with the international non-European context, and especially, predictably, the American. This is relevant for a sociology of the intellectual field and for the analysis of the social sciences as a global field (Heilbron 2014), because it says something about the dynamics that lead an author to global consecration. The United States, which plays a role of intellectual domination, and appropriation, of the intellectual life, is also able to put non-American authors under the spotlight. It is a sort of indirect link between Europe and the rest of the world that passes through America.

We observed a similar dynamic also within the European context, in which the United Kingdom plays an important role in the production of scientific knowledge based on Bourdieusian categories, and gains an absolutely disproportionate intellectual recognition (at least through the citation criteria).

We also showed which intellectual brokers and which journals are relevant subjects in the circulation of Bourdieu's work. But the most interesting, and we hope innovative, part of our analysis concerns the application of a relational perspective to the understanding of the international circulation of Bourdieu. This is an already affirmed approach to the analysis of scientific communities (Bellotti 2012), to the cocitation networks (Hummon and Dereian 1989) and also to the case of Bourdieu (Sapiro and Bustamante 2009). The added value of our analysis, which will be extended in further research, has been to explore the content of the scientific production under observation, discovering some patterns of (latent) collaboration between countries working on the same topics or applying the same Bourdieusian categories, and vice versa showing recurrent combinations of keywords connected through countries.

In future analyses we intend to deepen the knowledge of the structural properties of the international community of Bourdieu scholars, also with the aim, useful for a reflexive sociology, of identifying generalizable categories and of improving research tools for the analysis of other authors and central themes in the social sciences.

\section{Notes}

1 On this aspect of Bourdieu's intellectual biography, see Lane 2006.

2 While France and Algeria were the two countries Bourdieu investigated in his career (even in specific locations: Bearn, for example, or Paris), at least one book by Bourdieu had a European focus: see Bourdieu and Darbel 1967.

3 See, for instance, Kauppi 2003; Méranda 2010; and Cohen 2011.

4 There are different databases for indexing scientific literature, among the major ones are Web of Science (WoS), Google Scholar and Scopus. We chose to consider the last one as it better represents the population of European journals, compared to WoS, 
and it is not as inclusive as Google Scholar, so we could consider only quality scientific products. For a critical assessment of the three databases, see Lokman et al. 2007.

5 Also books (on Bourdieu, about Bourdieu, referring to Bourdieu and so on) of course work as media for the circulation of Bourdieu's ideas, as for any other author. However, books are much more difficult to investigate in any systematic way in the absence of reliable datasets. In any case, we would insist that academic journals are the main vehicles for an idea's reception and circulation in the social sciences, and our focus is on academic reception.

6 We considered the citations for the period 1979-2011, as we assume that at least two years are necessary for a scientific article to circulate and be quoted within another publication.

7 She is Emmanuelle Vaast, who earned her $\mathrm{PhD}$ in management of information systems from the Ecole Polytechnique, Paris, and is a former student at the Ecole Normale Supérieure and Sciences Po.

8 This is the case, for example, of Rogers Brubaker, who figures in our dataset only for his famous 1985 article on Bourdieu published in Theory and Society, which in the Scopus database counts 'only' 85 citations.

9 Sociologica was accepted in Scopus in 2013 but its articles do not figure (at least at the time of writing this chapter) in our data because of a mistake in the Scopus database, which conflates the Italy-based journal Sociologica with a Mexico-based journal of the same name.

10 At present, the only study we know of concerning the reception of Bourdieu in Eastern Europe is Bikbov (2009) on the important case of Russia. Insights about the Polish case are offered by Warczok and Zarych, a study in the uses of critical theory in general addressed through a case study of the uses of Bourdieu's theory in Poland. As the authors observe, 'Even though his theory is relatively well known in Poland, it is often used in a peculiar way. On the one hand, Bourdieu's theory may be seen as enjoying high prestige and it is difficult to ignore it in the local sociological field. On the other hand, because of the specific construction of the field, its critical nature appears embarrassing to many Polish sociologists'(Warczok and Zarych 2014, p. 340). We learn from this article that 'Bourdieu's theory appeared in the Polish sociological field between the 1970s and 1980s. However, it did not result in any creative applications of his models' (ibid). It was only after 1989 that 'several of Bourdieu's books were translated into Polish along with a growing stream of publications presenting syntheses of different parts of Bourdieu's work, usually without any empirical applications in a national context (for example, Matuchniak-Krasuska, 2010; Sztandar-Sztanderska, 2010)' (ibid.). In the process, also some prominent Polish sociologists such as Piotr Sztompka (internationally renowned also as a former student and a scholar of R. K. Merton) began to use elements of Bourdieu's theory to analyse Polish society (for example, Sztompka 1995). We are also aware of research being done in Hungary on the local reception of Bourdieu, the results of which however are not yet available (in this case, the major figure is probably Victor Karady, a Hungarian sociologist who was a student of Bourdieu in the seventies, see Maar 2009) In general, regarding Eastern Europe we do not have enough evidence and studies to say anything seriously about how Bourdieu has been received and how his work circulated before and after the fall of communism. A crucial vector of circulation of Bourdieu's ideas in the post-communist period may be identified however in the important research stream by scholars (sometimes also from Eastern Europe) engaged in studying the transition from communism to capitalism and 
more in generally in the post-communist society. See Stark and Bruszt (1998); Eyal, Szelényi and Townsley (2001); Urban (2010); Tomusk (2010); and Zarycki (2014). See also Derluguian (2005) for an insightful study (by a Eastern European scholar working in the United States) on an exceptional case of a local reception of Bourdieu's work contributing to the collapse of Soviet socialism in the Caucasian region.

11 Different keyword aggregations have been operated in the dataset in order to reduce the massive number of keywords listed in the Scopus database and the dispersion of information. Singular and plural words have been included in one single category (for example, practices and practice); when a particular concept appeared together with other words, the different keywords have been subsumed into what we identified, on the grounds of our reading of Bourdieusian theory, as the major concept: for example 'field theory' and 'concept of field' have been included in the general category of 'field', or 'aesthetic judgement' and 'aesthetic theory' in 'aesthetics'; also keywords clearly referring to the same semantic area have been conflated: football, basketball and so on have been aggregated with 'sport'; 'disease' and 'illness' with 'health'; and so on.

12 Note again that we selected only the keywords that appeared at least five times in Scopus.

13 On sociology as a European enterprise, see Nedelmann and Sztompka 1993 and more recently, Koniordos and Kyrtsis 2014.

14 In the intellectual genealogy of Bourdieu we can find scholars from many disciplines and also many countries - but all European countries. No scholar from Asia, Africa or even Latin America, that is the Global South, is ever quoted or referred to by Bourdieu. Indeed, it is difficult also to find references to influential Southern European intellectuals, such as Antonio Gramsci. The only exception to this 'Northern theory' exclusiveness is Bourdieu's intellectual relation with the Amazigh poet and linguist Mouloud Mammeri.

\section{References}

Bellotti, E. 2012. 'Getting Funded: Multi-Level Network of Physicists in Italy'. Social Networks 34: 215-29.

Borgatti, S. P. and M. G. Everett. 1997. 'Network Analysis of 2-Mode Data'. Social Networks 19: 243-69.

Borgatti, S. P., M. G. Everett and L. C. Freeman. 2002. Ucinet 6 for Windows: Software for Social Network Analysis. Harvard, MA: Analytic Technologies.

Bourdieu, P. 2002. 'Les conditions sociales de la circulation internationale des idées'. Actes de la recherche en sciences sociales 145: 3-8.

Cohen, A. 2011. 'Bourdieu Hits Brussels: The Genesis and Structure of the European Field of Power'. International Political Sociology 5, no. 3: 335-9.

Denord, F., J. Hjellbrekke, O. Korsnes, F. Lebaron and Br. Le Roux. 2011. 'Social Capital in the Field of Power: The Case of Norway'. Sociological Review 59, no. 1: 86-108.

Derluguian, G. M. 2005. Bourdieu's Secret Admirer in the Caucasus: A World-System Biography. Chicago: University of Chicago Press.

Eyal, G., I. Szelenyi and E. R. Townsley. 2001. Making Capitalism without Capitalists: Class Formation and Elite Struggles in Post-Communist Central Europe. London: Verso.

Fournier, M. L. Vécrin. 2009. 'Bourdieu in Canada'. Sociologica 1. http://www.sociologica. mulino.it/doi/10.2383/29571.

Freeman, L. C. 1977. 'A Set of Measures of Centrality Based on Betweenness'. Sociometry 40, no. 1: 35-41. 
Gemperle, M. 2009. 'The Double Character of the German "Bourdieu": On the Twofold Use of Pierre Bourdieu's Work in the German-Speaking Social Sciences'. Sociologica 1. http://www.sociologica.mulino.it/doi/10.2383/29573.

Hanneman, R. A. and M. Riddle. 2005. Introduction to Social Network Methods. Riverside: University of California Press.

Heilbron, J. 2014. 'The Social Sciences as an Emerging Global Field'. Current Sociology 62, no. 2: 685-703.

Hjellbrekke, J. B. Le Roux O. Korsnes F. Lebaron L. Rosenlund H. Rouanet. 2007. 'The Norwegian Field of Power Anno 2000'. European Societies 9 no. 2: 245-73.

Hummon, N. P. and P. Dereian. 1989. 'Connectivity in a Citation Network: The Development of DNA Theory'. Social Networks 11, no. 1: 39-63.

Kauppi, N. 2003. 'Bourdieu's Political Sociology and the Politics of European Integration'. Theory and Society 32, nos. 5-6: 775-89.

Koniordos, S. and A. Kyrtsis eds. 2014. The Routledge Handbook of European Sociology. London: Routledge.

Lane, J. F. 2006. Bourdieu's Politics: Problems and Possibilities. London: Routledge.

Lokman I. Meho and Kiduk Yang. 2007. 'Impact of Data Sources on Citation Counts and Rankings of LIS Faculty: Web of Science versus Scopus and Google Scholar'. Fournal of the American Society for Information Science and Technology 58, no. 13: 2105-25.

Maar, J. (ed.) 2009. L’hommage à Victor Karady: Temps, espaces, langages. Paris: L'Harmattan (special issue of Cahiers d'études hongroises).

Matuchniak-Krasuska A. 2010. Zarys socjologii sztuki Pierre`a Bourdieu. Warszawa: Oficyna Naukowa.

Méranda, F. 2010. 'Pierre Bourdieu and the Birth of European Defense'. Security Studies 19, no. 2: 342-74.

Nedelmann, B. and P. Sztompka eds. 1993. Sociology in Europe: In Search of Identity. Berlin: Walter de Gruyter.

Rahkonen, K. 2008. 'Bourdieu in Finland: An Account of Bourdieu's Influence on Finnish Sociology'. Sociologica II, no. 2, doi: 10.2383/27723.

Robbins, D. 1989. 'Bourdieu in England 1964-1977'. Higher Education Policy, 2: 40-6. 2008. 'French Production and English Reception: The International Transfer of the Work of Pierre Bourdieu'. Sociologica II, no. 2, doi: 10.2383/27720.

Rosenlund, L. 2000. Social Structures and Change: Applying Pierre Bourdieu's Approach and Analytic Framework. Stavanger: Stavanger University College.

2009. Exploring the City with Bourdieu: Applying Pierre Bourdieu's Theories and Methods to Study the Community. Saarbrücken: VDM.

Sailer, L. D. 1979. 'Structural Equivalence: Meaning and Definition, Computation and Application'. Social Networks 1, no. 1: 73-90.

Santoro, M. 2008. 'Putting Bourdieu in the Global Field: Introduction to the Symposium'. Sociologica 2 .http://www.sociologica.mulino.it/doi/10.2383/27719.

2009. 'How "Not" to Become a Dominant French Sociologist: Bourdieu in Italy, 1966-2009'. Sociologica 2-3.

http://www.sociologica.mulino.it/doi: 10.2383/31372

_ 2014. 'Effetto Bourdieu. La sociologia come pratica riflessiva e le trasformazioni del campo sociologico'. Rassegna Italiana di Sociologia, 1: 5-20.

Sapiro, G. 2015. 'The International Career of Distinction', in P. Coulangeon and J. Duval (eds.) The Routledge Companion to Bourdieu's Distinction, London: Routledge, pp. 29-42. 
Sapiro, G. and M. Bustamante. 2009. 'Translation as a Measure of International Consecration Mapping the World Distribution of Bourdieu's Books in Translation'. Sociologica 2-3. http://www.sociologica.mulino.it/doi/10.2383/31374.

Scott, J. 1991. Social Network Analysis: A Handbook. London: Sage.

Stark, D. and L. Bruszt. 1998. Postsocialist Pathways: Transforming Politics and Property in East Central Europe. Cambridge: Cambridge University Press.

Sztandar-Sztanderska, K. 2010. Teoria praktyki i praktyka teorii Wstęp do socjologii Pierre'a Bourdieu. Warszawa: Wydawnictwa Uniwersytetu Warszawskiego.

Sztompka, P. 1995. 'Cultural and Civilizational Change: The Core of Post-Communist Transition', in B. Grancelli (ed.) Social Change and Modernization: Lessons from Eastern Europe. Berlin/New York: Walter de Gruyter, pp. 233-48.

Urban, M. 2010. Cultures of Power in Post-Communist Russia: An Analysis of Elite Political Discourse. Cambridge: Cambridge University Press.

Tomusk, V. 2010. 'Reproduction of the "State Nobility" in Eastern Europe: Past Patterns and New Practices'. British Fournal of Sociology of Education 21: 2, 269-82.

Walker, G., B. Kogut and W. Shan. 1997. 'Social Capital, Structural Holes and the Formation of an Industry Network'. Organization Science 8, no. 2: 109-25.

Warczok, T. and T. Zarycki (2014) 'Bourdieu Recontextualized: Redefinitions of Western Critical Thought in the Periphery.' Current Sociology 62, no. 3: 334-51.

Zarycki, T. 2014. Ideologies of Eastness in Central and Eastern Europe. London: Routledge. 


\title{
Chapter 6
}

\section{THE PRINGIPLE OF DIFFERENTIATION IN JAPANESE SOCIETY AND INTERNATIONAL KNOWLEDGE TRANSFER BETWEEN BOURDIEU AND JAPAN*}

\author{
Shinichi Aizawa and Naoki Iso
}

\section{Introduction}

In this essay, we examine the history of the Japanese reception of Pierre Bourdieu's works generally, and his essays on Japan specifically, from the viewpoints of the principle of differentiation and the concept of capital, both regarding international knowledge transfer (Robbins 2012). ${ }^{1}$ The Japanese modernization and industrialization processes are always embedded within a unique knowledge transfer process. Japanese modernization processes, especially during the Meiji era, are often identified as Wakon Yōsai (和魂洋才), which means 'Japanese spirit, Western technology' (Hirakawa 1971, 2004; Chew 2014). Japanese modernization processes often emphasized the maximization of utility and function in a Japanese spirit influenced by Western technology. ${ }^{2}$ This tendency is often observed not only in science and technology but also in the field of social sciences and policymaking. For instance, consciousness of law is a remarkable example of the characteristic Japanese style of international knowledge transfer. One classical work, Japanese Law Consciousness, was written by jurist Takeyoshi Kawashima (1967). Since the 1870s, Japan had imported European jurisprudence mainly from France and Germany, later deriving Japanese law from American jurisprudence (Aoki 2005). Inevitably, such jurisprudence was traditionally not rooted in Japan and was often incompatible with Japanese customs. Therefore, the complicated relationship between the modern Japanese system and Japanese society has been one of the central issues in Japanese jurisprudence. ${ }^{3}$ From these 
studies, we can infer that the Japanese modernization process always includes an international knowledge transfer process, but that sometimes Japanese understanding is apt to be self-centred. This self-centredness is affected by social, geographical and linguistic circumstances. The Japanese reception of Bourdieu and the development of related research were also apt to be selfcentred, though the reading of foreign texts often has the same tendency.

Japanese self-centredness has not been commented upon from the Japanese side but from outside observations of it. One of the international classic and exemplary works used to reveal the Japanese mental structure is The Chrysanthemum and the Siword, written by Ruth Benedict in 1946. ${ }^{4}$ There was much criticism of this work, one example of which is the overly simplified version of the Japanese displayed in the work, constructed by the Japanese culture of that time. Benedict's work was also attacked for its ignorance of the historical and social changes in the Japanese. Knowing these facts, Bourdieu cited and criticized her work when he lectured in Tokyo in October 1989. ${ }^{5}$ Bourdieu suggested, regarding 'such a reading', that 'the curiosity for exotic particularism had inspired many works on Japan' (1998, 1). Going beyond the exotic particularism which Bourdieu detected in Benedict, this chapter introduces the characteristics of Japanese society, while reviewing the works of Bourdieu and of Japanese sociology generally.

Prior to this discussion, we offer a simple but important caveat: Bourdieu did not know the Japanese language, and, until recently, few Japanese social scientists studied French. Therefore, Bourdieu's works are usually read in Japanese or in English translations in Japan. Though over 20 of his works, including almost all the major works such as Distinction, were translated into Japanese, many of these were translated by Japanese scholars of French literature. As a result, Bourdieu's works tend to be interpreted and examined only in the context of the Japanese-speaking world. In Japan, there are many more specialists in German sociology than in French sociology. The small number of specialists in French sociology has influenced the Japanese reception of Bourdieusian sociology.

These various social, geographic and linguistic discrepancies have generated a peculiar reception of Bourdieu in Japan. The examination of such Japanese experiences raises important questions concerning the international reception of Bourdieu, including how international knowledge transfer has given rise to a peculiar knowledge in the Japanese reception of Bourdieu, how European canonical cultures are transformed in the cultural capital that is associated with Japan, how the Japanese social space and its principle of differentiation are different from those of the French and the British and how the formation of different types of capital in Japan depend on transnational social processes. We explore these points in this chapter. ${ }^{6}$ 
Six sections make up this chapter. First, we present the historical and intellectual context of Japanese sociology in section 2. Section 3 presents a short history of the Japanese reception of Bourdieu, in particular up to the $1990 \mathrm{~s}$, and the corresponding social background of Japanese society. Employing Bourdieu's ideas regarding Japanese modernisation and industrialisation, section 4 takes up the discussion about Japan in his works and concretely develops a framework for international knowledge transfer, building from the concept outlined in Practical Reason in particular. In section 5, we offer four new applications based on our advancement of Bourdieu's theory for international knowledge transfer. Section 6 summarizes the discussion in the preceding sections, makes concluding points and suggests future topics for research pertaining to international knowledge transfer from Japan.

\section{A Brief History of Knowledge Transfer to Japanese Sociology from the 1950 s to the 1980 s}

Bourdieu was critical of Benedict's The Chrysanthemum and the Sword: Patterns of Japanese Culture, one of the most influential works written on Japanese society, even in Japan. Bourdieu considered her book ethnocentric and devoid of an interest in the differences between Japanese individuals (1998, 1). However, as the Japanese cultural anthropologist Tamotsu Aoki recognized, Benedict is known as a cultural relativist in Japan (1999, 35). Regarding Benedict's work, two points must be considered: first, discussions of 'Japaneseness' and the Japanese national identity have been popular since the publication of the Japanese translation of The Chrysanthemum and the Sword in 1948. Second, such discussions were gradually adopted by sociologists rather than by anthropologists.

According to a report by the Nomura Research Institute on publications related to the subject of 'Japaneseness', over 698 books were published between 1946 and 1978. Adding to the statistics provided in the report, Aoki estimates that more than 2,000 books have been published, if books on Japanese culture and on 'Japaneseness' published between 1978 and 1988 are included. The popularity of such subjects can be regarded as the consumption of cultural nationalism (Yoshino 1995).

Japanese sociologists joined such discussions in the 1960s. One key moment was the Japanese translation of Tokugawa Religion: The Values of Pre-Industrial Japan by Robert N. Bellah (1957) that appeared in 1962. By examining religious ethics and social development in the Tokugawa era, Bellah attempted to analyse how Japan had successfully constructed a modern state and managed to industrialize. His theoretical insights were derived from the works of Max Weber and Talcott Parsons. Keiichi Sakuta developed his own theory of mass 
society and dealt with Benedict's work (1964). Sakuta's research was influenced by Émile Durkheim and David Riesman; however, Karl Marx and Max Weber seemed to be the most significant influences on Japanese social scientists in the 1960s. For instance, Hisao Otsuka's Methods of Social Science: Weber and Marx (1966) was one of the most widely read books in the social sciences and is still in print.

Although Durkheim's works were already sociological classics in the 1960s, German sociological theory was much more influential than was French sociological theory among Japanese sociologists in the latter half of the twentieth century. In the 1970s, Parsons had a substantial influence on Japanese sociologists, among whom American empirical sociology gradually became significant. In Japanese sociology, German sociology has been influential for theory and AngloSaxon sociology for empirical research. Kenichi Tominaga, professor emeritus at the University of Tokyo and one of the most influential sociologists in the latter half of the twentieth century in Japan, chose ten sociologists who, according to his own criteria, are the most important in the history of Japanese sociology (2011, 295-362). According to him, Henri de Saint Simon, Auguste Comte and Herbert Spencer are representative of the first generation. The second generation is represented by Durkheim, Georg Simmel and Weber. The figures of the third generation are Parsons, Alfred Schütz and Niklas Luhmann. Tominaga is a well-known anti-Marxist who has tried to ignore Marx. Consequently, Marx must be added to the list of the second generation. It is into this Japanese sociological context that the ideas of Bourdieu have been imported.

Not only from this context but also from the next example, one can see the difficulty in understanding Bourdieusian sociology in Japan through a dialogue between Bourdieu and Tominaga (2001). The dialogue took place in January 2000 in Tokyo and the theme was 'What Is Sociology?' These two sociologists' philosophies of sociology differ, most importantly regarding their ideas on class. According to Tominaga, there is no social group that corresponds to the 'cultural nobility', a concept presented by Bourdieu, in Japan (2001, 7). For Tominaga, the relational thinking and the basic concepts of Bourdieu were unfamiliar. Bourdieu recognized that their visions of sociology were very different and even contradictory. As a Japanese sociologist, Tominaga's understanding of Bourdieusian sociology was not uncommon.

\section{A Brief History of the Japanese Reception of Bourdieu}

\section{The initial reception of Bourdieu in Japan from the late 1970s to the 1980s}

This section details how Japanese sociologists imported Bourdieu's sociological ideas. We then merge this discussion with an evaluation of the validity of 
his concepts. Japanese sociologists' importation of Bourdieu's ideas reflects the sociohistorical conditions of Japanese society in period of the 1980 s to the 1990s. The Japanese importation of Bourdieu's sociological ideas was influenced by a prevailing self-image of Japan as a rich and equal society in the 1980s following the era of the economic miracle. Japan raised its world economic hegemony in the late 1970s and 1980s, achieving the second-largest economy in the world from the 1970s to 2010. Ezra Vogel's Japan as Number One: Lessons for America (1979) argued that Japanese society had been characterized by not only high economic growth but also by equality. William Cummings, an American education researcher, conducted ethnographic research in Japanese primary schools, which was published in Education and Equality in Fapan (1980). He drew attention to the relationship between social equality and high educational achievement in Japanese primary schools. Economic affluence and social equality had an impact on Japanese self-identification. In one famous example, the Japanese economist Yasusuke Murakami published The Era of New Middle Masses: Anatomy of Post-War Japan in 1984. The term 'middle masses' indicated, he said, that 'all Japanese are new middle masses', and this word applied to Japanese society at large. ${ }^{7}$ Therefore, Japanese people identified their society as an economic success society after the defeat of World War II or an equal society. Naturally, as comparative sociologist Ronald Dore described in Diploma Disease (1976), schools and the education system had a large influence on this social process.

One of the initial impacts of the arrival of Bourdieu's thought in Japan was the translation of Power and Ideology in Education, by Jerome Karabel and A. H. Halsey (1977), which appeared in 1980. The chapter written by Bourdieu, 'Cultural Reproduction and Social Reproduction' in 1973, was not translated at this time, but the introduction and structure of this book prepared readers for Bourdieu's ideas with the authors' discussion of the 'new' sociology of education. This 'new' sociology of education denied 'a "positivistic" version of structural functionalism using "input-output models", and it stressed 'the significance of the content of education' (Karabel and Halsey 1977, 46). Bourdieu was regarded as a new sociologist who, with Basil Bernstein, related 'the problem of educability to that of socially controlled cultural transmission' (Karabel and Halsey 1977, 44). The first Japanese reception of Bourdieu was influenced by an intellectual atmosphere that reflected the severely competitive examination ethos in Japan in the 1980s, in the manner described by Dore (1976).

Bourdieu's impact on the 'new' sociology of education was reflected in some Japanese scholarly papers written in the 1980s (Karabel and Halsey 1977, 44). Those authors used Bourdieu's works to examine social and educational structures, particularly in school organizations (Inoue 1983, 1986; Akinaga 1984, 1987). These authors' intellectual backgrounds were highly influenced 
by Marx or Durkheim. For instance, Akinaga (1984) discussed theoretical educational characteristics based on Bourdieu and the French Marxist philosopher Louis Althusser. Takashi Miyajima, who translated Reproduction in 1991, has written extensively about Bourdieu, and also translated Durkheim's Suicide and Rules of Sociological Method. Within this intellectual atmosphere Bourdieu was regarded as a theoretical sociologist of cultural reproduction. Miyajima, Akinaga and other scholars such as Hidenori Fujita, one of the most famous Japanese sociologists of education internationally, have applied Bourdieu's survey method to Japanese university students, as in Inheritors (Fujita et al. 1987; Miyajima and Fujita eds. 1991). Miyajima in particular put forward his theory of cultural reproduction based on that of Bourdieu (1994). ${ }^{8}$

These applications include some 'misreadings' of Bourdieusian ideas as compared to the heart of Bourdieu. As Bourdieu indicated in the preface to the 1990 edition of Reproduction, the book invoked 'an extraordinary simplification' of the process of reproduction in society and 'so many (mis)interpretations' (1990, vii-viii). Bourdieu's Inheritors and Reproduction were also easy to (mis)interpret for Japanese sociologists because these works had the same logic of debunking the myth of equality in school education after the wave of the 'new sociology of education'. This tendency of (mis)interpretation was captured critically in several works in the 1990s. For example, Bourdieu illustrated this point to Japanese scholars on his visit to Japan in 1989 (Bourdieu et al. 1990). Toru Onai summarized contemporary reproduction theory (1995), and Bourdieu was included with other excellent reproduction theorists such as Basil Bernstein and Bowles, Gintis and Willis. In his chapter on Bourdieu, Onai wrote that the Japanese 'misreading' of Bourdieu as focusing on cultural reproduction in Reproduction and Inheritors is common (1995, 103). However, it is interesting that Japan as an equal society and Britain as a class society have the same application of the theory with the same understandings, because these two societies have completely different social identifications. For instance, Hiroshi Ishida, an international sociologist of social stratification and the secretary-treasurer of the International Sociological Association RC28 (Social Stratification), compared Japan, the United States and Britain in terms of class structure and social mobility (1991). He concluded that Japanese society seemed more mobile than the American and British societies based on the patterns of absolute mobility, but that they have a similar structure of relative mobility despite the differences in their class identities (1991, 256).

\section{Translation of Distinction in the bubble economy society}

The Japanese translation of Distinction was published in 1989 and 1990 (divided into two volumes). Naturally, this translation extended Bourdieu's 
Japanese audience. This translation was published in the bubble economy, a social situation that led to a peculiar reception.

Unlike Reproduction and Inheritors, Distinction was spotlighted among Japanese scholars of French literature, philosophy and thought. French philosophers and thinkers such as Claude Lévi-Strauss, Michel Foucault, Louis Althusser, Roland Barthes, Jacques Derrida, Gilles Deleuze and others were popular during the 1980s in Japan. Many of their works were translated into Japanese. Japanese scholars who specialized in French literature or society devoted great attention to the translation and introduction of French Theory. Some attention was paid to Bourdieu, who was closely connected to this wave. For instance, The Logic of Practice was translated by Hitoshi Imamura, whose main focus was Althusser. ${ }^{9}$ Tetsuji Yamamoto, a philosopher and a disciple of Ivan Illich, and Norihiko Fukui, a scholar of European history, who cooperated in publishing a journal about French Theory, translated some articles such as 'Three Forms of Cultural Capital' and introduced Bourdieu's theory. Distinction is a remarkable example of this stream in Bourdieu as a philosopher rather than an empirical sociologist.

Such an intellectual atmosphere and social circumstances have influenced the Japanese reception of Distinction. The translation of Distinction by Yojiro Ishii, a scholar of French literature, was significant in capturing Bourdieu's theory; however, several other characteristics underlie Japan's unique sociological reception. First, Japan had a relatively low level of interest in social inequality, and especially poverty in that time. Reflecting on this social situation, the word 'classifying' in Distinction was translated as 'classification' in Japanese, which does not have a connection to social class. ${ }^{10}$ Therefore, it is difficult to grasp the meaning of the distinction between social classes from the Japanese translation. As a result, this translation, and the prevalent social conditions mentioned within it, emphasized the importance of culture or cultural capital, and put less emphasis on the importance of social distinctions, including economic and other inequalities. The prevailing social atmosphere at the time in Japan thus encouraged an understanding of Bourdieu as a sociologist of cultural reproduction.

Second, statistical terms and methods, especially regarding correspondence analysis, were often ignored in this translation, because Ishii is a specialist in French literature. Ishii and other Japanese theoretical sociologists of French sociology such as Otoyori Tahara grasped the essence of Distinction (Ishii 1993; Tahara 1993). However, the translation did not represent the statistics and the quantitative sociological method of the original. ${ }^{11}$ As a result, this translation encouraged surveys and studies using variables of cultural capital and measurement of cultural capital. Quantitative social field analysis using correspondence analysis was rarely attempted in Japan until the 2000s. Japanese 
quantitative sociology attempted to apply Bourdieu's framework in regression analysis in the 1990s. For example, Kataoka did not use correspondence analysis in her initial papers but rather tried to apply Bourdieu's works to measure cultural reproduction, using forms of regression analysis that were influenced by US sociology (1992). ${ }^{12}$ These applications often ignored the view of culture in society as it had been drastically revised by Bourdieu. ${ }^{13}$

Apart from Bourdieu's intentions, quantitative applications of his theoretical concepts using regression analysis were related to the discrepancies between qualitative sociology and quantitative sociology in Japan. Not only was this a methodological discrepancy but also one of style: the quantitative Japanese sociologist's style became inclined to execute regression analysis with causal models, which differed from Bourdieu's correspondence analysis and statistical spatial model. This style was not only influenced by the style status attainment model derived from American sociology but also by peculiarly Japanese social scientific interests. It is a well-known fact that the Japanese economic miracle, with its massive educational expansion, occurred from the 1950s to the 1970s. ${ }^{14}$ In that time, many Japanese people experienced upward social mobility within and between their generations. From this experience, Japanese interests concentrated on the question of who attained the most successful careers. Academically, and sometimes more popularly, this concept was termed Risshin-Shusse (立身出世), which means 'high-status attainment' in the Japanese modernization process. Many works were written using this concept as part of the analysis of the Meiji era. By the1960s, as Andrew Gordon, a scholar of Japanese history, indicates, the ratio of students coming from the bottom quintile in national and public universities was 19.7 per cent (Rohlen 1977), while the ratio of the poorest students was equal to the ratio of the poorest people in the country's population (Gordon 2002). In this social atmosphere, Japanese sociologists sought factors related to upward social mobility, such as the concept of cultural capital, other than economic capital.

Through such interpretations of Bourdieu, Japanese sociologists and intellectuals understood him largely as a sociologist who emphasized culture or cultural capital. In addition, the Japanese reception of Bourdieu had not paid attention to changes or advances in Bourdieu's theory itself. Although his sociological ideas kept developing, and his theoretical frameworks differed at various times, Japanese sociologists, such as Hara and Seiyama (2006), focused mainly on Reproduction and Distinction and considered them part of the same theoretical framework. In particular, the lack of interest on the part of Japanese thinkers in capturing a social map and social field using correspondence analysis, and resolving discrepancies between quantitative sociology and qualitative sociology, made it difficult to form a comprehensive theoretical theory of culture, social reproduction and social distinction in Japanese 
society. ${ }^{15}$ Japanese sociologists imported some of Bourdieu's concepts, such as cultural capital, habitus and practice, and applied their own frameworks, such as 'Japanese spirit, western technology' (Hirakawa 1971, 2005; Chew 2014).

\section{On Japan: Rethinking Practical Reason}

Employing Bourdieu's ideas regarding Japanese modernization and industrialization, this section examines his ideas in his works about Japan. He had his own interests in Japan as a society from which to generalize his theoretical ideas. In his lecture in Tokyo in 1989 entitled 'Social Space and Symbolic Space', he explained his own concept of social space as a method of class analysis for investigating Japanese society (Bourdieu 1998, 1-13). In addition, he asserted in his lecture at Collège de France on the state, that he regarded the Japanese state (along with the France and the United Kingdom) as one of three models of the modern state (Bourdieu 2012). Thus, Japan provided Bourdieu with an empirical instance to test his social theory.

'Social Space and Symbolic Space' is reprinted in Practical Reason, a collection of lectures given by Bourdieu outside France. In the preface he writes that the lectures had allowed him to address what he 'believed to be most essential in his work, that is, its most elementary and fundamental characteristics' (Bourdieu 1998, vii). According to Bourdieu, such characteristics are relational and dispositional, as are his basic concepts such as habitus, capital and field (1998, vii-viii). Bourdieu's entire scientific enterprise was based on 'the belief that the deepest logic of the social world can be grasped only if one plunges into the particularity of an empirical reality, historically located and dated, but with the objective of constructing it as a "special case of what is possible", as Bachelard puts it: an exemplary case in a finite world of possible configurations' (Bourdieu 1998, 2). Although Bourdieu's work may seem to be a case study on France, he always considered the examination of the case applicable to any society. Such an idea can be ethnocentric, but Bourdieu denies this charge, claiming his approach is 'more respectful of historical realities (and of people) and above all more fruitful in scientific terms than the interest in superficial features of the lover of exoticism who gives priority to picturesque differences' $(1998,2)$.

In 'Social Space and Symbolic Space', Bourdieu provides examples of different objects - such as sports, foods and politics - in comparing France and Japan. What Bourdieu attempted was to find Japanese objects equivalent to the French ones that he had discussed in his work. This effort was more guesswork than analysis, and he was conscious of that. He hoped his readers would 'try to apply the model in this other "particular case of the possible," that is Japanese society, that they will try to construct the Japanese social space 
and symbolic space, to define the basic principles of objective differentiation' (1998, 13). For Bourdieu, Japan would be an important field for challenging empirially his theoretical ideas presented in Distinction.

According to Haruhisa Kato, a scholar of French literature and one of the closest friends of Bourdieu during his lifetime, Bourdieu gradually became interested in Japan. ${ }^{16}$ Evidence of this interest is expressed in Bourdieu's letter to André Nouschi in 1958. Citing Benedict's work, Bourdieu examined Algerian civilizations before his lecture in Tokyo in October 1989 (2008, 381). Although Bourdieu did not mention it, Japanese society in the latter half of the twentieth century was often considered homogeneous (Mouer and Sugimoto 1986). In the 1980s, even many social scientists considered society to be eqalitarian both in the social reality and in people's consciousness (Murakami 1984). Kato, who was not only a social scientist but also a scholar of French literature, gave Bourdieu the impression that Japanese society was not egalitarian and that a certain value was assigned to cultural capital in Japan. ${ }^{17}$ Bourdieu seems to have accepted Kato's idea: he examined social equality, using the concept of social space, in his lecture in Tokyo. He tried to see Japanese society through his examination of French society.

Kato's idea raises questions about international knowledge transfer between France and Japan as one of the first modernized East Asian countries. First, Bourdieu indicated that, despite having an insufficient understanding of Japanese society, the possibility of applying the theoretical framework of Distinction - an ethnography of France, a Western European society, to Japan, an East Asian country - was the condition necessary for 'a comparativism of the essential'. Namely, social space is constructed based on the two principles of difference - for example, 'economic capital and cultural capital' (Bourdieu 1998, 6) - using the concept of field. Second, education played an important role in the Japanese application of Bourdieu's theoretical framework. This information provided crucial clues for observing Bourdieu's Japanese reception, which in turn depended on Japanese sociology. Third, it is possible to connect Bourdieu's lecture in Tokyo to his lectures on the state, from 1989 to 1992, at the Collège de France (2012). In Practical Reason, the third chapter, 'Rethinking the State: Genesis and Structure of the Bureaucratic Field' (Bourdieu 1998, 35-63), is closely related to the lectures On the State, in which he considered the Japanese state as one of three models of the modern state (2012).

In order to examine the modern state, Bourdieu chose France, England and Japan because, he believed, the founding officers of the three states were literate and their state bureaucracies' capital was a cultural component (2012, 76). Discussions of the modern state in State Nobility (Bourdieu 1996) are not about Japan, but many of them are applicable to Japanese society. These derived implications of Bourdieu's works have not been sufficiently recognized 
in Japan. The sociohistorical conditions of Japanese society provide an explanation for this oversight.

\section{Connecting Bourdieu and Japanese Sociology to the Future}

As section 3 shows, Japanese sociological interest in culture has been cultivated by the reception of Bourdieu. In sum, the Japanese reception of Bourdieu was inclined to import the analysis of culture, cultural capital and reproduction contrary to Bourdieu's intention, as indicated in the preface of the second version of Reproduction. Although they provided a theoretical path in a conflict between Marxism and anti-Marxism in Japanese sociology, this reception has not lined up with Bourdieu's research intentions about Japanese society. As he wrote in Practical Reason and as described above, Bourdieu cared about social differences in various aspects of Japanese society, and he illustrated this concern by staying in Japan. He hoped to illustrate the principle of difference in Japanese society as he had in French society. This section shows the connections and future research possibilities regarding Bourdieu's intentions, Japanese sociological works and Japanese social settings. ${ }^{18}$

\section{Cultural capital and symbolic domination in the elite of Japanese society}

Bourdieu presented the idea of the 'field of power', referring not to the political field but the metafield, which he first developed in The State Nobility, the original French version of which was published ten years after Distinction, which first appeared in 1979. As the Japanese translation of The State Nobility was published in 2012 and Bourdieu's On the State is still not yet translated into Japanese, Bourdieu's notion of the state has not received sufficient attention in Japan. However, some important Japanese research on elites has interesting connections to Bourdieu's theme.

Apart from Bourdieu's works, Japanese sociology of education has demonstrated a strong interest in elites in Japanese society. Ikuo Amano, Morikazu Ushiogi, Makoto Aso and other sociologists of education who were born around the 1930s (and therefore are close in age to Bourdieu, and are still living), have written many studies on universities, elitism and the historical formation process of the field of Japanese bureaucrats. ${ }^{19}$ Their research has not referred to Bourdieu but has referenced Weber, and their intentions resemble Bourdieu's. These Japanese studies of the history of the Japanese elite and Japan's bureaucracy may be applicable and innovative for Bourdieusian research.

The next generation produced several excellent research studies about the social position of Japanese elites and their social field, which reference 
Bourdieu. The most important of these were written by Yo Takeuchi (2003), who presented a clear application of Bourdieu's concepts to historical or qualitative analysis. His work used the concept of field effectively and succeeded in describing social change in the Japanese intellectual world in universities. Takeuchi has both a theoretical and a historical interest in Japanese education and upward mobility. He examined Japanese meritocracy and upward mobility, especially that of Risshin-Shusse, in the 1990s (1995, 1997). Continuing his work into the 2000s, he discussed the decline of the intellectual atmosphere in Japanese universities in their post-World War II history (2003, 2005, 201 la), and developed his views on contemporary Japanese politics of populism (2011b, 2014). According to his research, Japanese elitism that was intended for symbolic domination by the affluent, through various types of capital in the field, has diminished, contrary to the notion that an egalitarian atmosphere was on the rise in this historical process. Following the translation of $\mathrm{On}$ the State (at least into English), the Japanese interest in political or bureaucratic fields must increase, and this expansion of interest may lead to the combining of Japanese research on elites with 'new' Bourdieu works.

\section{Japanese egalitarianism and cultural capital: a non-distinct difference?}

As introduced by Gordon above, the Japanese equalization process was extremely drastic following World War II (Piketty 2014). This process, and the economic miracle that followed, brought about an equal and affluent social situation for Japanese people. The economic miracle provided not only equal housing commodities but also equal cultural activity. For example, in the early 1960s, popular icons in children's culture consisted of the 'Giants (a baseball team), Taiho (an eminent Sumo wrestler) and baked egg' (Sakaiya 2015). Japanese children liked the same things, which went beyond their social classes. The Japanese economic miracle process combined with secondary educational expansion (around 50 per cent in 1948 to over 90 per cent in 1972) and the spread of television to every household. As Takumi Sato, a media sociologist, indicates, television provided equal cultural knowledge (2008). The industrialization process in Japan that followed World War II resulted in equal prosperity for Japanese people. Consequently, the distinction of capital has become invisible. Japanese society appears affluent and with nondistinct differences because the Japanese government recommended a 'middle' level of cultural activity and social environment to the masses through schooling and local community activity in that era. As a result, the distinctions in capital have become invisible. ${ }^{20}$

Japanese cultural or social activity in the middle class is broadly standardized on some points. For example, the lifestyles of children are highly uniform, 
both within school and outside of school. Compared to other Organization for Economic Cooperation and Development (OECD) countries (OECD 2005), ${ }^{21}$ the whole instruction duration in Japanese compulsory schools is shorter than in England, France and Germany. French schools have 100 more hours in an academic year than do Japanese schools (940 hours in France and 817 hours in Japan at the lower secondary school level). In addition, the percentage of hours of lessons in academic subjects in Japan (54 per cent) is lower than in European countries (France 69 per cent, Germany 67 per cent and England 65 per cent). Contrary to images of Asian education in the West (European and US views), Japanese schools have few formal school lessons, especially in academic subjects. This fact indicates that Japanese schools might appear to expand various social differentiations within and outside of school. However, the reverse has occurred. In sum, Japanese children's cultural capital is not primarily differentiated due to the school system.

Two factors illustrating cultural capital come from schools: one is the relation between extra activity outside schools and cram schools, and the other (more significant) one is extra-class activity, especially at the lower secondary level. First, according to a Benesse (a famous private institution) survey in 2008, around 70 per cent of students attend extra activities after schools at the primary level. However, 65 per cent of students attend cram schools after school during the last year of compulsory schooling, while the number of students attending extra activities decreases to around 20 per cent. Attending extra activities after school during primary school and going to cram school during lower secondary school is common for Japanese children. Not only the national curriculum but also the content of these activities is standardized. In most areas in Japan, Japanese writing (Shuji) and Japanese arithmetic (Soroban or Kumon) are common activities for students, and there are many local baseball or soccer teams available to them. As students advance to the lower secondary level, extra-class school club activities (Bukatsudo; Bu means 'club' and Katsudo means 'activity'; many Japanese call this word Bukatsu) provide standardized activity and are extremely important for gaining cultural and social capital. According to the Benesse survey, over 60 per cent of students participate in extra-class school club activities six or seven days a week. As a result, Japanese schoolteachers, especially at the secondary level, work longer than teachers in other countries helping with these activities. It is common for Japanese schoolteachers to go be present at their school six or seven days a week despite not teaching class lessons on Saturday and Sunday. Nakazawa (2014) illustrates the educational role of extra-class school club activities and admits they have educational utility and function for students, despite their facing issues with time management. Such activity brings about affluent cultural and social capital for students: clubs teach the significance of continuity 
of practice and effort, respect for others and how to communicate with elderly people, rather than focussing on the mastery of subjects, as is the case with school education.

In sum, Japanese secondary schools have many visible cultural activities. Therefore, Japanese researchers have recognized them as affluent resources of cultural capital. However, they are standardized, and not to be distinguished culturally and not to be differentiated as an elitist education system for producing 'state nobility' (Bourdieu 1996). The affluent but non-distinct situation of cultural or social capital in Japan can be regarded as 'state commons', in contrast to 'state nobility'. One example of state commons in Japanese society is radio calisthenics, Japan's common physical exercise. Analysed historically by Takahashi (1998) and Kuroda (1999), radio calisthenics was invented between the World Wars and was popular immediately before World War II. This practice continues through today, and over 75 per cent of primary schools take part in radio calisthenics, with many community groups managing early morning radio calisthenics (from 6:30 a.m.) during summer vacation. This practice teaches Japanese children about both the importance of daily exercise and waking up early outside of school.

The national examination is also a case of 'state commons' contrasting with state nobility. Masako Ema Watanabe, a sociologist of education and scholar of comparative education, conducted an important comparison between forms of examinations in Japan, the United States and France, referring to Bourdieu (Watanabe 2015). She compared the Japanese National Centre Test, the American SAT and the French baccalauréat, and analysed the hidden curricula in these examinations. According to her research, the Japanese National Centre Test examines the ability to infer human emotions for the creation of community, in a multiple-choice format that is completely different from the French baccalauréat's writing-based format. She situated the French test as one that examines the mastery of a dialectical thinking style for innovation.

This difference in the form of examination reflects the different emphasis of national curricula, and the Japanese desire for similarity and equality to create a community for a state commons, in contrast to the French desire for talent for innovation by state nobility. In addition, the Japanese examination system reflects greater distance from the Japanese traditional cultural heritage than do French tests. Although it is often criticized as a test that encourages the 'cramming of knowledge', Japanese students can pass their entrance examination only by taking a paper test. A written test on paper is easier to pass for lower-class people than test forms such as an interview. In this respect, the Japanese education system fits the form of state commons rather than state nobility. 
For this reason, then, it is difficult to find Japanese differences culturally or socially rather than economically using the same style of surveys as those of Bourdieu. Kondo took advantage of this development by refining a multiple correspondence analysis method (2011), compensating for the lack of multidimensional and relational views in Japanese sociology. Analysing national representative survey data, he concluded that the 'volume of capital' appears clearly both in social and behaviour/opinion spaces but that differences in the composition of capital are small and quite unclear. In other words, he showed in his artile that Japanese social space is only explained by the axis of economic capital.

However, we question Kondo's conclusion. Some researchers have found special fields of Japanese practices that are not accounted for by economic capital alone. For example, Makoto Kobari reveals that the structure of students' exit from public primary schools is related to social class in urban areas (2004). ${ }^{22}$ Also focusing on each cultural activity, social fields are formed in Japanese practices. In relation to this point, Japanese music practices form various social fields, illustrated by various capital components. For example, Katsuya Minamida analysed Japanese rock music using the framework of Bourdieu (2001), and Mari Yoshihara analysed the social field of Asian (not only Japanese) classical music (2008). Japan has affluent and equal cultural capital, but differences between forms of capital are often invisible. ${ }^{23}$ Researchers have an inviting possibility for researching and clarifying this invisible distinction.

\section{Conclusion}

While sociological classics explain past societies, they also imply new understandings of contemporary and future societies. Distinction is one such work: the first page of the text provides an idea for rethinking the concept of cultural capital:

There is an economy of cultural goods, but it has a specific logic. Sociology endeavours to establish the conditions in which the consumers of cultural goods, and their taste for them, are produced, and at the same time to describe the different ways of appropriating such of these objects as are regarded at a particular moment as works of art, and the social conditions of the constitution of the mode of appropriation that is considered legitimate. (Bourdieu 1984, 1)

We suggest rethinking the idea of cultural capital on this basis. Cultural capital functions in an economy of cultural goods, and the value of cultural capital is equivalent to the economy's degree of legitimacy. In this sense, cultural capital does not necessarily mean the frequency of visiting museums or a preference 
for classical music. It is evident that the modern capitalist society is composed of an economy of economic goods. For Bourdieu, the other fundamental component of a society is an economy of cultural goods, understood through the idea of cultural capital. These two types of economy seem to exist in Japanese society, but the concept of cultural capital has not been used to understand the differences between the two. Therefore, researchers must redefine cultural capital through undertaking empirical research.

In the 2000s, faced with growing inequality in Japanese society and emerging from the country's economic and social difficulties, including a rapidly aging population and globalization, Japanese people have become sensitive to the differences among them. Now is the time to apply Distinction and to make the social conditions of a changing Japanese society more visible. ${ }^{24}$ In other words, researchers must clarify social fundamentals in Japanese society by referring to economic dimensions and to one new dimension. It is both a difficult and challenging time from Bourdieu's point of view. Bourdieu taught researchers not to use his framework without concern for intention but rather to analyse the Japanese spirit through his sociology.

*Earlier versions of this article were presented at the 2014 annual conference of the British Sociological Association held in Leeds, 23-25 April 2014, and the 2014 annual conference of the Japan Society of Educational Sociology at Matsuyama, 13-14 September 2014. We are grateful for the comments and suggestions made at these meetings. We express our appreciation to Haruhisa Kato, Takehiko Kariya, Hiroyuki Kondo, Takashi Murakami, Yoicho Sakuramoto, Mirai Shida, Mikael Bourqui, Yi Mo and Akiyoshi Yonezawa for their helpful comments and suggestions.

\section{Notes}

1 Robbins summarizes two significant points of the analysis of the international knowledge transfer process. First, this analysis means the comparative analysis of the social and political conditions of production and reception. Second, this analysis means the process of transcultural transmission (Robbins 2012, 3).

2 Wakon Yosai has various translations: 'Japanese spirit, Western learning' or 'Japanese spirit, Western practice'. All of these terms imply that Japanese modernization absorbed Western knowledge without losing its identity, and in this chapter we have used 'Japanese spirit, Western technology, as used by Warner 1994.

3 In another example, the Japanese modern bourgeois culture was invented through the influence of European canonical cultures (Aoki et al. 2000). Examples also exist outside the field of law. In Oguma's comprehensive review of the history of Japanese national identity, Japanese people borrow Western concepts that are then adjusted to their economic and social development (Oguma 2002). The Japanese modernization process in the Meiji era means the social transformation from a semicivilized to a civilized country, with Japanese colonies increasingly involved in this process. As a result, Japan imported knowledge from Western countries and sometimes people in colonial regions 
learned imported knowledge. Dual knowledge transfer often occurred in the Japanese modernization process (Oguma 2014).

4 She cited 'the chrysanthemum and the sword' as symbols of aesthetic and militaristic cultural aspects. She explained the Japanese ethics of the social act through cultural behavior, as 'taking one's proper station', as their reliance upon order and hierarchy. Continuing in chapter 10, she described this Japanese ethic as a 'shame culture' as compared with the Western and Christian 'guilt culture'.

5 He came to Japan twice (1989 and 2000) to give some lectures and stayed less than two weeks each time. The lecture became the first chapter of Practical Reason (Bourdieu 1998). After citing Benedict's work, which preceded his citation of the Japanese philosopher Tetsuro Watsuji and the Japanese psychologist Hiroshi Minami, Bourdieu admitted the value of her book but was critical of it.

6 As described above, our international knowledge transfer framework refers to Robbins's work. Unlike Robbins, we do not review all of Japanese Bourdieu reception and application (Robbins 2012, 6). Our process is inevitably selective, but we aim to capture possibilities for the advancement of Bourdieusian applications from FrenchJapanese international knowledge transfer. In this reviewing process, we attempt to reflect 'on their different views which logically make the comparative project itself differently defensible' (Robbins 2012, 4). We advance not only the dimension of knowledge, but also the dimension of Japanese sociohistorical conditions from this point of view.

7 However, the Japanese myth of equality has commonalities with developed countries in the post-war era. Naoto Mori, a sociologist, criticized this view using international and historical comparisons (2008).

8 However, Miyajima suggested that his understanding is too close to Durkheim (Miyajima 1994, 308).

9 On this point, Bourdieu was introduced in the same context as Jean Baudrillard. For example, Hitoshi Imamura and Fumi Tsukahara translated both The Logic of Practice by Bourdieu and The Consumer Society: Myths and Structures by Baudrillard. This stream might stress the relative importance of culture and consumption, which was imported from Bourdieu, in the reception in Japan. As a result, the Japanese reception of Bourdieu was close to the reception of Baudrillard.

10 Ishii admitted the multiplicity of important terms in the postscript of Distinction. He wrote that another bothering point was the choice of translated terms corresponds to some basic terms. The word 'distinction' is an example of the difficulty involved in translating Bourdieu's key terms and frequently used concepts into Japanese to convey his intention. In this case, Ishii chose a word from some word groups along with its context.

11 For example, Ishii (the translator of Distinction) and Yamamoto each wrote a book focusing on Distinction (Ishii 1993; Yamamoto 1994). This is more acceptable for Japanese readers than a translation of Distinction.

12 Following these articles, she used a correspondence analysis and applied her peculiar cultural analysis to tests of the 'cultural exclusion hypothesis' or 'cultural omnivore hypothesis' referred to by Peterson (1992) and Bryson (1996) (that is, Kataoka 2003).

13 Shuichi Iwatsubo, a statistician, translated 'correspondence analysis' into Japanese in 1987 (Iwatsubo 1987), and the first detailed application of French correspondence analysis was translated by Noboru Osumi and Yasumasa Baba, both statisticians, in 1994 from Lebart et al. (1984). Before the arrival of French correspondence analysis, Chikio Hayashi, a well-known Japanese statistician, devised his quantification theory and Type III analysis, which is similar to correspondence analysis. Many Japanese 
scholars have understood correspondence analysis as analogous to his Type III analysis. However, the recent work of Japanese psychometrician Takashi Murakami partly rejected the idea that these two analyses are comparable (Murakami 2013).

14 See Flath 2014 on history of the Japanese economy.

15 The Japanese introduction of this developing process was introduced by Iso's work (Iso 2008, 2011), which preceded the introduction of Bourdieu to Japanese speaking world.

16 Interview by Iso, 2 August 2014 at Komaba Campus of the University of Tokyo.

17 Interview by Iso, 2 August 2014 at Komaba Campus of the University of Tokyo.

18 For this connection, it is important, like Iso's $(2011,2013)$ attempt, to achieve a comprehensive understanding of Bourdieu's theories in Japanese by refining the concepts of field and class, and by conducting intense readings and analyses of Bourdieu's work, as well as those of other French-speaking researchers throughout the world.

19 Some of them have studies not only in Japanese but also in English (that is, Amano 1990, 2011). We add Takane's paper (Takane 1981), which analysed the Japanese political elite quantitatively. Sadly, he passed away just after this book was published.

20 However, these efforts do not correspond to the highest levels of cultural capital, for example, playing the violin or dancing ballet, and the social environment.

21 This tendency continued also in Education at a Glance in 2009.

22 Additionally, Aizawa developed this discussion and found a distinction among mothers whose children go to private primary school and go to private schools in all stages, mothers whose children go to private secondary school and mothers whose children go to public schools. These differences are not only illustrated by their economic situation but are also influenced by cultural or social capital (Aizawa, 2015).

23 See Bestor et al. eds. (2011) on contemporary Japanese culture.

24 Our future work will 'visualize', in the sense of Bourdieu's term, the Japanese distinction referred to in Distinction, as in Bennett et al. 2009 or Savage et al. 2013. The authors are in the process of translating Culture, Class, Distinction into Japanese (Bennett et al. 2009).

\section{References}

Aizawa, Shinichi (2015). 'Kyōiku: Shiritsu gakkō ni shingaku-suru hitobito no dēta kara mietekuru Kyōiku-kakusa to raifu stairu' [Education: data analysis of educational inequality and lifestyles of attendees for private schools], in Jun Kobayashi and Masahiro Yamada (eds.) Dēta de yomu Kakusa-shakai: Raifu-sutairu to raifu-kōsu no miraikei [Unequal society from data analysis: future form of lifestyle and life course], Tokyo: Shinyōsha, $144-57$.

Akinaga, Yuuichi. 1984. " "Kyōiku-teki" na kankei no tokushitsu ni tsuite: Aruchusēru to Burudyū no hihanteki kentou' [On the character of 'pedagogic relationships': a critical review of Althusser and Bourdieu]. Bulletin of the Graduate School of Education, University of Tokyo 23: 287-96.

1987. 'Gendai ni okeru “mibun” to kyōiku: "Bunkateki saiseisan” eno shikaku’ [Are new statues emerging in Japan?: a note for empirical study on "cultural reproduction"]. Journal of Educational Sociology 42: 92-105.

Amano, Ikuo. 1990. Education and Examination in Modern Fapan. Tokyo: University of Tokyo Press.

2011. The Origins of Japanese Credentialism. Victoria: Trans Pacific Press. 
Aoki, Tamotsu. 1990. 'Nihonbunkaron' no Hen'yō [Phases of 'theories of Japanese culture' in transition], Tokyo: Chūō Kōron Shinsha.

2000. Hai Karuchā [High culture], Iwanami shoten.

Aso, Makoto. 1978. Erito keisei to kyōiku [Education and Japan's modernization], Tokyo: Fukumura-shuppan.

2009. Nihon no gakureki erīto [Education elite of Japan], Tokyo: Kodansha Academic Library.

Bellah, Robert. 1957. Tokugawa Religion: The Values of Pre-industrial Japan. New York: Free Press: Falcon's Wing Press.

Bennett, Tony Mike Savage Elizabeth Silva Alan Warde Modesto Gayo-Cal David Wright. 2009. Culture, Class, Distinction. Abington: Routledge.

Bestor, Victoria Lyon, Theodore C. Bestor and AkikoYamagata eds. 2011. Routledge Handbook of Japanese Culture and Society. Abington: Routledge.

Bourdieu, Pierre. 1990. 'Preface', in Pierre Bourdieu and Jean-Claude Passeron. Reproduction in Education, Society and Culture, 2nd ed. London: Sage Publications.

1998. Practical Reason: On the Theory of Action, Oxford: Polity.

2008. Esquisses algériennes, ed. Tassadit Yacine, Paris: Seuil.

2012. Sur l'état: cours au Collège de France (1989-1992), ed. Patrick Champagne et al., Paris: Raisons d'agir/Seuil.

Bourdieu, Pierre Horio Teruhisa and Kato Haruhisa, 1989-2000, 'Ima kyōiku ni nani wo motomeruka' [What do we expect from education?], Jōkyō shuppan henshūbu ed., Burudȳu wo yomu [Reading Bourdieu], Tokyo: Jōkyō shuppan: 164-85.

Bourdieu, Pierre and Kenichi Tominaga. 2001. 'Shakaigaku toha nanika' [What is sociology?], Kan: History, Environment, Civilization 5: 4-28.

Chew, Matthew M. 2014. 'Rethinking the Relationship between Intellectuals and Nationalism: A Sociology of Knowledge Approach to Philosopher's Construction of National Cultural Identities in Modern Japan and China'. Current Sociology 62, no. 3: 314-33.

Cummings, William. 1980. Education and Equality in Fapan. Princeton: Princeton University Press.

Dore, Ronald. 1976. The Diploma Disease: Education, Qualification and Development. Berkeley: University of California Press.

Flath, David. 2014. The Fapanese Economy. Oxford: Oxford University Press.

Fujita, Hidenori Miyajima Takashi Akinaga Yuuichi Hashimoto Kenji and Shimizu Kokichi. 1988. 'Bunka no Kaisousei to bunka teki saiseisan' [Cultural stratification and cultural reproduction], Bulletin of the Graduate School of Education, University of Tokyo 27: 51-89.

Gordon, Andrew. 2002. A Modern History of Japan: From Tokugawa Times to the Present. Oxford: Oxford University Press.

Hara, Junsuke and Seiyama Kazuo. 2005. Inequality amid Affluence: Social Stratification in Fapan. Victoria: Trans Pacific Press.

Hirakawa, Sukehiro. 1971. Wakon Yōsai no uchi to soto kara no Meiji Nihon [The genealogy of Japanese spirit, western technology: Meiji Japan from inside and outside]. Tokyo:

Kawade Shobo.

2004. Japan's Love-Hate Relationship with the West, Global Oriental.

Inoue, Tadashi. 1983. Kyōikuseido ni okeru jichiryōiki to shakaiteki seiyaku jyōken [Autonomy and social conditions of the educational institutions]. Fapanese Fournal of Educational Research 50, no. 3: 242-53. 
1986. 'P. Burudyū no "Bunka-shihon" gainen no shakai-teki kiso to seido-teki ichi' [The position of Pierre Bourdieu's 'cultural capital' in modern society]. Fournal of Educational Sociology 41: 166-81.

Ishida, Hiroshi. 1991. Social Mobility in Contemporary Japan. Palo Alto, CA: Stanford University Press.

Ishii, Yōjiro. 1993. Sai to yokubō: Burudyū Disutankushion wo yomu [Difference and desire: reading Bourdieu's Distinction]. Tokyo: Fujiwara shoten.

Iso, Naoki. 2008. 'Saiseisan igo no Burudyū: 1970-nendai ni okeru 3tu no kisogainen no keisei' [Bourdieu after Reproduction: essay on the formation of three basic concepts in the 1970s]. Shakaigaku-shi Kenkyu [The Japanese Journal of the History of Sociology] 30: 125-40.

_2011. 'Burudyū no kaikyū bunseki' [Bourdieu's class analysis], Shakaigaku-shi Kenkyu [The Japanese Journal of the History of Sociology] 33: 85-100.

2013. Pièru Burudyū niokeru Shakaigaku-teki Shikō no Seisei [The Formation of the Sociological Thought of Pierre Bourdieu]. PhD thesis, Hitotsubashi University.

Iwatasubo, Shuichi. 1987. Sūryōkahō no Kiso [Basis of quantification theory]. Tokyo: Asakura Shoten.

Karabel, Jerome and A. H. Halsey eds. 1977. Power and Ideology in Education. Oxford: Oxford University Press.

Kataoka, Emi. 1992. 'Shakai-kaisō to bunka-teki saiseisan' [Social and cultural reproduction processes in Japan]. Sociological Theory and Methods 7, no. 1: 33-55.

_ 2003. 'Taishū bunka shakai' no bunkateki saiseisan; kaisou saiseisan, bunkateki saiseisan to jendā kouzou no rinkēji' [Cultural reproduction and gendered structure of Japanese culture: class, culture and gender], in Takashi Miyajima and Yojiro Ishii (eds.) Bunka no kenryoku: Hansha suru Burudyū [Power of culture: Bourdieu and Japan sociology]. Tokyo: Fujiwara shoten, 101-35.

Katō, Haruhisa. ed. 1990. Piēru Burudyū: Chōiki no ningen gaku [Pierre Bourdieu: transdisciplinary anthropology]. Tokyo: Fujiwara shoten.

Kawashima, Takeyoshi. 1967. Nihonjin no Hō Ishiki [Legal consciousness of Japanese]. Tokyo: Iwanami shoten.

Kobari, Makoto. 2004. 'Kaisō mondai to shite no shōgakko-juken: Kazoku no keizaiteki jinkō-teki, bunka-teki haikei ni chakumokushite' [An emprical study on the social classes of parents who choose the elementary schools attached to national university or private elementary schools: from the points of view of economic, demographic and cultural backgrounds'], Fapanese Fournal of Educational Research 71, no. 4: 422-34.

Kondo, Hiroyuki. 2011. 'Shakai kūkan no kōzō to sōdōsei kasetsu' [Structures of social space and the homology thesis: examination of Bourdieu's approach in Japan]. Sociological Theory and Methods 26, no. 1: 161-77.

Kuroda, Isamu. 1999. Rajio taisō no tanjō [Birth of radio calisthenics]. Tokyo: Seikyūsha.

Lebart, L., A. Morineau and K. M. Warwick. 1984. Multivariate Descriptive Statistical Analysis: Correspondence Analysis and Related Techniques for Large Matrices. Hoboken, NJ: Wiley \& Sons.

Minamida, Katsuya. 2001. Rokku myüjikku no shakaigaku [Sociology of rock music]. Tokyo: Seikyūsha.

Miyajima, Takashi. 1994. Bunkateki saiseisan no shakaigaku: Burudyū riron kara no tenkai [Sociology of the cultural reproduction: theoretical development from a theory of Bourdieu]. Tokyo: Fujiwara shoten.

Miyajima, Takashi and Fujita Hidenori. 1991. Bunka to shakai: saika, kouzouka, saiseisan [Culture and society: differentiation, structurization, and reproduction]. Tokyo: Yūshindō kōbunsha. 
Miyajima, Takashi and Ishii Yojiro. 2003. Bunka no kenryoku: hansha suru burudyū [Power of culture: reflections for Bourdieu]. Tokyo: Fujiwara shoten.

Mori, Naoto. 2008. 'Sōchūryū no shisō toha nani dattanoka: chū-ishiki no genten wo saguru' [What did the middle masses think about?: Searching for the origin of middleclass consciousness]. Shisō Chizu [Thought map] 2: 233-70.

Mouer, Ross and Yoshio Sugimoto. 1986. Images of Japanese society: A Study in the Structure of Social Reality. Kegan Paul International.

Murakami, Takashi. 2013. 'Sūryōka-sanrui to tajūtaiō-bunseki' [Quantification theory type III and multiple correspondence analysis]. Shakai to Chōsa [Society and survey] 12.

Murakami, Yasusuke. 1984. Shin-chūkan taishū no jidai: Sengo nihon no kaibou-gaku [The age of new middle-standing mass: anatomy of postwar Japan]. Tokyo: Chūōkōron sha.

Nakazawa, Atsushi. 2014. Undoubu katsudou no sengo to genzai naze supōtsu wa gakkō kyōuiku ni musubitsukerareru noka [Sports club activities: why are sports connected to school education?]. Tokyo: Seikyūsha.

Nomura Research Institute. 1979. Sengo Nihonjinron Nenpyo [Chronology of post-war Nihonjinron]. Tokyo: Nomura Research Institute.

Oguma, Eiji. 2002. A Genealogy of Japanese Self-Images. Victoria: Trans Pacific Press.

2014. The Boundaries of 'the Fapanese': vol. 1: Okinawa 1818-1972-Inclusion and Exclusion. Victoria: Trans Pacific Press.

Onai, Tōru. 1995. Saiseisan-ron wo yomu: Bānsutein, Burudyū, Bōruzu=Gintisu, Uirisu no saiseisan-ron Reading reproduction theories: reproduction theory on Bernstein, Bourdieu, Bowles-Gintis, and Willis]. Tokyo: Tōshindō.

Organization for Economic Cooperation and Development (OECD). 2005. Education at a Glance, OECD.

Otsuka, Hisao. 1966. Shakaikagaku nohoho: Weba to Marukusu [Method of social science: Weber and Marx]. Tokyo: Iwanami Shoten.

Pikketty, Thomas. 2014. Capital in the Twenty-First Century. Cambridge, MA: Harvard University Press.

Robbins, Derek. 2012. French Post-War Social Theory: International Knowledge Transfer. Los Angeles/London/New Delhi/Singapore/Washington, DG: Sage Publications.

Rohlen, Thomas P. 1977. 'Is Japanese Education Becoming Less Egalitarian? Notes on High School Stratification and Reform'. Fournal of Japanese Studies 3, no. 1: 37-70.

Sakaiya, Taichi. 2015. Sakaiya Taichi ga mita sengo nanajunen nanairono Nihon [Postwar seventy years from the view of Sakaiya Taichi]. Tokyo: Asahi Shinbun Shuppan.

Sakuta, Keiichi. 1964. Hajinobunka saikō [Rethinking shameculture]. Tokyo: Chikuma-Shobo.

Satō, Takumi. 2008. Terebi-teki kyōyō: ichioku sōhakuchika e no keifu [TV-like education: a genealogy of the idea that all-Japanese-are-knowledgeable]. Tokyo: NTT shuppan.

Savage, Mike, Fiona Devin, Niall Cunningham, Mark Taylor, Yaojun Li, Johs Hjellbrekke, Brigitte Le Roux, Sam Friedman and Andrew Miles. 2013. 'A New Model of Social Class? Findings from the BBC's Great British Class Survey Experiment'. Sociology 47, no. 2: 219-50.

Tahara, Otoyori. 1993. Kagaku-teki chi no shakaigaku: Durukēmu kara Burudyū made [Sociology of scientific knowledge: from Durkheim to Bourdieu]. Tokyo: Fujiwara shoten.

Takahashi, Hidemi. 1998. Subarashiki rajio taisō [Wonderful radio calisthenics]. Tokyo: Shōgakkan.

Takeuchi, Yō. 1995. Nihon no meritokurashī [Japanese meritocracy]. Tokyo: University of Tokyo Press. 
1997. Ricchinshusse-shugi: Kindai nihon no roman to yokubou [Careerism: romance and desire in modern japan]. Tokyo: NHK Shuppan.

2003. Kyōyō shugi no botsuraku: Kawariyuku erīto gakusei bunka [Collapse of Kyōyōshugi: change of elite-student culture]. Tokyo: Chūō kōron shinsha.

2005. Maruyama Masao no judai: daigaku, chishikïin, jānarizumu [The era of Maruyama Masao: university, intellectual, journalism]. Tokyo: Chūō kōron shinsha.

2011 la Daigaku no karyū-ka [Lowerization of universities]. Tokyo: NTT Publishing.

2011 b. Kakushin-gensō no sengoshi [Postwar history of the fantasy of Japanese innovatism]. Tokyo: Chūō kōron shinsha.

2014. Taishū no Genzō [Phantom of the mass]. Tokyo: Chūō kōron shinsha.

Tominaga, Kenichi. 2011. Shakaigakuwaga shōgai [Sociology, my life]. Kyoto: Minerva-shobō.

Vogel, Ezra F. 1979. Japan as Number One: Lessons for America. Cambridge, MA: Harvard University Press.

Warner, Malcolm. 1994. 'Japanese Culture, Western Management: Taylorism and Human Resources in Japan' Organization Studies 15: 509-33.

Watanabe Ema Masako 2015. 'Typology of Abilities Tested in University Entrance Examinations: Comparisons of the United States, Japan, Iran and France', Comparative Sociology 23, pp. 79-101.

Yamamoto Tetsuji. 1994. Piēru Burudyū no sekai [The world of Pierre Bourdieu]. Tokyo: Sankō sha.

Yoshihara Mari. 2007. Musicians from a Different Shore: Asians and Asian Americans in Classical Music. Temple University Press.

Yoshino, Kosaku. 1995. Cultural Nationalism in Contemporary Japan: A Sociological Enquiry. London: Routledge. 


\title{
Chapter 7
}

\section{WORLDS WITHIN AND BEYOND WORDS: BOURDIEU AND THE LIMITS OF THEORY}

\author{
Sheena Jain
}

While verbal expressions, whether oral or written, sometimes fail to convey all that we wish to, and as precisely as we want to, this is seldom viewed as a limitation inherent in language itself. More often than not, it is attributed, with some justification, to a lack of adequate skills on the part of the speaker or author. Just as often, the fact that theoretical expressions in the social sciences are linguistically mediated is something that is taken for granted and regarded as unproblematic, while it is in the conceptual framework of the theory being considered that the source of any shortcoming or of power that the expressions carry is located.

However, the role of language as a constitutive element in the practice of theory has been framed, reflected upon and even critiqued in diverse ways in certain intellectual traditions, including discussions with reference to forms of sociological thought. And this is not surprising, since a close intermeshing of thoughts and words, and their amalgamation in conceptual vocabularies, has been a staple of representations of the social world in most social sciences. Yet the expectation that words would, in some sense, deepen our understanding of the world we live in, and that they may take us closer to the truths of human social existence, is one whose realization is considered, perhaps today more than ever before, as being extremely complicated. For we are being sensitized to the fact that the journey to and fro between words and the world is complex, uncertain and even impossible according to some schools of thought.

In what follows, I first unravel the threads linking words and the world in certain prominent forms of social theory as a backdrop for identifying some distinctive features of Pierre Bourdieu's theoretical practice and theory of practice. I then outline the main events and salient features of a contemporary episode in working-class history, in order, next, to discuss how far the 
features of Bourdieu's theory enumerated earlier, and his political perspective, can deepen our understanding of the events described. Finally, I reflect briefly on the general assumption that theory provides some sort of a grip on social reality.

Social hermeneutics is my starting point for discussing theoretical traditions since it is clearly premised on the relevance of forms of linguistic expression for purposes of social analysis. It proceeds on the basis of an analogy between texts constructed via the medium of language and interpreted by readers, on the one hand, and structures of social life 'constructed' so to speak, by meaningful social action, and read and interpreted by social actors and students of society, on the other.

Though hermeneutics is not an exclusively Western intellectual tradition, its sociological lineage may be traced back, via Friedrich Schleiermacher's modern hermeneutics in the eighteenth century, to Wilhelm Dilthey's social hermeneutics in the nineteenth and early twentieth centuries. As hermeneutics made a transition from the interpretation of written texts to the interpretation of social action, the task of deciphering meaning was seen as one fraught with many complexities, evoking varied responses, initially from Dilthey, and more emphatically from Hans-Georg Gadamer, Jürgen Habermas and Paul Ricoeur, whose works followed his.

Gadamer, for instance, was concerned that the interpreter herself brings something of her own to bear on the reading, so that he spoke of prejudices. Their negative effects could be positively resolved, however, by what he termed a 'fusion of horizons'- that is, through the shared sociocultural traditions of the scholar and the subject. For Habermas and Ricoeur, on the other hand, a common sociocultural context was insufficient to reveal meaning. Its deeper layers had to be unearthed and perceived not by interpretation alone but by methods of explanation as well, akin to those used by psychoanalysis in the case of individual neuroses, and also through the mediation of structuralist analysis according to Ricoeur. The hidden transcript that would surface through this 'depth hermeneutics' would enable a discerning of how distortions, ellipses and contradictions are patterned by elements such as power and desire, which are obscured by a naive reading.

This more complex rendering of how the social text can be read seemed to turn the earlier dualism of understanding versus explanation into a complementarity, challenging the rigid separation of the methods of the human sciences from those of the natural sciences. And though Max Weber, too, had proposed a coming together of interpretive understanding and causal explanation, in Habermas's and Ricoeur's work, these modes of knowing engaged with social action encompassing not just subjective consciousness and overt 
behaviour as for Weber, but also the dimensions of the unconscious, of desire and of power. Moreover, while for Weber, Verstehen was the primary method for explaining social action, even when supplemented by scientific techniques of a positivistic kind, the meshing of interpretive and explanatory methods took a very different form in the conceptions of Habermas and Ricoeur. Their perspectives were also very far removed from the idea of a unified science, as proposed by advocates of a positivist methodology for the human sciences, such as Karl Hempel and Ernst Nagel.

Ricoeur argued, for instance, that neurotic behaviour lies at the very intersection of intentional action and unconscious compulsion, making a radical disjunction between reason and cause unhelpful and inappropriate. And it is this that makes the language of psychoanalysis a mixed discourse. He thus introduced the notion of a 'semantics of desire', to suggest that psychoanalysis discloses a dimension of experience where meaning and force coincide, so that there is a need to develop an intermediate concept of desire, as being at once a motive and a cause (Thompson 1985, 46-7). It follows that psychoanalysis and the social sciences in general must evolve a framework that integrates the moments of understanding and explanation into a systematic and coherent methodology. It is significant that Ricoeur incorporates structuralism within his dialectic of interpretation, in consonance with his view that social phenomena are semiological in nature, but he does not do this without adding a hermeneutic supplement. This supplement aims to enable a move from the structures of the texts, whether oral or written, or whether of social life read as a text, to their referential dimension, including the world that is not hidden in the text but opens up in front of it. In other words, a possible world, which is not bound to a particular situation, though suggested by it (Thompson ed. 1987, 15).

However, while the aspect of interpretation noted above gave it a subversive potential, Ricoeur sees the link between interpretation and critique as always partial, fragmentary and limited. This is not only because of the plurivocality of texts that do not permit of a last word, even as competing interpretations vie for validation through a process akin to that of juridical reasoning, so that a particular interpretation may be validated. It is also because, being part of the very world we seek to understand, there is no position outside of history and society from which we can survey the social historical sphere. Furthermore, in abandoning the positivist model, hermeneutics rejects, at the same time, a disjunctive conception of the relationship between science and ideology. Instead, 'all knowledge of the social world is preceded and supported by a relation of belonging, an "ideological" relation in the primordial sense - upon which we can never fully reflect' (Thompson ed. 1987, 24).

In Habermas's theoretical framework, in contrast, the discerning of ideological distortions is a major concern, and thus implies the possibility of 
knowing the truth, with reference to which distortions may be defined as such. Without going into the details of his ideas of communicative rationality and of the ideal speech situation within which his concept of truth is embedded, we may, in the context of our discussion here, note that this concept is based on a rejection of the centrality of the subject-object relation involving monologic or instrumental activity as in the positivist tradition. It is supported instead by arguments for an alternative conception that is ultimately dependent on subject-subject relations - that is, relations concerned with the interaction of a subject with an object that can be regarded as another subject, involving dialogic or communicative interaction. It offers, simultaneously, an alternative to the relativism of certain contemporary philosophers of science, such as Thomas Kuhn and Paul Feyerabend.

While it may seem that we have digressed somewhat from the theme of reading social reality as a text, it is relevant to explore, as we have done here, whether and how a social science reading can discern the truth of a text. In the process of doing so, we have encountered some divergent paths that have been taken.

Significantly, insofar as language is the vehicle used for the representation of truth by all the traditions discussed thus far, and given its apotheosis in Habermas's idea of linguistic rationality as the ultimate form of reason and incontrovertible basis for arriving at the truth, a positive link between words and the world seems axiomatic for these thinkers, however complex and incomplete the journey linking them may be.

It is against this backdrop that the impact of Jacques Derrida's radical hermeneutics can be measured - that is, of Derridian deconstruction that argues the inefficacy of language itself as a communicative medium. Consequently, the notion that a text is a unified, coherent whole, perhaps communicating a message and in some way representing or recreating a reality external to it, is shown to be an illusion. This is because language, made up of signifiers that only refer to that which transcends them, that is, the signified, is regarded as inescapably metaphysical. This transcending of the empirical facticity of the signifier by an ideally conceived signified is metaphysical according to Derrida, and attempts by the structuralism of Saussurean linguistics and Lévi-Straussian anthropology to break free from metaphysics still relied on metaphysical assumptions. This is apparent in their retaining as natural such oppositions as those between speech and writing, mind and body, inside and outside, good and evil, accident and essence, identity and difference, presence and absence, space and time, the literal and the figurative, or even male and female, whose use in both tradition and in more recent sciences suggest, moreover, that in practice, one pole in these oppositions is privileged over the other. ${ }^{2}$ Importantly, Derrida maintains that though we cannot imagine 
or bring about the end of metaphysics, we can undertake a critique of it from within by identifying and reversing the hierarchies it has established (Culler 1987, 82). However, deconstructive critique, unlike Kantian critique, which is defined in opposition to dogmatism, is always dogmatic since language is metaphysical. Thus even when deconstruction challenges a particular dogmatism, it cannot escape it altogether. Nevertheless, Derrida's critique of hierarchized binaries has been very influential - in literary criticism of course but also in social science research, since it focuses on a pervasive and deep-rooted dimension of social reality. In the work of certain anthropologists for instance, hierarchized binaries are read as culturally contingent forms of power, vulnerable to subversion. The particular conceptual form in which they appear in Bourdieu's work will be discussed below.

It may be meaningful at this point to consider the status of 'truth' in Derrida's deconstruction. It has been observed that rather than denying the possibility of truth, Derrida may be interpreted as regarding truth as trivial, and not the main issue for his concerns (Hoy 1985, 57). Moreover, according to him, there may be too many statements in a text that are true, so that the practical difficulty is in selecting from the plethora of truths a useful subset. There is, in other words, no such thing as truth in itself, but only a surfeit of it - truth is plural (Hoy 1985, 57). Thus in certain anthropological works, this translates into the equivocality of multiple voices coming from a field. There is also therefore an undecidability of textual meaning. Very much along the lines of hermeneutics from Gadamer on, Derrida maintains that there is no uniquely privileged standpoint for understanding, including any special authority of the speaker or author for determining the meaning of what is said or written (Hoy 1985, 51).

Moreover, methods of interpretation must, according to Derrida, desist from searching for either 'hidden meaning' or some causal relation to an aspect of external reality. Texts can refer only to other texts, generating an intersecting and indefinitely expandable web called intertextuality. Not surprisingly then, Derrida's reference to Plato's frequent presentation of writing as a drug or as a pharmakon has elicited the comment that in Derrida's view, 'the narcotic effect of words leads us to take reality as a dream, and dreams as reality, and philosophy loses sight of the difference' (Hoy 1985, 58).

If I have so far outlined certain intellectual traditions with reference to problems of interpretation, analysis and representation of social reality and truth, this has been to enable a location of Bourdieu's sociological contribution from a perspective that is somewhat different from the usual.

According to Bourdieu, the attempt to read social reality as a text is inherently problematic, for the logic of practice is not analogous or homologous to language, thought or any other such paradigm. Such analogizing falls into 
the 'fallacy of seeking to contain in concepts a logic made to do without concepts' (Bourdieu 1990, 92). Referring critically to the work of Clifford Geertz, for instance, Bourdieu asks whether Geertz has transformed social connections into communication connections $(1985,92)$. Instead, Bourdieu's theory of practice is acutely sensitive to the importance of discerning how practical reason, rather than 'rational' reason is realized in social action by means other than those of conscious ratiocination. The analysis of this logic of practice with the aid of concepts such as habitus, capital and fields is the key to understanding the construction of social reality according to him.

Bourdieu's perspective is rooted in a conception of sociology as a postpositivist science that draws upon the French epistemological tradition of philosophers of science such as Georges Canguilhem and Gaston Bachelard, and is informed by Bachelard's notion of truth as rectified error. While eschewing claims of arriving at absolute truths, it implies regarding the pursuit of truth as a meaningful enterprise, which proceeds, via breaks, to rectify errors, resulting in progressive approximations to absolute truth. Thus Bourdieu regards his concepts as heuristic and his theories as open-ended constructs, whose real meaning lies in their use in actual empirical research. This makes his approach distinct from both the positivist position in which the status of truth is absolute and unquestioned, and from the postmodern ontology of the undecidability of meaning or of the impossibility of representation. Significantly, for Bourdieu, the limitations of theory in relation to absolute truth do not stem from qualities inherent in language, but emanate in part at least, from the inherent distance between practice as such and the theory of practice.

Further, even as Bourdieu like Bachelard views the errors of common sense or prenotions as obstacles to be overcome and rectified by scientific truths, he does not regard as justified the assumption by the scientist of a position of omniscience. Asserting that 'in a sense, agents know the social world better than the theoreticians' (Bourdieu et al. 1991, 252), he views the struggle for truth as one in which social actors themselves participate, with the difference that the sociologist objectifies their views by constituting the space of points of view. This in turn evokes a notion of objectivity that is constructed by rather than apart from the perspectives of those who create social reality, but not without an objectification encompassing the social coordinates of all, including those of the scientist herself. Importantly then, relativity does not dissolve into relativism. Thus Bourdieu offers in place of either relativism or constructivism a form of reflexive objectivity that he terms 'participant objectivation'. While rejecting the ideal of detached observation, he draws inspiration in delineating this form of objectivity from Bachelard's emphasis on the scientific value of reflective and critical thought, as against the grounding of knowledge in 
presumed perceptual passivity. Participant objectivation is thus proposed as an alternative to the commonly used anthropological method of participant observation in which a claim to objectivity is based on an identification of the subject with object. It can also be contrasted with Gadamer's solution to the problem of prejudice via a 'fusion of horizons', insofar as the latter does not problematize shared sociocultural contexts in terms of particular locations, experiences and trajectories, as participant objectivation does.

Bourdieu's Bachelardian concept of truth as rectified error and his method of participant objectivation are also intrinsically related to the ideas of 'reality' and 'realism' that underpin his theoretical practice. Far from the naive realism of empiricists, Bourdieu adopts what he terms following Bachelard, a rational realism, which is also an applied rationalism. It implies a primacy of theory, and a dialectic between theory and verification at every stage of the scientific process, in which the 'values of coherence' and 'fidelity to the real' are closely associated. This is because, according to Bourdieu, 'the epistemological vector points from the rational to the real and not, as all philosophers from Aristotle to Bacon professed, from the real to the general' (Bourdieu et al. 1991, 158). It also entails plunging into the particularity of an empirical reality with the objective of constructing it as a special case of what is possible, that is, 'as an exemplary case in a finite world of possible configurations' (Bourdieu 1998, 2). This, significantly, allows one to question the 'possible', which among all others is actualized, and opens up a space for things to have been (and for them to still be) otherwise. (Bourdieu 1998, 40). It also subverts a lapse into empiricism by freeing analysis from the confines of a narrowly defined substantive reality. Further, what is 'real' at any point of time according to Bourdieu is the mediated outcome of current theory and existing equipment, and more generally, in Bachelard's words, 'What is belief in reality? [...] It is essentially the conviction that there is more to an entity than is immediately given' (Bourdieu 2004, 3; Bachelard, quoted in Tiles 1984, 48).

It is extremely important to note that the elements of critique that form the basis of Bourdieu's rejection of positivism do not lead him to an idealist hermeneutics with its dichotomous conception of the natural and the human sciences. This is so even though idealist modes of analysis predominate in scholarly writings on the subject of the symbolic, a realm that figures as a central dimension of Bourdieu's theory of practice. He delineates, instead, a dialectic of the material and the symbolic from a materialist perspective that takes Karl Marx's First Thesis on Feuerbach as its point of departure. It breaks out of the twin errors of the 'objectivism' of Feuerbachian materialism that fails to regard reality as human practice in a subjective way, and the 'subjectivism' of idealism, which develops the subjective dimension without a grasp of real, concrete activity. In terms of contemporary social theory, it overcomes the 
conceptual antinomy between a social physics and a social phenomenology that has been a long-standing feature of the history of sociology.

It is notable, too, that while the concepts of habitus, of forms of capital and of fields constitute key elements of his theory of practice, of these, the concept of habitus plays a particularly crucial role in articulating these elements so as to transcend the dualism of the objective and the subjective. Without going into the details of its construction, what needs to be grasped is that Bourdieu ventures, via the concept of habitus, into regions of social practice that go beyond a theoretical canvas such as that of Marx, for instance, illuminating the springs that animate thought and action in the world of everyday practice. The concept thus includes within its ambit phenomena ranging from forms of bodily hexis, common sense and myth, to elaborations of literary, metaphysical and scientific thought. Importantly, it enables analysis to move away from the debilitating influence of the Cartesian mind-body dualism, highlighting the role of embodied forms of knowledge that generally operate below the level of conscious thought and pattern social reality. This is so even as these forms are viewed as being capable of generating creative and novel kinds of action in particular conjunctures, at times involving conscious design and effort as well. In this, the concept is inherently a critique of the Marxist and feminist advocacy of consciousness raising as a means for initiating radical change. For it is argued that the transformation of embodied subordination demands undertaking exercises that go beyond a symbolic mastery of the habitus, since the efficacy of such mastery is limited to the realm of ideas and of conscious thought. Further, in amplifying the interaction of the material and symbolic via the concept of habitus, Bourdieu also critiques and innovates with diverse intellectual traditions, including the Weberian, the Durkhemian, the Marxist, the structuralist and the phenomenological, so as to construct a number of new concepts such as those of symbolic power, symbolic capital and symbolic violence. These greatly sharpen and enrich the conceptual vocabulary of his theory of practice.

Bourdieu's critique of positivism also sidesteps the idealism of Derridian deconstruction, seeing its ritual transgressions of philosophy as in fact respecting the philosophical game and as indifferent to sociohistorical realities, as all philosophy is, according to him $(1984,494-5)$. He concurs, however, with Derrida's critique of structuralism's binaries as flawed due to their metaphysical foundations (Bourdieu 1990, 94). Interestingly, Bourdieu himself carries binary oppositions away from the metaphysical realm and places them within the framework of his theory of practice as elements of practical logic. This logic meets the demands of urgency to act, which is a constant and inevitable feature of human existence, by resting upon a basic binary of yes or no. Unlike the logician's logic however, the binaries of practical logic, shaped by 
social hierarchies, are often fuzzy and prone to slippages. Further, in addition to reinforcing social hierarchies while structuring the common sense of everyday life, they also tend to reproduce them by entering the constitution of lasting cultural forms including myths, rituals and art.

Bourdieu's reconstitution of binary oppositions within the logic of practice is one example of how his theory offers an alternative to hermeneutic, deconstructive and structuralist modes of analysis. Further, while in these theoretical traditions the natural and human sciences are either riven asunder in terms of conventional intellectual dichotomies as in hermeneutics and deconstruction, or, if united as in structuralism, exist on a metaphysical plane, the 'two cultures' share common ground within Bourdieu's post-positivist scientific framework. The most crucial element that makes this possible is the rejection of an opposition between the scientific and the human as a projection of the opposition between subject and object: a premise inspired by the French epistemological tradition of the history and philosophy of science (Tiles 1987). This creates a general foundation for a humanistic and embodied science, for the study of society as well as for the natural sciences, even as the substantive differences between them call forth distinctive methods of study. Thus rather than regarding the fact that science is a product of human practice as a limitation whose effects must be systematically minimized and ideally eliminated, as positivism aspires to do, this tradition builds upon it positively, underscoring the role of reflective and critical thought. Artistic creation too is included by Bourdieu within the common logic of practice that informs the natural and human sciences. Analysing the structures and dispositions characterizing these fields in several of his writings, he argues in particular in his study of the French literary field, which is focussed on Gustave Flaubert, that the 'interest in disinterestedness' is common to the scientific and the artistic field, and that through the most thoroughgoing struggles within each of these fields, genuine universals are engendered (1996, xviii).

The positive values inhering in science by virtue of its being a product of human practice are manifest, for example, in Bourdieu's method of participant objectivation. For it creates the possibility of combining, in order to know social reality, the felt experiences of the scholar as well as those of her subject/subjects, together with the equally human capacities to reflect, to reason and to criticize. In fact, this form of knowledge creation defies the dualism of understanding and explanation just as it unties the epistemological knot separating the natural, the human and the social sciences, integrating reason, reflection and emotion. It thus allows a theoretical reconstruction of practice that is as true to the form of practice itself as is possible, that is, as undistorted by the kind of scholastic fallacies enumerated by Bourdieu in several of his writings. 
It is with reference to this overcoming of the dualism of explanation and understanding that the contrast between Bourdieu's and Habermas's views on language also becomes apparent. For while for Habermas, it is through a combination of these two modes of knowing that the potential that inheres in language for achieving perfect communication becomes evident, and can be released for inquiry as well as social emancipation, Bourdieu denies language per se this universal potential $(2004,82)$. According to him, there are, in fact, no transhistorical universals of communication as Habermas supposes, but rather, historically and socially situated and dated forms of linguistic communication. It is thus that he identifies the scientific field as an exemplary locus, at one extreme, for the realization of communicative efficacy, capable of yielding universal truths through a system of cross controls imposed by the logic of competition, and, more critically, at the other extreme, also finds language existing as a medium of dissimulating truths and inflicting what he calls symbolic violence. Language is thus viewed as being related to social divisions and hierarchies, as well as particular material and social environments, via the logic of practice. This perspective brings language down to earth as it were, from the extant idealist conceptions that underpin its analysis in other traditions, including ideas of its ability or otherwise to represent reality. It also distinguishes Bourdieu's insights from Derrida's attribution of metaphysical qualities to linguistic phenomena that result in the aporiatic notion of 'différance'. And while averse to Habermas's deification of language, Bourdieu reposes considerable confidence in the ability of language to convey meaning, to represent reality and also to function socially as a medium of symbolic power. Thus in addition to his essays collected in the book Language and Symbolic Power, there is, in his study of Martin Heidegger's work called The Political Ontology of Martin Heidegger, a complex and penetrating analysis that reveals the sociological subtext of Heidegger's writing by unravelling the meaning of its linguistic form.

Keeping in mind Bourdieu's perspective on the representation of truth and reality, and invoking where relevant certain concepts of his theory of practice, I now recount and reflect on a recent episode in working-class history that has created something of a stir, not least within the working class itself. It has spawned diverse interpretations in the form of reports by left-wing political parties and other civil society organizations, and coverage by the electronic and print media, including detailed accounts and analyses in a workers' broadsheet called Faridabad Majdoor Samachar (FMS). Drawing primarily on FMS and conversations with persons associated with it, I attempt to see how certain features of the 'events' of 18 July 2012, in the Maruti Suzuki car factory at Manesar in Gurgaon, India, as reconstructed and analysed by these 
sources, yield meaning in relation to Bourdieu's sociology, with special reference to his politics. Though tentative, the exercise is expected to shed some light on the strengths and limitations of his contribution and also to give an insight into what at first glance appears to be the case, namely that these events move ahead and beyond, not just of Bourdieu's concepts but of the practice of theory itself.

Prime Minister Indira Gandhi's son Sanjay's dream project of making small cars in India did not take off, and after his death, the company he set up was statized in 1983. A collaboration agreement was signed with the Suzuki Motor Corporation and the first car rolled out of the company's factory in Gurgaon, Haryana, the same year. A second factory of the company was established in the Industrial Model Town, Manesar, in 2007.

In 2011, in the factory in Manesar, there were 950 permanent workers, 500 trainees, 200 apprentices, 1,200 workers hired through contractors for work in direct production process and around 1,500 workers hired through contractors for various auxiliary functions. The pace of work was such that a car was being assembled in 45 seconds. Some permanent workers attempted to organize another union against the existing union. Strong-arm tactics of the management to make permanent workers (most of whom were not even aware of the attempt at another union formation) accept the existing union gave rise to a surcharged atmosphere. All-round discontent coalesced into a sudden stoppage of work. On 4 June 2011 when A and B shift workers were together in the factory, they took over the entry and exit points. Most workers in factories today in the subcontinent are temporary workers - the percentage of permanent workers varies from 0 to 5 per cent to 25 per cent of the workforce. On 4 June permanent workers, trainees, apprentices and workers hired through contractors came together, and in this way a workers' organization appropriate in the current conditions took shape, transcending the legal framework wherein only permanent workers can be members of the factory trade union. What started on 4 June and continued for 13 days should be termed a 'deoccupation' of the factory. Around 3,000 workers stayed in an atmosphere of freedom inside the factory premises during those days.

The company and the government were taken aback. During the deoccupation many more bonds developed between the various categories of workers. The company was forced to take a step backwards and revoke the termination of 11 workers, for production to restart.

There was a dramatic change in the atmosphere in the factory. The bonds between workers continued to grow and management officials were increasingly on the defensive. The company was forced to plan and prepare to re-establish its control. It went to far away industrial training institutes and secretly recruited hundreds of young boys. On 28 August, a weekly day off, 
400 police men came at night to the factory. Company staff had arrived earlier. With metal sheets, the factory was secured in military fashion. On the twenty-ninth morning when workers arrived for their 7 a.m. shift, there were notices announcing dismissals and suspensions, and entry premised on signing of good conduct bonds for permanent workers.

All the workers, both permanent and temporary, stayed out of the factory. Inside the factory were the new hires and workers brought from the company's Gurgaon factory, with a few permanent workers from the Manesar plant itself. Arrangements for their stay inside the factory had been made. Managerial and supervisory staff members also had to work in the production process with the workers in 12-hour shifts. This was a well-rehearsed chess game of managements to soften workers and impose major conditions.

Repeated attempts were made to instigate workers to violence. The workers refused to be instigated, even when some of them were called by the state government for negotiations and were arrested there.

Three thousand-plus workers self-organized in two 12-hour shifts outside the factory. At any time, there were more than 1,500 workers spread out near the workers' entry gate. This continued for the whole of September 2011. Many kinds of discussions took place. Bonding between different categories of workers acquired new dimensions. Many kinds of political tendencies flocked to the factory gates: parliamentary left, non-parliamentary left, radicals, activists of democratic and civil rights organizations, students from universities, and central trade unions. Significantly, in place of peasants, factory workers made a dramatic appearance on the sociopolitical stage in the subcontinent. The workers who were in their twenties, were not demoralized or softened even after being made to sit outside the factory for a month. The managements' well-rehearsed chess game came to a dead end. However, the workers had not reached out to workers in other factories to increase their strength. A stalemate-like situation emerged. In this scenario, a tripartite agreement between the existing union, company and the labour department of the state government was signed on 30 September. It was accepted by the workers. When workers went to the factory on 3 October 2011 as per the agreement, permanent workers, trainees and apprentices were taken on duty, but 1,500 workers hired through contractors were kept out. This was another master stroke by the company.

The company had also suspended 44 permanent workers. A scuffle with one suspended permanent worker on the morning of 7 October created an entirely new situation. When workers of the $\mathrm{A}$ and $\mathrm{B}$ shifts were together inside the factory, once again they took over the exit and entry points. The factory was deoccupied for the second time. This time it was not just the deoccupation of this factory but also, simultaneously, 11 other factories in the area were deoccupied by workers. 
Once again, the company and government were taken aback. Despite the presence of 400 policemen and hundreds of other guards, the Maruti Suzuki factory was deoccupied by workers. The simultaneous deoccupation of 11 other factories opened up new possibilities, with 2,000 factories in the neighbourhood. All-round pressure was applied and the deoccupation of seven factories was called off, but it continued in four factories of the Suzuki group. The hand of the government was also restrained by an election for a parliamentary seat. After the casting of votes on 13 October, 4,000 additional policemen were sent to the Manesar factory on the thirteenth night itself.

Leaders of various outfits had been loudly proclaiming that if the government used the police to force workers out of the factory, they would close down the whole industrial area, that is, the entire state. On 14 October, Maruti Suzuki Manesar workers' repeated attempts to contact these leaders were in vain. The high court orders to get the factory vacated and the administration's efforts to cajole the workers to obey court orders had not led anywhere. After withstanding the pressure of 4,000 additional policemen the whole day, on 14 October, around 8 p.m., the workers decided to leave the factory and join their 1,500 temporary worker comrades outside the factory to deal with the new situation.

What is striking is that the company and the government were not able to understand the activities of the workers. Its ripples were widespread and the dangers were very visible to the government. A third agreement was forced by the government. The 1,500 workers hired through contractors were taken back. The company secretly gave a significant amount of money to 30 permanent workers it considered troublemakers and the state government provided them jobs in exchange for their resignations. These workers had acquired credibility among their coworkers through their active role in six months of struggles. By getting rid of these workers from the factory, the company and the government in fact threw away what could have been a potential leverage for them among the workers. Production recommenced in the four factories on 22 October.

'What do the workers want?' was incomprehensible to the government and the company. The company proceeded to give concession after concession. Now instead of 45 seconds, the scheduled time for making a car was increased to one minute. Wages for trainees, apprentices and workers hired through contractors, were increased. Permanent workers were promised a significant wage increment. Parents were included in the health insurance scheme. The number of annual holidays was increased. Massive wage cuts on absence for one or two days were stopped. The management sent its officials to help registration of a second union of permanent workers. Promptly, the company recognized the new union and commenced negotiations for a long-term agreement. The 
new leaders had neither credibility nor opposition among workers and were considered as an ad-hoc body for the negotiations. In the meantime, the second assembly plant had commenced production in the factory, increasing the number of workers to more than 4,000.

It has been observed that important questions dealing with life, time, relations, representation, articulation and factory life were brought to the fore by the deoccupations of June and October 2011. In the words of a worker,

Inside the Maruti Suzuki factory, 7-14 October was the best time. No tension of work. No agonizing about the hours of entry and exit. No stress over catching a ride in a bus. No fretting about what to cook. No sweating over whether dinner has to be eaten at 7 or at 9 p.m. today. No anguishing over what day or date it is. We talked a lot with each other about things that were personal. All of us drew closer to each other than we have ever been before, during these seven days. ${ }^{3}$

In the same vein, when the issue of 30 workers being bought made the rounds in end October, a worker said,

Earlier we used to pass on the issues to the president, general secretary, department coordinator - that they will tell. But now every worker himself answers. On every issue, every one gives his opinion. The atmosphere has changed. ${ }^{4}$

From February-March 2012, despite the numerous and very significant concessions made by the company, the workers were beginning to feel and express that in fact nothing had changed. Any talk of the importance of concessions was regarded as promanagement talk. Despite having struggled so much, wage workers remained wage workers. What had changed? This was the backdrop for the events on 18 July 2012.

An everyday occurrence, a confrontation between a supervisor and a worker took place in the morning. The worker was suspended and negotiations between the management and the union commenced. The labour department of the state government reached the factory to facilitate a resolution. It was time for the B shift. Workers of the A shift refused to leave the factory. A and $\mathrm{B}$ workers were together. All that was simmering gathered momentum and by evening, had turned into a hurricane. The leaders negotiating with the management were helpless. In their own words, 'if we try to stop workers, we will be the first to be beaten up' ${ }^{5}$

Concession after concession had been given from October-November 2011 onwards - concessions which were very significant by any yardstick in the wages system. Wage workers revolted against being wage workers. The two symbols of the wages system: managers and factory buildings, were the 
targets of the workers' attack. Large numbers of guards and 60-70 policemen remained silent spectators. No guard or policeman was injured. This was not some action by a group of 20 or 50 workers but rather thousands of new and old, permanent and temporary workers participated in the revolt. It so happens that this occurred on 18 July - it could as well have happened on 15 May or 25 August. As a matter of fact, the managers and the buildings were symbols, the reality being the social relations they expressed, but in practice, embodied and tangible forms become targets first, and it is through this that the social relations make an appearance. After attacking for half an hour to 45 minutes, the workers disappeared from the factory. The bosses were in a state of trepidation, not just in the national capital region, but elsewhere as well.

Six hundred commandos were permanently placed by the state in IMT Manesar, 147 workers were arrested, and arrest warrants issued for 65 others. A total of 546 permanent workers were discharged and 2,500 workers hired through contractors were simply removed. Until mid-October 2014 none of the workers locked in jail had been given bail. Arrest warrants of 65 other workers are still pending. According to the chairman of Maruti-Suzuki, 'This is class war'. ${ }^{6}$ According to a Maruti Suzuki Manesar worker, 'If the 18 of July had been a thing of the whole of IMT Manesar, it would really have been something?'

To recap: what would be considered very significant concessions in the wages system had been given to all the workers before 18 July 2012. There was assurance and negotiations were on that would put the permanent workers of the factory amongst the best-paid workers in the region. The factory had commenced production in 2007 and all the workers were in their twenties. The workers were not led or controlled by this or that group/organization/tendency. The workers' action was not a sudden outburst of rage. It was not a reaction to some instigation of the company. Permanent workers, trainees, apprentices, workers hired through contractor companies, new workers who had been hired to run the second assembly plant - all these workers, around 4,000 workers, in a meticulous operation on the evening of 18 July 2012 attacked two symbols of the wages system: managers and factory buildings. It was not this or that bad manager who became the target but rather any and every manager, hundreds of managers. MANAGERS AS SUCH WERE A TARGET. It is this that makes happenings such as that in the Maruti Suzuki Manesar factory one of global importance. Suppression that triggers explosion is well known but concessions being rejected en masse is a new phenomenon. It is a radical point of departure. Maruti Suzuki Manesar is a good example but what is more important is that amongst factory workers in the national capital region in India, similar things at different stages and levels are gaining currency. 
In the following days, the 2,000 factories in IMT Manesar offered a significant ground for workers to meet other workers and to bond with them. In place of that, central trade unions acted fast and moved the venue $25 \mathrm{~km}$ away to Gurgaon by constituting a committee of 16 trade union leaders who would decide what steps were to be taken. Of the discharged permanent workers numbering 546, those remaining outside the jail were pushed into becoming an audience for this committee. Other workers' representatives/supporters, critical of central trade unions, but who also saw workers as victims and as lacking consciousness, erased the active role of the workers on 18 July. They made out the company to be the active force that had conspired and hired bouncers to attack workers to instigate them. Poor workers only reacted to the bouncers' attack and so were caught in the management's trap. Sixty to seventy thousand leaflets containing these falsehoods were distributed amongst workers in IMT Manesar, Gurgaon, Delhi and Faridabad. Knowingly or unknowingly these do-gooders encouraged the workers to set out on paths that were tiresome and exhausting. Petitions, demonstrations, protests by the family members of the jailed and sacked workers, hunger strikes, bicycle protest tours - steps that gave some support to the workers' cause, but that, if relied upon solely, only made workers tired and exhausted. Because of the ineffectiveness of the committee of 16 , those more to the left gained ground. And the venue was moved $200 \mathrm{~km}$ away to a peasant-dominated area.

By July 2013 the complete bankruptcy of all those who considered workers as poor, exploited victims had reached a stage where these 'struggles' came to an ignominious end - on 18 July 2013 in a candlelight protest in daylight in a park provided by the government, a portrait of the manager who died in 2012 was carried.

It is significant that while reflecting on the activities of workers at the Maruti-Suzuki Manesar factory, a worker with long experience commented that to call these activities an 'occupation' is to see what the workers were doing through a reduced lens. 'Occupation' is a misnomer, it is misleading. Occupation is how existing social hierarchies are held in place. Companies and governments today are on an overdrive to gain possession of everything. What we want is to create a commons. Given this context, to call what the workers of IMT Manesar did 'occupation' is to refute the essence of their actions; it is akin to trampling over the possibilities they created. ${ }^{8}$

Workers of Maruti Suzuki abundantly expressed that between 7 and 14 October, when they unshackled the factory from the control of the management and government, they felt a joyousness of life that is usually unimaginable. The significance of what the workers did therefore lies in it being a point of departure from where a series of deoccupations followed. Refracted through this lens, the significance of the 'occupy' movement that started in the 
United States becomes clear - as actually being a movement calling for deoccupation, a taking away of the control that companies and governments have. ${ }^{9}$

The outline of activities and their analysis put forward above draws together the critical elements constituting the 18 July events and also extrapolates from them the possibilities of and potentiality for more widespread radical workingclass actions that go beyond trade union-centred demands for concessions and reforms within the existing system, challenging the very foundations of capitalist society, namely, the system of wage labour. Further, this is not seen as the mechanical outcome of a particular historical conjuncture but an event that foregrounds the imperative of conscious activities and self-organization on the part of the working class. Moreover, what it describes is not in the least a product of wishful thinking, as can be gleaned from recognizing a potentiality that inheres more generally in particular features of the contemporary phase of capitalist development globally.

About 200 years ago, the use of coal and steam power in place of human and animal energy had been such a big leap in productive forces that it severed the producers from their tools and led to the establishment of wage labour. Subsequently oil and electricity run machines brought about other significant increases in productive forces, but the leap effected by electronics is incomparable. Globally, electronics has changed social life to such an extent that things that were current some years ago, now appear to be ancient.

Electronics entered production in 1970 in America, Europe and Japan. It entered China ten years later. Ten years after China, electronics entered production in India. In 1992 there were discussions among managements in Japan about temporary and permanent workers. Permanent workers were expensive, but had some loyalty to the company. Temporary workers were cheaper, but had no loyalty at all towards the company. These were among the matters being discussed. It was the growing weakness of companies and governments that was manifest in their inability to keep permanent workers. The world over, within these 10 years, the number of temporary workers increased tremendously. Moreover, the entry of electronics in production rapidly expanded the speed of new inventions. The growing possibility of the coming of new machines narrowed the space for the hiring of permanent workers further. Factories that for more than a hundred years had been becoming larger and larger were now easily broken up into hundreds of spatially dispersed units. Auto hubs, in India, as in Gurgaon, Pune, Chennai and elsewhere globally, are manifestations of this trend. Significantly, as has been pointed out, the growing numbers of temporary workers do not indicate the strength of companies and governments but rather their weakness. The total absence of loyalty towards the company, the experiences of 20- to 25-yearolds of working in 10 to 20 workplaces, destroys many an illusion and makes 
temporary workers dangerous for companies and governments. In other words, this scenario, together with the bonds forged between the temporary and permanent workers in Maruti Suzuki over previous years, strengthened by the shared experiences of their 'deoccupation' of the factory, provided the tinder for the events of 18 July and forms a potential basis for radical workingclass activity in the future, here and elsewhere as well. Innumerable examples of such activities taking place in and around Delhi are increasingly visible. ${ }^{10}$

The account above also provides a canvas, though fragmentary, for theoretical reflection, and a possible testing ground for the very practice of theory itself.

From the point of view of Bourdieu's theory of practice, the relationship of the working class to its social and material environment during routine phases of social reproduction can be analysed as being one of ontological complicity, with the structures of the milieu and those of persons' dispositions more or less adjusted to one another and taken for granted. This is what Bourdieu calls a condition of doxa. The precise constitution of the habitus, and the structure of the field in which individual practices are located would, however, vary from one segment of the working class to another. For instance, it would have been different for the workers in their twenties, temporarily employed at Maruti Suzuki, as compared to the permanent workers who were in a minority. There would also be variations over time, history being an important dimension of social analysis. However, insofar as these segments worked within a common system of capitalist production, both kinds of workers would be recognized, within the framework of Bourdieu's theory, as being subject to relations of dominance and subordination that are characteristic of such a mode of production. Such relations are, moreover, known to permeate the wider social order as well, with occasional cracks and fissures in the doxa allowing a glimpse into the historicity of the phenomenon.

But though relations of domination and subordination are often articulations of relations of exploitation in contemporary society, we would be hard put to find in Bourdieu's theory of practice resources for conceptualizing the latter. Bourdieu no doubt goes a long way towards enriching the concept of social class by capturing, for instance, the overt as well as the virtually subterranean forms in which hierarchical relations are reproduced and transformed. So also, by distinguishing between various forms of capital, he renders comprehensible some of the tangled links between the economic and other dimensions of social reality, such as the political and the cultural. But while economic capital, measurable in terms of labour time, is at the base of all forms of capital according to him, it is not linked conceptually to the production of surplus value, and thus to a system of exploitation underlying certain relations of 
domination and subordination (Bourdieu 1986, 253). These relations are thus disinterred from the social relations of wage labour and capital within which in reality they are embedded.

In relation to the situation of the working class in Maruti Suzuki, Manesar, as it evolved up to 18 July 2012, Bourdieu's perspective would therefore at best be able to suggest that we understand the transformation of the doxic acceptance of a relationship of domination and subordination that was 'misrecognized' as being 'natural' into one of a 'recognition' of the economic basis of the same, in the limited sense of an awareness of the financial control exercised by the company over the workers. It would stop short, however, of any attempt at coming to grips with what actually transpired, that is, a transcendence of a circumscribed, economistic understanding, and the vibrant movement towards an awareness, though not discursively articulated, on the part of the workers, of being shackled as wage workers, whose emancipation entails the destruction of the system of wage labour itself. This understanding, which could be described as 'practical recognition' rather than 'conscious recognition', seems to elude the grasp of Bourdieu's political sociology, despite the richness of his concept of practical logic.

An inability to conceptually go beyond a grasp of what may be termed trade union consciousness also implies an absence of a basis for critiquing the role of trade unions in relation to processes of radical social transformations. This limitation was expressed in Bourdieu's own recourse to trade unions, on numerous occasions, as among the fora for his speeches, while participating in the movement of resistance to neo-liberalism (see Bourdieu 1998b). It is also what has rendered invisible certain forms of working-class activism in Bourdieu's work, such as the emerging modes of self-organization, of which the 'deoccupations' highlighted by the accounts in FMS are an example. Moreover, the 'faith' in trade unions in a context of their rapidly growing irrelevance, given diminishing numbers of permanent workers in industry the world over, also seems to reflect Bourdieu's naiveté in his activist role, a role that merged forcefully with his work as a scholar, though at a late stage of his life. To be fair to Bourdieu, however, he did have an incipient critique of political representation and of delegation, in relation to which he referred to a form of capital he termed 'political capital' over which unions and parties in some countries were known to have a monopoly (1998a, 16; 1991, 174). But these discussions remained hemmed in by a theoretical framework of domination and failed to address the issue of exploitation.

According to Fredric Jameson, movements that put an emphasis on domination rather than exploitation express themselves politically in democratic programmes that are often too easily co-opted by the capitalist state (2011, 150). In the case of Maruti Suzuki in Manesar, this was, implicitly, the tack 
taken by various civil society organizations and statist parties of the left, whom FMS reports refer to as wearying the workers by taking them along the futile path of constitutional and legal measures. What is more, this was done on the basis of falsehoods regarding the events of July 18. In short, the scenario that is emerging globally, of which these events are a part, brings into sharp focus the limits of theoretical formulations such as Bourdieu's premised on the idea of domination, and also demonstrates, significantly, the bankruptcy of political practices based on them.

Bourdieu's confidence in the virtues of the welfare state is also of a piece with his attitude towards trade unions. Lamenting, like many, its retreat in the current conjuncture, he overlooks its long-standing role as an institution that serves to make intolerable situations seems bearable, and to blunt the edge of organizations and movements agitating for radical and systemic transformations (see Bourdieu 1998b). In an alternative reading, the dismantling of such a state in a situation of crisis may in fact be seen as providing a welcome opportunity for creative forces to come into play and bring about change. Bourdieu's perspective was far removed from such a view, and hence also carried a certain nostalgia for conditions in the past that may have been less desirable than he regarded them to be.

But if Bourdieu's political sociology fails to illuminate certain facets of contemporary working-class politics, including some elements characterizing the events at Maruti Suzuki, Manesar, there is nevertheless much that is of value in his theory of practice for analysing significant dimensions of the overall process as it unfolded. A Bourdieusian conceptual framework focussed on the interaction between the immediate material, social and symbolic environment of the workers, and the wider 'field' of the composition and transformation of the working class and its global tendencies, provides important insights into the broader implications of this specific happening.

To look at the experiences of the workers within the factory during phases of 'deoccupation' first, which were multidimensional and momentous in their consequences, they included the creation of bonds between different categories of workers, whose interests are widely regarded in current literature on working-class politics as being too dissimilar for concerted action. It was a process that had begun earlier, but that occurred with greater intensity in the shared environment of 'deoccupation' under exceptional conditions of an absence of control by authorities and the constraints of routine. The experience gave tangible form to the idea of life as other than that of being a majdoor, or wage worker, together with the perception that this was possible only if the chains imposed by the system of wage labour could be broken. Significantly, the sense of well-being and joy that pervaded these experiences was not a result of economic benefits and material rewards. Rather, it was the access to 
enormous emotional, mental and social riches made possible by an absence of constraints of time and of routines, and by the freedom to relate to one another as persons, rather than as alienated parts of a mechanical and inhuman apparatus, that created for the workers a heightened awareness of what they desired and what came in its way.

Bourdieu's theory of practice makes it easy for us to discard certain prevalent notions, in order to understand more meaningfully the contours of consciousness and being that emerged in these contexts and beyond. Thus the idea of a vanguard creating unity among workers on the basis of struggles for economic demands or/and by laying bare discursively the structure of class relations and class conflict is one that does not resonate with this reality at all. What was striking, on the contrary, was the widespread understanding of the disadvantages of relying on trade union leaders, including an awareness of their being in cahoots, more often than not, with the management. As reported in FMS, speeches and attempts at 'consciousness raising', to the extent that they persist, are usually regarded as worthless preaching from the pulpit with no real meaning and impact.

How, then, can we conceptualize what happened, and how far does it help us to think along with Bourdieu?

The concept of habitus, which considers the structuring and restructuring of dispositions and practices stemming from a common material, social and symbolic environment, seems to provide an insight into the forms of sociality and consciousness that emerged among workers during, between and after periods of deoccupation. Particularly in its rejection of the location of consciousness in a Cartesian realm severed from the indissolubly social, material and symbolic environment in which people live their lives, the concept highlights consciousness as an aspect of embodied selves constructed by processes that lie beyond discursive injunctions. It also thus reveals the fallacy governing certain organizations and activities claiming to be of the working class, that implicitly rest on a Cartesian dualism, seeing consciousness as something that can be brought in from the outside, as it were, to the working class.

The transformation of consciousness discussed here was also not a product of deliberately designed and executed exercises accompanying symbolic mastery of a common habitus, as Bourdieu's perspective on processes of emancipation would suggest. What it does vindicate, however, is Bourdieu's insistence that changes in practice require much more than methods such as those of 'consciousness raising', that they require, especially, participation in situations (which in this instance were not consciously planned) that work at more subliminal levels of mind and body. A theoretical perspective such as the one offered by Bourdieu that does not split asunder the material and the 
symbolic, mind and body, reason and emotion, makes such realities somewhat comprehensible.

To go further along with Bourdieu, it is clear that close proximity and interaction in a shared environment, especially for a limited duration, are not sufficient to explain the emergence of a common consciousness and concerned practices that strive towards altering existing conditions. The features characterizing the wider 'field' within which such activity has taken place are also of great significance, for they provide some of the structural elements constituting the resources and constraints that would have influenced the construction of the social reality being discussed, as well as its reciprocal effect on the 'field'.

Relevant here is our earlier description of the global features of the contemporary phase of capitalist development, with the sharp increase in productivity effected by electronics, rapid and continuous technological innovations and the tremendous growth in the numbers of temporary workers in industry worldwide. Relevant, too, is the emergence of numerous spatially dispersed units in place of large factories as in the past, the changing demographic profile of workers, mostly unmarried 20 to 25 years old with experiences of working in many factories in many places and an absence of loyalty towards any one company. These features constitute important ingredients for the construction of the structure of the 'field' in which the industrial working class is located today, in dialectical relation with which habituses are constituted and practices such as the ones we have been discussing are generated.

It is also meaningful therefore to remind ourselves of Bourdieu's notion of reality as a special case of what is possible, so that the events at Maruti Suzuki, Manesar, need to be viewed as one specific manifestation of a possibility inherent in the conditions characterizing the global situation today, but which is not necessarily realized everywhere. This preliminary analysis is therefore far from an empiricist account of an isolated social reality, its empirical particularities and their effects being significant, but without reality being reduced to them.

The understanding that the targets of the workers' attack on 18 July 2012 were managers and factory buildings since they were symbols of the system of exploitation to which the workers were subject and against which they revolted, as proposed in FMS, gains greater analytical depth in the light of Bourdieu's theory of the symbolic. For symbolic systems, according to him, are instruments of cognition, communication and power that must be related to practical activity oriented towards practical functions (see Jain 2013). As major functionaries of the apparatus of authority governing the production process in the factory, managers were undoubtedly embodiments of power vis-à-vis the workers, a power that could easily be cognized and communicated symbolically by their very existence as persons in the factory. The factory buildings too were a locus of the workings of a system of power, defining 
boundaries and spaces to which the workers were constrained to conform and remain confined in for long hours, and that materially and structurally communicated to them their identities as wage workers. Bourdieu's theory thus serves to reinforce the interpretation of the workers' targets as appropriate symbols of the oppressive system of wage labour.

The qualities of fuzziness and of the absence of logical logic that Bourdieu's theory recognizes to be intrinsic to most kinds of practice including the symbolic also render comprehensible the seeming contradictions characterizing the workers' expressions of jubilation as they arose in revolt. They included, on the one hand, the popular religious cry of jai bajranbali! (hail to the powerful), as well as, on the other, the slogan inquilab zindabad! (long live the revolution), widely considered to be a secular, revolutionary slogan. ${ }^{11}$ Thus in more ways than one, Bourdieu's theoretical perspective provides the possibility of a rich and nuanced texture of analysis of elements that could easily slip out of the grasp of more conventional approaches.

Further, in keeping with his mapping of the dimensions of the 'real' and of 'reality', Bourdieu's theoretical framework allows us to perceive in the events of deoccupation and July 2012 in Manesar more than what is immediately given. It urges an analytical sharpening towards what in Ricoeur's interpretive framework would be termed that which is not hidden in the text but opens up in front of it: in other words, a possible world that is not bound to a particular situation, though suggested by it (Thompson ed. 1987, 15).

It is important, however, to be aware of the caveats that have gone into shaping Bourdieu's position regarding the link between words and the world. To recount some of the major ones: scientific truths are defined as approximate truths, arrived at by concepts that are heuristic. Objectivity is conceptualized as a position constituted by the space of varied points of view, including the common sense of practical knowledge. Empirical reality is constructed as a special case of what is possible, revealing all discarded possibles and retrieving the possibility that things could have been (and still could be) otherwise. The 'real' is noted as being mediated by current theory and existing equipment including a belief in reality as the conviction that there is more to an entity than is immediately given. These features of Bourdieu's theory that emerge from his contributions to a theory of the practice of theory make it malleable, contingent and provisional, and also more open to revision and even rejection than is usually granted by scholars to their work.

Thus viewing a particular reality in the light of what is suggested by Bourdieu's theory of practice does not invite a severely judgemental response regarding the accuracy of his conceptual framework but rather a sensitive appraisal of what it may have to offer. For instance, we could query the validity of Bourdieu's premise of all forms of capital, including symbolic capital, 
being ultimately transformed forms of economic capital, by pointing out that while the 'recognition' by the working class in Manesar of their oppression as stemming from the system of wage labour may be regarded as a form of symbolic capital, it does not, in fact, seem to be a transformed form of economic capital. However, we would do well not to reject Bourdieu's theory as a consequence but to consider this anomaly to be, instead, an example of how his work initiates and provokes meaningful sociological questions.

Indeed, what our engagement with the link between social theory and social reality seems to be pointing towards is not just the fact that theories are abstractions that provide some grasp of reality and its dynamism, rather than a total grip on reality, but also that social reality can change in ways that theory finds almost impossible to take into consideration. In other words, especially in fast-changing times like ours, practice often may outstrip theory. Truly meaningful words about the world may then emerge from practice itself, from creative participation in processes of social transformation. One may also take a leaf from sociology's wisdom tree on method and ask whether the meaning that the reality of the industrial proletariat today has for the fortunes of humanity at large is akin to what totemism meant for Émile Durkheim with reference to religion - revealing in an elementary but sharp form the critical properties of a pervasive, powerful and epochal social phenomenon.

\section{Notes}

I would like to acknowledge the assistance I received from Fahad Hashmi and Sarwar Khan in preparing the manuscript of this chapter.

1 See Hoy 1985.

2 Faridabad Majdoor Samachar, no. 282, December 2011: 1 [Translation from Hindi]

3 Ibid.

4 Conversation with Sher Singh, editor, Faridabad Majdoor Samachar.

5 Faridabad Majdoor Samachar, no. 296, February 2013: 2 [Translation from Hindi]

6 Ibid.

7 See Faridabad Majdoor Samachar, no. 304, October 2013.[Translation from Hindi]

8 See Ibid.

9 See Faridabad Majdoor Samachar, no.300, June 2013 and no.301, July 2013.[My distillation in English of what was said in some reports that appeared in Hindi]

10 Conversation with Sher Singh, editor, Faridabad Majdoor Samachar.

\section{References}

Barry, P. ed. 1987. Issues in Contemporary Critical Theory. London: Macmillan Education. Bourdieu, P. 1984. Distinction: A Critique of the Fudgement of Taste. London/Melbourne/ Henley: Routledge \& Kegan Paul.

- 1985, 'Dialogue a propos de l' histoire culturelle'. Actes de la recherche en sciences sociales 59: 86-93. 
1986. 'Forms of Capital', in J. G. Richardson (ed.) 241-58.

1990. The Logic of Practice. Oxford: Polity Press.

1991. Language and Symbolic Power. Oxford: Polity Press.

1996. The Rules of Art. Oxford: Polity Press.

1998a. Practical Reason. Oxford: Polity Press.

1998b. Acts of Resistance. Oxford: Polity Press.

2004. Science of Science and Reflexivity. Oxford: Polity Press.

Bourdieu, P. J.-C. Chamboredon and J.-C. Passeron. 1991. The Craft of Sociology. Berlin: Walter de Gruyter.

Culler, J. 1987. 'Jacques Derrida', in P. Barry (ed.) 1987, 82-104.

Griffith, P. A. ed. 1987. Contemporary French Philosophy. Cambridge: Cambridge University Press.

Hoy, D. 1985. 'Jacques Derrida', in Q. Skinner (ed.), 1985, 41-64.

Jain, S. 2013. Practising the Symbolic: Pierre Bourdieu's Contribution. Delhi: Aakar Books.

Jameson, F. 2011. Representing Capital. London: Verso.

Richardson, J. G. ed. 1986. Handbook of Theory and Research for the Sociology of Education. New York/Westport/London: Greenwood Press.

Skinner, Q. ed. 1985. The Return of Grand Theory in the Human Sciences. Cambridge: Cambridge University Press.

Thompson, J. 1985. Critical Hermeneutics: A Study in the Thought of Paul Ricoeur and Fürgen Habermas. Cambridge: Cambridge University Press.

Thompson, J. ed. 1987. Paul Ricoeur: Hermeneutics and the Human Sciences. Cambridge: Cambridge University Press/Paris: Éditions de la Maison des Sciences de l'Homme.

Tiles, M. 1984. Bachelard: Science and Objectivity. Cambridge: Cambridge University Press. 1987. 'Epistemological History: The Legacy of Bachelard and Canguilhem', in P. A. Griffith (ed.), 1987, 15-156. 



\title{
Chapter 8
}

\section{SOCIAL TRANSFORMATION AND GULTURAL REPRODUCTION: A BOURDIEUSIAN ANALYSIS OF POST-REFORM CHINA}

\author{
Yang Yang and Xuanyang Gao
}

\section{Introduction}

Pierre Bourdieu successfully constructed his sociology by combining the Durkheimian tradition with new developments in anthropology, ethnography, culture studies and education in post-war France. The core of Bourdieu's writings concerns social space and reproduction: the relationship between the different forms of capital and their relations with inequality and power are perpetuated and reproduced in and through various fields, for example, education. Also, such ongoing and successful reproduction imposes a sense of cultural legitimacy and a social definition of reality. Bourdieu's theoretical innovation contributed to a great extent to the establishment, as well as the development, of sociology as a discipline in the final quarter of the twentieth century. The intellectual nobility that his theory offers and that Bourdieu himself represents as a public intellectual is already clear and secure.

Along with the wide circulation of his theory, debates over 'the specific validity of Bourdieu's concepts in different socio-political situations' have intensified, precisely as Derek Robbins proposes in the introduction to this volume, leading to the ultimate question: is Bourdieu's sociology Franco-centric or universal? This chapter intends to firstly reflect Chinese scholars' encounter with Bourdieu's work, and, more importantly, to consider this very question in a Chinese context - to see whether Bourdieu's theory can be applied to China, particularly to the post-reform era, starting from the initiation of the economic reform in 1978 and continuing to the present day. The chapter begins with a brief presentation of Bourdieu's sociological theorization. It outlines reproduction theory through the interrelationship between his three primary 
concepts, namely, capital, habitus and field. The second part provides an overview of the reception of Bourdieu's work in China. The third part argues that the rapid, vast and apparently crisis-ridden restructuring has led to the emergence of three 'new' social groups in today's Chinese society - the new middle class, the entrepreneurs and the political elite. The reform has left the country with a dynamic market economy but has also contributed to the creation of a lopsided system that is unable to address the new complexity. In line with Bourdieu's theorization on the forms of capital, this part discusses the logic and the problematics of capital conversion and social reproduction in China's post-reform period. Next, the fourth part focuses on the issues of cultural reproduction in this continuous and accelerating material process. The functionality of education in the socialist state is explained in comparison with the social objectives of the educational system revealed in Bourdieu's sociology. Confucianism has resurfaced since the 2000s, as an official discourse as well as a feature of a new national identity expected to dissolve the social tensions engendered by the rapidity of development. Although a comparative analysis of Confucian thinking and Bourdieusian theorization is not the paramount concern of this chapter, this part does briefly discuss what these two paradigms have achieved. The chapter concludes with the methodological issues at stake in reading Bourdieu in China.

\section{Capital, Habitus, Field and Reproduction}

Bourdieu no doubt accomplished a 'symbolic revolution' in sociology. Capital, habitus and field are the fundamental concepts on which his theory of practice and reproduction is based. For Bourdieu, the interlocking relationship between capital, habitus and field generates practices. He further presents a concise formulation in Distinction (1984: 101):

$[($ habitus $)($ capital $)]+$ field $=$ practice

To analyse the socially concealed structure of the lifestyle of individuals and to comprehend the unity disguised beneath the diversity of behaviours, Bourdieu concludes that practice cannot be reduced to the independent effect of any one of these three but rather it is deduced from their combined effort. By further extending the concept of capital into three fundamental dimensions, namely the economic, social and cultural, Bourdieu is able to account for much broader power resources. In The Forms of Capital (1997), he offers detailed definitions: economic capital remains the traditional embodiment of capital, immediately and directly convertible into money or property rights; social capital is, in short, the 'membership of a group' that aggregates the 
resources linked to the possession of a durable network of more or less institutionalized relationships of mutual acquaintance and recognition; and cultural capital is mainly institutionalized in the form of academic qualifications. Such 'conceptual expansion' greatly enriches Bourdieu's sociocultural analysis.

In describing the relationship between capital, habitus and field, Bourdieu firstly writes that no capital exists or functions without a field. A given social agent's position in a field is determined by three dimensions - volume of capital, composition of capital and exchange in these two properties over time (Bourdieu 1984). Each field is unique, characterized by its own defining capital and its logic for exchange. The field, as a structure of objective relations between positions, undergirds and steers the reproduction strategies whereby social agents strive to safeguard or ameliorate their social positions. Secondly, habitus, as 'a system of dispositions', embraces the entire set of relations between a social agent and the world, and generates responses according to a set of principles that have already been socially inculcated into the given social agent. Individuals have become preoccupied with a determinate future since early age ('even before birth', as Bourdieu writes in Pascalian Meditations, 2000) because they adjust their subjective expectations in line with their perception and appreciation of the possibilities and impossibilities, freedoms and necessities, and opportunities and prohibitions, which necessarily approach due to their material conditions, that is, the volume and composition of their capital. A secondary habitus or any subsequent one may be constructed, given that the primary habitus, which has no antecedent at all, is the basis for the subsequent formation of any other. Thirdly, the interaction between field and habitus operates in two ways. On the one hand, field structures habitus. Field has the power to create doxa, which is a form of intuitive knowledge shaped by social experience and shared by all agents in the same field, leading to an adherence to the rules and logic of a given field. Such implicit and explicit acceptance is the absolute form of (mis)recognition of arbitrariness, which commences even before entering the field. On the other hand, habitus in turn contributes to 'constituting the field as a meaningful world, a world endowed with sense and value' (Bourdieu and Wacquant 1992, 127).

Thus, when a social agent makes his or her way through the world, the specific reproduction strategy adopted, is governed by the habitus, a socially structured system that functions below consciousness, and in the meanwhile is constrained by the rules of the field. The agent is then led towards a predefined future and his or her so-called position-seeking journey becomes a section of the collective trajectory constituted by all of those who share similar conditions of existence. In this way, existing social structures are perpetuated and reproduced through such an inherent match between habitus and field, and through the collectivity of individual movements. Here, it is almost 
a truism that Bourdieu's sociology falls into pessimistic determinism and lacks the liberal spirit that believes in the potential of human practice. It is equally important to note that Bourdieu's theorization of society and reproduction developed over time. In many of his later writings, such as An Invitation to Reflexive Sociology (1992), Pascalian Meditations (2000) and Science of Science and Reflexivity (2004), Bourdieu devotes increasing amounts of time to steering away from determinism. Even without those attempts, it would be a considerable injustice to Bourdieu to regard him as a 'hyperdeterminist' sociologist who has not written enough on concepts such as free will, rationality or social mobility and so on. It is exactly the opposite. Bourdieu has defined concepts such as the 'mismatch between habitus and field', the 'raising of consciousness', 'hysteresis', 'explicit aspirations' and more (see Yang 2014). However, it is also correct that those discussions were buried underneath his overpowering arguments concerning the structuralist proclivity of capital, habitus and field (Yang 2014). Freedom in Bourdieu's theory is always 'marginal', as he writes in Pascalian Meditations (2000: 234-6).

\section{Bourdieu's Work in China}

Bourdieu became well known to Chinese scholars only in the 1990s. Free Exchange (1995), which transcribes Bourdieu's conversation with German American artist, Hans Haacke, was his first book translated into Chinese (by Gui Yufang) and it was published in 1996 by Joint Publishing Company, entitled Ziyou Fiaoliu. Bourdieu's early but classic essays that had positioned his name in the field of sociology and anthropology - Algeria 1960 ([1977], 1979) have still not been translated. Two signature works of Bourdieu - La reproduction (1970) and Esquisse d'une théorie de la pratique (1972), where the concept of habitus was defined extensively, were both introduced to English readers in 1977 (Reproduction and Outline of a Theory of Practice), while the Chinese translation of the former, Zai Shengchan, became available only in 2002, over 30 years after the original French edition, and the latter is not yet available in Chinese. La distinction (1979; Distinction, 1984), which can fairly claim to be one of the most important monographs in post-war sociology, was introduced to English readers in 1984, but has not been translated into Chinese. Two other works in which Bourdieu discusses at length the theory of practice - Le sens pratique (1980; The Logic of Practice, 1990) and Raisons Pratiques (1994; Practical Reason, 1998) were published in Chinese as Shijian Gan in 2003 and as Shijian Lixing in 2007 by Yilin Press and Joint Publishing respectively.

For Bourdieu's writings between the 1990s and 2000s, there was not such a long wait for the Chinese edition. Méditations pascaliennes (1997; Pascalian Meditations, 2000) was translated into Chinese in 2009 by Liu Hui, entitled 
Pasikaershi de Chensi by Joint Publishing; Science de la science et réflexivité (2001; Science of Science and Reflexivity, 2004) was made available in Chinese in 2006, entitled Kexue zhi Kexue yu Fanguanxing by Guangxi Normal University Press, five years after the original French edition. The volume that centres around Bourdieu's dialogue with American sociologist Loïc Wacquant - An Invitation to Reflexive Sociology (1992) - was also published in Chinese fairly quickly in 1998, under the title Shïian yu Fansi, by Central Compilation and Translation Press. Finished just before his death, Bourdieu's ethnographic account of his home town - Le bal des célibataires (2002) - was translated into English (The Bachelors' Ball, 2008) and Chinese (Danshezhe Wuhui, 2009) at almost the same time. Le sociologue et l'historien, which is based on Bourdieu's discussions with leading historian, Roger Chartier, was published in French in 2010; its English version, The Sociologist and the Historian, appeared in December 2014, while the Chinese translation, Shehuixuejia yu Lishixuejia (Ma Shengli, Peking University Press), was made available in 2012.

Bourdieu's other works that have been translated into Chinese also include Guanyu Dianshi (2000; Sur la télévision, 1996; On Television, 1999); Ezhi Yehuo (2007; Contre-Feux, 1998, 2001; Counterfire, 2003); Haidegeer de Zhengzhi Cunzailun (2009; L'ontologie politique de Martin Heidegger, 1988; The Political Ontology of Martin Heidegger, 1991); and Ziwo Fenxi Gangyao (2012; Esquisse pour une autoanalyse, 2004; Sketch for a Self-Analysis, 2008). Les usages sociaux de la science (1997), which is not yet available in English, was also translated into Chinese in 2005, entitled Kexue de Shehui Yongtu. Another volume of Bourdieu's original work in Chinese is a collection of his dialogues and conversations, published in 1997, entitled Wenhua Ziben yu Shehui Lianjinshu (Cultural capital and social alchemy; title translated by the authors).

In translating and publishing Bourdieu's work in China, three major publishing companies, namely Commercial Press, Joint Publishing Company and the Central Compilation and Translation Press, have taken a primary role. In particular, between 2003 and 2011, Commercial Press released a companion to Translations of Contemporary Thought and Culture in France, which consisted of over 40 volumes, covering many of the greatest figures in contemporary French intellectual history, such as Jean-Paul Sartre, Maurice Merleau-Ponty, Jacques Derrida, Emmanuel Levinas and so on. Four works from Bourdieu were included in this collection: Fichengren (2002; Les héritiers, 1964; The Inheritors, 1979); Zaishengchan (2002; La reproduction, 1970; Reproduction, 1977); Guojia Fingying (2004; La noblesse d'état, 1989; State Nobility, 1996); and Yanyu Yiweizhe Shenme (2005; Ce que parler veut dire: L'économie des échanges linguistiques, 1982). The last of these titles does not have an English counterpart but most of the essays from this book were included in the English volume Language and Symbolic Power (1991). Liu Hui, who translated Yishu de Faze (2001; Les règles de 
l'art, 1992; The Rules of Art, 1996) by Central Compilation and Translation Press; Nanxing Tongzhi (2002; La domination masculine, 1998; Masculine Domination, 2001) by Haitian Publishing House and then by China Remin University Press; and Pasikaershi de Chensi (2009; Méditations pascaliennes) by Joint Publishing, and Xing Kechao, whose works include Fichengren (2002; Les héritiers) and Zai Shengchan (2002; La reproduction), both by Commercial Press as aforementioned, are arguably the best known amongst the translators.

The volume of research on Bourdieu and the use of his concepts in empirical studies can address the popularity of Bourdieusian sociology in China. A few high-quality monographs dedicated to providing a comprehensive review of Bourdieu's framework were published in the 2000s, such as Budie de Shehui Lilun (Bourdieu's social theory, 2004; title translated by the authors), by Xuanyang Gao; Pierre Bourdieu's Ultimate Concern (2009), by Liu Yonghua and so forth. Additionally, theoretical studies conducted by Chinese scholars on Bourdieu have frequently undertaken a comparative approach, reviewing and scrutinizing Bourdieu's theory in comparison with the work of other sociologists or philosophers in the same period, for example, Michel Foucault. Those volumes from the field of the history of sociology (or of philosophy and social theories) were also instrumental in drawing considerable attention to Bourdieu's work.

The quantity of articles discussing Bourdieu published in Chinese peerreviewed journals has continued to increase since the early 2000s, when more of his work became available in Chinese. As in English-language countries, Bourdieu's concepts are more likely to be employed in the fields of education, anthropology, cultural studies and, of course, sociology. Cultural capital, symbolic capital, habitus and field are the terms applied most prominently. A statistical analysis on the trend of Bourdieusian study in China is not the intention of this chapter. We would like, instead, to mention the research conducted by Nabo Chen and Xiaowei Zang (2009) in which more data with respect to this topic can be found. In their article, Chen and Zang further explain that the late reception of Bourdieu should be considered within a greater context, which was the underdevelopment of sociology as a discipline in China in the first three quarters of the twentieth century. Social science subjects, such as sociology, were traditionally neglected and very often of low regard in China, while since the 1980s, when China opened up and became better connected with the rest of the world, sociology and political sciences were re-established (Chen and Zang 2009). Indeed, only since the early 2000s has the development (or the 'renaissance' as labelled by the Chinese media) of humanities and social sciences been drawn to the agenda, promoted as part of the project to improve China's soft power, which certainly encourages more interaction in those fields. Another factor pointed out by Chen and Zang (2009) is that those 
Chinese scholars with overseas educational experience had become 'a major driving force' for the circulation of Bourdieu's theories in China.

Bourdieusian studies have accumulated in China and his concepts are used, interpreted, or even misinterpreted, and adapted without conceding a complete understanding of Bourdieu's original conceptualization. There are a number of reasons for such a situation. First and foremost, in the period when Bourdieu wrote most of his work - the 1960-1980s - Chinese intellectual history was mainly immersed in the Cultural Revolution (1966-76), which tremendously and negatively affected the nation's academic performance, particularly in the social sciences and humanities. There was not only limited translation of Bourdieu's works but his original texts were also difficult to come across, meaning that few of Bourdieu's books were imported. Compared with nations, such as the United States and the United Kingdom in which Bourdieu's intellectual projects were already known or readily accessible in the 1970s, Bourdieusian sociology has not been developed in China even today, and this has impeded methodological discussion in relation to the interpretation and application of the theory. There are a great number of scholars like Michael Grenfell, Richard Jenkins, Derek Robbins and so forth in the United Kingdom, and David Swartz, Wacquant and so on in the United States, who have dedicated their lifetimes to researching Bourdieu, while there are only a few such in China. Additionally, many of those English-speaking academics acquired personal contact with Bourdieu himself, which provided them with a basis for in-depth analysis of the dialectical relationship between the author and the theory, while in China such a connection was extremely sparse. It is also the case that Chinese scholars are more likely to encounter Bourdieu through those who study him, in other words by means of scholarly articles about Bourdieu, rather than through Bourdieu's original texts.

Another reason for the late reception and moderate circulation of Bourdieu's work in China may lie in his unique academic style. Bourdieu's use of language is always characterized by 'long, complicated ways of speaking, a conscious distancing from ordinary languages, the idiosyncratic definition of words in contrast to their conventional meanings, etc.' JJenkins 1992, 163). This, to a degree, makes translation work difficult. For example, until now Distinction has not been translated into Chinese and this is undoubtedly because of Bourdieu's use of language: there have been many deliberations regarding the accuracy of language in translating this long and meandering book. To argue this point further, translation is even more challenging with respect to some of Bourdieu's highly abstract concepts, such as habitus. Some Chinese writers translated it as xi xing (习性) or guan xi (惯习), which in our view may have simplified the notion and scarcely reflects the epistemological perspective it purports to convey. In Bourdieu's Social Theory (2004), Gao, as one 
of the few Chinese academics who worked with Bourdieu, deliberates on the role that habitus plays in Bourdieu's complete framework. Gao also provides a fresh translation of habitus - shengcun xintai (生存心态), which well reflects the philosophical concerns embedded in this particular concept, as transcending the dichotomies between mind and body, between the social and the individual, and between the objective and the subjective.

\section{A Bourdieusian Analysis of Social Transformation in Post-Reform China}

\section{Historical account}

In writing about how Bourdieu should be read in a Chinese context, we firstly propose that close attention should be paid to the Chinese local contextuality. This is the post-reform era, from the economic reform (also known as 'Open Door Policy') in 1978 to the present, to be specific, in contemporary China as the particular period, we think, to which Bourdieu's theory can be the most relevant, and we shall proceed to argue this.

Contemporary China has been chronologically defined as starting in 1949, when the People's Republic of China was founded. Before the 1978 economic reform, the basic doctrine that directed China and the Chinese people, if described in the simplest term, was socialism; the nation's economy and culture were based on classlessness. The country was remodelled by an ideology of democratic centralism under the leadership of the Communist Party of China (CPC). In the first two decades of New China, the nation had undergone the political and social process of eliminating all the contradictions and antagonisms inherited from its prolonged imperial history and the catastrophic war period. The Cultural Revolution (1966-76) began in the mid-1960s, largely owing to Mao Zedong's faith in the making of a new culture, one that would be perpetually revolutionary. It is self-evident that this momentous movement in Communist China hurled the nation into utter political chaos and economic disruption.

When the Cultural Revolution culminated in 1976, so did Mao's China. China was then eager for reforms. Within just a few years, the new CPC leadership was formed, with the ambition to lead China to rebirth and prosperity. The Chinese economic reform, led by Deng Xiaoping, was the most decisive turning point in post-1949 Chinese history. The policy was endorsed in the Third Plenum of the Eleventh Central Committee of the CPC in December 1978, and marked the inauguration of China's reform and opening up. A new model of a decentralized economic system was firstly experimented with in a few coastal cities, including Shenzhen, Zhuhai, Xiamen and Shantou in 1979, and further expanded to another 14 coastal cities in 1984, including 
Shanghai, Dalian, Tianjin, Ningbo and so forth. With the successful experience gained from those 'special economic zones', the focus of the reform during 1984-92 was mainly the decentralization of the state-controlled industries and enterprises. Between the early 1990s and early 2000s, privatization was promoted and business investors and joint enterprises were notably encouraged. Through a series of effective national strategic plans, the centralist economic system was replaced with the market-oriented model and the process was surprisingly steady. Starting around the turn of the century, China entered the new phase of the reform, engaging with overseas direct investment, which eventually brought China onto the global stage. Compared with the 4.4 per cent real annual GDP growth between 1953 and 1978, China's average annual GDP grew by 9.9 per cent during the reform period (19792011), the fastest rate in the world (Morrison 2012).

Over the past 30 years, the economic and social systems have been experiencing an ongoing restructuring, remodelling, adjustment and readjustment, which has significantly increased the level of similarity between today's Chinese society and that of the Western countries. Economy, culture and social space were eventually affiliated and evolved into a new and intricate web of new constitution. The reform not only helped millions escape from poverty but also achieved a radical and rapid transformation of the entire economy. The real growth in industries and in the tertiary sector caused a decline in employment in agriculture. More and more people abandoned the land for jobs in cities, which created those now copiously overpopulated areas. Women's employment more directly reflected the development of service industries. For intellectuals and artists, reform signified greater freedom as well as stronger pressure to produce for the market. A new wave of development in cinema, literature, and other cultural industries soon emerged, aimed at responding to freedom, democracy and (in)equality that transpired with reform and openness. Public sectors, such as education and health care, were also restructured to meet the demand of the nation's sustainable development. The unprecedented prosperity also stimulated an overwhelming psychological desire for quality of life in China. Housing prices surged in the early 2000s and have continued to rise ever since, despite all the policies aimed at assuaging the situation. Car ownership was also initiated, which unfurled more public and private space, increased mobility and eventually changed people's lifestyle. The consumer market began to flourish in the late 1990s and reached its maturity after China entered the World Trade Organization in 2001. Fashion and shopping in urban China have transformed into an unprecedented level due to the abundant choices and high-end luxurious products that the market began to provide. Although always criticized as soulless materialism, a new consumer society as inevitable, which is, on the one hand, demanded by the 
economic reform and, on the other hand, reinforced by the emphasis on quality of life and individualism. The inextricable connection between one's material conditions and social status that unifies Bourdieu's sociocultural analysis was solidified.

\section{Social transformation and neze rules}

The great prosperity, however, masks new complexes in Chinese society and creates tensions that the government has failed to address. Firstly, the coexistence of a 'quasi-free-market economy' and the state-controlled postcommunist system has led to the formation of three new classes in China. As an incidental remark here, the common-sense definition and indicators of class stratification, for example, social position and economic opportunity, material access and behaviour, are relevant to the Chinese context with one exception, which is that the term 'class' can be deliberately elided in official discourses, regardless of its veritable existence. However, the term is not forbidden and it is, in fact, frequently used in academic studies in China. The first new group formed in post-reform China was the so-called new middle class, owing to the growth in business and finance, trade and retail, information and technology, education and other quaternary industries. This new social group is characterized by their possession of cultural capital, which enables them to take control over what Bourdieu calls the symbolic markets. Their social reproduction takes place through the ownership of the dominating forms of culture or communication. Possibly rich in cultural capital, this group possesses relatively low status in terms of economic capital and social capital. The second new social group engendered by the structural change is that of entrepreneurs. China, in the early stage of the reform, was once a land abundant with opportunities (which is still believed to be the case today) and these possibilities were open to all who were able to comprehend policy direction and market demand. Those who have become successful entrepreneurs in China have not necessarily advanced from a family background that traditionally relies on this particular reproduction strategy, although since the reform has deepened and the market has launched its rule the situation has been transformed to some degree. The rapidity of restructuring and the frequently changing policy focuses have left little guarantee of a stable business environment (particularly in the early phases of the reform), which inevitably has caused Chinese entrepreneurs to be more sensitive and observant to the political environment. This has now transmuted into a negative image: the culture of Chinese entrepreneurs and of their companies is more often regarded as pragmatism, which favours short-term profit and lacks innovation-driven momentum. To acquire insight and information for investment, social capital 
and the expanding of the social network are viewed as the golden rule in the Chinese business world (Batjargal and Liu 2004). The capital possessed by entrepreneurs is comprised largely of economic and social capital, and their social reproduction is achieved predominantly through the continual conversion between these two forms of capital, rather than simply as investment and reinvestment in accordance with pure economic interest. The 'socialism with Chinese characteristics' or 'market socialism' has led to the formation of the third new social group, namely the political elite, which refers to those with a high volume of political capital in other words, those who belong within the superior hierarchy of the Party. In China's model of socialist economy, the state retains a major role in building the infrastructure, directing investment, and acting as the final landowner, and the state-owned companies remain powerful (if they cannot be strengthened). Such an economic system has magnified the ability of political capital to manoeuvre other types of capital in today's Chinese society, and this group of people holds the key to initiating such influence (Sun 2009). Although political capital cannot be transmitted by inheritance, it is converted to a privilege in other fields or in the same field in generation-to-generation reproduction.

Secondly, the emergence of those new powers has completely redrafted the relationship pattern and the conversion rate between different categories of capital. Political capital does exist in modern liberal/democratic societies, but its defining role is unique to the Chinese context. At the macrolevel, the domination of political capital explains the party/state relationship, while at the microlevel, power is directly expressed in the new group, whose role is to decide, manage and implement national policies. Instead of being neo-liberal in perspective and able to adapt to fair practices, Chinese society displays an inability to escape a culture that is overly accustomed to an emphasis on interpersonalization (the possession of a network of influential people, which is similar to Bourdieu's social capital) rather than on the institutionalization of relationships (Shambaugh 2013). The concept of social capital in the Chinese context captures the indigenous social phenomenon called guanxi, whose effects have become a tacit assumption ('doxa' in Bourdieu's language) of 'successful social practices' in the business sector, as mentioned above, and in many others. Social capital operates horizontally across diverse fields, but vertically in a hierarchy. Social agents who struggle to conceive an up-classing or to avoid down-classing are dependent on social capital to extract the full yield from their total volume of various forms of capital, which Bourdieu argues in a number of his works. In addition, unlike political capital, which can be both the means and the end in a social agent's position seeking, the effect of social capital lies more often in exchange, in other words, in the 'practical state' as Bourdieu (1997, 51-3) writes in The Forms of Capital. These two capital states 
are always more closely coupled than the relationship shared by any other two forms of capital. However, political capital appears more easily convertible to social capital than vice versa. The ultimate domination of political capital also leans towards the stimulation of the reconversion of capital held in other forms, including the economic, cultural and social, to this particular one that is believed to be more legitimate and profitable in the Chinese context.

Thirdly, decision making with respect to reproduction strategy does not necessarily originate from the primary habitus of the social agent. The making of a new structure must inevitably brave a phase in which the old and the new systems coexist and when power relations appear blurred, as addressed in theories and in Chinese official dialogues. This is namely the transitional period. During such radical times, field and habitus fall out of line - previous routes of social reproduction are virtually discontinued, all forms of prophesy open up the future and restorations follow the crisis. The promises provided by the new system constitute a 'temporal habitus', which subverts the primary disposition and becomes attuned to what is almost anarchism, as believing in absolute freedom and improbable possibilities. The structural gaps encourage a less resigned but also less realistic relationship with the future than the traditional sense of proper limits, which was once the basis of an acute sense of order. Social agents are committed to mobility, the idea of banking on the seemingly positive future and the expectation of a new self. Having not yet established a proper order that facilitates such psychological demand, social agents can only be left with a grim reality, in which their positions are illdefined and uncertainly located. The nation has entered an unprecedented growth in economy without being fully equipped with compatible social and cultural mechanisms. The informal institution and practices therefore come into play in order to eschew sudden depletion in reproduction, in compliance with the defining capital in the field - political capital. The 'unthinkable' is enacted to venture beyond the objective opportunities with which social agents were originally aligned. It can immediately be judged that informal practices are more feasibly associated with and fulfilled by social capital, whose power, as the mediation in capital conversions, is again reinforced. A vicious circle is thus created. In the Chinese context, all, or the majority of fields share the same logic of reproduction: opportunities for position upgrading are assigned to those who exercise informal practices. In other words, those who manage to utilize social capital together with another defining capital in a given field, that is, economic, cultural or political, tend to gain the advantage of acquiring further power in that particular field. This results in a high degree of corruption and develops into a culture that overvalues social capital and political capital as its genesis, and eventually overwrites meritocracy and regulations. The implementation of the new order becomes increasingly difficult, since 
it must break through not only the traditional system but also the side effects remaining after such a transitional period.

Thus, to conclude here, the logic of social reproduction in China rests on Bourdieu's theory that (1) social space is constructed by two dimensions - overall capital volume and dominant/dominated capital - and it allows two types of movements, vertical as upwards or downwards and transverse as one field to another; and (2) a social agent's position in a field is defined by the volume and composition of his or her capital and the exchange in those two properties, as discussed previously. The emergence of the new social groups initiates the profound implications of the structural change in Chinese society in the post-reform era. Differing from Bourdieu's conceptualization in which economic structure is the real foundation, the ruling principle of the efficacy of reproduction lies in the dominating power of political capital, in which other capital forms are embedded. As the informal institution and practices became a tacit rule in social reproduction, the coherence between capital, habitus and field is hard to maintain. The confusions discussed in this part describe the social transformation of Chinese society, and the new rules engendered, since the reform.

\section{A Bourdieusian Analysis of Gultural Reproduction in Post-Reform Ghina}

\section{Educational system}

Bourdieu holds a particular perception of the relationship between the social structure, the cultural and individual action. His philosophy refuses 'the sharp demarcation between the external and the internal, the conscious and the unconscious, the bodily and the discursive' (Bourdieu and Wacquant 1992, 19). For an individual, it is the work of habitus that produces rationality without intention and practises without deliberation. For a society, it is collective habitus that contributes to social trajectory, or the sum total of the past intending to dictate to the future. Therefore, the very process forming habitus stands as the core of everything and the prominent position of habitus installs education as a central pillar in Bourdieu's theory. The educational system, acting as the most orthodox pedagogic authority in a given society, exerts its power of imposing a legitimate culture on the basis of three fundamental constitutions: curriculum, pedagogic practice and assessment. Bourdieu further argues that the most disguised truth of the educational system in modern societies is twofold: the first is that the culture of the dominating classes is regarded as the legitimate culture, and the second is that the inculcation of such a legitimate culture is limited to the 'audience of legitimate addresses', in other words, those who are the closest to the legitimate culture (Bourdieu and Passeron 
1977). The seemingly neutral academic selection will thus enable only those who were originally rich in cultural capital to triumph. The educational system then joins capital, habitus and field to undergird the perfect reproduction.

Bourdieu's analysis indeed opens a new vista for examining the social aspects of education. However, his overt intention to conclude that all educational systems involve the same pedagogic logic is somewhat fallible. The Chinese educational system is a typical example and there are two main reasons for this. Firstly, China's educational system and its pedagogic practices are examination oriented. Examination is not only applied to college recruitment, but also, in fact, academic performance is essential at all levels of schooling in China. The most straightforward explanation for this is arguably the size of the student population. According to the Ministry of Education (MOE), in the first year when the National College Entrance Examination (NCEE) resumed after the Cultural Revolution in 1977, the total number of candidates was 5.7 million. This figure almost doubled in 2007, and reached 10.1 million, and the most up-to-date official statistics show that 9.15 million students participated in the NCEE in 2012 (MOE, 2013). To select talent from such a large accumulation of students, examination appears to be the most, if not the only effective and fair criterion. The deeper rationale for adopting such a specific model is due largely to the consideration that social capital and informal practices may hinder matters if other kinds of recruiting systems, such as evaluation and interview, are employed. There has been an ongoing debate concerning how the Chinese educational system may be reconstructed to exert a new set of criteria that can better reflect an all-round measurement of talent as well as reduce the burden on students and on parents and teachers. Various opinions have been raised and heard by the public, by intellectuals, and by the government. The American system, the UK system and many others have been discussed and evaluated. Over the reform period, a significant effort has been made regarding curriculum and the subjects included in the final NCEE, while the intrinsic logic remains unchanged. Although there are other important considerations that suspend the reform with respect to the selection mechanism in China's educational system, such as the consistency of measurements, regional differentiations and in-land cultural diversities, the concern that artificial factors may distort the original intention cannot be disregarded. Yet, as every concept has at least two facets, the frequently criticized performance-based education in China does not fall prey to Bourdieu's view that education is merely an epiphenomenon of the external order; rather, it does indeed persist in its intrinsic logic. Clearly, educational attainment is related to the economic capital available to a family and the time devoted to it directly by the child and indirectly by the parents. In this sense, in the Chinese context, the system still transfers social inequality to an academic outcome, 
which then performs as the basis of future chances in life. The important point, however, is that the logic of reproduction in post-reform Chinese society as argued previously - social capital almost becomes a 'standard currency' - is no longer functional in the field of education, and in fact education might be the sole uncharted territory beyond the influence of social capital in today's Chinese society, thanks to this examination model.

Secondly, political capital remains powerful in the education sphere of China. The dominating power of political capital in education lies in the state's control over the curriculum, the funding and the general management. The education system is less centralized indeed, when compared with that before the reform, but the state still decrees what should be taught, the pace it will take and the sequence. Furthermore, regulations apply more strictly to the preuniversity levels. For the NGEE, the state also plays an important role in designating the yearly enrolment score for different levels of colleges and universities, such as the national key university, provincial key university and so forth, although such decision making has already been partially disseminated to the Department of Education in each province and to the universities. The state provides general management of those higher educational institutions and the educational department at provincial levels, particularly in the allocation of resources, infrastructural development, quality control, funding management and systematic reform. Again, such control, or supervision, proves to have a positive outcome, particularly in the post-reform era when the new orders are still in the making. It becomes possible for the state to direct, but not control and cultivate an ideology appropriate to the specific economic and social conditions in China by means of such as teacher training, curriculum planning, funding support and so on. The problem of what the educational system promotes in a country has to do with the question of what to encourage in the society, what the national identity is and ultimately, what makes China. This is perhaps the most important question after all.

\section{In searching for legitimate culture}

Before the reform, China had experienced a century of vicissitudes. The modernization of China was a process of constant negotiation with the Western dominion. The self-sufficient traditional economy reached its climax in the Qing dynasty. Although China had begun to engage in maritime traffic in the eighteenth century, after a number of incidents and conflicts with foreigners, Qing Emperor Qian Long (1750-93) enforced an 'isolation policy' (biguan suoguo), to limit all international commerce at one port of Guangzhou. Such a policy locked China for almost a century until the First Opium War 
(1838-42), which began China's fall into the era of wars. The Second Opium War erupted in 1856, followed soon by the Sino-French War in 1884 and the First Sino-Japanese War in 1894. The Qing army lost in almost all of those wars, and the idea of China declined. Led by Qing Emperor Guang Xu (1875-1908) the Hundred Days Reform (wuxu bianfa) opened in September 1898. The short-lived reform (11 June-21 September 1898) failed to bring any real change to China, although it best reflected the nation's and the people's desire for a reawakening and self-strengthening. After a decade of struggle, the revolutionary forces triumphed in 1911, in what is known as the Xinhai Revolution, on the basis of which the Republic of China was born. Soon after China entered the republican era, the famed May Fourth Movement took place in 1919. The young scholars believed that only through a spirit of scepticism and criticism could the modernization of China be achieved. Western ideas of science and democracy were enthusiastically promoted and traditional Chinese philosophy and practice were severely attacked. The movement spurred new progress in culture and education, as well as the birth of the CPC in 1921. However, the triumph was brief and impermanent. The Second Sino-Japanese War broke out in 1937, which instigated another eight years of a war period, followed by a further four years of civil war. As introduced earlier, the post-war restoration lasted for only 20 years before the commencement of the Cultural Revolution (1966-76), which again condemned the country to another miserable decade.

The wars left China and the Chinese people with deeply emotional wounds - a strong sense of victimization and humiliation. Nationalism was unleashed through the traumatic experience with the West and a general will for modernization was then raised by the process of liberation. Even today, despite economic success both domestically and globally, the Chinese thinking about the nation's own evolving identity is still somehow rooted in those historical moments. The fragile identity reflects existing insecurities about China's potential and future and mirrors a lack of confidence in its own culture. Facing the inevitable and ever-increasing encounter with the Western countries in the post-reform era or in the era of globalization, one message that China needs to send - not to the world but to herself - is that of self-belief. Nationalism and patriotism are indeed the fundamental basis of a nation - of any nation - but they need to be revitalized with new elements in order to unify the Chinese under the new challenges the world has asserted.

The search for a legitimate culture must be a movement inward. In fundamental disagreement with what Bourdieu defines, a nation's legitimate culture should never be the culture of the dominating group, but should be that which can resonate to the greatest extent with the society, and in China no philosophy other than Confucianism can achieve this. Though by no means 
the only philosophy that China has produced or embraced, the history of Confucianism and its influence are the most profound. There were several phases in the development of Confucian thought. It emerged as an ethicalsociopolitical teaching between 551 and 479 BC. After several centuries of Buddhist dominance, Confucianism was revived in the Song (960-1279) and Ming (1368-1644) dynasties, constituting neo-Confucianism. The latest phase in the twentieth century and the present day is represented by New Confucianism, which strives to 'overcome Western dominance by radically questioning the internal truth of humankind' and urges 'the renaissance of Chinese tradition after Westernization' (Zhang 1997, 43). Following over two millennia of evolution, five core subjects may summarize the Confucian code of life: benevolence (or humaneness) (ren, 仁), righteousness (yi, 义), etiquette (or proper rite) ( $l i$, 礼), knowledge ( $z h i$, 智), and integrity (xin, 信). By heavily emphasizing ethics and morality, Confucianism is based on the perception that man is, by nature, good and the belief that social order can be sustained by the proper behaviour of individuals.

If names be not correct, language is not in accordance with the truth of things. If language be not in accordance with the truth of things, affairs cannot be carried on to success. When affairs cannot be carried on to success, proprieties and music will not flourish. When proprieties and music do not flourish, punishments will not be properly awarded. When punishments are not properly awarded, the people do not know how to move hand or foot. (Confucius, Analects, book 13, chap. 3, vs. 5-6)

The above verses from Analects explain the basic moral precepts of Confucianism - the 'rectification of names' (zheng ming, 正名). In Confucian classics, a true government is 'when the prince is prince, and the minister is minister; when the father is father, and the son is son' (Confucius, Analects, bk. 12, chap. 11, vs. 2). Those words from Analects emphasize precisely the strict adherence to the proper interpretation of order and the rightful practices. Although this chapter does not intend to compare Bourdieu with Confucius, Bourdieu's concept of the dialectical relationship between habitus and social structure to a degree echoes this idea. On the one hand, social agents act according to the field rules and the specific principles assigned by their positions in the field, as implied in names, which are in fact socially constructed with symbolic meanings. On the other hand, only when proper practices are delivered by social agents is the structure, for example, truth and language, affair and proprieties, punishment, and awards established and maintained, as explained in the relationship between individual habitus, collective habitus and social reproduction. 
There will then be peace and order, prosperity and happiness everywhere the perfect stability that is only made possible when field and habitus are in perfect harmony. Confucian values and ethics are, without the need for further justification, universal to any society - both Western and Chinese and certainly present no dissension with Bourdieu's theory in any sense. The principal distinction between these two paradigms is that Bourdieu's sociology is a sociocultural theorization of power relations in society, while what Confucius (or Confucianism, when referring to the entire school of thought) has produced is primarily a philosophy on the regimentation of life and the cultivation of proper social behaviours. Given that cultural reproduction is a relay effect, Bourdieu explains, comprehensively, how it relays, while Confucianism offers what should be relayed.

Confucianism is indeed an overriding political, social and cultural philosophy immanent in China. However, its role as a legitimate cultural form in Chinese history is episodic, as briefly discussed above. Specifically, in the postreform period, the renovation of Confucian doctrine was first introduced by the party in the early 2000s. Compared with those orthodox sayings from the original classics, what the country really seeks in Confucianism are the essential values that can be best related to the general public and the potential to dissolve the social tensions in the new era. For this, the concept of 'harmony' is brought to the fore. In the sixteenth National Congress of the CPC in 2004, the party proclaimed a political slogan that reflects an explicit Confucian origin, namely 'harmonious society' (Xinhua 2004). This movement signals that the focus of China's structural reform and adjustment has been directed from promoting economic growth to solving social issues. The government has made a concerted effort to restore a strong national identity. The Fifth Plenum of the Seventeenth Central Committee of the CPC in 2010 indicated that 'culture is the spirit and soul of a nation, and is the power to propel development of a country and the revitalization of a nation' and continued to emphasize the importance of cultural innovation, the country's soft power and education (Xinhua 2010). The Chinese dream of building a harmonious society implies the government's attempts to secure social stability through cultural uniformity. If Confucian norms can be successfully restored and maintained, the uneven power of different forms of capital in today's Chinese society may be rectified. The institutionalization of a liberal social order can then become attainable. To conclude, cultural reproduction in China is characterized by its socialist constitution and political culture: the cornerstone of the inculcation of certain forms of legitimate culture is a political imperative, while education (including both the diffuse and the institutionalized forms) functions as one of the designated authorities in the society to ensure the lasting success of the process. 


\section{Conclusion}

The main task of this chapter was seeking to elucidate why Bourdieu's framework renders a theoretical construct in comprehending the social transformation and cultural reproduction in post-reform China. To conclude, the methodological stance is threefold. Firstly, Bourdieu's theorization may only be viewed as a framework to think with. Besides the unconventionally distinguished approach he contributed to social science, Bourdieu's work has never neglected the epistemological dimensions. His theory was written with the aim of transcending different cultures and facilitating the understanding of social reality. Secondly, to use his theory as a framework also implies that no individual concept may be pulled out or plugged in to suit a particular context. The real efficacy of the concepts only lies in their interrelatedness. Thirdly, the Bourdieusian framework should be read with sensitivity to the particularity of the local context.

Given the Chinese particularity, a Bourdieusian analysis of post-reform China should break through two theoretical assumptions. Firstly, it must change the structuralist view that field and habitus are always of a high level of homogeneity. The transitional Chinese system entails a fuzzy classification and blurred edges - it is opened to new possibilities and associated with risks, precisely when the spontaneous match between habitus and field is out of sync. This opaqueness is the stark reality of today's Chinese society. For the ambiguous yet undeniable disparity between formal structuration and informal operation, the term 'transitional period' has been used in a mystified way - neither the state nor the public has fully grasped the intrinsic properties or successfully proposed an optimal feasible solution. In such times of crisis, the conversion between different forms of capital may deviate into another shape, resulting in the emergence of new dominating classes, namely the new middle class, the entrepreneurs and the political elite. The ultimate power of political capital and the overexploitation of social capital are two key features. Secondly, it must question Bourdieu's view that all educational systems perform according to the same pedagogic logic. Two distinctive characteristics of China's education are its semicentralized nature and the examination-based selection system, which have an immediate effect on the system's ability in strategic planning when a new culture needs to be illuminated.

Simply because society is a process, no single theory can provide a definite conclusion; rather, each interpretation produces a unique angle of explanation of a given form of reality. This Bourdieusian analysis is only one of many. In this sense, Bourdieu's framework indeed explains Chinese society in the post-reform era, arguably more appropriately and thoroughly than any other theory would. 


\section{References}

Ascher, W. and J. M. Heffron eds. 2010. Cultural Change and Persistence: New Perspectives on Development. Palgrave MacMillan.

Batjargal, B. and M. Liu. 2004. 'Entrepreneurs' Access to Private Equity in China: The

Role of Social Capital'. Organization Science 15, no. 2: 159-72.

Bourdieu, P. 1977. Outline of a Theory of Practice. Cambridge: Cambridge University Press. - 1979. Algeria 1960. Cambridge: Cambridge University Press. 1984. Distinction: A Social Critique of the Judgement of Taste. New York/London:

Routledge.

1988. Homo Academicus. Cambridge: Polity.

1990. The Logic of Practice. Cambridge: Polity.

1993. The Field of Cultural Production. Cambridge: Polity.

1996. The State Nobility. Cambridge: Polity

1997. The Forms of Capital, in A. H. Halsey, H. Lauder, P. Brow and A. S. Wells

(eds.), Education, Cultural, Economy, Society. Oxford: Oxford University Press.

1998. Practical Reason: On the Theory of Action. Cambridge: Polity.

2000. Pascalian Meditations. Cambridge: Polity.

2004. Science of Science and Reflexivity. Cambridge: Polity.

2008. The Bachelors'Ball. Cambridge: Polity.

Bourdieu, P. and J. C. Passeron. 1977. Reproduction in Education, Society and Culture. London/ Thousand Oaks/New Delhi: Sage Publications.

Bourdieu, P. and L. J. D. Wacquant. 1992. An Invitation to Reflexive Sociology. Chicago: University of Chicago Press.

Buchholz, L. 2006. 'Bringing the Body Back into Theory and Methodology'. Theory and Society 35, no. 4: 481-90.

Chang, J. H. 2000. 'Symbolic Interaction and Transformation of Class Structure: The Case of China'. Symbolic Interaction 23 no. 3: 223-51.

Chen, N. and X. Zang. 2009. 'Bourdieu and Chinese Sociology'. Sociologica 2009, 1: 1-16.

Clothey, R. 2005. 'China's Policies for Minority Nationalities in Higher Education:

Negotiating National Values and Ethnic Identities'. Comparative Education Review 49, no. 3: 389-409.

Confucius. Analects. Translated by J. Legge. 1983. Clarendon Press.

Deng, Z. and D. J. Teriman. 1997. 'The Impact of the Cultural Revolution on Trends in Educational Attainment in the People's Republic of China'. American Fournal of Sociology 103, no. 2: 391-428.

Doleželová-Velingerová, M., O. Král and G. Sanders. The Appropriation of Cultural Capital: China's May Fourth Project. Cambridge/London: Harvard University Press.

Donald, S. H. and Y. Zheng. 2009. 'Post-Mao, Post-Bourdieu: Class Culture in Contemporary China'. Fournal of Multidisciplinary International Studies 6, no. 2: 1-11.

Elman, B. A. 1991. 'Political, Social and Cultural Reproduction via Civil Service Examinations in Late Imperial China'. Journal of Asian Studies 50, no. 1: 7-28.

Fairbank, J. K. ed. 1983. The Cambridge History of China, Vol. 13: Republican China 1912-1949 Part 1. Cambridge: Cambridge University Press.

Fairbank, J. K. and A. Feuerwerker ed. 1986. The Cambridge History of China, Vol. 13: Republication China 1912-1949 Part 2. Cambridge: Cambridge University Press.

Fong, V. L. 2002. 'China's One-Child Policy and the Empowerment of Urban Daughters'. American Anthropologist 104, no. 4: 1098-109. 
Gao, X. 2004. Bourdieu's Social Theory. Shanghai: Tong Ji University Press. (originally in Chinese).

Garcelon, M. 2010. 'The Missing Key: Institutions, Networks, and the Project of Neoclassical Sociology'. Sociological Theory 28, no. 3: 326-353.

Gladney, D. C. 1994. 'Representing Nationality in China: Refiguring Majority/Minority Identities'. Fournal of Asian Studies 53, no. 1: 92-123.

Hanser, A. 2007. 'Is the Customer Always Right? Class, Service and the Production of Distinction in Chinese Department Stores'. Theory and Society 36, no. 5: 415-35.

Hung, H. 2008. 'Agricultural Revolution an Elite Reproduction in Qing China: The Transition to Capitalism Debate Revisited'. American Sociological Review 73, no. 4: 569-88.

Jenkins, R. 1992. Pierre Bourdieu. London/New York: Routledge.

Keane, M. 2011. China's New Creative Clusters: Governance, Human Capital and Investment. London/New York: Routledge.

Ledeneva, A. 2008. "Blat" and "Guanxi": Informal Practices in Russia and China'. Comparative Studies in Society and History 50, no. 1: 118-44.

Li, D. L. 2007. 'Capturing China in Globalization: The Dialectic of Autonomy and Dependency in Zhang Yimou's Cinema'. Texas Studies in Literature and Language 49, no. 3: 293-317.

Ministry of Education, China (MOE). 2013. China Education Year Book. Online: http:// www.moe.gov.cn/publicfiles/business/htmlfiles/moe/s8492/index.html (originally in Chinese, accessed 29 December 2014).

Morrison, W. M. 2012. China's Economic Conditions. Congressional Research Service Report for Congress. Online: http://fpc.state.gov/documents/organization/194783.pdf (accessed 30 Nov 2014).

Platteau, J. and R. Peccoud. Culture, Institutions, and Development: New Insights into an Old Debate. London/New York: Routledge.

Robbins, D. 2000. Bourdieu and Culture. London/Thousand Oaks/New Delhi: Sage Publications. 2012. French Post-War Social Theory. Los Angeles/London/New Delhi/Singapore/ Washington, DC: Sage.

Shambaugh, D. 2013. China Goes Global: The Partial Power. Oxford: Oxford University Press.

Song, G. and T. K. Lee. 2010. 'Consumption, Glass Formation and Sexuality: Reading Men's Lifestyle Magazines in China'. China Fournal 64: 159-77.

Sowerwine, C. 2001. France since 1870: Culture, Politics and Society. New York: Palgrave.

Sun, L. 2009. 'Societal Transition New Issues in the Field of the Sociology of Development'. Polish Sociological Review, 167: 329-49.

Svendsen, G. L. H. and G. T. Svendsen. 2003. 'On the Wealth of Nations: Bourdieuconomics and Social Capital'. Theory and Society, 32, no. 5/6: 607-31.

Van Crevel, M. 2005. 'Not Quite Karaoke: Poetry in Contemporary China'. China Quarterly 183: 644-69.

Wang, H. 2009. The End of the Revolution: China and the Limits of Modernity. London/ New York: Verso.

Wang, S. 2006. 'The Uneven Distribution of Cultural Capital: Book Reading in Urban China'. Modern China 32, no. 3:315-48.

Waung, W. S. K. 1971. Revolution and Liberation: A Short History of Modern China 1900-1970. London: Heinemann Educational Books.

Wu, Y. 2008. 'Cultural Capital, the State, and Educational Inequality in China, 19491996’. Sociological Perspectives 51, no. 1: 201-27. 
Xinhua News. 2004. 'Communist Party of China Central Committee on Strengthening the Party's Governance Capability'. Xinhua News, 27 September. Online: http://news. xinhuanet.com/zhengfu/2004-09/27/content_2027021.htm (originally in Chinese, accessed 29 Dec 2014).

2010. 'Full text of Communique of the Fifth Plenum of the 17th CPC Central Committee'. Xinhua News, 18 October. Online: http://news.xinhuanet.com/ english2010/china/2010-10/18/c_13563388_5.htm (accessed 29 December 2014).

2014. 'Report on the Work of the Government'. Xinhua Newes, 14 March. Online:http://news.xinhuanet.com/english/special/2014-03/14/c_133187027_ 2.htm (accessed 29 December 2014).

Yang, X. 2002. The Chinese Postmodern: Trauma and irony in Chinese Avant-Garde Fiction. Ann Arbor: University of Michigan Press.

Yang, Y. 2014. 'Bourdieu, Practice and Change: Beyond the Criticism of Determinism'. Educational Philosophy and Theory 46, no. 14: 1522-40.

Yeh, M. 1998. 'International Theory and Transnational Critics: China in the Age of Multiculturalism'. Boundary 25, no. 3: 193-222.

Zhang, Q. 2005. 'A Chinese Yuppie in Beijing: Phonological Variation and the Construction of a New Professional Identity'. Language in Society 34, no. 3, 431-66.

Zhang, X. 1997. Chinese Modernism in the Era of Reforms: Culture Fever, Avant-garde Fiction, and the New Chinese Cinema. Durham/London: Duke University Press.

1998. 'Nationalism, Mass Culture, and Intellectual Strategies in Post-Tiananmen China'. Social Text 55: 109-40.

Zhou, X. P. Moen and N. B. Tuma. 1998. 'Educational Stratification in Urban China: 1949 94'. Sociology of Education 71, no. 3: 199-222. 


\title{
Chapter 9
}

\section{BOURDIEU'S USE AND REGEPTION: A LATIN AMERICAN PERSPEGTIVE ON THE PROBLEMS OF GONCEPTUAL TRANSFER}

\author{
María-Luisa Méndez
}

\section{Bourdieu and the Neutralization of the Historical Context}

In an article entitled 'On the Cunning of Imperialist Reason', Pierre Bourdieu and Loïc Wacquant (1999) refer to theorization as 'the power to universalize particularisms linked to a singular historical tradition by causing them to be misrecognized as such' (Bourdieu and Wacquant 1999, 41). In other words, theorization is understood as a form of neutralization of the historical context. In this, as in other pieces, Bourdieu showed reluctance to extract concepts understood as structured structures - from the contexts of their production, or from their structuring structures (Robbins 1994). This, he thought, was a way of imposing (Western) sociological theory as a form of symbolic violence exercised upon epistemic communities, and that would end up blurring the particular contexts in which academic discourses are produced.

This chapter has resonances with concerns regarding 'the "ethos of usage” of Bourdieu's analytical categories' (Bennett et al. 2013, 135) in contexts other than the Global North, but it also attempts at connecting these uses to the sociopolitical contexts of circulation and reception of his intellectual legacy. This chapter follows a growing interest in divergent uses of Bourdieu's work in various national contexts such as Australia (Bennett et al. 2013) and Turkey (Karademir Hazır 2014), among many others. Similar to the situation described in respect of the Antipodean uptake (Bennett et al. 2013), Bourdieu has been mostly known in Latin America by his work in the field of the sociology of education. ${ }^{1}$ According to Beigel, 'there are few studies on the circulation of Bourdieu's work within Latin America' (2008, 9), 
and as argued by Baranger (2010) his first works that circulated in the region were those he produced with Jean-Claude Passeron, particularly Reproduction (1977). During the 1990s, however, Bourdieu's theory of the habitus and his ideas about an engaged sociology gained more visibility, particularly with the books Distinction (1984) and In Other Words: Towards a Reflexive Sociology (1995), among others. This came to be most evident after his death, with the robust reception given to the book An Invitation to a Reflexive Sociology (1996; 2002), which was first published in Spanish in 2005. It is not the interest of this chapter, however, to describe the influence of Bourdieu's work on the Latin American sociological field per se (see Heise and Tudor 2007; Dezalay and Garth 2002; Beigel 2008). Rather, in thinking about the take-up of Bourdieu in this region it becomes pertinent to reflect largely on the ways in which the Latin American scholars discussed here engage in cross-cultural debates, both theoretically and methodologically, and how this brings about not only problems of conceptual transferability but also problems of positioning within local and international academic fields.

In this chapter I focus on Bourdieu's critical ideas concerning the allegedly universal validity of Western European social science. In so doing, I investigate in detail the implications of Bourdieu's work in a global context, particularly as expressed in the development of the 'Bourdieusian' sociological field in Chile. Following his own questioning, my attempt is to reflect on the tensions involved in conceptual transfer for a generation of academics who conducted - as I did - postgraduate studies in the Global North. I explore not only disciplinary aspects of this exchange but also the sociopolitical dimensions involved in the reception of Bourdieu's work within Latin American societies, specifically in the case of Chile.

I focus on four major topics that I consider particularly relevant for discussing the experience of being caught in problems of conceptual transfer. On the one hand, I refer to the ways in which Bourdieu's ideas on the mismatch between habitus and field have helped illuminate problems of cultural malaise in societies, such as that in Chile, which experienced rapid processes of social mobility. Closely connected to the first point, the second aspect that I examine is how a particular angle of Bourdieu's work (habitus and sense of place) has been considered in relation to the study of place making within the new/ traditional urban middle classes. The third point I attempt to develop is how Bourdieu's culturally sensitive perspective on the reproduction of inequality has been influential in the development of a sociological field in societies such as Chile where concern about inequality is a pressing topic. Finally, I refer to the development of an area of studies of cultural practices and inequality reproduction in Chile, but also in dialogue with other countries in Latin America and other parts of the world. 


\section{The Sociopolitical Context of Latin American Sociological Endogenous Thinking}

At a global scale, the circulation of Bourdieu's ideas and the patterns of reception of his work have differed in relation to particular intellectual traditions and academic institutions (Santoro 2008, 5). As argued previously, in the case of Latin America, his influence has been mostly visible in the field of the sociology of education, and more recently in the area of social stratification and lifestyles (Méndez 2015). This chapter aims at reflecting on the ways in which Bourdieu's work has been received over the past ten years by a generation of young academics who conducted postgraduate programs in the Global North, particularly the United Kingdom.

Given the temporal angle provided in this chapter, and also the relevance that Bourdieu himself gave to attending to the sociopolitical contexts of production and the reception of ideas, it is important to offer a brief account of the development of the social sciences in South America over the past decades. This will help illuminate the argument of the chapter in terms of the particular circumstances under which Bourdieu's work has circulated: a reconfiguration of the academic field in sociology, and the associated redefinition of positions within the field.

According to Beigel $(2008,13)$, the decades of the fifties and sixties saw the expansion of a

'vigorous sub-regional circuit' around public universities in Argentina, Chile, Uruguay, and Brazil, alongside the emergence of a radical sociology that went hand in hand with the development of Dependency Theory. By the end of the sixties, social sciences had achieved high standards of institutional development and intellectual autonomy, as well as production of endogenous concepts and methodological approaches. $(2008,14)$

In the case of Chile, a first phase of creation, institutionalization and professionalization could be signalled from the mid-1950s until 1973 (Garretón 2005, 359). However, this context of intellectual production was seriously damaged by a series of dictatorships that 'interrupted repeatedly the institutional development of social sciences' (Beigel 2008, 9). Among other things, sociology undergraduate programmes were closed, while academics and leading intellectuals disappeared, were forced into exile or simply expelled from universities (Petras 1990), while others stayed at their universities but were forced to turn back the clock regarding theoretical approaches in order to focus on abstract and atemporal versions of social problems. ${ }^{2}$ At the same time, there was scarce reproduction within the increasingly more precarious 
academic institutions, which finally led to a gap or a 'lost' generation of academics in the social sciences (Güell 2002).

Public universities were the institutions mostly hit by economic and political restrictions (Beigel 2008). Academic work became gradually more likely to receive external funding from government aid agencies as well as private foundations in the Global North, especially Europe, Canada and the United States. For some authors this shift in the conditions of production of academic work, became 'the basis for the creation of a new intellectual world: the externally-funded research centre' (Petras 1990, 719), whereas for others (Garretón 2005) these new academic centres were a chance to compensate for this vast loss by developing the disciplines in the social sciences with particular thematic focuses of specialization. According to Petras (1990, 719), the seventies marked a clear division between two opposed intellectual types: organic intellectuals (1960s) and those connected to new academic institutes and centres, described as institutional intellectuals (1980s).

The nineties brought back democracies, and many programmes in social sciences throughout the region were reopened. In the period of the late nineties and the early 2000s, the social sciences gained back space at universities, and public institutions and national scientific organisms were created or reemerged as key actors in funding research and scholarships for international postgraduate training programmes (for example, the National Commission for Scientific and Technological Research (CONICYT) in Chile, Consejo Nacional de InvestigacionesCientíficas y Técnicas (CONICET) in Argentina or various federal universities in Brazil).

According to some authors, not only the first years of dictatorships with the concomitant violation of human rights and then the later creation of independent centres of social sciences funded by external agencies but also the transition to democracy have had contradictory consequences for academic institutions and communities. On the one hand, there is a possible loss of institutional autonomy in defining research agendas, given that the funding comes from agencies and foundations with particular political programmes, while on the other hand, there is an incipient but steady development of national academic institutions. At the present-day, the distinction between generations of academics not only involves the organic and the institutional intellectuals but it now also becomes relevant to differentiate between the latter and the nuclei of young scholars throughout the region.

In the case of Chile, the 2000s brought together a series of changes regarding the development of the social sciences. For example, there was the creation of a series of new schemes to support disciplinary and interdisciplinary research, such as the establishment of the Scheme of Development of Human Capital, among other publicly funded initiatives. This meant that over the last decade a number of no less than 3,000 young scholars have 


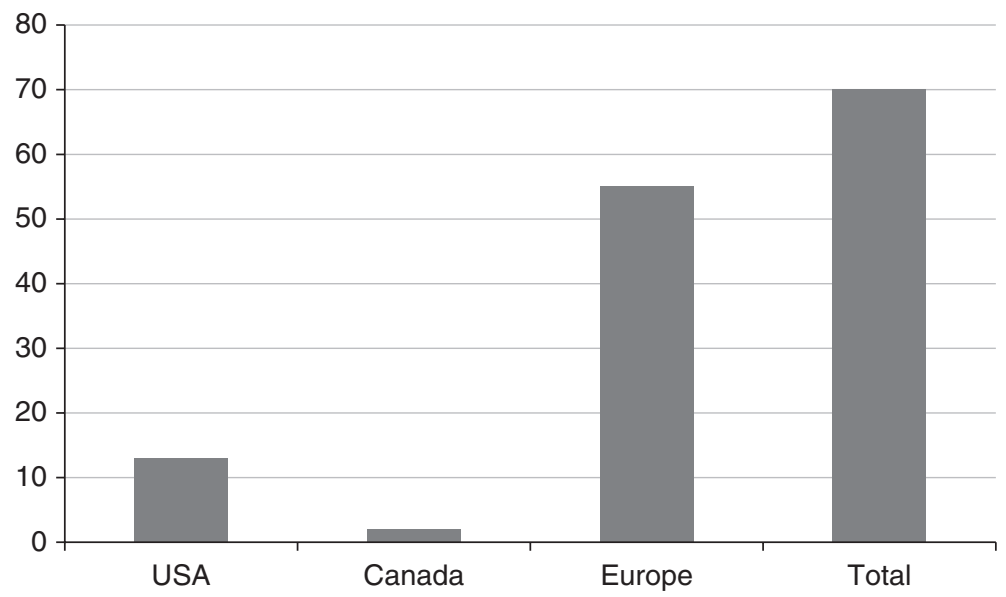

Figure 9.1

\begin{tabular}{lc}
\hline Place of study & $\begin{array}{l}\text { People returning with } \\
\text { accomplished PhDs in sociology }\end{array}$ \\
\hline USA & 13 \\
Canada & 2 \\
Europe & 55 \\
Total & 70 \\
\hline
\end{tabular}

Source: CONICYT

conducted postgraduate studies in the Global North and in Chile, as shown in the previous two figures which provide data disaggregated by place of study (Figure 9.1) and in the next two figures that show data on the returning year (Figure 9.2). In relation to the social sciences, and particularly sociology, there are currently $70 \mathrm{PhD}$ students who are funded by CONICYT.

Over the past decade and a half, there has been a reconfiguration of academic institutions in that the social sciences that have gone hand in hand with the arrival of young academics trained in the Global North. Parallel to this, the metrics in which academic productivity is measured have also changed drastically towards the use of indicators such as International Scientific Indexing (ISI) publications, which sets the incentives in targeting international journals, most of which publish articles in the English language. As argued by Ramos, 'these publications, especially those in ISI, are considered to be a privileged indicator of individual productivity and so they influence professional advancement. In that way, Chilean scientific institutions themselves, wherein the very researchers participate, promote the reproduction of this stratified structure of a central social science, more highly valued, and a 


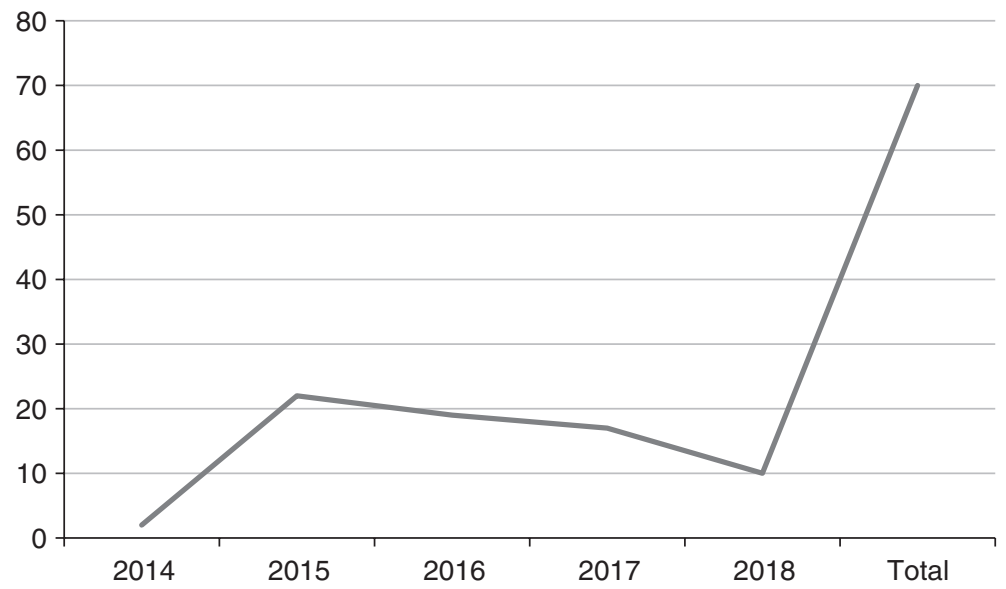

Figure 9.2

\begin{tabular}{lc}
\hline Returning year & $\begin{array}{l}\text { People returning with } \\
\text { accomplished PhDs in sociology }\end{array}$ \\
\hline 2014 & 2 \\
2015 & 22 \\
2016 & 19 \\
2017 & 17 \\
2018 & 10 \\
Total & $\mathbf{7 0}$ \\
\hline
\end{tabular}

Source: CONICYT

peripheral science' $(2014,708)$. Although this depiction may give the sense of a rather dependent intellectual field, this chapter echoes the arguments of Beigel (2008) and Ramos (2014) regarding the rather complex relationship between the local and global, in which there is actually a constant (and reflexive) tension between dependency and intellectual autonomy.

This chapter reflects on the conditions of academic production in the social sciences, in a period of expansion of academic institutions and careers: how the social sciences are increasingly becoming a more autonomous field, but within particular conditions of reception and dialogue with international circuits of ideas such as those coming from Bourdieu's work. I take as a case study a new generation of young scholars in sociology, who are immersed in international research networks, especially in the Global North, and more precisely in the United Kingdom, to assess the extent to which Bourdieu's international sociology was effectively received as a science with 'a critical debunking role of existing relations of domination' (Swartz, 2013, 3). In other 
words, I consider whether in this case a more universal theoretical discourse of sociological explanation prevailed or rather one that aimed at underlying the particular conditions of social production of this discourse (Robbins 2008).

The chapter confirms the relevance of considering the emergence of an autonomous field as a key aspect in understanding the reception of Bourdieu's oeuvre in a Latin American case. In this chapter I show that the reception of Bourdieu's theoretical works among these scholars is heavily informed, on the one hand, by the time and place where they conducted their postgraduate studies, and on the other, by the ways in which they got involved in new local struggles in the definition of the positions of the new and consolidating sociological field.

\section{The Backdrop: The Development of the Sociological Field in the United Kingdom in the Early 2000s}

This case takes as a backdrop the development of the sociological field in the United Kingdom in the early 2000s as this is arguably a starting point in the intellectual trajectories of the generation of scholars mentioned above. In this part, I aim at offering a reflection of the ways in which the internal positions in this field also influenced the reception of particular aspects and understandings of Bourdieu's work in other parts of the world, given the circulation of these young scholars.

This period was anticipated by almost two decades of critiques of class analysis from a number of theoretical perspectives such as feminism, postmodernism and the cultural turn. Some authors, notably Jan Pakulski and Malcom Walters (1996), claimed that class as a concept had failed in accounting for the new ways in which inequalities are increasingly being articulated on the basis of consumption patterns. These and other authors asserted that in a stage of advanced capitalism, class categories and identities tend to lose their explanatory potential. On a similar line of thought, authors such as Zigmund Bauman (2001), Anthony Giddens (1990), Ulrich Beck (1992), Scott Lash and John Urry (1994) emphasized that the decline of class identities was related to the transformations of the welfare state and the broader processes associated with what was broadly described as reflexive modernity. According to this perspective, if ascribed class biographies were characteristic of a period of the Fordist welfare state, in times of risk and uncertainty identities become reflexive, in other words, depend more on the decisions of individuals. Thus, identity and class solidarities increasingly become weaker (Beck 1992).

Given the relatively shared view regarding the weakening of collective class identities, there was a group of academics who attempted to reframe the question of class identity by placing the focus on processes of the disidentification 
of class (Skeggs 1997), and stressing that in order to offer a revitalized version of (cultural) class analysis it should be acknowledged that one of the main problems lies in the uncertainties about the relationship between culture, identity and structural positions, particularly in a period when more people do not see themselves as members of any class. Here the work of Bourdieu on misrecognition gave space to a whole new way of approaching the question of class identity from a sociological perspective, informed at the same time by the cultural turn. In other words, how to acknowledge as well the importance of class in shaping social identity despite the fact that people are now less willing to talk about themselves and others in explicit 'class' terms. There were, at the time, a number of authors who claimed that class continued to be a signifier by which people measure themselves in relation to others, despite the fact that traditional sociological approaches to class analysis may not provide enough tools to explore the more symbolic and embodied dimensions of class (Skeggs 1997; Reay 1998; Crompton et al. 2000; Savage 2000, among others).

Thus, Bourdieu became a key author for academics interested in revitalizing class analysis, in that his work helped illuminate how processes of inequality reproduction and cultural differentiation are intertwined in everyday life. At the same time, the concept of social space appeared as a nuanced understanding of social class. ${ }^{3}$ Together with the reframed question about class identity, Bourdieu's work also became a key point of reference to amplify the spectrum of class subjectivities that are immersed in relations of domination and symbolic violence. Here, the interest in studying middle-class identities also flourished, together with questions about the ways in which class identities work in a neo-liberal age.

These questions resonated profoundly in the research interests of young sociologists, because the transition to neo-liberalism and its consequences in terms of sociocultural change challenged as well as mainstream social science in Latin America, in that traditional approaches, specifically in terms of social stratification, proved to be insufficient for deeply understanding emergent processes of social and cultural differentiation within the 'new' middle classes. Thus the context in which these scholars developed their work had interesting parallels with the incipient questions arising from Chilean recent sociological field: social mobility, consumption, the middle classes, cultural change.

Despite these apparent common trajectories, this chapter attempts to relate these intellectual trajectories by showing that the reception of Bourdieu's work through British academia is not straightforward, and that there are shifts in interpretations and innovative claims. I concentrate on four major topics that I consider particularly relevant for discussing the experience of being caught in problems of conceptual transfer. First, I discuss the ways in which Bourdieu's ideas on the mismatch between habitus and field have helped 
illuminate problems of cultural malaise in societies, such as the Chilean society, which experienced rapid processes of social mobility. Closely connected to the first point, the second aspect that I examine is how a particular angle of Bourdieu's work (habitus and sense of place) has been considered in relation to the study of place making within the new/traditional urban middle classes. On the third part, I then attempt to elaborate how Bourdieu's culturally sensitive perspective on the reproduction of inequality has been influential on the development of sociological fields in societies such as Chile where the concern on inequality is a pressing topic. Finally, I refer to the internationally connected area of studies of cultural practices and inequality reproduction.

\section{Neo-liberalism, social mobility and the mismatch between habitus and field}

Although a great part of Bourdieu's work has been seen as mainly concerned with processes of cultural distinction and social reproduction, in the book Pascalian Meditations (2000) he displays a particularly interesting way of understanding what has been usually seen as one of the key concepts in relation to those processes: the habitus.

The fact that the responses habitus generates without calculation or project generally appear as adapted, coherent and immediately intelligible should not lead one to see them as a kind of infallible instinct, capable of producing responses miraculously adjusted to all situations. The adjustment, in advance, of habitus to the objective conditions is a particular case, no doubt particularly frequent (in the universes familiar to us), but it should not be treated as a universal rule. $(2000,159)$

In this book, habitus appears rather as a key theoretical device that helps illuminate the mismatch between institutions and dispositions in moments of drastic change:

It is no doubt on the basis of the particular case of adjustment between habitus and structure that critics have often seen a principle of repetition and conservation in a concept, habitus, which originally forced itself upon me as the only way to understand the mismatches which were observed, in an economy like that of Algeria in the 1960a (and still today in many 'developing' countries), between the objective structures and the incorporated structures, between the economic institutions imported and imposed by colonization (or nowadays by the constraints of the market) and economic dispositions brought to them by agents formed in the precapitalist world [...] I was thus led to question the 
universality of the so-called rational economic dispositions and, by the same token, to address the question of the economic conditions - and cultural conditions- of access to these dispositions. (2000, 159-60)

It is also significant that Bourdieu uses his own work on Algeria - and, by extension, the example of 'developing' countries that may go through processes of modernization - to characterize the mismatch between the objective structures of new economic institutions and the embodied structures of previous economic dispositions. The later may appear as not prepared for or attuned with the transformations of the conditions of existence, such as the liberalization of markets, laicization, democratization of public institutions and so forth.

In the case of Latin America - also a non-Euro-American national context the political, economic and cultural changes imposed by almost two decades of dictatorships and structural adjustment (Veltmeyer et al. 1997) 'led to a series of adaptive solutions' (Portes 2003, 41). In this circumstances, Chile showed a particularly stark and rapid transition to a neo-liberal economic model, imposed by a dictatorship but later reproduced during a period of democracy. ${ }^{4}$

This context has been at core of the concerns of the whole of the sociological production in the country, and it has certainly informed the work of the generation of young scholars mentioned above. In the case of my $\mathrm{PhD}$ thesis in sociology at the University of Manchester (2006), I took the case of Chile to explore the ways in which processes of structural change such as privatization of public companies and services, liberalization of housing markets and so forth entail mismatches between people's habitus and the new rules of the game in different fields of social life. Furthermore, I examined how processes of social mobility entail that certain habituses may appear as ill-adapted to the new rules of the game because they are attuned to an earlier stage of objective conditions, while others will seem more attuned to the new logic of the field, or the 'model'. I conducted more than 30 in-depth interviews with people broadly described as middle class, who came from different socioeconomic backgrounds, and who exhibited particular self-identities such as the emergents, the intellectuals, the responsible people and the average person.

Bourdieu's arguments in Pascalian Meditations seem extremely persuasive:

In situations of crisis or sudden change, especially those seen at the time of abrupt encounters between civilizations linked to the colonial situation or toorapid movements in social space, agents often have difficulty in holding together the dispositions associated with different states or stages, and some of them, often those who were best adapted to the previous state of the game, have difficulty in adjusting to the new established order. $(2000,161)$ 
Here, it is possible to identify Bourdieu's ideas on the mismatch between habitus and field, or the concept of hysteresis, which describes situations in which the dispositions of the habitus 'are out of line with the field and with the collective expectations which are constitutive of their normality' $(2000,160){ }^{5}$

Indeed, as Bourdieu argues, the habitus can be confronted with conditions of actualization different from those in which they were produced, which is particularly evident 'whenever agents perpetuate dispositions made obsolete by transformations of the objective conditions (social ageing), or occupy positions demanding dispositions different from those they derive from their conditions of origin' (2000, 160-1).

These arguments are complementary, in my view, to what, a decade before, Bourdieu and Wacquant had referred to when describing 'the naturalization of the schemata of neo-liberal thought' (1999, 42). Indeed, this naturalization was not without subjective costs or suffering: 'if dispositions may waste away or weaken through lack of use (linked, in particular, to a change in social position or condition), or as a result of heightened consciousness associated with an effort of transformation (such as the correction of accents, manners, etc.), there is an inertia (or hysteresis) of habitus which have a spontaneous tendency (based in biology) to perpetuate structures corresponding to their conditions of production' (Bourdieu 2000, 160). The interviews I carried out showed those tensions of the habitus, which reflected that people did not feel completely at ease with the new or current position in the social field. Those tensions appeared as subtle issues such as manners, accent, ease and most notably unease with the individual's sense of place in the social structure and the place of living between different identities or fractions within the middle classes.

Along the lines of the arguments regarding the differentiation within the urban middle classes, the work of Joel Stillerman on the middle classes from a perspective of a Bourdieusian urban sociology has connected consumer culture to middle-class lifestyles in Santiago. Stillerman, an American sociologist who has extensively studied labour movements in Chile, has worked in the country at various periods of time. Most recently, in the late 2000s, he was head of department at the Department of Sociology of Universidad Diego Portales. In his article entitled 'The Contested Spaces of Chile's Middle Classes' (2010) he offers an ethnographic study of what he sees as three segments of the Chilean middle class. Following Bourdieu, Stillerman identifies these groups around the axes of occupation and education: left-wing intelligentsia, successful professionals and lower middle class. According to Stillerman, there are four key aspects through which these groups claim a symbolically distinctive lifestyle: their patterns of consumption, childrearing, education and identity.

Also inspired by the work of Lamont (1992), Stillerman claims that these competing groups are permanently negotiating their boundaries, and in 
contrast to Bourdieu's argument, he states that 'in contemporary Chile, high and low culture do not occupy two opposite poles; rather, these individuals contrast the simultaneous appropriation of high and folk culture to consumption of mass culture and hedonism' $(2010,10)$.

Along similar lines, Tomás Ariztía, a Chilean sociologist whose postgraduate studies were conducted at the London School of Economics and Political Science (LSE) during the early 2000s and who joined the Department of Sociology at Universidad Diego Portales as well, was also influenced by the prominence of Bourdieu's work during the past decade in British academia. Supervised in his doctoral studies by Don Slater at the Department of Sociology at LSE, Ariztía was interested in the middle classes and consumption in Santiago, and particularly in the meanings of class and social mobility produced throughout the process of construction and housing sale. In his work on the middle classes and housing, Ariztía (2014) brings together cultural class analysis (Skeggs 2005; Savage et al. 2001), actor network theory (Callon 2006) and material culture studies (Miller and Rose 1997; Slater 2002), and puts these into dialogue with the field of housing studies (Allen 2008; Bridge 2001). Two of his articles were published in Sociological Review and fournal of Consumer Culture, which connected his work to a broader and international research community.

Ariztía (2014) studied market professionals and how they produced advertising categories that help enact a particular middle class identity. In Ariztía's research, Bourdieu is read as a key figure in putting forward an argument that relates habitus and middle-class real estate projects: 'Bourdieu argued that the design and promotion of real estate projects involve a company in active efforts to capture new owners, which they do by seducing buyers with advertising connected with their "habitus"' (Ariztia 2014,3). Notwithstanding this assertion, however, Ariztía argues that middle-class cultures are constantly being made and renegotiated by practices, discourses and cultural knowledge provided by market experts, who act as cultural producers: 'social and spatial mobility are also performed through decorating the new home' $(2012,104)$. In his study of the new middle classes in Chile, Ariztía shows how model homes, magazines and many other repertoires of legitimate taste help families 'perform and address their new social and spatial circumstances' $(2012,104)$, in other words, help them deal with their new positions in the social structure. In the process, people assemble narratives, practices and objects, and are not strictly or exclusively guided by the dispositions of the habitus. In this work, materialities have agency in the process of redecorating the house, and thus, not only the agency of the family but also of their possessions is highlighted as a form of putting distance between traditional ways of understanding the relationship between taste, consumption and class making. 
In these terms, Ariztía brings into his work a notion in which middleclass cultures are assembled through various resources and actors, and also focuses on the enactment of these cultures. Thus, his work is distanced from Bourdieu's in that it emphasizes the performative character of urban middleclass cultures rather than the reproduction, transmission and mismatch of middle-class habitus.

In this section I have attempted to show how Bourdieu's work on the mismatch between habitus and field was particularly relevant for engagement with issues of social mobility and processes of cultural differentiation within the middle classes. Bourdieu was also a key author for a group of new academics who attempted to define a new and innovative field of research in Chile by positioning themselves within a larger sphere of the circulation of ideas. At the same time, engaging with these debates in the English and Spanish languages allowed them to be recognized inside and outside their epistemic communities.

\section{Place Making and Place Claiming within the New/Traditional Urban Middle Classes}

Cultural class analysis showed as well that not only was it important to focus on class identities per se but also to pay attention to understanding processes of classification and classificatory struggles between/within classes. In this respect, and despite the relatively shared argument regarding the idea that class is still a marker by which people relate their life histories even if they reject the class terminology and thus "wish to see themselves as "outside" classes' (Savage et al. 2001, 1), the study of the ambivalent nature of contemporary class identities and therefore the various repertoires of class talk, became a pressing topic during the first decade of the 2000s.

Claims to ordinariness were argued to work at the same time as involving processes of differentiation and also disidentification of class. That is, people would see themselves as ordinary, as a way of avoiding identification with higher and lower positions, and might pursue ordinary lives in which they can be treated equally and without suspicion of any forced and explicit selfidentification (Savage 2000). Ordinariness would work as 'cultural counterweight to the strategies of cultural exclusion that can be associated with claims of cultural capital, in all its diverse forms, and help to validate popular claims of "ordinariness" as a central motif in cultural life' (Savage 2000, 65). This ordinariness codes new kinds of distinctions and hierarchies, though these may be implicit rather than stated overtly (Savage et al. 2005, 11). My work was particularly influenced by these ideas, in that the inductive analysis of my material on the Chilean middle class showed how claiming authenticity and 
attributing authenticity (another form of ordinariness) is now a vital part of urban politics, place belonging and class identity.

In this respect, Bourdieu's cultural sociology offered a key angle from which to refer to these classificatory schemes:

These classificatory schemes (structuring structures) are essentially, the product of the incorporation of the structures of the fundamental distributions which organise the social order (structured structures) $[\ldots]$ In other words, they are what makes it possible for all agents to refer to the same oppositions (such as high/low, up/down, rare/common, light/heavy, rich/poor, etc.) to think the world and their position in the world, while sometimes giving opposite signs and values to the terms they counterpose: thus the same freedom of manners may be seen by some as 'shameless', impolite, rude, and by others as 'unaffected', simple, unpretentious, natural. (Bourdieu 2000, 98)

Following Bourdieu's understanding of the habitus as classificatory schemes, my research (Méndez 2008) explored how claims to ordinariness also involve claims to distinctiveness such as naturalness versus artificiality; ordinary versus fake; born and bred versus self-fashioning; pretentiousness versus 'being real'; full versus empty places; or insiders versus outsiders. These findings led me to explore what I found was the grand narrative, or the grammar (Boltanski 2002) that epitomizes these classificatory struggles: the claims of authenticity. On the one hand, being authentic means being true to one's origins or 'just being an average person', and on the other it means being true to oneself, or with the project that 'one has for one self'. These two - at times conflicting - versions of authenticity operate between and within neighbourhoods as ways of establishing boundaries between 'us' and 'them' (Southerton 2002), in other words, between who belongs and who does not belong.

Part of my work on this topic was published in Sociological Review, and it represented an attempt to engage in debates on middle-class identity that were circulating within British journals such as the one mentioned above and British fournal of Sociology and Sociology, and in books published by authors such as Wendy Bottero (2004), Steph Lawler (2005), Mike Savage et al. (2001) and Savage (2005), to name a few. In addition, my challenge was to elaborate a position in the sociological arena in Chile in which I could claim that traditional approaches to social stratification lacked key elements in addressing cultural change, and that in order to develop a more up-to-date research programme it was pressing to also translate this debate into the interests of the Latin American sociological field. Once I had returned to Chile after my $\mathrm{PhD}$, I not only published in these international journals but also wrote articles in Spanish for books that re-examined the question of the middle classes in the 
region. ${ }^{6}$ Following Bourdieu and the influence of British academia, my position in this field was in favour of a culturalist and a relational approach to the study of class. ${ }^{7}$

\section{Habitus and Sense of Place}

As argued at the beginning of this chapter, Bourdieu's work had been already well known in Chile in the previous decade, particularly in the area of education. However, it is possible to contend that most of the scholarship done in the area tended to conceive cultural capital in a rather instrumentalist way in which self-interest was a key mechanism for action. ${ }^{8}$ In this sense, the research on the middle classes and their classificatory struggles not only showed the importance of considering the relevance of symbolic violence but also drew attention to habitus in its embodied dimension. Indeed, not only theoretically but also inductively and empirically, ideas such as malaise or unease required a more nuanced consideration.

In the book Globalization and Belonging, Savage et al. (2005) argue that when the correspondence between habitus and field is put under tension 'people feel ill at ease and seek to move - socially and spatially - so that their discomfort is relieved. For Bourdieu this is crucial to the "dialectic of positions and dispositions". Mobility is driven as people, with their relatively fixed habitus, both move between fields (places of work, leisure, residence and so forth), and move to places within fields where they feel more comfortable. Mobility and stability are hence reciprocally interrelated through the linkage between fields and habitus' (Savage et al. 2005, 9).

According to Savage et al., Bourdieu's sympathy with a phenomenological philosophy (Robbins 1994; 2005) has involved paying more attention to the notion of embodied habitus and its relation to a sense of place. According to Bourdieu, 'the sense of one's place, as the sense of what one can or cannot "allow oneself", implies a tacit acceptance of one's position, a sense of limits ("that's not meant for us") or - what amounts to the same thing - a sense of distances, to be marked and maintained, respected, and expected of others' (1991, 235). This feeling of being at ease or comfortable in 'one's' place is precisely what links habitus and field. This is also what makes people 'locate' other people in certain places, and this is precisely what becomes problematic when mismatch occurs.

In Ariztía's, Stillerman's and in my own research it is found that in people's search for places where they can feel at ease or not feel ill-adapted, their residential trajectories become synonymous with personal narratives, selfidentities and self-fashioning. Thus, this approach helped put some distance between traditional stratification and class analysis that defines occupation as 
a key factor for identity and lifestyle, and one that pays attention to aspects arising out of consumption practices, residential trajectories and boundary work (Lamont 1992). These were conceptual devices that helped define an emergent field of research in Chile.

In my case, I concluded that tensions between contested claims of authenticity are precisely ways of understanding the mismatch between habitus and a new (residential) field. Indeed, these narratives are at the base of people's ways of dealing with their senses of place. They inform and help them justify their decision. Following Bourdieu, these narratives are in fact discourses that help reproduce objective relations of power through visions of the social world. These narratives of place are structuring principles of the world that are rooted in the objective structures of the social world and 'are also present in people's minds in the form of categories of perceptions of those relations' (Bourdieu 1991, 236).

In defining their sense of place, I found that people use as referents those that they can position locally and that this is why they not only refer to other areas but also re-establish stratification categories within the places where they live. In other words, identity and sense of place can be both defined with a place, within a place and against a place. I showed how the ways in which a person describes a particular area also provides elements for understanding his or her sense of place.

According to Zukin (2010),

claiming authenticity becomes prevalent at a time when identities are unstable and people are judged by their performance rather than by their history or innate character. Under these conditions, authenticity differentiates a person, a product, or a group from its competitors; it confers an aura of moral superiority, a strategic advantage that each can use to its own benefit. In reality, few groups can be authentic in the contradictory ways that we use the term: on the one hand, being primal, historically first and true to a traditional vision, and on the other hand, being unique, historically new, innovative, and creative. In modern time, though, it may not be necessary for a group to be authentic; it may be enough to claim to see authenticity in order to control its advantages. (2010, xii)

Thus, authenticity claims as forms of embodied cultural capital, become tools of cultural power in that they allow people to claim moral superiority or moral ownership (Méndez 2008; 2010) in the city, and the city's histories of change and struggle. Tastes in urban space, the feeling of a neighbourhood, heritage protection, residential belonging and authenticity claims are ways of understanding contemporary urban politics. Thus a politics of belonging depends 
on resources (cultural capital) and position, but it also involves being able to perform and deploy a narrative of authenticity.

\section{Cultural Capital and the Reproduction of Inequality}

Bourdieu's culturally sensitive perspective on the reproduction of inequality is at the heart of all these discussions. Bourdieu helps us explore how social advantage may be produced and reproduced in various fields, not only the occupational. As Swartz argues, 'cultural resources and symbolic categories and classifications interweave prevailing power arrangements into everyday life practices. Indeed, cultural resources and processes help constitute and maintain social hierarchies' (2013, preface). In the previous sections I have attempted to show how social differentiation within the middle classes in Chile works through classificatory struggles, most notably in the the residential space. In this final section I aim to explore the circulation of Bourdieusian ideas and methodological devices in the study of cultural capital and the reproduction of inequality.

In 2009 the book Culture, Class, Distinction (Bennett et al. 2009) was published by Routledge in the series Culture, Economy and the Social, and it crystallized a collective research project by a group of academics based at the time at the University of Manchester ${ }^{9}$ and the Open University, in the United Kingdom. This co-authored book was a collective project that began in the early 2000s, and was led by Tony Bennett, Mike Savage, Elisabeth Silva and Alan Warde as the main researchers, and Modesto Gayo-Cal and David Wright as coapplicants. The book has been described as a major contribution to international debates on class and inequality reproduction and also as a multimethod empirical endeavour that assesses Distinction by bringing into the debate the relationships between cultural practices and class, gender, age and ethnicity.

The team of researchers built alliances and worked closely with former collaborators of Bourdieu, Brigitte La Roux and Henry Rouanet, particularly in the application of the quantitative technique of multiple correspondence analysis (MCA) and in the use of the statistical package for this analysis, SPAD. Working as a research associate at the Centre for Research on Sociocultural Change (CRESC), at the University of Manchester, Gayo-Cal was a key person in developing the analysis of the national survey on cultural practices in contemporary Britain (Gayo-Cal 2006; Gayo-Cal et al. 2006), and also in testing empirically the thesis of the cultural omnivore (Warde et al. 2007; 2008; Warde and Gayo-Cal 2009), put forward by Peterson and Kern in the late nineties (Peterson and Kern 1996).

Gayo-Cal joined the Department of Sociology at Universidad Diego Portales in 2007 and, while continuing to work with the British team, he began 
implementing a research program on cultural practices, cultural consumption and inequality in Chile for which he received funding from the National Commission for Scientific and Technological Research. His work, along with that of his colleagues in Santiago, has been influential in the development of a sociological field in Chile that empirically and theoretically explores the relation between cultural capital and social hierarchies, particularly in a society in which the concern with inequality is a pressing topic. Developing a sociology heavily influenced by Bourdieu but also by the debates that arose from the exchange with the British team, Gayo-Cal has been a key figure in using statistical data on cultural practices and elaborating the social space of cultural participation in Chile, showing the drastic differences not only between social classes but also between age groups and gender (Gayo-Cal et al. 2009; 2013). Gayo-Cal (2013) has also explored qualitatively these topics at a regional level, comparing cultural consumption between generations of parents and children in Santiago, Buenos Aires and Montevideo.

The case of Gayo-Cal shows how the circulation of ideas and methods such as MCA can benefit the local sociological field, that is, how available data were used in producing high-quality academic work and international publications.

The cases discussed above have been an attempt to reflect more profoundly on the implications of avoiding the naturalization of the historical context proposed by Bourdieu. They show awareness of the need to engage with international intellectual circuits while also claiming the particularities not only of the cases of study but mostly of the contexts of reception and local academic fields (for example, continuing publishing for a Latin American audience while maintaining international networks with the English-speaking world). Does this involve a lack of intellectual autonomy in the national sociological field? No, of course it does not. It shows that providing stability, independence and continuity in the social sciences in Chile has been a long-term project, and that only over the past decade have there been signs of a more consolidated academic community. However, acquiring symbolic capital and positioning within this field involves providing a dual referential horizon, and also attempting to be reflexive with regards the risks of reproducing symbolic violence upon national epistemic communities.

\section{Notes}

1 According to Sapiro and Bustamante, 'Les Héritiers is the only book translated in Spanish, Italian, and English, highlighting the centrality of the sociology of education in the first stage of Bourdieu's international reception' (Sapiro and Bustamante 2009, 23).

2 In Chile, for example, the Catholic University reopened the undergraduate program in 1990. 
3 Regarding the differences between the two concepts: (1) In a more applied way, Bourdieu offers a relational approach that looks at the multidimensional conformation of social space instead of a unidimensional taxonomy, exclusively based on occupation. (2) Bourdieu also refers to vertical as well as horizontal movements along the social space, which is a contribution to seeing mobilities not only in relation to a single standard but also along fields. (3) However, although Bourdieu distinguishes three real classes (dominant, petit bourgeoisie and working class in Distinction), he argues that social class is a probability of individuals of constituting in real groups in accordance to their proximities or compatibilities, rather than an entity existing beforehand. (4) Finally, and more profoundly, Bourdieu has drawn the attention to the spatial and temporal dimensions of the social, in which the social space is a three-dimensional space constituted by the volume of capital, the composition of capitals and the change of two properties over time.

4 Over these past four decades in Chile there have coexisted two 'models': the liberal authoritarian excluding model and the liberal democratic including model (Castells 2005; among others). These are both liberal models because they stress the importance of the market and openness to international economy in order to achieve economic growth. The excluding liberal authoritarian model excludes large parts of the population from the gains of economic growth through the exercise of authoritarian control over power. In this model the mechanisms of the market are predominant and the state is not involved in applying public policies that may correct the effects of inequalities. The including liberal democratic model is a result of the transition to democracy, which although maintaining the relevance of market mechanisms as the main source of resource allocation, is also concerned with the implementation of public policies directed towards including the whole population in the benefits of economic growth. Under dictatorship, the state put forward the functioning of the market as the central mechanism that provided social integration, leaving people to deal with the market individually. This is one of the areas that has been most problematic for democracy: the ways in which people perceive and relate to the state.

5 This is what Bourdieu describes as the Don Quixote effect. Bourdieu gives the example of the Don Quixote effect, in which two different habitus face each other. One is Don Quixote, a man who has read too many novels of knighthood and who sees himself and the world around him as a narrative of those novels, and the second one is Sancho Panza, who is probably the ultimate example of concreteness and closeness to necessity. The metaphor is that, although Don Quixote possesses cultural capital, his habitus, the habitus of a knight is ill-adapted to the new conditions of existence, which do not seem to give value to those values. His counterpart, Sancho, although in a less privileged position, seems more attuned with the circumstances.

6 These books were published by prestigious Latin American editorial houses, but most important they were milestones in the redefinition of the current state of the field of study of social stratification in Latin America.

7 This is similar to what Robbins argues about Bourdieu being more 'interested in the encounters between the cultures of persons rather than in cultures for themselves' (Robbins 2005, 15). In the case of my study, I was seduced by Bourdieu's ideas about the encounter of diverse social trajectories in social space.

8 In this respect, Swartz argues that concepts such as cultural capital 'have been abstracted from the critical political perspective he invested in his work' (Swartz 2013, 3).

9 The research project was based at the Economic and Social Research Council Centre for Research on Socio-cultural Change (CRESC), at the University of Manchester. 


\section{References}

Allen, C. 2008. Housing Market Renewal and Social Class. New York: Routledge.

Ariztía, T. 2012. 'Decorating the New House: The Material Culture of Social Mobility'. In Sinclair, J. and Pertierra, A. (Eds.) Consumer Culture in Latin America. New York: Palgrave Macmillan, 93-106.

Ariztía, T. 2014. 'Housing Markets Performing Class: Middle-Class Cultures and Market Professionals in Chile'. Sociological Review 62, no. 2: 400-20.

Baranger, D.2010.'La recepción de Bourdieu en Argentina'. Desarrollo Económico 50, no. 197: 129-46.

Bauman, Z. 2001. The Individualized Society. Cambridge: Polity.

Beck, U. 1992. Risk Society: Towards a New Modernity. London: Sage.

Beigel, F. 2008. 'Academic Autonomy and Social Sciences: The Chilean Circuit'. In Technical Session Papers, Coping with Academic Dependency: how? Patna: SEPHIS-ADRI, February 4-7.

Bennett, T., M. Savage, E. Silva. A. Warde. M. Gayo-Cal and W. Wright. 2009. Culture, Class, Distinction. London: Routledge.

Bennett, T., J. Frow, G. Hage and G. Noble. 2013. 'Antipodean Fields: Working with Bourdieu'. Fournal of Sociology 49, no. 2-3: 129-50.

Boltanski, L. and E. Chiapello. 2002. El Nuevo Espiritu del Capitalismo. Madrid: Akal.

Bottero, W. 2004. 'Class Identities and the Identity of Class'. Sociology 38, no. 5: 985-1003.

Bourdieu, P. 1984. Distinction: A Social Critique of the Judgement of Taste. London: Routledge and Kegan Paul.

1991. 'Social Space and the Genesis of 'Classes', In Thompson, J. (Ed.) Language and Symbolic Power. Oxford: Polity Press, 229-51.

1995. In Other Words: Towards a Reflexive Sociology. Oxford: Polity Press.

Bourdieu, P. and J. Passeron. 1977. Reproduction in Education, Culture and Society. London: Sage.

Bourdieu, P. and L. Wacquant 1996, 2002. An Invitation to Reflexive Sociology. Chicago: University of Chicago Press.

Bourdieu, P. and L. Wacquant '1999. 'On the Cunning of Imperialist Reason'. Theory, Culture \&8 Society 16, no. 1: 41-58.

Bourdieu, P. 2000. Pascalian Meditations. Oxford: Polity Press.

Bridge, G. 2001. 'Estate Agents as Interpreters of Economic and Cultural Capital: The Gentrification Premium in the Sydney Housing Market'. International Fournal of Urban and Regional Research 25, no. 1: 87-101.

Callon, M. 2006. 'What Does It Mean to Say That Economics Is Performative?' CSI Working Paper Series.

Castells, M. 2005. Globalización, Desarrollo y Democracia: Chile en el Contexto Mundial. Santiago: Fondo de Cultura Económica.

Crompton, R. F. Devine. M. Savage. A. and J. Scott (Eds.) 2000. Renewing Class Analysis. Oxford: Blackwell Publishers/The Sociological Review.

Dezalay, F. and B. Garth.2002. The Internationalization of Palace Wars: Laweyers, Economists, and the Contest to Transform Latin American States. Chicago: University of Chicago Press.

Garretón, M. 2005. 'Social Sciences and Society in Chile: Institutionalization, Breakdown and Rebirth in Chile'. Social Sciences Information 44, no. 2-3: 359-409.

Gayo-Cal, M. 2006. 'Leisure and Participation in Britain'. Cultural Trends 15, no. 2-3: 175-92.

Gayo-Cal, M., M. Savage and A. Warde. 2006. 'A Cultural Map of the United Kingdom'. Cultural Trends 15, no. 2-3: 213-37.

Gayo-Cal, M. B. Teitelboim and M. L. Méndez. 2009. 'Patrones culturales de uso del tiempo libre en Chile: Una aproximación desde la teoría Bourdieuana'. Universum 24, no. 2: 42-72. 
Gayo-Cal, M. B. Teitelboim and M. L. Méndez. 2013. 'Exclusividad y fragmentación: Los perfiles culturales de la clase media en Chile'. Universum 28, no. 1: 97-128.

Giddens, A. 1990. The Consequences of Modernity. Cambridge: Polity Press in association with Blackwell.

Güell, P. 2002. 'La Generación De Sociólogos De Los Setenta Post-Golpe: Una Cuestión De Poder'. Revista de Sociología no. 16: 80-102.

Heise, T. and A. Tudor. 2007. 'Constructing (Film) art: Bourdieu's Field Model in a Comparative Context'. Cultural Sociology 1, no 2: 165-87.

Karademir Hazır, I. 2014. 'Boundaries of Middle-Class Identities in Turkey'. Sociological Review 62, no. 4: 675-97.

Lamont, M. 1992. Money, Morals, and Manners: The Culture of the French and American UpperMiddle Class. Chicago/London: University of Chicago Press.

Lash, S. and J. Urry. 1993. Economies of Signs and Space. London: Sage.

Lawler, S. 2005. 'Disgusted Subjects: The Making of Middle Class Identities'. Sociological Review 53, no. 3: 429-46.

Méndez, M. L. 2008. 'Middle Class Identities in a Neoliberal Age: Tensions Between Contested Authenticities'. Sociological Review 56, no. 2: 220-37.

2010. 'Las clases medias en Chile: transformaciones, sentido de pertenencia y tensiones entre distintos proyectos de movilidad'. In Hopenhayn, M. R. Franco and A. León (Eds.) Las clases medias en América Latina. México D.F.: Siglo XXI-CEPAL.

2015. 'Contesting the Highbrow Y Lowbrow Distinction: How Latin American Scholars Engage in Cross-Cultural Debates'. In M. Hanquinet and M. Savage (Eds.) Routledge International Handbook of the Sociology of Art y Culture. London: Routledge.

Miller, P. and N. Rose. 1997. 'Mobilising the Consumer: Assembling the Subject of Consumption'. Theory, Culture \& Society 14, no. 1: 1-36.

Pakulski, J. and M. Walters. 1996. The Death of Class. London:Sage.

Peterson C. and C. Kern. 1996. 'Changing Highbrow Taste: From Snob to Omnivore'. American Sociological Review 61, no. 5: 900-7.

Petras, J. and M. Morley. 1990. U.S. hegemony under siege. Class, Politics and Development in Latin America. London: Verso.

Portes, A. and K. Hoffman. 2003. Las estructuras de clase en América Latina: composición y cambios durante la época neoliberal. Santiago: CEPAL.

Ramos, C. 2014. 'Local and Global Communications in Chilean Social Science: Inequality and Relative Autonomy'. Current Sociology 62, no. 5: 704-22.

Reay, D. 1998. Class work: Mothers' Involvement in Their Children's Primary Schooling. London: Taylor \& Francis.

Robbins, D. 1994. Bourdieu and Culture. London: Sage

2005. 'The Origins, Early Development and Status of Bourdieu's Concept of "Cultural Capital"'. British Fournal of Sociology 56, no. 1: 13-30.

2008. 'French Production and English Reception: The International Transfer of the Work of Pierre Bourdieu'. Sociologica 2. doi: 10.2383/27720.

Santoro, M. 2008. 'Putting Bourdieu in the Global Field: Introduction to the Symposium'. Sociologica 2.

Sapiro, G. and M. Bustamante. 2009. 'Translation as a Measure of International Consecration: Mapping the World Distribution of Bourdieu's Books in Translation'. Sociologica 3.

Savage, M. 2000. Class Analysis and Social Transformation. Buckingham: Open University Press. 2005. 'Working Class Identities in the 1960s: Revisiting the Affluent Worker Study'. Sociology 39, no. 5: 929-46. 
Savage, M., G. Bagnall and B. Longhurst. 2001. 'Ordinary, Ambivalent and Defensive: Class Identities in the North-West of England'. Sociology 35, no. 4: 875-92.

Skeggs, B. 1997. Formations of Class \& Gender: Becoming Respectable. London: Sage. 2005 'The Making of Class and Gender through Visualizing Moral Subject Formation'. Sociology 39, no. 5: 965-82.

Slater, D. 2002. 'From Calculation to Alienation: Disentangling Economic Abstractions'. Economy and Society 31, no. 2: 234-49.

Southerton, D. 2002 'Boundaries of "Us" and "Them": Class, Mobility and Identification in a New Town'. Sociology 36, no. 1: 171-93.

Stillerman, J. 2010. 'The Contested Spaces of Chile's Middle Classes'. Political Power and Social Theory 21: 209-238.

Swartz, D. 2013. Symbolic Power, Politics, and Intellectuals: The Political Sociology of Pierre Bourdieu. Chicago: University of Chicago Press.

Veltmeyer, H. 1997. 'New Social Movements in Latin America: The Dynamics of Class and Identity'. Fournal of Peasant Studies 25, no. 1: 139-69.

Warde, A. D. Wright, D and M. Gayo-Cal. 2007. 'Understanding Cultural Omnivorousness: Or, the Myth of the Cultural Omnivore'. Cultural Sociology 1, no. 2: 143-64.

2008. 'The Omnivorous Orientation in the UK'. Poetics 36, no. 2: 148-65.

Warde, A. and M. Gayo-Cal. 2009. 'The Anatomy of cultural omnivorousness: The Case of the United Kingdom'. Poetics 37, no. 2: 119-45.

Zukin, S. 2010. Naked City: The Death and Life of Authentic Urban Places. New York: Oxford University Press. 


\section{NOTES ON GONTRIBUTORS}

Shinichi Aizawa is associate professor in the School of Contemporary Sociology at Chukyo University, and was a visiting research fellow in the Nissan Institute of Japanese Studies at the University of Oxford (2011-2012). He earned a $\mathrm{PhD}$ at the University of Tokyo. His research interests centre on sociology of education, social stratification and, especially, on quantitative and qualitative historical analysis of Japanese society and international comparison about secondary education. One of his recent works concerns Japan's postwar history of 'high-school-education-for-all' (in Japanese, Shinyo-sha).

Andrea Gallelli ( $\mathrm{PhD}$ in sociology, University of Turin) is currently a postdoctoral research fellow at the Department of Philosophy and Communication of the University of Bologna. He works on the network analysis of cultural (and intellectual) production as well as on cultural consumption.

Xuanyang Gao is chair professor in Shanghai Jiao Tong University (SJTU), China, dean of the Institute for Advanced Study in European Culture, and head of the Philosophy Department in SJTU. In his early career, he worked with Pierre Bourdieu and Jacques Derrida. From the 1980s to the early 2000s, he held professorships in France, Taiwan and Hong Kong. In 2004, when he was given the title Distinguished Overseas Teacher by the State Administration of Foreign Experts Affairs, he returned to mainland China. He then worked in Tong Ji University, Shanghai, as Distinguished Professor until 2010 when he joined his current institution. In the past 30 years, he has been using interdisciplinary methodology in his research on society, culture and politics in France, Germany, Britain and America. He has published extensively on contemporary French and German philosophy, contemporary social theory and art criticism. He has written more than 30 monographs, including Budie de Shehui Lilun (Bourdieu's social theory), and over 50 journal articles, including a series of contributions to the Encyclopédie Philosophique Universelle.

Naoki Iso is Japan Society for the Promotion of Science (JSPS) Research Fellow, Department of Sociology, Sophia University, Tokyo. He studied sociology at the Centre de sociologie européenne, Ecole des hautes études en sciences sociales, Paris, and also at Hitotsubashi University, Japan. He holds a $\mathrm{PhD}$ in social sciences from the latter. His research focuses on the sociology of 
Pierre Bourdieu as well as issues of social class and inequality, and particularly the cultural dimensions of contemporary class division, both in France and in Japan.

Sheena Jain studied sociology at Miranda House, University of Delhi, and at the Jawaharlal Nehru University, New Delhi. She commenced her research work on Pierre Bourdieu's social theory as a Commonwealth Scholar at the University of Cambridge, UK, in 1987. She has taught in Miranda House and was professor in the Department of Sociology, Jamia Millia Islamia, until July 2014. Her publications include, among others, a book entitled Practising the Symbolic: Pierre Bourdieu's Contribution (2013); the articles 'Bourdieu's Sociology: A Post Positivist Science' in Thesis Eleven, August 2013; 'Bourdieu's Theory of the Symbolic: Traditions and Innovations', in Meenakshi Thapan and Roland Lardinois (eds.) Reading Bourdieu in a Dual Context (2006); and 'Structure and Culture: The Debates', in Susan Visvanathan (ed.) Structure and Transformation:Theory and Society in India. She is currently engaged in independent study and research in Delhi.

María-Luisa Méndez is a Chilean sociologist, with a $\mathrm{PhD}$ in sociology from the University of Manchester, UK. She is professor in the Department of Sociology at Universidad Diego Portales, Chile, and principal investigator at the Centre for Social Conflict and Cohesion Studies, COES. Her work addresses the question of the middle classes in Latin America from the perspective of a Bourdieusian cultural sociology.

Derek Robbins is emeritus professor of international social theory in the School of Social Sciences at the University of East London. He is the author of The Work of Pierre Bourdieu (1991), Bourdieu and Culture (2000), On Bourdieu, Education and Society (2006), French Post-War Social Theory: International Knowledge Transfer (2011), and, most recently, Cultural Relativism and International Politics (2015); the editor of two 4-volume collections of articles on Pierre Bourdieu in the Sage Masters of Contemporary Social Thought series (2000, 2005) and of a 3-volume collection of articles on Jean-François Lyotard in the same series (2004). He has also published many articles and book chapters on the work of Bourdieu. He edited and introduced Jean-Claude Passeron's Sociological Reasoning, in March 2013. He is currently writing 'Bourdieu and Social Constructionism' (provisional title).

Marco Santoro is associate professor of sociology in the Department of Philosophy and Communication of the University of Bologna, and a member of the Centre de sociologie européenne. He is a founding editor of the journal Sociologica: Italian fournal of Sociology Online, and a member of the editorial boards of Poetics, Cultural Sociology and American Fournal of Cultural Sociology. He 
works on cultural production (especially music), the history of the social sciences, culture and stratification, professions and organized crime.

Simon Susen is reader in sociology at City University London. He is the author of The Foundations of the Social: Between Critical Theory and Reflexive Sociology (2007), The 'Postmodern Turn' in the Social Sciences (2015) and Pierre Bourdieu et la distinction sociale:Un essai philosophique (2016). Along with Celia Basconzuelo and Teresita Morel, he edited Ciudadanía territorial y movimientos sociales:Historia y nuevas problemáticas en el escenario latinoamericano y mundial (2010). Together with Bryan S. Turner, he edited The Legacy of Pierre Bourdieu: Critical Essays (2011), The Spirit of Luc Boltanski: Essays on the 'Pragmatic Sociology of Critique' (2014) and a Special Issue on the work of Shmuel Noah Eisenstadt, which appeared in the Fournal of Classical Sociology 11(3): 229-335, 2011. In addition, he edited a Special Issue on Bourdieu and Language, which was published in Social Epistemology 27(3-4): 195-393, 2013. He is an associate member of the Bauman Institute and, with Bryan S. Turner, coeditor of the Fournal of Classical Sociology.

Frédéric Vandenberghe is research professor in sociology at the Institute of Social and Political Studies in Rio de Janeiro. He has taught at many European and American uiversities, but has now settled in Brazil. With a strong interest in critical realism, hermeneutics and phenomenology, his work is situated at the intersection of German social philosophy, Anglo-Saxon social theory and French sociological theory. He is the author of Une histoire critique de la sociologie allemande, 2 vols. (1997-1998), La sociologie de Georg Simmel (2001), Teoria social realista (2009) and What's Critical about Critical Realism?

Yang Yang is distinguished research associate at the Department of Philosophy, Research Fellow at the Institute for Advanced Study in European Culture, Shanghai Jiao Tong University, China. A Cambridge Overseas Trust scholar, Yang completed her doctorate degree at the University of Cambridge, UK. Her research is in the area of the sociology and philosophy of education, with a particular focus on issues of cultural capital, knowledge and social stratification. 



\section{INDEX OF NAMES}

'Maisons de Culture' 122

'New Confucianism' 39, 243

'Wakon Yōsai' 179

$4^{\text {th }}$ Republic 120

Abendroth, W. 2

Accardo, A. 79, 80, 83, 85

Acciaioli, G. 81, 85

Adamson, M. 86

Adkins, L. 75, 85

Aizawa, S. 32, 36, 39, 42, 179, 196

Akinaga, Y. 183, 196, 197

Algeria 6, 11, 26, 35, 38, 43, 119, 120 , $121,122,127,146,173,174,230$, $246,257,258$

Algerian independence 120

Algerian War of Independence 6

Algiers 119, 120, 140

Algiers, University of 6

Allen, C. 260, 268

Althusser, L. 10, 13, 129, 142, 184, 185, 196

Amano, I. 189, 196

Ambroise, B. 81, 85

America 34, 108, 154, 161, 174, 176, 183, 200, 217, 249, 251, 256, 258, 271,272

American SAT 192

Aoki, T. 179, 181, 194, 197

Archer, M. v, 32, 33, 34, 96, 97, 103, 104, 105, 106, 107, 108, 109, 110, 111 , $112,113,114,115$

Argentina 155, 251, 252

Aristotle 146, 207

Ariztía, T. 260, 261, 263, 268

Aron, R. 13, 24, 40, 47, 91, 121, 122, 129, 139,142

Ascher, W. 246

Aso, M. 189, 197

Association pour la Recherche Démographique, Économique et Sociale (ARDES) 120
Atkinson, W. 159, 160

Australia 155, 157, 160, 249

Austria 14, 148, 149, 155, 164, 167

Baba, Y. 195

Bachelard, G. 126, 127, 128, 131, 135, $142,187,206,207,225$

Bacon, F. 207

Bagnall, G. 270

Baranger, D. 250

Barbagli, M. 151

Barlow, J.

Barnard, H. 75, 82, 85

Barry, P. 224, 225

Barthes, R. 185

Basconzuelo, C. 92, 273

Bassett, K. 75, 85

Batjargal, B. 237, 246

Baudelot, C. 10, 13

Baudrillard, J. 195

Beardsley M. C. 12, 15

Béarn 26, 46, 98, 123

Bechelloni, G. 151

Beck, U. 172, 255

Becker, G. 8, 13, 99

Beigel, F. 249, 251, 252, 254

Belgium 148, 149, 155, 160, 164, 167

Bellah, R. 181, 197

Bellotti, E. 174, 176

Bénatouil, T. 79, 85

Benedict, R. 120, 180, 181, 182, 188, 195

Benesse 191

Bennett, T. 160, 196, 197, 249, 265

Bergson, H. 120

Berkeley, University of California at 158

Berlin Wall 145

Bernstein, B. 129, 183, 184, 199

Bestor, V. 196, 197

Bhaskar, R. 103, 109, 111, 114, 115

Bikbov 147, 175 
Blum, L. 119

Boas, F. 120

Bohman, J. 75, 81, 85

Boltanski, L. 79, 80, 81, 84, 85, 86, 92, 93, 114, 133, 139, 141, 262, 268, 273

Bonn, University of 2

Bonnewitz, P. 76, 78, 79, 80, 81, 86

Borgatti, S. P. 165, 169, 176

Boschetti, A. 75, 86

Bottero, W. 268

Boudon, R. 152

Bourqui, M. 194

Bowie, A. 2, 14

Bowles, S. 184, 199

Boyne, R. 76, 77, 78, 80, 82, 84, 87, 134

Brazil 155, 157, 160, 251, 252, 273

Breslau, D. 80, 83, 87

Bridge, G. 260, 268

Bristol, University of 159

British Sociological Association 194

Brown, N. 14, 89, 91, 172

Brown, R. 14

Browne, C. 84, 87

Brubaker, R. 81, 87, 159, 175

Bruszt, L. 176, 178

Bryson, B. 195

Buchholz, L. 246

Buckley, W. 104, 112

Bulgaria 149, 150

Burkitt, I. 75, 87

Bustamante 147, 149, 174, 178, 266

Caisse Algérienne de Développement 120

Calhoun, C. 26, 46, 75, 87, 88, 89, 135, 142,159

Callejo, J. 147

Callon, M. 268

Cambridge, University of 14, 15, 39, 86, 87, 89, 90, 93, 115, 134, 140, 159, $178,225,246,272,273$

Canada 155, 157, 160, 176, 252, 253

Canguilhem, G. 120, 128, 206, 225

Caro, J.-Y. 77, 78, 81, 82, 87

Carpiano, R. 159, 160

Cartwright, D. 15

Cassirer, E. 9, 25, 128, 146

Castel, R. 40, 46, 141
Castells, M. 268

Celikates, R. 79, 81, 84, 85, 87, 92

Central Compilation and Translation Press 231

Centre de sociologie européenne (CSE), 32, 40, 96, 121, 123, 129, 133, 134, 161, 271, 272

Centre for Psychosocial Studies 135

Chamboredon, J.-C. 3, 4, 7, 14, 76, 77, $78,79,80,81,82,83,87,117,124$, 141,225

Champagne, P. 75, 76, 78, 86, 88, 89, 197

Chang, J. 246

Chappel, T. 45, 46

Chartier, R. 231

Chen, N. 39, 232, 246

Chennai 217

Chew, M. 179, 187, 197

Chiapello, E. 268

Chicago, University of 13, 87, 88, 89, 93, 135, 137, 138, 141, 158, 176, 246, 268,269

Chile 41, 42, 250, 251, 252, 257, 258, 259, 260, 261, 262, 263, 264, 265, 266, $268,269,272$

China 39, 155, 197, 217, 227, 230, 231, 232, 233, 234, 235, 236, 239, 240, 241, 242, 244, 245, 246, 247, 248, 271, 273

China Remin University Press 232

Cicourel, A. 81, 82, 88

Clercq, D. de 159, 160

Clerk Maxwell, J. 9

Clothey, R. 246

Cohen 24

Cohen, A. 176

Coleman, J. 136, 137, 138, 141, 157

Collège de France 5, 11, 41, 188

Colliot-Thélène, C. 88

Comédie Française 102

Commercial Press 231

Communist Party 39, 234, 248

Comte, A. 119, 127, 182

Confucianism 39, 228, 242, 243, 244

Confucius 41, 243

CONICYT (National Commission for Scientific and Technological Research), 253 
Connell, R. 146

Coole, D. 93

Corcuff, P. 88

Crang, M.

CRESC 265

Croatia 148, 149, 155, 171

Croce, B. 152

Crompton, R. 256

Cronin, C. 88

Crossley, N. 159, 160

Crowley, J. 88

Crozier, M. 8, 14, 128

Culler, J. 205, 225

Cultural Revolution 233, 234, 240, 242, 246

Cummings, W. 183, 197

Cunningham, N. 199

Czech Republic 155, 171

Danaher, G. 76, 78, 81, 83, 93

Darbel, A. 6, 14, 36, 38, 46, 141, 142, 174

Deer, C. 88

Deleuze, G. 101, 185

Delhi 47, 142, 199, 216, 218, 225, 246, 247, 272

Delsaut, Y. 118, 141

Deng, Z. 246

Denmark 148, 149, 155, 169, 170

Denord, F. 153, 176

Dereian, P. 174, 177

Derluguian, G. 176

Derrida, J. 37, 131, 132, 142, 185, 204, 205, 208, 210, 225, 231, 271

Descartes, R. 2, 45, 134

Devine, F. 199, 268

Dewey, J. 109

Dezalay, Y. 75, 88, 250

Diego Portales, universidad 259, 260, 265, 272

Dilthey, W. 28, 47, 202

Dimaggio, P. 159

Discepolo, T. 129, 141

Dodier, N. 88

Doleželová-Velingerová, M. 246

Donald, S. 246

Dore, R. 183, 197

Dortier, J.-F. 88

Dumais, S. 159, 160
Duncan, I. 88

Durkheim, E. 90, 95, 97, 98, 100, 108, 109, 120, 126, 127, 132, 146, 172, 173, 182, 184, 195, 199, 224

Eagleton, T. 81, 87

Ecole des Hautes Etudes en Sciences

Sociales 127

Ecole Normale Supérieure 6, 119

Egger, S. 86

Eickelpasch, R. 88

Elias, N. 98, 116, 156

Ellis, E. 93

Elman, B. 246

Elster, J. 152

Encrevé, P. 85, 88, 91, 93

Engler, S. 88

Establet, R. 10, 13

Estonia 148, 149, 171

Europe 35, 36, 42, 85, 103, 145, 146, 147, $148,150,153,154,155,157,159$, $161,164,165,166,167,170,172$, $173,174,175,176,177,178,185$, $217,252,253$

European Union (EU), 145

Evens, T. 88

Everett, M. 165, 176

Eyal, G. 176

Fairbank, J. 246

Faridabad 210, 216, 224

Faridabad Majdoor Samachar

FMS 210, 224

Ferguson, K. 93

Feuerbach, L. 207

Feuerwerker, A. 246

Feyerabend, P. 204

Fichte, J. G. 2, 7, 118

Filgueira, C.

Fink, E. 23, 45, 46

Finland 148, 149, 155, 169, 170, 177

Fischer, J. 115

Flath, D. 196, 197

Flaubert, G. 103, 209

Fong, V. 246

Fornel, M. de 81, 88, 96

Foucault, M. 90, 95, 173, 185, 232

Fournier, M. 176 
France 5, 8, 10, 11, 12, 13, 14, 21, 24, 26, $37,39,40,43,44,86,88,89,108$, $119,120,121,122,124,125,127$, $128,129,132,133,134,139,140$, $141,145,150,155,164,167,169$, $172,174,175,179,187,188,191$, 192, 197, 200, 227, 231, 247, 271, 272

Frankfurt Institute for Social Research 2 Frankfurt School 95, 114

Frankfurt, H. 115

Frankfurt, University of 2

Frazer, J. G. 120

Freeman, L. 168, 176

French baccalauréat 192

French Revolution 129

Frère, B. 92

Friedman, M. 8

Friedman, S. 199

Fujita, H. 184, 197, 198

Fukui, N. 185

Gadamer, H.-G. 2, 3, 5, 90, 202, 205, 207

Gallelli, A. 35, 36, 145

Gandhi, I. 211

Gandhi, S. 211

Gandillac, M. de 142

Gao, X. 32, 39, 40, 41, 42, 227, 232, 233, 234,247

Gaonkar, D. 75, 88

Garcelon, M. 247

Garcia-Gomez, J. 25

Garfinkel, H. 99, 108

Garretón, M. 251, 252, 268

Garrigou, A. 121

Garth, B. 250

Gascony 119

Gayo-Cal, M. 197, 265, 266

Geertz, C. 206

Geldof, K. 89

Gemperle, M. 147, 177

Georgia 148, 149

Germany 2, 128, 148, 149, 150, 155, 161, $164,167,169,172,179,191,271$

Gibbons, M. 93

Giddens, A. 75, 89, 96, 103, 114, 134, 156, 172,255

Giner, S. 89

Gingras, Y. 89
Gini, C. 173

Gintis, H. 184, 199

Ginzburg, C. 114

Gladney, D. 247

Goffmann, E. 99, 108, 138, 172

Goldmann, L. 142

Goldthorpe, J. 152, 161

Gordon, A. 186, 190, 197

Gorsky, P. 159

Gouhier, H. 119

Gouldner, A. 89

Gramsci, A. 152, 176

Grancelli, B. 178

Greece 145, 148, 149, 150

Grenfell, M. 28, 89, 233

Griffith, P. 225

Griller, R. 89

Guangxi Normal University Press 231

Güell, P. 252, 269

Guéroult, M. 119

Gurgaon 37, 210, 211, 212, 216, 217

Gurwitsch, A. 9, 10, 14, 24, 25, 47, 131

Habermas, J. 1, 2, 3, 4, 5, 14, 15, 90, 156, 172, 202, 203, 204, 210, 225

Habib, I. 38, 47

Hacking, I. 89

Haitian Publishing House 232

Halbwachs, M. 97, 98

Halsey, A.H. 183, 198, 246

Hamel, J. 89

Hanks, W. 89

Hanneman, R. 165, 177

Hanser, A. 247

Hara, J. 186, 197

Hardy, K. 159, 160

Harker, R. 85, 88

Harré, R. 105, 111, 115

Harvard 114, 132, 173, 176, 199, 200, 246

Harvard School 114

Hasan, R. 15

Hashimoto, K. 197

Hashmi, F. 224

Hayashi, C. 195

Heffron, J. 246

Hegel, G. W. 2, 7

Heidegger, M. 20, 23, 25, 28, 47, 133, 140 , $146,210,231$ 
Heidelberg, University of 2

Heilbron, J. 75, 76, 78, 79, 81, 83, 89, 174,177

Heise, T. 250

Held, D. 89, 134

Hempel, K. 203

Héran, F. 89

Herriot, E. 119

Herz, M. 89

Hirakawa, S. 179, 187, 197

Hirsch, W. 116

Hjellbrekke, J. 153, 176, 177, 199

Hoarau, J. 89

Hobbes, T. 109, 146

Hoffman, K. 269

Holloway, J. 89

Holt, D. 159, 160

Holton, R. 89

Honneth, A. 19, 79, 81, 84, 85, 114, 115

Horkheimer, M. 2

Houdart, P. 75, 90

Hoy, D. 205, 224, 225

Hui, L. 230, 231

Hummon, N. 174, 177

Hung, H. 247

Hungary 148, 149, 175

Husserl, E. 19, 20, 21, 22, 23, 24, 25, 27, 28 , $37,46,47,100,120,131,132,142,146$

Il Mulino 151

Illich, I. 185

Imamura, H. 185, 195

India 37, 47, 210, 211, 215, 217, 272

Inglis, D. 90

Inoue, T. 183, 197

Institut National de la Statistique et des Études Économiques (INSEE), 120

Ireland 155, 171

Ishida, H. 184, 198

Ishii, Y. 185, 195, 198, 199

Iso, N. v, 32, 36, 37, 39, 40, 42, 179, 196, 198

Italy 148, 149, 150, 151, 152, 153, 155, 172,176

Iwatasubo, S. 195, 198

Jain, S. 37, 38, 39, 201, 222, 225

James, D. 9, 76, 78, 81, 85, 89, 91, 97, 136, 157,243
Jameson, F. 219, 225

Japan 37, 135, 179, 180, 181, 182, 183, 184, 185, 186, 187, 188, 189, 191, 192, 193, 194, 195, 196, 197, 198, 199, 200, 217, 271

Japan Society of Educational Sociology 194

Japanese National Centre Test 192

Jaurès, J. 119

Jenkins, R. 76, 78, 81, 90, 233

Joint Publishing 230, 231

Joint Publishing Company 230, 231

Jugoslavia 148

Junger, E. 133

Kabyle 11, 35, 140

Kafka, F. 102, 103, 116

Kant, I. 2, 6, 9, 14, 23, 25, 34, 89, 108, $109,118,119$

Karabel, J. 183, 198

Karademir Hazır, I. 249, 269

Karady, V. 175, 177

Karakayali, N. 75, 76, 78, 80, 81, 82, 90

Kariya, T. 194

Karsenti, B. 81, 90

Kastnern R. 88

Kataoka, E. 186, 195, 198

Kato, H. 188, 194, 197, 198

Kauppi, N. 90, 177

Kawashima, T. 179, 198

Kazuo, S. 197

Keane, M. 247

Kenway, J. 90

Kern, C. 265

Khan, S. 224

Kobari, M. 193, 198

Kobayashi, J. 196

Kögler, H. 75, 76, 78, 80, 81, 90

Kogut, B. 178

Kokichi, S. 197

Kondo, H. 193, 194, 198

König, M. 81, 90

Koniordos, S. 176, 177

Korsnes, O. 176, 177

Král, O. 246

Kuhn, T. 204

Kuroda, I. 192, 198

Kyrtsis, A. 176, 177 
L'Estoile, B. de 88

Lagrave, R.-M. 85, 88, 91, 93

Lahire, B. 32, 33, 96, 97, 98, 99, 100, 101, 102, 103, 106, 108, 109, 110, 111, $112,113,114,116$

Lamont, M. 259, 264, 269

Landgrebe, L. 23, 27, 28, 47

Lane, J. 177

Lash, S. 255

Latour, B. 101, 172

Latvia 149, 171

Lauder, P. 246

Lawler, S. 269

Lazarsfeld, P. 125, 146, 152, 173

Le Figaro 129

Le Roux, B. 176, 177, 199

Lebaron, F. 176, 177

Lebart, L. 195, 198

Ledeneva, A. 247

Lee, T. 247

Legge, J. 243

Leibniz, G. W. 21, 45, 119, 146

Les Temps Modernes 9

Levi, G. 114

Levinas, E. 159, 160, 231

Lévi-Strauss, C. 90, 122, 124, 125, 130 , 140, 185

Lévy-Bruhl, L. 24

Lewandowski, J. 90

Lewin, K. 9, 15

Li, Y. 199, 247

Liberation 125, 247

LiPuma, E. 26, 46, 87, 88, 89, 135, 142

Lithuania 149, 155, 171

Liu, H. 230, 231, 232

Liu, M. 237, 246

Lizardo, O. 159, 160, 161

Lockwood, D. 95, 104, 116

Lojkine, J. 88

Lokman, I. 175, 177

Lomnitz L.

London School of Economics 159

Longhurst, B. 270

Löwith, K. 2

Luhmann, N. 99, 182

Lyon 100, 116, 197

Lyotard, J.-F. 11, 15, 21, 22, 24, 47, 135, 142,272
Ma Shengli, Peking University Press 231

Maccarini, A. 115

Mach, E. 25

Machiavelli, N. 146

Mahar, C. 85, 88

Malinowski, B. 120

Mammeri, M. 176

Manchester, University of 15, 159, 258, 265, 272

Mandelbrot, B. 100

Manesar, Gurgaon, India 37, 210, 211, 212 , 213, 215, 216, 219, 220, 222, 223, 224

Mao 234, 246

Maranda, P. 140

Marburg, University of 2

Marshall, T. H. 173

Maruti Suzuki 37, 210, 213, 214, 215, 216, 218, 219, 220, 222

Marx, K. 10, 19, 23, 38, 47, 88, 89, 91, 95, $99,117,120,126,146,182,184,199$, 207, 208

Marxism 38, 47, 92, 132, 151, 189

Marxist 37, 39, 116, 126, 182, 184, 208

Matuchniak-Krasuska, A. 175, 177

Mauger, G. 6, 15, 88, 121, 142

Mauss, M. 90, 97, 100

McLeod, J. 75, 90

McNay, L. 90

Mead, G.H. 34, 97, 109

Meiji era 179, 194

Melnick, A.

Méndez, M.L. vi, 39, 41, 42, 44, 249, 251, 262, 264

Menger, C. 1

Méranda, F. 177

Merleau-Ponty, M. 9, 15, 19, 20, 22, 47, 100, 120, 131, 231

Merton, R. K. 146, 152, 173, 175

Mesny, A. 90

Metropolitan Opera 102

Mialet, H. 90

Miles, A. 199

Miller, P. 269

Mills, M. 159, 160

Minami, H. 195

Minamida, K. 193, 198

Miyajima, T. 184, 194, 195, 196, 197, 198, 199 
Mo, Y. 194

MOE 240, 247

Moen, P. 248

Mollet, E. 90

Molnar, V.

Monod, J.-C. 90

Montefiore, A. 140

Morandi, H. 115

Morel, T. 92, 273

Mori, N. 195, 199

Morrison, W. 235, 247

Moss, P. 90

Mouer, R. 188, 199

Moulins 6, 119

Mounier, P. 90

Müller-Doohm, S. 91

Murakami, T. 194, 196, 199

Murakami, Y. 183, 188, 199

Murphy, K. M. 20

Nagel, E. 203

Nakazawa, A. 199

Nazi occupation 5

Nedelmann, B. 176, 177

neo-Kantian 118, 127

Netherlands 47, 149, 155, 161, 167

New York 14, 15, 47, 102, 115, 116, 141, $142,178,197,225,246,247,268,270$

New Zealand 155, 157

Newton, I. 113

Nice, R. 86

Nietzsche, F. 107

Nomura Research Institute 181, 199

Norris, C. 139, 142

Norway 148, 149, 153, 155, 169, 170, 176

Nouschi, A. 188

Noya, J. 90, 91

OECD 191, 199

Ogien, A. 96, 115

Oguma, E. 194, 199

Onai, T. 184, 199

Orientalism 120

Osumi, N. 195

Otsuka, H. 182, 199

Pakulski, J. 255

Panayotopoulos, N. 91
Panofsky, E. 9, 15, 29, 47, 128, 142

Pareto, V. 152, 173

Paris 13, 14, 15, 32, 36, 45, 46, 47, 85, 86, 87, 88, 89, 90, 91, 92, 93, 96, 102, 115, $116,125,127,139,140,141,142,145$, 158, 174, 175, 177, 197, 225, 271

Paris VIII at Vincennes, University of 127

Parsons, T. 114, 146, 152, 173, 181, 182

Pascal, B. 5

Passeron, J.-C. 3, 4, 5, 7, 8, 10, 14, 15, 40, $46,76,77,78,79,80,81,82,83,87$, $91,98,116,117,118,121,123,124$, 128, 129, 139, 141, 142, 197, 225, 239, 246, 250, 272

Peccoud, R. 247

Peirce, C. S. 97

Pels, D. 91

People's Republic of China 234

Peristiany, J. G. 128, 140

Peters, G. 116

Peterson, R. 195, 265

Petras, J. 251, 252

Pfeuffer, A. 81, 82, 86, 87

Piaget, J. 100, 142

Pikketty, T. 190, 199

Pinto, L. 76, 81, 84, 85, 86, 89, 91

Pitt-Rivers, J. 124, 128, 140

Plato 22, 45, 46, 130, 205

Platt, R. 31, 47

Platteau, J. 247

Plessner, H. 34, 109

Poland 148, 149, 150, 155, 171, 175

Popper, K. 1, 2, 3, 5

Portes, A. 157, 158, 258, 269

Portugal 148, 149, 155

Postone, M. 26, 46, 87, 88, 89, 135, 142

Pouillon, J. 140

Poupeau, F. 129, 141

Prandini, R. 115

Presses Universitaires de France 121

Pune 217

Putnam, R. K. 157

Rademacher, C. 88

Rahkonen, K. 147, 177

Ramos, C. 253, 254, 269

Rancière, J. 129, 130, 131, 139, 142

Raphael, L. 91 
Rawolle, S. 159, 160

Reay, D. 159, 160, 256

Reckwitz, A. 116

Rehbein, B. 93

Rennes, J. 81, 85, 86

Resistance 5, 88, 91, 120, 125, 225

resistance movement 5

Revel, J. 91, 114, 116

Richardson, J. 225

Ricoeur, P. 23, 24, 37, 47, 114, 116, 202, 203, 223, 225

Riddle, M. 165, 177

Riesman, D. 182

Rio de Janeiro 102, 273

Rivet, J.-P. 6, 14, 36, 38, 46, 142

Robbins, D. 1, 6, 15, 19, 27, 30, 34, $47,76,78,79,81,82,83,85$, $87,89,90,91,117,139,142$, $147,159,160,177,179,194$, 195, 199, 227, 233, 247, 249, 255, 263, 269

Robespierre, M. 119

Rohlen, T. 186, 199

Romania 148, 149, 150

Rorty, R. 105

Rose, N. 85, 88, 91, 93, 260, 269

Rosenberg, J. 38, 47

Rosenlund, L. 153, 177

Rouanet, H. 177, 265

Russia 148, 149, 150, 155, 171, 175, 178,247

Ryle, G. 116

Saalmann, G. 93

Sailer, L. 169, 177

Saint Martin, M. de 76, 78, 84, 88, 141

Saint Simon, H. de 182

Sakuramoto, Y. 194

Sakuta, K. 181, 182, 199

Sala Cecília Meireles 102

Salento, A. 153

Sallaz, J. 147

Sanders, G. 246

Santoro, M. v, 35, 36, 39, 145, 147, 151, $176,177,251$

Sapiro, G. 86, 89, 147, 149, 174, 177, 178, 266

Sartre, J.-P. 13, 15, 19, 109, 231
Satō, T. 190, 199

Saussure, F. de 104, 117

Savage, M. 159, 160, 196, 197, 199, 256, 260, 261, 262, 263, 265, 269,270

Sawyer, R. 116

Sayad, A. 43, 46, 122, 141

Scheler, M. 34, 109

Schelling, F. von 2

Schelling, F. W. J. von 15

Schirato, T. 75, 76, 78, 81, 83, 85, 91, 93

Schleiermacher, F. 202

Schmoller, G. von 1

Schücking, L. 139

Schultheis, F. 6, 81, 82, 86, 87

Schütz, A. 20, 109, 182

Schwengel, H. 93

Scopus database 153, 165, 175, 176

Scott, J. 165, 168, 178

Seibel, C. 6, 14, 36, 38, 46, 142

Seiyama, K. 186, 197

Serbia 148, 149, 171

Serres, M. 101

Shambaugh, D. 237, 247

Shan, W. 178

Shida, M. 194

Shusterman, R. 85

Silva, E. 159, 197, 265

Simmel, G. 34, 99, 109, 182, 273

Singer, B. 91

Singh, S. 224

Sintomer, Y. 91

Skeggs, B. 256, 260, 270

Skinner, Q. 225

Slater, D. 260, 270

Slovenia 148, 149, 171

Socrates 45

software Ucinet 169

Song, G. 247

Sorbonne 121

Sorokin, P. 173

Southerton, D. 262, 270

Sowerwine, C. 247

Spain 148, 149, 150, 155, 169, 172

Specter, M. G. 2, 15

Spencer, H. 182

Spinoza, B. 146

St. Thomas Acquinas 146 
Stabile, C. 91

Stark, D. 178

Steinmetz, G. 159

Stillerman, J. 259, 260, 263

Sugimoto, Y. 188, 199

Sun, L. 237, 247

Susen, S. 28, 30, 31, 32, 34, 47, 49, $75,76,77,78,79,80,81,82,83$, 84, 85, 86, 87, 89, 91, 92, 93, 96, $116,139,142$

Suzuki Motor Corporation 211

Svendsen, G. L. 247

Svendsen, G. T. 247

Swartz, D. 76, 78, 79, 81, 83, 93, 147, 233, 254,265

Sweden 148, 149, 155, 169, 170

Swidler, A. 116

Switzerland 155, 164, 167, 172

Szelenyi, I. 176

Szeman, I. 89, 91

Sztandar-Sztanderska, K. 175, 178

Sztompka, P. 175, 176, 177, 178

Tahara, O. 185, 199

Takahashi, H. 192, 199

Takane, M. 196

Takeuchi, Y. 190, 199

Taylor, M. 199

Teriman, D. 246

Terray, E. 93

Teruhisa, H. 197

Theodore, A. 1

Thévenot, L. 114

Thompson, J. 89, 134, 159, 203, 223, 225

Thrift, N.

Throop, C. J. 20

Tiles, M. 207, 209, 225

Tokyo, University of 47, 85, 180, 182, 187, 188, 196, 197, 198, 199, 271

Tominaga, K. 182, 197, 200

Tomusk, V. 176, 178

Townsley, E. 176

Tran Duc Thao 19, 23

Tsukaharan, F. 195

Tudor, A. 250

Tuma, N. 248

Turkey 155, 249, 269
Turner, B. 28, 81, 85, 86, 87, 91, 92, 93, $96,116,139,142,273$

UK/United Kingdom 39, 42, 90, 134, 148, $149,150,155,158,160,161,162,163$, 164, 165, 168, 169, 171, 174, 233, 240, $251,254,255,265,272,273$

Ukraine 148, 149

United States 8, 154, 155, 157, 200, 252

Urban, M. 178

Urry, J. 255

US/USA 152, 154, 155, 157, 158, 159, $160,162,163,172,173,174,176$, 184, 186, 192, 217, 233, 253

Ushiogi, M. 189

Vaast, E. 159, 160, 175

Van Crevel, M. 247

Vandenberghe, F. 32, 33, 34, 37, 42, 76, $78,81,82,93,95,96,114,116$

Vázquez García, F. 93

Vécrin, L. 176

Veltmeyer, H. 258

Verdès-Leroux, J. 93

Vienna Circle 2, 25

Vogel, E. 183, 200

Vuillemin, J. 119

Wimsatt, W. K. 12

Wacquant, L. 26, 31, 38, 44, 45, 46, 47, $75,76,77,78,79,80,81,82,83,87$, 93, 96, 135, 138, 141, 147, 152, 158, 159, 160, 229, 231, 233, 239, 246, 249, 259, 268

Wagner, H.-J. 81, 93

Wahl, J. 23, 24, 45, 47

Walker, G. 178

Walters, M. 255

Wang, H. 247

Wang, S. 247

Warczok, T. 178

Ward, K. 52, 89

Warde, A. 159, 161, 197, 265

Warner, L. 172, 194, 200

Warwick, M. 92, 198

Watanabe, E. 192, 200

Watsuji, T. 195

Waung, W. 247 
Webb, J. 75, 76, 78, 81, 83, 85, 91, 93

Weber, M. 1, 86, 87, 95, 99, 109, 117, 120, $126,146,173,181,182,189,199$, 202, 203

Weimar Germany 115

Weiss, J. 93

Wells, A. 246

Wiley, N. 93, 97

Wilkes, C. 85, 88

Williams, R. 87, 139

Willis, P. 184, 199

Wimsatt, W. K. 15

Wittgenstein, L. 85, 109

Woolgar, S. 31, 47

Wright, D. 197, 265

Wrong, D. 95, 116

Wu, Y. 247

Xiaoping, D. 234

Xinhua Neres 244, 248

Yacine, T. 120, 121, 140, 141, 197

Yamada, M. 196
Yamamoto, T. 85, 185, 195, 200

Yang, Y. 32, 39, 40, 41, 42, 177, 227, 230, 248,273

Yeh, M. 248

Yonezawa, A. 194

Yonghua, L. 232

York, University of 159

Yoshihara, M. 193, 200

Yoshino, K. 181, 200

Young, M. F. D. 14, 15, 29, 47, 124, 128,140

Zang, X. 39, 232, 246

Zarycki, T. 176, 178

Zavisca, J. 147

Zhang, Q. 243, 247, 248

Zhang, X. 248

Zheng, Y. 246

Zhou, X. 248

Zimmermann, K. 75, 76, 78, 81, 82, 83, 88

Zollschan, G. 116

Zukin, S. 264, 270 


\section{INDEX OF SUBJEGTS}

'censure' 133

'classlessness' 234

'consciousness' 49, 72, 79

'constitutive' 21, 25, 131

'critical realism' 34

'critical sociology' 34, 49

'critique' 49, 72, 79

'deconstructionism' 131

'différance' 210

'distance-taking' 49, 72, 80

'eidos' 21

'emancipation' 49, 72, 84

'emotive' or 'affective' fallacy 12

'epistemology' 49, 72, 83

'essences' 24

'fields' 5, 29, 132

'fractal sociology' 100

'gentilitial democracy' 11, 35

'griffe' 118

'habitus' 9, 10, 39, 43, 44

'harmonious society' 244

'hexis' 9

'historicization' 49, 72

'hysteresis' 42, 43, 44, 230

'intentional' fallacy 12

'intentionality' 23

'Japaneseness' 181

'Kulturgeschichte' 23

'majdoor' or wage worker 220

'Neo-Confucianism' 243

'New Confucianism' 243

'nominalism' 34

'objectivism' 207

'omnivore' 33

'passeurs' 45

'political capital' 219

'position-taking' 41

'postmodern' 31, 43

'principle of non-consciousness' 110

'realism' 34, 207 'rules' 131

'rupture' 49, 72, 82

'science' 4, 34, 49, 72, 77, 242

'self-awareness' 49, 72, 79

'self-objectification' 49, 72, 80

'semantics of desire' 203

'socio-genetic understanding' 34

'strategies' 131

'structuralist' 29, 152

'subjectivism' 207

'symbolic violence' 27, 45, 131, 249

'the entrepreneurs' 228

'the political elite' 228

'transcendental' 21, 22, 25

'understanding' 49, 72, 74, 84

'vigilance' 49, 72, 78

a priorism 118

aesthetics 142, 171, 176

affectivity 123

agency $8,33,44,68,73,103,104,105$,

$109,110,111,112,132,170,260$

agency/structure 8

allodoxia 45

applied rationalism 207

ars inveniendi 7

authenticity 74, 107, 261, 262, 264, 265

bibliometric analysis 35,147

capital 8, 10, 14, 27, 37, 38, 39, 43, 46, 53, $71,98,119,136,151,153,157,158$, $161,167,169,170,171,176,179,180$, 185, 186, 187, 188, 189, 190, 191, 192, 193, 196, 206, 208, 215, 218, 219, 223, 227, 228, 229, 230, 232, 236, 237, 238, 239, 240, 241, 244, 245, 261, 263, 264, 265, 266, 269, 273

Cartesian dualism 221

Cartesian mind-body dualism 208 
cartography 147

class $8,11,33,37,39,43,51,60,91,99$, $100,101,102,119,124,132,167,169$, $170,182,184,185,187,190,191,192$, 193, 199, 201, 210, 215, 217, 218, 219, 220, 221, 222, 224, 228, 236, 245, 255, 256, 258, 259, 260, 261, 262, 263, 265, $268,269,270,272$

club activities 191

colonial ethnology 120

communicative rationality 204

Confucianism 39, 228, 242, 243, 244

constitutive phenomenology 13, 24, 25

constructivism 206

consumption 98, 100, 101, 157, 165, 171, 174, 181, 255, 259, 260, 264, 266, 269, 271

Contexts 98, 99, 109

correspondence analysis 185, 186, 195, 265

correspondence theory 117

critical realism 34, 103, 109, 111, 273

cultural capital 8, 11, 39, 43, 167, 185, $187,188,192,193,229,236$

cultural reproduction 184, 228, 244

cultural turn 255, 256

culture 8, 10, 40, 43, 56, 78, 101, 103, 104, $111,112,121,123,139,152,159,164$, 167, 170, 171, 180, 181, 185, 186, 189, 190, 194, 195, 196, 197, 227, 234, 235, $236,237,238,239,241,242,244,245$, 256, 259, 260, 269, 271, 273

data collection 1

deconstruction 204, 205, 208, 209

deoccupation 211, 212, 213, 217, 218, 220, 221, 223

determinism 10, 33, 95, 132, 230

dispositional 44, 96, 98, 102, 108, 112, 187

dispositions 13, 25, 31, 33, 43, 44, 60, 62, 97, 98, 99, 100, 101, 102, 106, 108, 110, $111,113,114,209,218,221,229,257$, 258, 259, 260, 263

domination 34, 36, 38, 51, 60, 70, 71, 73, 86, 88, 105, 119, 129, 131, 134, 135, 137, 174, 189, 190, 218, 219, 232, 237, 254,256

doxa 218, 229, 237 economic capital 39, 186, 193, 218, 224, 228, 236, 240

education 8, 10, 27, 29, 36, 40, 43, 98, $119,121,123,128,129,134,136,146$, 151, 159, 161, 167, 170, 171, 183, 184, 188, 189, 190, 191, 192, 197, 227, 228, 232, 235, 236, 239, 240, 241, 242, 244, $245,249,251,259,263,266,271,273$ educational attainment 240 elites 189

empiricism 21, 22, 118, 207

endogenous 41, 251

epistemic community 12, 126, 133, 136

epistemological rupture 127

ethnocentrism 54, 56, 57

examination $7,50,58,62,72,180,183$,

187, 188, 192, 240, 245

existentialism 20

exogenously 41

field 5, 7, 8, 9, 14, 26, 27, 29, 32, 35, 39, 41, 42, 44, 45, 51, 53, 54, 56, 58, 71, 90, 95, 98, 99, 100, 101, 103, 105, 106, 107, $108,113,114,118,119,123,124,125$, 126, 127, 128, 132, 134, 136, 137, 138, $139,140,146,147,148,151,152,153$, 156, 158, 159, 161, 167, 169, 170, 171, $172,173,174,176,177,179,185,186$, 187, 188, 189, 193, 194, 205, 209, 210 , 218, 220, 222, 228, 229, 230, 232, 237, 238, 239, 240, 241, 243, 245, 249, 250, 251, 254, 255, 256, 257, 258, 259, 260, 261, 262, 263, 264, 266

fractals 102

functionalism 95, 114

gatekeepers 45

genetic structuralism 32, 95, 114

Gestalt psychology 9

grand narratives 11

habitus 7, 8, 9, 10, 25, 27, 32, 39, 41, 42, $43,45,67,83,85,89,95,98,100,101$, $105,107,110,111,113,114,123,146$, 152, 167, 169, 170, 171, 187, 206, 208, 218, 221, 228, 229, 230, 232, 233, 238, 239, 243, 245, 250, 256, 257, 258, 259, $260,261,262,263,264$ 
health 102, 167, 169, 170, 171, 173, 176, 213

hermeneutic 1, 2, 3, 4, 124, 203, 209

hermeneutics 115, 169, 202, 203, 204, 205, 207, 209, 273

heuristic 7, 206, 223

historical-hermeneutic sciences 1

human sciences 1, 20, 114, 202, 207, 209

humanistic 124, 152, 209

hyperempiricism 117

ideal speech situation 204

idealism 7, 21, 22, 23, 132, 207, 208

Imperialist Reason 44, 46, 249

indigenous $6,9,26,37,39,42,120,122$, 152,237

inequality $37,167,185,194,196,227$, 240, 250, 256, 257, 265, 266, 269, 272

intellectual fields 4

internal conversations 97, 105, 106, 107, 110,113

international circulation of ideas 146, 148, 153, 158

international knowledge transfer 179, 180, 181, 188, 199

Japanese modernization 179, 186, 194

Japanese Spirit 179, 187, 197

language 6, 24, 34, 37, 50, 52, 104, 128, $129,133,134,146,158,164,167,169$, 180, 201, 202, 203, 204, 205, 206, 210 , $232,233,237,243,253$

legitimate culture 41, 239, 242, 244

Lévi-Straussian anthropology 204

metaphysics 204

Methodenstreit 1

micro and macro 112

middle class 236, 256, 259, 260, 261

middle classes 41, 250, 256, 257, 259, 260, 261, 262, 263, 265, 272

mimeticism 12

morphogenetic 33, 96, 103, 104, 105, 111 , 112,114

multiple correspondence analysis 153, 170, 193

narrative 1, 107, 262, 265

Nationalism 197, 200, 242, 248 natural sciences 1, 3, 37, 50, 124, 202, 209

negative philosophy 5

negative sociology 5

neoliberalism 219, 256

network analysis 35, 148, 153, 165, 168,

178, 271

nomological sciences 1

objectification 26, 49, 58, 60, 67, 72, 73,

74, 80, 123, 130, 206

omnivorous 101

participant objectivation 206

patriotism 242

peasant 123, 125, 128, 140, 216

performative 12, 62, 261, 268

phenomenology 19, 20, 21, 23, 25, 34, 47,

$54,131,132,152,208,273$

philosophical anthropology 34,108 ,

109, 115

photography 10, 122, 128, 151

political capital 40, 219, 237, 238, 239,

241, 245

politics of belonging 264

populism 133, 190

positivism 1, 3, 21, 25, 114, 125, 127, 207, 208, 209

Positivissmusstreit 1

postmodernists 105

post-reform China 236, 245

post-structuralism 130, 131

practical logic 208, 219

practice $2,3,4,8,12,26,27,29,36,37$, $38,52,54,56,57,59,65,67,103$,

$110,117,118,122,126,127,130$,

132, 133, 138, 147, 158, 187, 192,

201, 204, 205, 206, 207, 208, 209,

210, 215, 218, 220, 221, 223, 224,

228, 230, 239, 242

pragmatic 12, 20, 29, 38

pragmatism 32, 97, 134, 236

praxeological 63, 103, 130

praxeological theories 103

primary experience $21,26,31,54,118$,

123, 132

psychoanalysis 55, 57, 98, 202, 203

psychologism 132

public sphere 2 
qualitative 1, 36, 114, 122, 186, 190, 271 quantitative $1,114,122,147,185,186$, 265,271

rational choice 33

rational realism 207

realist 38, 103, 104, 105, 110, 111, 117 , 134,152

reflexivity $9,26,29,30,33,34,44,45,49$, $50,51,52,53,54,55,56,57,58,59,60$, $61,62,63,66,67,68,69,70,71,72,73$, $74,76,77,78,79,80,82,83,84,103$, 105, 106, 107, 109, 110, 112, 113, 114, 136,138

regression analysis 153,186

relational 54, 56, 58, 59, 103, 116 ,

$165,166,169,174,182,187,193$, 263, 267

relative autonomy 34, 125, 171, 269

relativism 24, 30, 74, 204, 206

reproduction $7,8,10,14,27,30,37,38$, 39, 41, 63, 95, 104, 105, 106, 108, 113 , $115,128,129,132,141,184,185,186$, 189, 218, 227, 228, 229, 230, 231, 236, 238, 239, 240, 241, 243, 244, 245, 250, 251, 253, 256, 257, 261, 265

Risshin-Shusse 186, 190

Saussurean linguistics 204

scale 57, 98, 100, 102, 105, 108, 112, 114, 137, 251

scholastic 9, 52, 54, 62, 63, 65, 66, 81, 82, 96, 209

school system 191

Selbstberwusstsein 51

sense of place 250, 257, 259, 263, 264

skholè, 62, 80

social capital 157, 158, 167, 191, 192, 228, 236, 237, 238, 241, 245

social constructivists 105

Social hermeneutics 202

social mobility 41, 105, 133, 184, 186, 230,

250, 256, 257, 258, 260, 261

social reproduction 228, 237, 238, 239

social space $43,99,101,158,166,171$,

180, 187, 188, 227, 235, 239, 256, 258, 266, 267

socialist economy 237 socio-analytic encounter 34, 43, 119, 139

sociological psycho-analysis 103

sociologism 10

sociology ii 1, 2, 5, 7, 9, 26, 27, 28, 30, $34,36,38,39,42,44,49,50,51,52$, $53,54,56,57,58,59,61,62,66,67$, 70, 72, 74, 89, 93, 95, 96, 97, 98, 100, 102, 103, 105, 107, 108, 110, 112, $113,118,120,123,126,127,128$, 129, 134, 136, 137, 138, 139, 141, $146,151,152,158,161,165,173$, 174, 176, 177, 180, 181, 182, 183, 184, 185, 186, 188, 189, 193, 194, 206, 208, 211, 219, 220, 224, 227, 228, 230, 232, 233, 244, 249, 251, 253, 254, 259, 262, 266, 271, 272, 273

soft determinism 10, 33, 132

spatial circulation of ideas 147

spontaneous sociology $6,117,123,130$

State 37, 39, 46, 47, 178, 187, 188, 189, 192, 231, 235, 236, 241, 245, 246, 247,271

state commons 192

state nobility 192

statistics 6, 36, 123, 185, 240

status attainment 186

structural equivalence 169

structural functionalism 32, 95, 183

structuralism 9, 21, 32, 95, 100, 124, 125,

130, 131, 203, 204, 208, 209

structure $7,15,32,33,35,43,49,51$, 72, 103, 104, 105, 111, 112, 125, 132, 133, 134, 142, 146, 147, 148, 153, 180, 183, 184, 193, 199, 218, 221, 222, 228, 229, 238, 239, 243, 253, 257, 259, 260

structured structures 5, 249

structuring structures 5, 132, 249

subjective/objective 8,131

symbolic power 52, 53, 132, 152, 208, 210 symbolic violence $9,27,45,95,131,139$,

208, 210, 249, 256, 263

taste 119, 122, 167, 193, 260

trade unions 212, 216, 219, 220

transfuges de classe 33, 101

unified science 137, 203 
verstehen 203

welfare state 220,255

Western Technology 179, 187, 197 workers $6,100,122,210,211,212,213,214$,

215, 216, 217, 218, 219, 220, 221, 222, 223 working class 38, 210, 217, 218, 220, 221

World War II (WWII), 183, 190 



\section{INDEX OF TITLES OF BOOKS BY BOURDIEU CITED IN THE VOLUME}

Acts of Resistance 225

Algeria 1960230

Algerian Sketches 141

Esquisses algériennes 141, 197

An Invitation to Reflexive Sociology 31, 46, 87, 93, 135, 138, 230, 231, 246, 268

Réponses 26, 31, 46, 87, 135, 138, 141

Ce Que Parler Veut Dire 7, 14, 30, 46, 86, 231

Counterfire 231

Contre-Feux 231

Distinction: A Social Critique of the Fudgement of Taste 141

La distinction 11

Esquisse pour une auto-analyse 87, 119, 141,231

Free Exchange 230

Gothic Architecture and Scholastic Thought 9, 29

Homo Academicus 8, 14, 29, 46, 86, 134, 136,141

Images d'Algérie 14

In Other Words 14, 20, 46, 86, 134, 141, 250, 268

Choses Dites 14, 46, 134, 141

Inheritors 123, 184, 185, 231

Les Héritiers 151, 231, 266

Les héritiers, les étudiants et la culture 123, 141

La reproduction 10, 232

Language and Symbolic Power 14, 46, 210 , 225, 231, 268

Le déracinement 43, 46, 122, 128, 141

Leçon sur la leçon 86

Les usages sociaux de la science 86, 231

Masculine Domination 232

La domination masculine 86, 232

On Television 231

Sur la télévision 231

On the State 46, 188, 189, 190

Sur l'État 37, 44, 46
Outline of a Theory of Practice 85, 130, 131, 140, 230, 246

Esquisse d'une théorie de la pratique 130, 140, 230

Pascalian Meditations 5, 14, 42, 44, 46, 86, 229, 230, 246, 257, 258

Méditations pascaliennes 5, 14, 46, 86, 93, 230, 232

Photography. A Middle-brow Art 142

Un art moyen 123, 134, 141

Political Interventions: Social science and political action 141

Practical Reason 46, 85, 181, 187, 188, 189, 195, 197, 225, 230, 246

Raisons pratiques 37, 46, 87, 115, 230

Science of Science and Reflexivity 90, 225, 230, 231, 246

Science de la science et réflexivité, 31, 46, 87, 231

Social Theory for a Changing Society 136, 141

Sociology in Question 86

State Nobility 46, 178, 188, 189, 192, 231, 246

La Noblesse d'État 40, 46, 231

The Algerians 122, 140

Sociologie de l'Algérie 13, 45, 121,

122,139

The Bachelors' Ball 46, 231

Le bal des célibataires 26, 46, 231

The Craft of Sociology 3, 14, 117, 124, 141, 225

Le métier de sociologue 3, 7, 14, 87, 117, $118,124,125,126,127,130,135,136$, 137,141

The Field of Cultural Production 246

The Forms of Capital 228, 237, 246

The Logic of Practice 46, 86, 134, 141, 185 , 201, 225, 230, 246

Le sens pratique 26, 46, 86, 134, 141, 230 
The Love of Art 123, 134, 141

L'amour de l'art 123, 134, 141

The Political Ontology of Martin Heidegger 210, 231

The Rules of Art 5, 14, 225, 232

Les règles de l'art 5, 14, 231
The Social Structures of the Economy 87

The Sociologist and the Historian 231

The Weight of the World 4, 14

La misère du monde 4, 14, 86, 138, 141

Travail et travailleurs en Algérie 6, 14, 36, 38, $46,122,124,130,142$ 